\title{
Porphyrin-Ryleneimide Hybrids: Tuning of Visible and Near-Infrared Absorption by Chromophore Desymmetrization
}

\author{
Supplementary Information
}

by Sunit Kumar, ${ }^{\dagger}$ Yogesh Kumar Maurya, ${ }^{\dagger}$ Seongsoo Kang, ${ }^{\ddagger}$ Piotr Chmielewski, ${ }^{\dagger}$ Tadeusz Lis, $^{\dagger}$ Joanna Cybińska, ${ }^{\dagger, \#}$ Dongho Kim, ${ }^{*, *}$ and Marcin Stępień*,+

\section{Table of Contents}

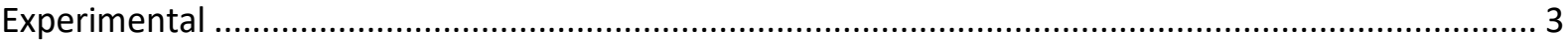

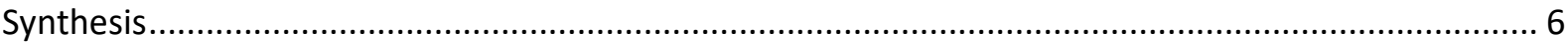

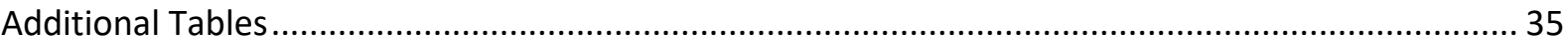

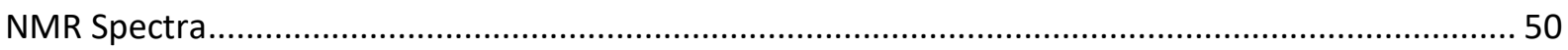

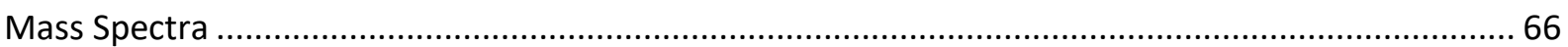

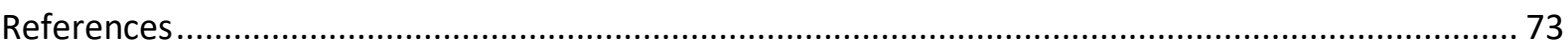


Experimental 
General. Tetrahydrofuran and diethyl ether were dried using a commercial solvent purification system. Dichloromethane and chlorobenzene were distilled from calcium hydride when used as reaction solvents. All other solvents and reagents were used as received. ${ }^{1} \mathrm{H}$ NMR spectra were recorded on high-field spectrometers $\left({ }^{1} \mathrm{H}\right.$ frequency 500.13 or $600.13 \mathrm{MHz}$ ), equipped with broadband inverse or conventional gradient probeheads. Spectra were referenced to the residual solvent signals (chloroform-d, 7.24 ppm). Two-dimensional NMR spectra were recorded with 2048 data points in the $t_{2}$ domain and up to 2048 points in the $t_{1}$ domain, with a $1 \mathrm{~s}$ recovery delay. All 2D spectra were recorded with gradient selection. ${ }^{13} \mathrm{C}$ NMR spectra were recorded with ${ }^{1} \mathrm{H}$ broadband decoupling and referenced to solvent signals $\left({ }^{13} \mathrm{CDCl}_{3}, 77.0 \mathrm{ppm}\right)$. High resolution mass spectra were recorded using electrospray or MALDI ionization in the positive mode. Electrochemical measurements (THF and DCM, $\left.0.1 \mathrm{M}^{2} \mathrm{TBAPF}_{6}\right], 293 \mathrm{~K}$ ) were performed on an EA9C Multifunctional Electrochemical Analyzer using a glassy-carbon working electrode, platinum wire as the auxiliary electrode, and silver wire as a reference electrode. The voltammograms were referenced against the half-wave potential of $\mathrm{Fc}^{+} / \mathrm{Fc}$.

Photoluminescence excitation (PLE) and emission (PL) spectra were taken with the FSL980-sm Fluorescence Spectrometer from Edinburgh Instruments Ltd. A $450 \mathrm{~W}$ Xenon arc lamp (PL and PLE) and a Super Continuum Fianium laser were used as excitation sources. Emission spectra were corrected for the recording system efficiency and excitation spectra were corrected for the incident light intensity. PLE and PL spectra and QY were measured using cooled extended red Hamamatsu photomultiplier operating in a range of $200-1050 \mathrm{~nm}$. Quantum yield measurements were performed by using an Edinburgh Instruments integrating sphere equipped with a small elliptical mirror and a baffle plate for beam steering and shielding against directly detected light. For the measurement, the integrating sphere replaces the standard sample holder inside the sample chamber. Calculations of quantum yields were made using the software provided by Edinburgh Instruments.

Femtosecond Transient Absorption Spectroscopy. The femtosecond time-resolved transient absorption (TA) spectrometer used for this study consists of a femtosecond optical parametric amplifier (Quantronix, Palitra-FS) pumped by a Ti:sapphire regenerative amplifier system (Quantronix, Integra-C) operating at $1 \mathrm{kHz}$ repetition rate and an accompanying optical detection system. The generated OPA pulses had a pulse width of $\sim 100 \mathrm{fs}$ and an average power of $1 \mathrm{~mW}$ in the range of 560 to $680 \mathrm{~nm}$, which were used as pump pulses. For $800 \mathrm{~nm}$ excitation, fundamental pulses were used without passing through the OPA system. White light continuum (WLC) probe pulses were generated using a sapphire window ( $2 \mathrm{~mm}$ thick) by focusing of a small portion of the fundamental $800 \mathrm{~nm}$ pulses, which were picked off by a quartz plate before entering into the OPA. The time delay between pump and probe beams was carefully controlled by making the pump beam travel along a variable optical delay (Newport, ILS250). Intensities of the spectrally dispersed WLC probe pulses were monitored by a miniature spectrograph (OceanOptics, USB2000+). To obtain the time-resolved transient absorption difference signal $(\Delta \mathrm{A})$ at a specific time, the pump pulses were chopped at 500 $\mathrm{Hz}$ and absorption spectra intensities were saved alternately with or without pump pulse. Typically, 6000 pulses were used excite samples and to obtain the TA spectra at a particular delay time. The polarization angle between pump and probe beam was set at the magic angle ( $54.7^{\circ}$ ) using a Glan- S5 laser polarizer with a half-wave retarder to prevent polarization-dependent signals. The crosscorrelation FWHM in the pump-probe experiments was less than $200 \mathrm{fs}$, and chirp of WLC probe 
pulses was measured to be $800 \mathrm{fs}$ in the $400-800 \mathrm{~nm}$ regions. To minimize chirp, all reflection optics were used in the probe beam path, and a quartz cell of $2 \mathrm{~mm}$ path length was employed. After completing each set of fluorescence and TA experiments, the absorption spectra of all compounds were carefully checked to rule out the presence of artifacts or spurious signals arising from, for example, degradation or photo-oxidation of the samples in question.

X-ray crystallography. X-ray quality crystals were grown by slow diffusion of $n$-hexane into a chloroform solution of $\mathbf{2} \mathbf{b}-\mathrm{H}_{2}$ and $\mathbf{3} \mathbf{b}-\mathrm{H}_{2}$. Diffraction measurements were performed on a k-geometry Ruby PX diffractometer ( $\omega$ scans) with graphite-monochromatized Mo Ka radiation. The data were collected at $100 \mathrm{~K}$, corrected for Lorenz and polarization effects. Data collection, cell refinement, data reduction and analysis were carried out with the Xcalibur PX software, CRYSALIS CCD and CRYSALIS RED, respectively (Oxford Diffraction Ltd., Abignon, England, 2009). An analytical absorption correction was applied with the use of CRYSALIS RED. All structures were solved by direct methods with the SHELXS-97 program and refined using SHELXL-97 ${ }^{1}$ with anisotropic thermal parameters for non- $\mathrm{H}$ atoms. In the final refinement cycles, all $\mathrm{H}$ atoms were treated as riding atoms in geometrically optimized positions. CCDC Mercury and CrystalExplorer ${ }^{2,3}$ were used for visualization of solvent-accessible surfaces. In the final refinement cycles, all $\mathrm{H}$ atoms were treated as riding atoms in geometrically optimized positions. CCDC 2015790 and 2015791 contains the supplementary crystallographic data for this paper. These data can be obtained free of charge from the Cambridge Crystallographic Data Centre via http://www.ccdc.cam.ac.uk/data_request/cif.

Computational methods. Density functional theory (DFT) calculations were performed using Gaussian 16. ${ }^{4}$ DFT geometry optimizations were carried out in unconstrained C1 symmetry, using extended tight binding $(\mathrm{xTB})^{5,6}$ or semi-empirical models as starting geometries. DFT geometries were refined to meet standard convergence criteria, and the existence of a stationary point was verified by a normal mode frequency calculation. Geometry optimizations, frequency calculations, and thermochemistry calculations were performed using the hybrid functional B3LYP combined with the $6-31 G(d, p)$ basis set..$^{7-9}$ In the calculations of absorption spectra, up to 50 electronic transitions were calculated by means of time-dependent DFT (TD-DFT), using the above level of theory, PCM solvation (using dichloromethane parameters). ${ }^{10}$ 
Synthesis 
<smiles>c1cc2c3c(cccc3c1)-c1c[nH]cc1-2</smiles>

8H-acenaphtho[1,2-c]pyrrole (4). Compound 4 was prepared by following literature procedure. ${ }^{11}$ Yield $80 \%$. ${ }^{1} \mathrm{H}$ NMR $(500 \mathrm{MHz}$, chloroform-d , $300 \mathrm{~K}): \delta 8.16(1 \mathrm{H}, \mathrm{b}), 7.61\left(2 \mathrm{H}, \mathrm{d},{ }^{3} \mathrm{~J}=8.4 \mathrm{~Hz}\right), 7.56$ $\left(2 \mathrm{H}, \mathrm{d},{ }^{3} \mathrm{~J}=6.5 \mathrm{~Hz}\right), 7.47(2 \mathrm{H}, \mathrm{m}), 7.02(2 \mathrm{H}, \mathrm{s}) .{ }^{13} \mathrm{C}$ NMR $(125 \mathrm{MHz}$, chloroform-d , $300 \mathrm{~K}): \delta 137.7$, $133.7,130.9,128.7,127.5,123.9,118.5,110.6$.

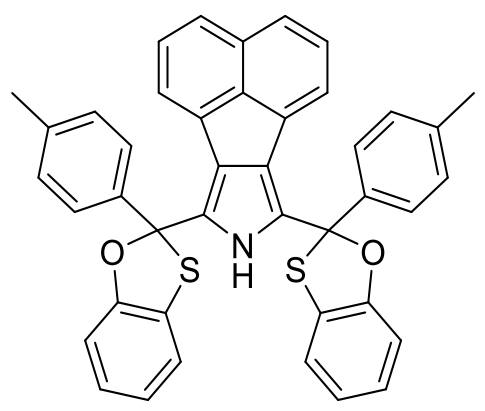

7,9-bis(2-(p-tolyl)benzo[d][1,3]oxathiol-2-yl)-8H-acenaphtho[1,2-c]pyrrole (5). 2-Hydroxythiophenol $(0.8 \mathrm{~mL}, 0.075 \mathrm{~mol})$ and p-toluic acid $\left(1.05 \mathrm{~g}, 0.075 \mathrm{~mol}, 1\right.$ equiv.) were dissolved in $\mathrm{POCl}_{3}(12 \mathrm{~mL})$ in a $25 \mathrm{~mL}$ round-bottom flask and heated to $110{ }^{\circ} \mathrm{C}$ in an oil bath with continuous stirring for $10 \mathrm{~min}$; the mixture turned deep red. The reaction mixture was cooled to room temperature, and $\mathrm{HBF}_{4} \cdot \mathrm{Et}_{2} \mathrm{O}$ $(2.70 \mathrm{~mL})$ was added, followed by the addition of dry ether $(20 \mathrm{~mL})$, which precipitated out the benzoxathiolium salt as a yellow powder. The powder was collected by vacuum filtration and used without further purification or characterization (yield: $1.4 \mathrm{~g}$ ). ${ }^{12}$ All of the benzoxathiolium salt was placed into a $250 \mathrm{~mL}$ round-bottom flask containing pyrrole $(360 \mathrm{mg}, 0.018 \mathrm{~mol})$, pyridine $(0.413 \mathrm{~mL}$, $0.051 \mathrm{~mol})$, and mixture of acetonitrile and chloroform $(5: 5 \mathrm{~mL})$ with continuous stirring. The salt got dissolved immediately upon addition and the solution became hot and turned dark yellow. The reaction mixture was stirred for $1 \mathrm{~h}$, and then $\mathrm{CH}_{2} \mathrm{Cl}_{2}(10 \mathrm{~mL})$ and $\mathrm{H}_{2} \mathrm{O}(10 \mathrm{~mL})$ were added. The aqueous and organic layers were separated, and the aqueous layer was extracted with $\mathrm{CH}_{2} \mathrm{Cl}_{2}$. The combined organic layers were washed with $5 \% \mathrm{NaOH}(\mathrm{aq})(20 \mathrm{~mL})$ and water and then dried over sodium sulfate, and the solvent was evaporated. The crude product was purified by silica gel column chromatography using petroleum ether/ethyl acetate $(90: 10, \mathrm{v} / \mathrm{v})$ which afforded pure compound $\mathbf{5}$ as a yellow solid (900 mg, 75\%). ${ }^{1} \mathbf{H}$ NMR $(500 \mathrm{MHz}$, chloroform- $d, 300 \mathrm{~K}): \delta 8.84(1 \mathrm{H}, \mathrm{b}), 7.62(4 \mathrm{H}$, m), $7.53\left(2 \mathrm{H}, \mathrm{d},{ }^{3} \mathrm{~J}=8.1 \mathrm{~Hz}\right), 7.25(2 \mathrm{H}, \mathrm{m}), 7.18\left(4 \mathrm{H}, \mathrm{q},{ }^{3} \mathrm{~J}=8.1 \mathrm{~Hz}\right), 7.14(2 \mathrm{H}, \mathrm{m}), 7.05(2 \mathrm{H}, \mathrm{m}), 6.94$ $(4 \mathrm{H}, \mathrm{m}), 6.68\left(2 \mathrm{H}, \mathrm{t},{ }^{3} \mathrm{~J}=7.6 \mathrm{~Hz}\right), 2.37(6 \mathrm{H}, \mathrm{s}) .{ }^{13} \mathrm{C}$ NMR $(125 \mathrm{MHz}$, chloroform-d , $300 \mathrm{~K}): \delta 154.5$, $154.5,139.2$, 139.1, 138.1, 138.0, 137.1, 132.3, 130.3, 129.6, 129.3, 128.8, 128.7, 127.3, 126.8, 126.7, 126.4, 125.7, 124.6, 124.4, 124.3, 123.0, 122.9, 122.1, 122.0, 121.3, 111.0, 110.9, 98.6, 98.5, 21.2. HRMS (ESI-TOF): $m / z$ : [M + Na] $]^{+}$Calcd for $\mathrm{C}_{42} \mathrm{H}_{29} \mathrm{NO}_{2} \mathrm{~S}_{2} \mathrm{Na}$ : 666.1532; Found 666.1543. 


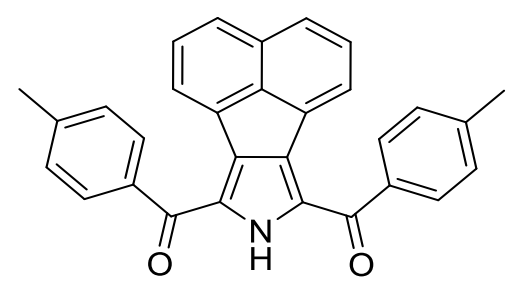

(8H-acenaphtho[1,2-c]pyrrole-7,9-diyl)bis(p-tolylmethanone)

(6).

7,9-bis(2-(ptolyl)benzo[d][1,3]oxathiol-2-yl)-8H-acenaphtho[1,2-c]pyrrole $(5 ; 1.0 \mathrm{~g}, 0.015 \mathrm{~mol})$ was added to the hydrolysis reagent constituted of mercury (II) oxide $(0.74 \mathrm{~g}, 0.033 \mathrm{~mol})$ in THF (25 mL) and $48 \%$ aqueous tetrafluoroboric acid $(1 \mathrm{~mL})$. The reaction was exothermic, and mercury(II) oxide was dissolved at once. The mixture was allowed to stir at room temperature for $3 \mathrm{~h}$ until the disappearance of the starting material (TLC test: petroleum ether/ethyl ether, 80:20). The reaction mixture was then extracted with dichloromethane and the extracts were washed successively with $10 \%$ potassium iodide solution, $5 \%$ sodium hydroxide solution, and water. After evaporation of the solvent, The crude 2,5-dipivaloylacenapthopyrrole (6) was purified The crude product was purified by silica gel column chromatography using petroleum ether/ethyl acetate $(80: 20, \mathrm{v} / \mathrm{v})$ and afforded pure compound 6 as a yellow solid (530 mg, 80\%). ${ }^{1} \mathrm{H}$ NMR ( $500 \mathrm{MHz}$, chloroform-d , $300 \mathrm{~K}$ ): $\delta 9.67(1 \mathrm{H}, \mathrm{b})$, $7.92\left(4 \mathrm{H}, \mathrm{d},{ }^{3} \mathrm{~J}=8.1 \mathrm{~Hz}\right), 7.74\left(2 \mathrm{H}, \mathrm{d},{ }^{3} \mathrm{~J}=7.9 \mathrm{~Hz}\right), 7.38(6 \mathrm{H}, \mathrm{m}), 7.09\left(2 \mathrm{H}, \mathrm{q}^{3} \mathrm{~J}=7.1 \mathrm{~Hz}\right), 2.25(6 \mathrm{H}, \mathrm{s}) .{ }^{13} \mathrm{C}$ NMR (125 MHz, chloroform-d , $300 \mathrm{~K}): \delta$ 186.4, 143.8, 137.1, 135.5,133.9, 131.2, 130.2, 129.7,129.2, 127.5, 126.7, 123.8, 21.8. HRMS (ESI-TOF): $\mathrm{m} / \mathrm{z}:[\mathrm{M}+\mathrm{H}]^{+}$Calcd for $\mathrm{C}_{30} \mathrm{H}_{22} \mathrm{NO}_{2}:$ 428.1645; Found 428.1629 .

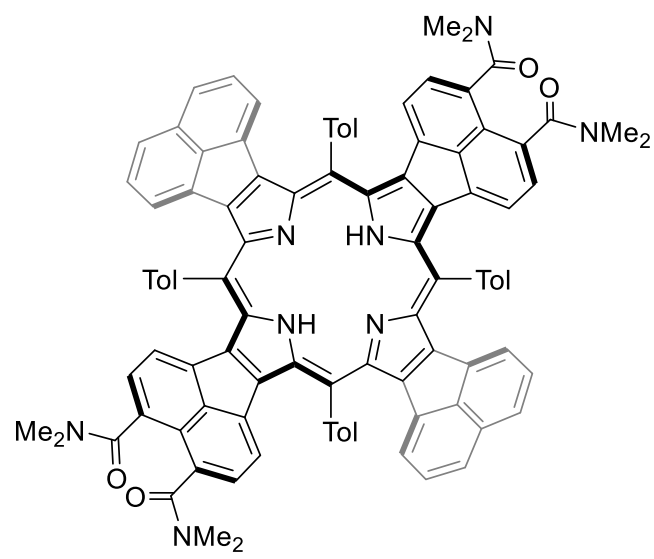

$\mathbf{t D}_{2} \mathbf{A}_{\mathbf{2}}$ porphyrin (2a- $\left.\mathrm{H}_{2}\right)$. To the solution of the diacylated acenapthopyrrole $\mathbf{6}(200 \mathrm{mg}, 0.46 \mathrm{mmol})$ in $48 \mathrm{~mL}$ of THF/MeOH (3:2 v/v), was added $\mathrm{NaBH}_{4}(880 \mathrm{mg}, 23.20 \mathrm{mmol})$ under $\mathrm{N}_{2}$ atmosphere. The reaction was stirred at room temperature for an additional $2 \mathrm{~h}$ at room temperature. After completion of the reaction, as indicated by TLC analysis, the reaction was quenched with a saturated aqueous solution of $\mathrm{NH}_{4} \mathrm{Cl}(10 \mathrm{~mL})$ and extracted with dichloromethane $(2 \times 25 \mathrm{~mL})$. The combined organic layers were dried over anhydrous sodium sulfate, and the solvent was removed on a rotary evaporator under high vacuum to afford dicarbinols as yellow sticky solids. The appropriate crude dicarbinol without further purification was treated with 1 equiv. of NDA pyrrole ${ }^{13}$ (149 mg, 0.48 $\mathrm{mmol}$ ) in the presence of a catalytic amount of $p$-Toluenesulfonic acid monohydrate(PTSA) (53.36 $\mathrm{mg}, 0.29 \mathrm{mmol})$ in chloroform/methanol $(80.8 \mathrm{~mL}, 100: 1 \mathrm{v} / \mathrm{v})$ under nitrogen atmosphere for $1 \mathrm{~h}$. Then 2,3- dichloro-5,6-dicyano-1,4-benzoquinone (DDQ, $153.99 \mathrm{mg}, 0.67 \mathrm{mmol}$ ) was added and the mixture was stirred for additional $2 \mathrm{~h}$. The solvent was evaporated and the residue was purified by 
column chromatography on alumina (grade $\mathrm{V}$ ) with dichloromethane/methanol $(100: 0.3 \mathrm{v} / \mathrm{v})$ to give the product as violet solid (80 mg, 12\%). ${ }^{1} \mathrm{H}$ NMR $(500 \mathrm{MHz}$, chloroform-d , $300 \mathrm{~K}): \delta 8.64(8 \mathrm{H}, \mathrm{b})$, $7.72(8 \mathrm{H}, \mathrm{m}), 7.64(4 \mathrm{H}, \mathrm{b}), 7.18(4 \mathrm{H}, \mathrm{b}), 7.01(4 \mathrm{H}, \mathrm{b}), 5.79(4 \mathrm{H}, \mathrm{b}), 5.64(4 \mathrm{H}, \mathrm{b}), 3.07(6 \mathrm{H}, \mathrm{s}), 3.02(12 \mathrm{H}$, s), $2.82(6 \mathrm{H}, \mathrm{s}), 2.81(6 \mathrm{H}, \mathrm{s}), 2.67(6 \mathrm{H}, \mathrm{b}),-0.51(2 \mathrm{H}, \mathrm{b}) .{ }^{13} \mathrm{C}$ NMR $(151 \mathrm{MHz}$, chloroform-d , $300 \mathrm{~K}): \delta$ $170.8,170.7,140.1,140.0,139.7,139.6,137.0,134.5,134.0,133.3,131.0,130.7,129.5,127.3,126.8$, 124.4, 123.3, 39.4, 39.3, 34.8, 34.7, 21.7. HRMS (ESI-TOF): $\mathrm{m} / \mathrm{z}$ : $[2 \mathrm{M}+\mathrm{H}]^{2+}$ Calcd for $\mathrm{C}_{200} \mathrm{H}_{150} \mathrm{~N}_{16} \mathrm{O}_{8}$ : 1452.5938; Found 1452.5948 .

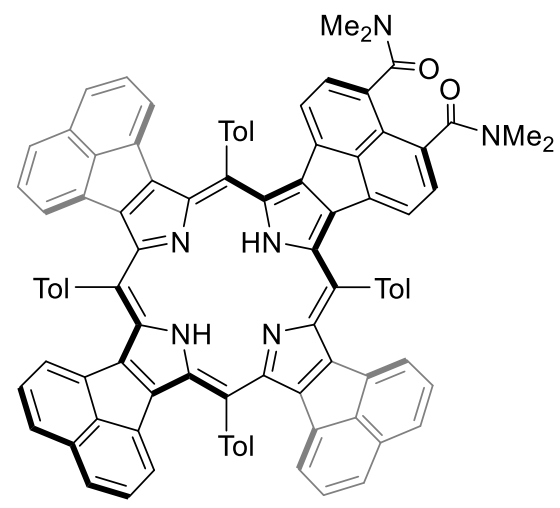

$\mathbf{D}_{3} \mathbf{A}$ porphyrin $\left(\mathbf{3 a}-\mathrm{H}_{2}\right)$. Porphyrin $\mathbf{3 a}-\mathrm{H}_{2}$ was synthesized by following the same procedure as given for $\mathbf{t D}_{2} \mathbf{A}_{\mathbf{2}}$ porphyrin $\mathbf{2 a}-\mathrm{H}_{2}$ by using dicarbinal-acenapthopyrrole $\mathbf{5}$ (195 $\mathrm{mg}, 0.44 \mathrm{mmol}$ ), acenapthopyrrole ${ }^{11} 4$ (42.81 mg, $\left.0.22 \mathrm{mmol}\right)$, NDA pyrrole ${ }^{13}(74.63 \mathrm{mg}, 0.22 \mathrm{mmol}), p$-toluenesulfonic acid monohydrate $(55.36 \mathrm{mg}, 0.29 \mathrm{mmol})$ and DDQ (153.99 $\mathrm{mg}, 0.67 \mathrm{mmol})$. The crude compound was purified by column chromatography on alumina (grade $\mathrm{V}$ ) with dichloromethane to give the product as violet solid (60 mg, 10\%). ${ }^{1} \mathbf{H}$ NMR $(500 \mathrm{MHz}$, chloroform-d , $300 \mathrm{~K}): \delta 8.66(8 \mathrm{H}, \mathrm{b}), 7.73$ $(8 \mathrm{H}, \mathrm{m}), 7.63(6 \mathrm{H}, \mathrm{b}), 7.17(6 \mathrm{H}, \mathrm{b}), 7.00(2 \mathrm{H}, \mathrm{b}), 5.78(6 \mathrm{H}, \mathrm{b}), 5.65(2 \mathrm{H}, \mathrm{b}), 3.05(3 \mathrm{H}, \mathrm{s}), 3.07(6 \mathrm{H}, \mathrm{s})$, $3.02(6 \mathrm{H}, \mathrm{s}), 2.82(3 \mathrm{H}, \mathrm{s}), 2.81(3 \mathrm{H}, \mathrm{s}), 2.66(3 \mathrm{H}, \mathrm{b}),-0.53(2 \mathrm{H}, \mathrm{b}) .{ }^{13} \mathrm{C}$ NMR (151 MHz, chloroform-d, $300 \mathrm{~K}): \delta 170.6,170.0,158.3,158.1,157.8,157.6,142.5,142.2,141.2,141.1,141.0,140.6,140.1$, 140.0, 139.8, 139.7, 138.1, 138.0, 137.4, 137.3, 136.0, 135.6, 135.1, 134.7, 132.7, 131,4, 130.6, 129.7, 129.2, 127.7, 127.4, 127.3, 126.2, 125.8, 125.7, 123.2, 120.9, 120.8, 120.6, 117.3, 115.4, 113.5, 39.5, 39.4, 34.9, 21.8, 21.7. HRMS (ESI-TOF): $\mathrm{m} / \mathrm{z}$ : $[\mathrm{M}+\mathrm{H}]^{+}$Calcd for $\mathrm{C}_{94} \mathrm{H}_{65} \mathrm{~N}_{6} \mathrm{O}_{2}$ : 1310.5196; Found 1310.5235. 


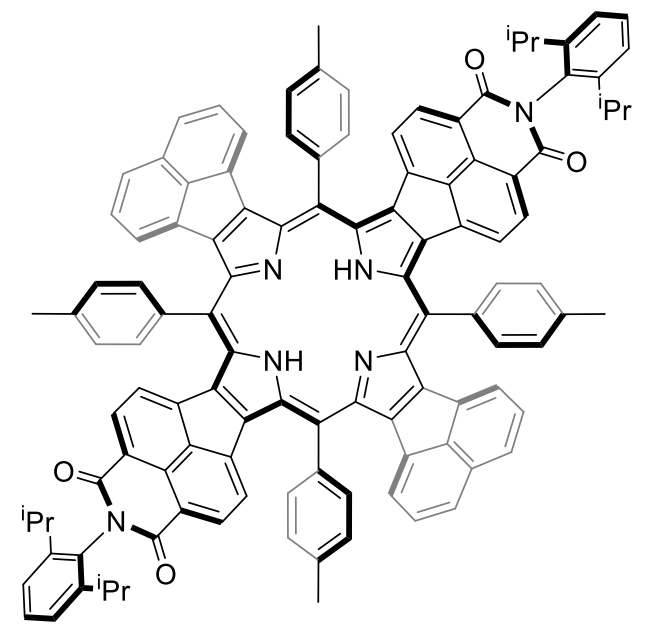

$\mathbf{t D}_{2} \mathbf{A}_{\mathbf{2}}$ porphyrin (2b- $\left.\mathrm{H}_{2}\right)$. A solution of compound $\mathbf{2 a}-\mathrm{H}_{2}(50 \mathrm{mg}, 0.034 \mathrm{mmol})$ in concentrated hydrochloric acid $(5 \mathrm{~mL})$ was refluxed for overnight. The resulting dark-blue precipitate was filtered, washed with water and diethyl ether, and dried in vacuum to give product $\mathbf{2 c}-\mathrm{H}_{2}$ in quantitative yield as a dark blue powder ( $45 \mathrm{mg})$. The solid was suspended in glacial acetic acid $(0.2 \mathrm{~mL})$, and 2,6diisopropylaniline $(128 \mu \mathrm{L}, 0.64 \mathrm{mmol}$ ) was added. The mixture was purged with nitrogen for $5 \mathrm{~min}$ and refluxed in a pressure tube at $160^{\circ} \mathrm{C}$ in an oil bath for $24 \mathrm{~h}$. The reaction mixture was cooled down, diluted with water, and extracted with dichloromethane. The organic phase was washed with aqueous sodium bicarbonate and brine, dried over anhydrous sodium sulfate, and concentrated in vacuum. The crude compound was purified by alumina (grade $\mathrm{V}$ ) column chromatography on with dichloromethane to give the product as dark blue solid (40 mg, 72\%-over two steps). ${ }^{1} \mathbf{H}$ NMR (500 $\mathrm{MHz}$, chloroform- $d, 300 \mathrm{~K}): \delta 8.62(8 \mathrm{H}, \mathrm{m}), 8.03\left(4 \mathrm{H}, \mathrm{d},{ }^{3} \mathrm{~J}=7.6 \mathrm{~Hz}\right), 7.81\left(4 \mathrm{H}, \mathrm{d},{ }^{3} \mathrm{~J}=6.7 \mathrm{~Hz}\right), 7.75(4 \mathrm{H}$, d, $\left.{ }^{3} J=6.9 \mathrm{~Hz}\right), 7.71\left(4 \mathrm{H}, \mathrm{d},{ }^{3} J=7.9 \mathrm{~Hz}\right), 7.44\left(2 \mathrm{H}, \mathrm{t},{ }^{3} J=7.8 \mathrm{~Hz}\right), 7.32\left(2 \mathrm{H}, \mathrm{dd},{ }^{3} J=8.0 \mathrm{~Hz}\right), 7.23(6 \mathrm{H}, \mathrm{m})$, $5.82\left(4 \mathrm{H}, \mathrm{d},{ }^{3} \mathrm{~J}=7.2 \mathrm{~Hz}\right), 5.68\left(4 \mathrm{H}, \mathrm{d},{ }^{3} \mathrm{~J}=7.6 \mathrm{~Hz}\right), 2.88(14 \mathrm{H}, \mathrm{m}), 2.62\left(2 \mathrm{H}, \operatorname{sept},{ }^{3} \mathrm{~J}=6.9 \mathrm{~Hz}\right), 1.23(12 \mathrm{H}$, d, $\left.{ }^{3} J=6.7 \mathrm{~Hz}\right), 1.00\left(12 \mathrm{H}, \mathrm{d},{ }^{3} \mathrm{~J}=6.9 \mathrm{~Hz}\right),-0.34(2 \mathrm{H}, \mathrm{b}) .{ }^{13} \mathrm{C}$ NMR $(151 \mathrm{MHz}$, chloroform-d , $300 \mathrm{~K}): \delta$ $164.0,148.64,145.8,142.0,140.9,139.3,137.5,136.7,135.0,134.2,132.8,132.1,131.0$, $130.9,129.5,129.3,128.5,128.0,127.4,125.8,125.4,125.0,123.9,123.8,123.5,121.9,121.3,29.1$, 28.9, 24.1, 23.8, 22.3, 21.9 . HRMS (ESI-TOF): $\mathrm{m} / \mathrm{z}$ : [M + H] $]^{+}$Calcd for $\mathrm{C}_{116} \mathrm{H}_{85} \mathrm{~N}_{6} \mathrm{O}_{4}:$ 1626.6660; Found 1626.6772. 


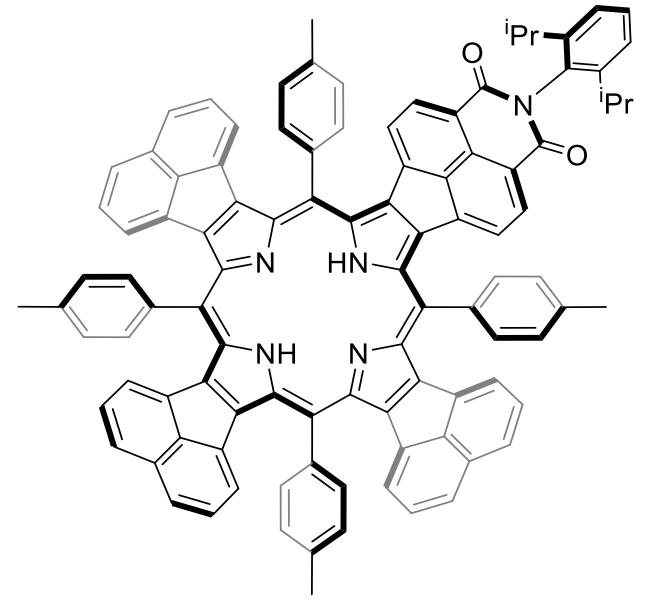

$\mathbf{D}_{3} \mathbf{A}$ porphyrin $\left(\mathbf{3 b}-\mathrm{H}_{2}\right)$. Porphyrin $\mathbf{3} \mathbf{b}-\mathrm{H}_{2}$ was synthesized by following the same procedure as given for $\mathbf{t D}_{2} \mathbf{A}_{2}$ porphyrin $\mathbf{2} \mathbf{b}-\mathrm{H}_{2}$ by using porphyrin $\mathbf{3 a}-\mathrm{H}_{2}(50 \mathrm{mg}, 0.038 \mathrm{mmol})$, hydrochloric acid $(5 \mathrm{~mL})$, 2,6- diisopropylaniline $(144 \mu \mathrm{L}, 0.75 \mathrm{mmol})$ and glacial acetic acid $(0.2 \mathrm{~mL})$. The crude compound was purified by column chromatography on alumina (grade $\mathrm{V}$ ) with dichloromethane to give the product as violet solid ( $35 \mathrm{mg}, 66 \%$ over two steps). ${ }^{1} \mathrm{H}$ NMR (500 MHz, chloroform-d , $\left.300 \mathrm{~K}\right): \delta 8.64(8 \mathrm{H}, \mathrm{m})$, $8.02(2 \mathrm{H}, \mathrm{m}), 7.80\left(2 \mathrm{H}, \mathrm{d},{ }^{3} \mathrm{~J}=7.9 \mathrm{~Hz}\right), 7.75(6 \mathrm{H}, \mathrm{m}), 7.67(6 \mathrm{H}, \mathrm{b}), 7.44\left(1 \mathrm{H}, \mathrm{t},{ }^{3} \mathrm{~J}=7.9 \mathrm{~Hz}\right), 7.32\left(1 \mathrm{H}, \mathrm{d},{ }^{3} \mathrm{~J}\right.$ $=8.0 \mathrm{~Hz}), 7.25\left(1 \mathrm{H}, \mathrm{b}\right.$, overlap with $\left.\mathrm{CDCl}_{3}\right), 7.20(6 \mathrm{H}, \mathrm{m}), 5.77(6 \mathrm{H}, \mathrm{b}), 5.66(2 \mathrm{H}, \mathrm{b}), 2.86(13 \mathrm{H}, \mathrm{m}), 2.63$ $\left(1 \mathrm{H}\right.$, sept, $\left.{ }^{3} J=6.7 \mathrm{~Hz}\right), 1.24\left(6 \mathrm{H}, \mathrm{d},{ }^{3} J=6.7 \mathrm{~Hz}\right), 1.00\left(6 \mathrm{H}, \mathrm{d},{ }^{3} J=6.9 \mathrm{~Hz}\right)-0.34(2 \mathrm{H}, \mathrm{b}) .{ }^{13} \mathrm{C}$ NMR $(151$ $\mathrm{MHz}$, chloroform-d , $300 \mathrm{~K}): \delta$ 164.0, 151.8, 148.3, 145.9, 141.4, 140.6, 140.1, 139.5, 139.4, 137.1, 135.0, 133.1, 132.1, 131.1, 130.8, 129.5,129.3, 127.3, 125.4, 123.9, 123.7, 121.7, 121.1, 120.7, 29.7, 29.1, 28.8, 24.1, 23.8, 21.8, 21.7. HRMS (ESI-TOF): $\mathrm{m} / \mathrm{z}:[\mathrm{M}+\mathrm{H}]^{+}$Calcd for $\mathrm{C}_{102} \mathrm{H}_{70} \mathrm{~N}_{5} \mathrm{O}_{2}:$ : 1397.5557; Found 1397.5596 .

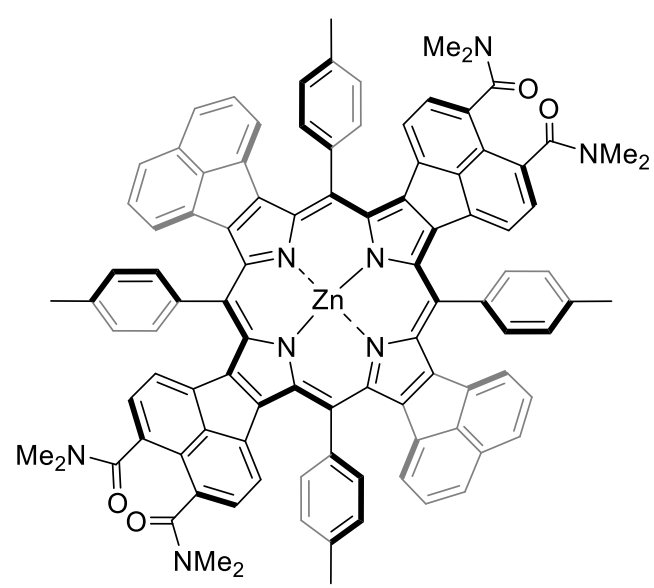

$t D_{2} A_{2}$ porphyrin (2a-Zn). An excess of $\mathrm{Zn}(\mathrm{OAc})_{2} .2 \mathrm{H}_{2} \mathrm{O}(20 \mathrm{mg}, 0.068 \mathrm{mmol})$ was added to a solution of porphyrin $2 \mathrm{a}-\mathrm{H}_{2}(20 \mathrm{mg}, 0.013 \mathrm{mmol})$ in $\mathrm{CHCl}_{3} / \mathrm{MeOH}(18 \mathrm{ml}, 5: 1)$ and the mixture was allowed to stir for $2 \mathrm{~h}$ at room temperature. Upon completion of the reaction, the solution was washed with water and dried over anhydrous sodium sulfate. The solvent was evaporated and the crude compound was purified on a column of alumina (grade $\mathrm{V})(\mathrm{DCM} / \mathrm{MeOH}, 100: 0.1)$ to give the product as a violet amorphous solid (18 mg, 87\%). ${ }^{1} \mathrm{H}$ NMR (500 MHz, chloroform/pyridine-d, $300 \mathrm{~K}$ ): $\delta 8.56(8 \mathrm{H}, \mathrm{m})$, $7.66(8 \mathrm{H}, \mathrm{m}), 7.55\left(4 \mathrm{H}, \mathrm{d},{ }^{3} \mathrm{~J}=8.0 \mathrm{~Hz}\right), 7.11\left(4 \mathrm{H}, \mathrm{t},{ }^{3} \mathrm{~J}=7.5 \mathrm{~Hz}\right), 6.95(4 \mathrm{H}, \mathrm{m}), 5.61\left(4 \mathrm{H}, \mathrm{t},{ }^{3} \mathrm{~J}=7.7 \mathrm{~Hz}\right)$, $5.50(4 \mathrm{H}, \mathrm{m}), 3.04(6 \mathrm{H}, \mathrm{s}), 3.01(6 \mathrm{H}, \mathrm{s}), 2.99(6 \mathrm{H}, \mathrm{s}), 2.79(6 \mathrm{H}, \mathrm{s}), 2.77(6 \mathrm{H}, \mathrm{s}), 2.67(6 \mathrm{H}, \mathrm{s}) .{ }^{13} \mathrm{C}$ NMR 
(151 MHz, chloroform/pyridine-d , $300 \mathrm{~K}$ ): $\delta$ 171.0, 146.5, 146.1, 145.9, 145.7, 141.1, 141.0, 139.4, $139.3,137.5,137.4,137.3,135.7,134.9,134.0,133.7,133.4,130.8,130.6,130.1,129.6,129.4,128.8$, 127.0, 126.7, 126.6, 126.4, 124.9, 124.4, 123.4, 121.7, 39.5, 39.3, 34.8, 34.6, 29.6, 21.6. HRMS (ESITOF): $m / z:[2 \mathrm{M}+2 \mathrm{H}]^{+}$Calcd for $\mathrm{C}_{200} \mathrm{H}_{146} \mathrm{~N}_{16} \mathrm{O}_{8} \mathrm{Zn}_{2}: 1516.0058$; Found 1516.0491.

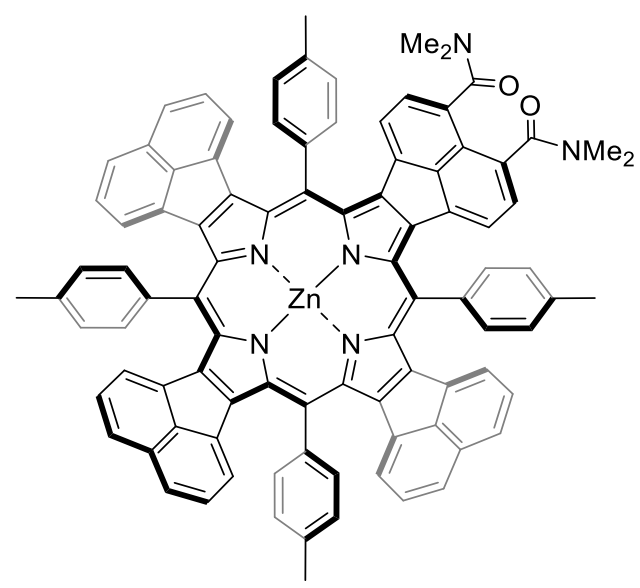

$\mathbf{D}_{3} \mathbf{A}$ porphyrin (3a-Zn). Porphyrin $\mathbf{3 a}-\mathrm{Zn}$ was synthesized by following the same procedure as given for $\mathbf{t D}_{2} \mathbf{A}_{2}$ porphyrin $\mathbf{2 a}-\mathrm{Zn}$ by using porphyrin $\mathbf{3 a}-\mathrm{H}_{2}(20 \mathrm{mg}, 0.015 \mathrm{mmol})$, zinc acetate (16.6 $\mathrm{mg}, 0.075$ $\mathrm{mmol})$, and $\mathrm{CHCl}_{3} / \mathrm{MeOH}$ (18 $\left.\mathrm{ml}, 5: 1\right)$. The crude compound was purified by column chromatography on alumina (grade $\mathrm{V}$ ) with dichloromethane to give the product as violet solid (17 $\mathrm{mg}, 82 \%) .{ }^{1} \mathbf{H}$ NMR (500 MHz, chloroform- $d, 300 \mathrm{~K}): \delta 8.59(8 \mathrm{H}, \mathrm{m}), 7.75(6 \mathrm{H}, \mathrm{m}), 7.61(8 \mathrm{H}, \mathrm{m}), 7.13(8 \mathrm{H}, \mathrm{m}), 5.68(8 \mathrm{H}$, m), $2.85(24 \mathrm{H}, \mathrm{m}) .{ }^{13} \mathrm{C}$ NMR $(151 \mathrm{MHz}$, chloroform-d , $300 \mathrm{~K}): \delta 145.8,145.2,144.9,140.9,140.6$, $139.5,137.2,136.8,134.9,134.8,134.7,134.0,133.8,130.8,130.7,129.5,129.4,129.1,127.1,127.0$, $126.8,125.1,121.99,121.6,39.1,34.6,31.93,29.7,29.3,22.6,21.6,21.5$. HRMS (MALDI-TOF): $m / z$ : $[\mathrm{M}+\mathrm{MeOH}+\mathrm{H}]^{+}$Calcd for $\mathrm{C}_{95} \mathrm{H}_{67} \mathrm{~N}_{6} \mathrm{O}_{3} \mathrm{Zn:}$ : 1405.4538; Found 1405.4335 .

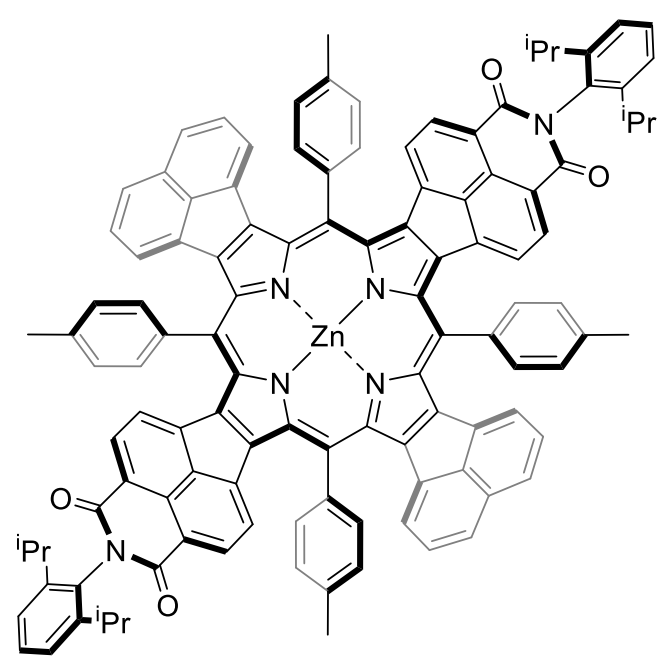

$\mathbf{t D}_{2} \mathrm{~A}_{\mathbf{2}}$ porphyrin ( $\mathbf{2 b}-\mathrm{Zn}$ ). Porphyrin $\mathbf{2 b}$ - Zn was synthesized by following the same procedure as given for $\mathbf{t} \mathbf{D}_{2} \mathbf{A}_{\mathbf{2}}$ porphyrin $\mathbf{2 a}$ - $\mathbf{Z n}$ by using porphyrin $\mathbf{2} \mathbf{b}-\mathrm{H}_{2}(20 \mathrm{mg}, 0.012 \mathrm{mmol})$, zinc acetate $(13.3 \mathrm{mg}$, $0.061 \mathrm{mmol})$, and $\mathrm{CHCl}_{3} / \mathrm{MeOH}(18 \mathrm{ml}, 5: 1)$. The crude compound was purified by column chromatography on alumina (grade $\mathrm{V}$ ) with $\mathrm{CH}_{2} \mathrm{Cl}_{2} / \mathrm{n}$-hexane (80:20) to give the product as dark blue solid (19 mg, 92\%). ${ }^{1} \mathrm{H}$ NMR (500 MHz, chloroform-d , $\left.300 \mathrm{~K}\right): \delta 8.57(8 \mathrm{H}, \mathrm{m}), 8.05\left(4 \mathrm{H}, \mathrm{d},{ }^{3} \mathrm{~J}=7.6 \mathrm{~Hz}\right.$ ), 
$7.82\left(4 \mathrm{H}, \mathrm{d},{ }^{3} J=7.4 \mathrm{~Hz}\right), 7.75\left(4 \mathrm{H}, \mathrm{d},{ }^{3} J=7.5 \mathrm{~Hz}\right), 7.66\left(4 \mathrm{H}, \mathrm{d},{ }^{3} J=7.9 \mathrm{~Hz}\right), 7.45\left(2 \mathrm{H}, \mathrm{t}^{3}{ }^{3} J=8.0 \mathrm{~Hz}\right), 7.33$ $\left(2 \mathrm{H}, \mathrm{dd},{ }^{3} \mathrm{~J}=8.2 \mathrm{~Hz}\right), 7.26(2 \mathrm{H}, \mathrm{m}), 7.17\left(4 \mathrm{H}, \mathrm{t},{ }^{3} \mathrm{~J}=7.7 \mathrm{~Hz}\right), 5.67\left(4 \mathrm{H}, \mathrm{d},{ }^{3} \mathrm{~J}=7.3 \mathrm{~Hz}\right), 5.61\left(4 \mathrm{H}, \mathrm{d}^{3}{ }^{3}=7.7\right.$ $\mathrm{Hz}), 2.89(14 \mathrm{H}, \mathrm{m}), 2.62\left(2 \mathrm{H}, \mathrm{sept},{ }^{3} \mathrm{~J}=6.9 \mathrm{~Hz}\right), 1.25\left(12 \mathrm{H}, \mathrm{d},{ }^{3} \mathrm{~J}=6.7 \mathrm{~Hz}\right), 1.00\left(12 \mathrm{H}, \mathrm{d},{ }^{3} \mathrm{~J}=6.8 \mathrm{~Hz}\right) .{ }^{13} \mathrm{C}$ NMR (151 MHz, chloroform-d , $300 \mathrm{~K}): \delta$ 164.0, 147.6, 147.0, 146.4, 145.8, 145.4, 140.5, 140.2, 139.7, $137.0,136.8,134.7,134.4,134.3,132.1,131.0,130.9,129.4,129.3,129.1,129.0,128.3,128.2,127.5$, 127.1, 125.4, 125.4, 125.3, 125.3, 123.9, 123.8, 123.7, 123.1, 122.4, 121.7, 29.1, 28.9, 24.1, 23.8, 21.8. HRMS (ESI-TOF): $m / z$ : [M] ${ }^{+}$Calcd for $\mathrm{C}_{116} \mathrm{H}_{82} \mathrm{~N}_{6} \mathrm{O}_{4} \mathrm{Zn}$ : 1688.5743; Found 1688.5785 .

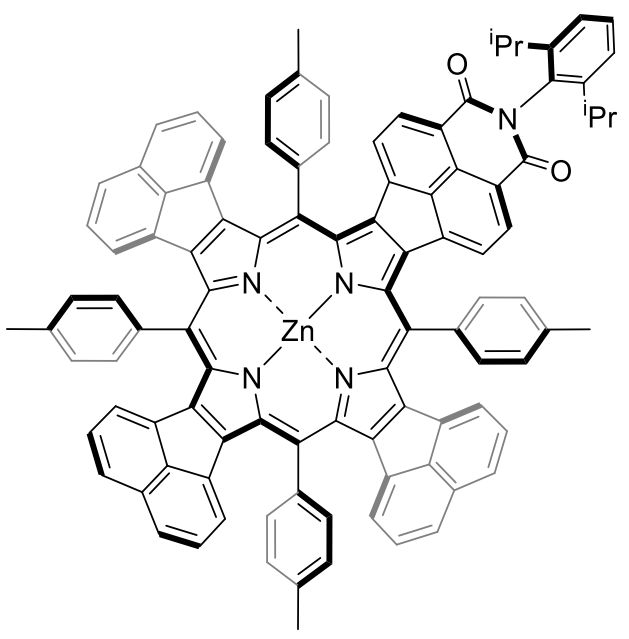

$D_{3} \mathbf{A}$ porphyrin ( $\left.3 b-Z n\right)$. Porphyrin $\mathbf{3 b}-\mathrm{Zn}$ was synthesized by following the same procedure as given for $\mathbf{t D}_{2} \mathbf{A}_{2}$ porphyrin $\mathbf{2 a}-\mathrm{Zn}$ by using porphyrin $\mathbf{3 b}-\mathrm{H}_{2}(20 \mathrm{mg}, 0.014 \mathrm{mmol})$, zinc acetate $(15.5 \mathrm{mg}$, $0.070 \mathrm{mmol})$, and $\mathrm{CHCl}_{3} / \mathrm{MeOH}(18 \mathrm{ml}, 5: 1)$. The crude compound was purified by column chromatography on alumina (grade $\mathrm{V}$ ) with $\mathrm{CH}_{2} \mathrm{Cl}_{2} /$ n-hexane (70:30) to give the product as dark blue solid (19 mg, 91\%). ${ }^{1} \mathrm{H}$ NMR (500 MHz, chloroform-d , $\left.300 \mathrm{~K}\right): \delta 8.59(8 \mathrm{H}, \mathrm{m}), 8.03\left(2 \mathrm{H}, \mathrm{d},{ }^{3} \mathrm{~J}=7.6 \mathrm{~Hz}\right)$, $7.81\left(2 \mathrm{H}, \mathrm{d},{ }^{3} \mathrm{~J}=6.9 \mathrm{~Hz}\right), 7.75(6 \mathrm{H}, \mathrm{m}), 7.64\left(6 \mathrm{H}, \mathrm{d},{ }^{3} \mathrm{~J}=7.9 \mathrm{~Hz}\right), 7.44\left(1 \mathrm{H}, \mathrm{t},{ }^{3} \mathrm{~J}=7.9 \mathrm{~Hz}\right), 7.33\left(1 \mathrm{H}, \mathrm{d},{ }^{3} \mathrm{~J}=\right.$ $6.9 \mathrm{~Hz}), 7.26\left(1 \mathrm{H}\right.$, overlap with $\left.\mathrm{CDCl}_{3}\right), 7.17(6 \mathrm{H}, \mathrm{m}), 5.68(6 \mathrm{H}, \mathrm{m}), 5.60(2 \mathrm{H}, 3 \mathrm{~J}=7.6 \mathrm{~Hz}), 2.88(6 \mathrm{H}, \mathrm{s})$, $2.87\left(1 \mathrm{H}, \mathrm{m}\right.$, merged with singlets), $2.88(6 \mathrm{H}, \mathrm{s}), 2.63\left({ }^{1} \mathrm{H}\right.$, sept, $\left.{ }^{3} \mathrm{~J}=6.8 \mathrm{~Hz}\right), 1.25\left(6 \mathrm{H}, \mathrm{d},{ }^{3} \mathrm{~J}=6.7 \mathrm{~Hz}\right)$, $1.00\left(6 \mathrm{H}, \mathrm{d},{ }^{3} \mathrm{~J}=6.9 \mathrm{~Hz}\right) .{ }^{13} \mathrm{C}$ NMR $(151 \mathrm{MHz}$, chloroform-d, $300 \mathrm{~K}): \delta 170.9,164.1,147.5,147.3$, 147.0, 146.5, 146.3, 146.2, 145.9, 145.2, 144.4, 140.5, 140.4, 140.3, 140.0, 139.8, 138.3, 137.1, 136.8, $134.7,134.5,133.6,133.5,132 . .1,131.1,131.0,130.9,129.4,129.31,127.4,127.3,127.2,127.1$, 125.50, 125.3, 125.1, 123.9, 123.7, 122.2, 121.8, 121.5, 118.0, 29.7, 29.1, 28.9, 24.1, 23.8, 21.8, 21.6 . HRMS (MALDI-TOF): $\mathrm{m} / \mathrm{z}$ : [M] $]^{+}$Calcd for $\mathrm{C}_{102} \mathrm{H}_{67} \mathrm{~N}_{5} \mathrm{O}_{2} \mathrm{Zn}$ : 1459.4640; Found 1659.4700 . 
Additional Figures 


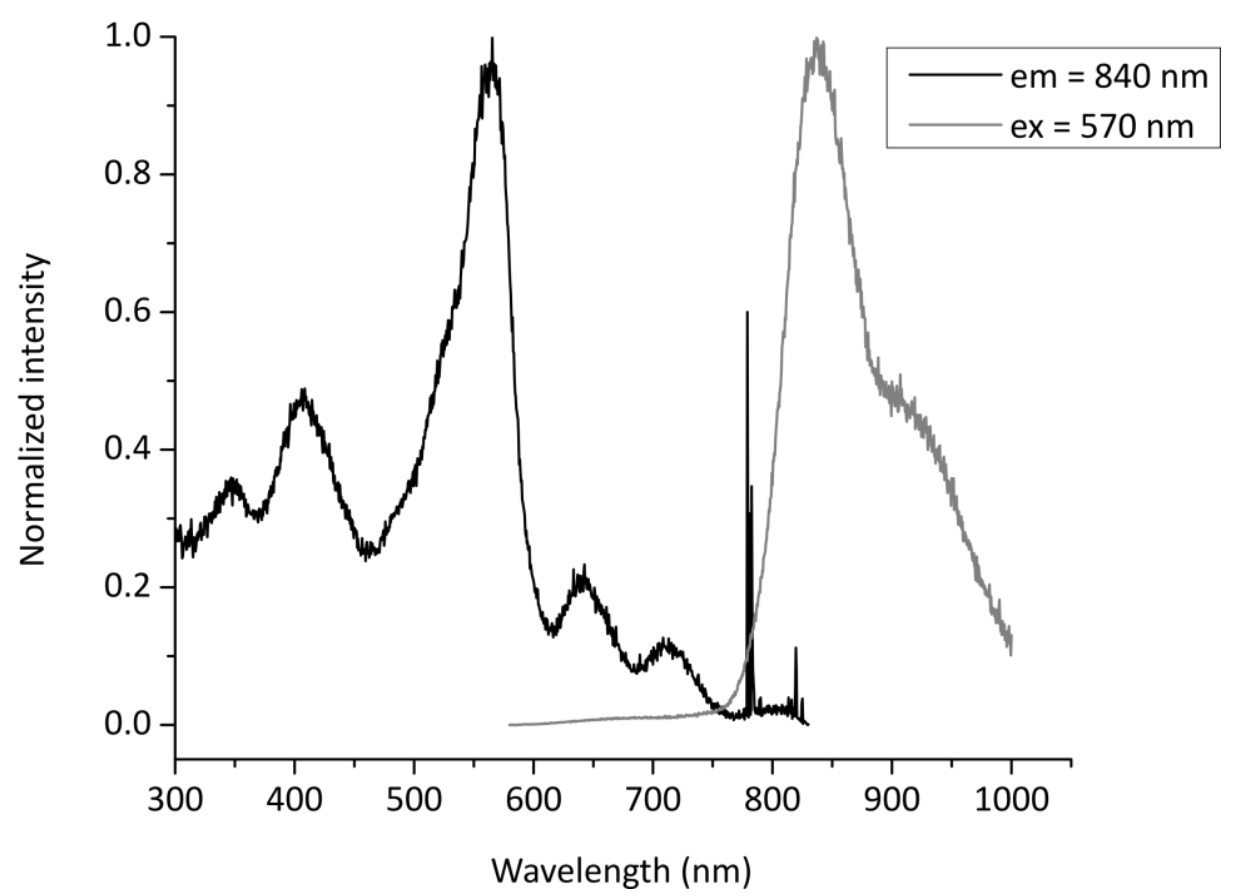

Figure S1. Normalized emission (excited at $570 \mathrm{~nm}$ ) and excitation spectra (monitored at $840 \mathrm{~nm}$ ) of compound $\mathbf{2 a}-\mathrm{H}_{2}$ recorded in DCM .

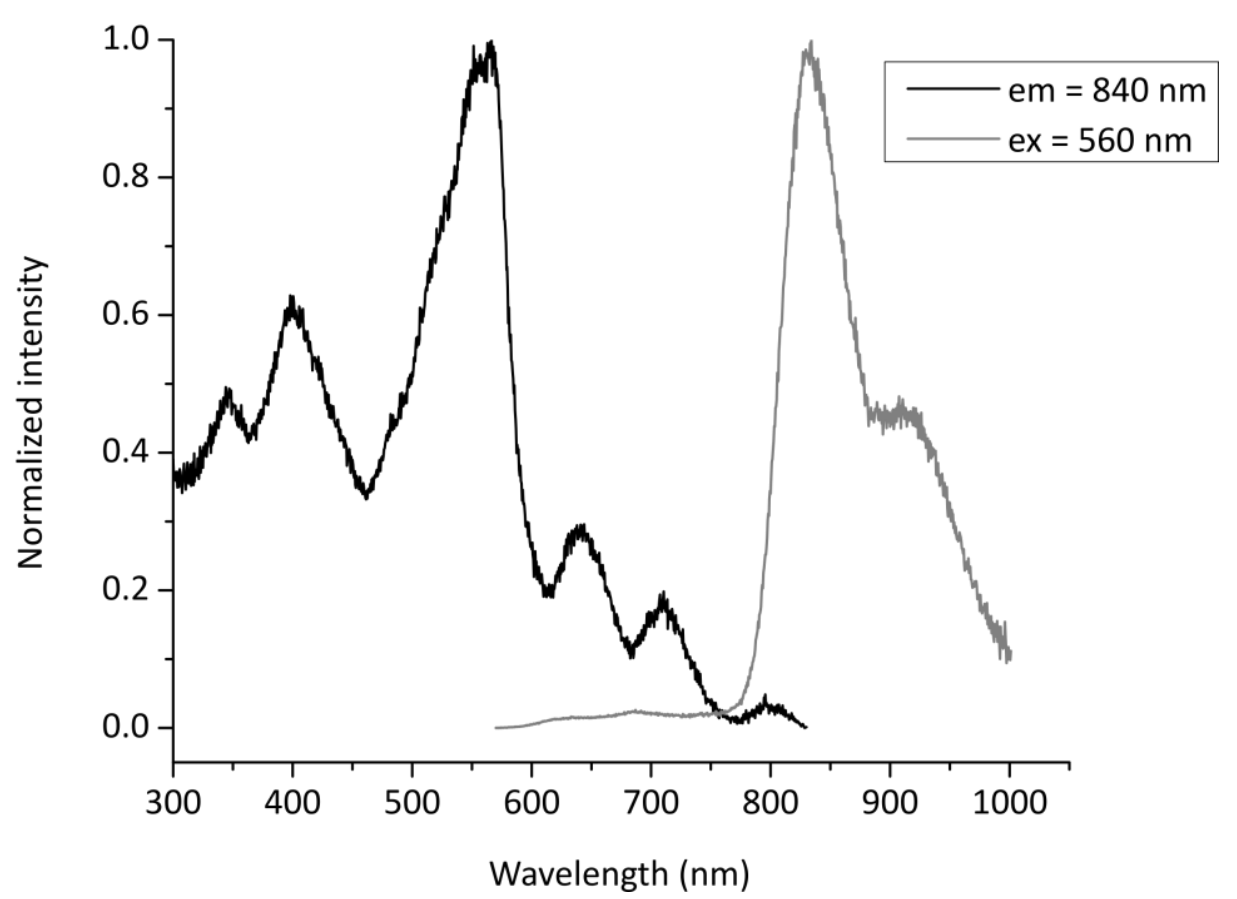

Figure S2. Normalized emission (excited at $560 \mathrm{~nm}$ ) and excitation spectra (monitored at $840 \mathrm{~nm}$ ) of compound $3 a-\mathrm{H}_{2}$ recorded in DCM . 


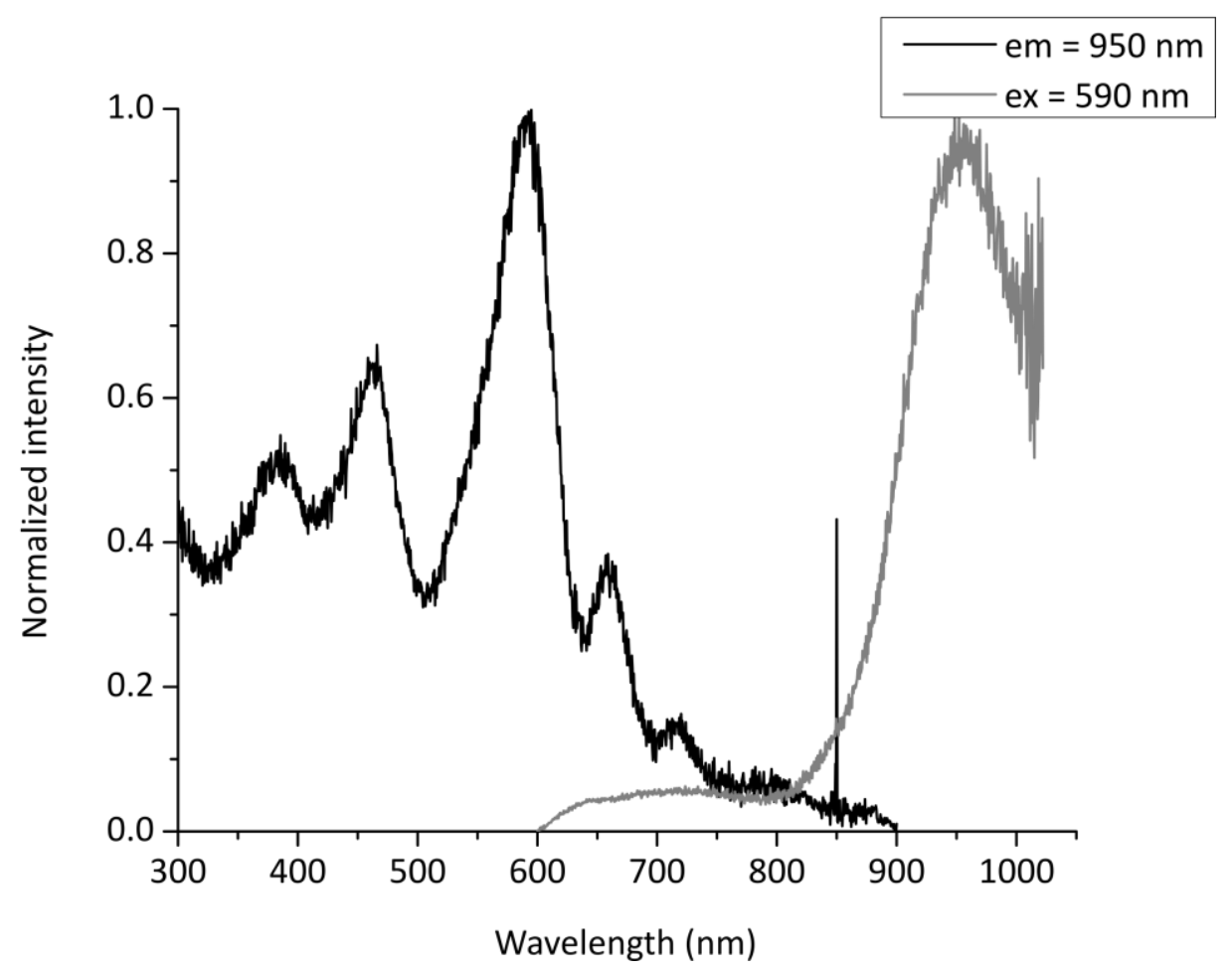

Figure S3. Normalized emission (excited at $590 \mathrm{~nm}$ ) and excitation spectra (monitored at $950 \mathrm{~nm}$ ) of compound $\mathbf{2} \mathbf{b}-\mathrm{H}_{2}$ recorded in DCM .

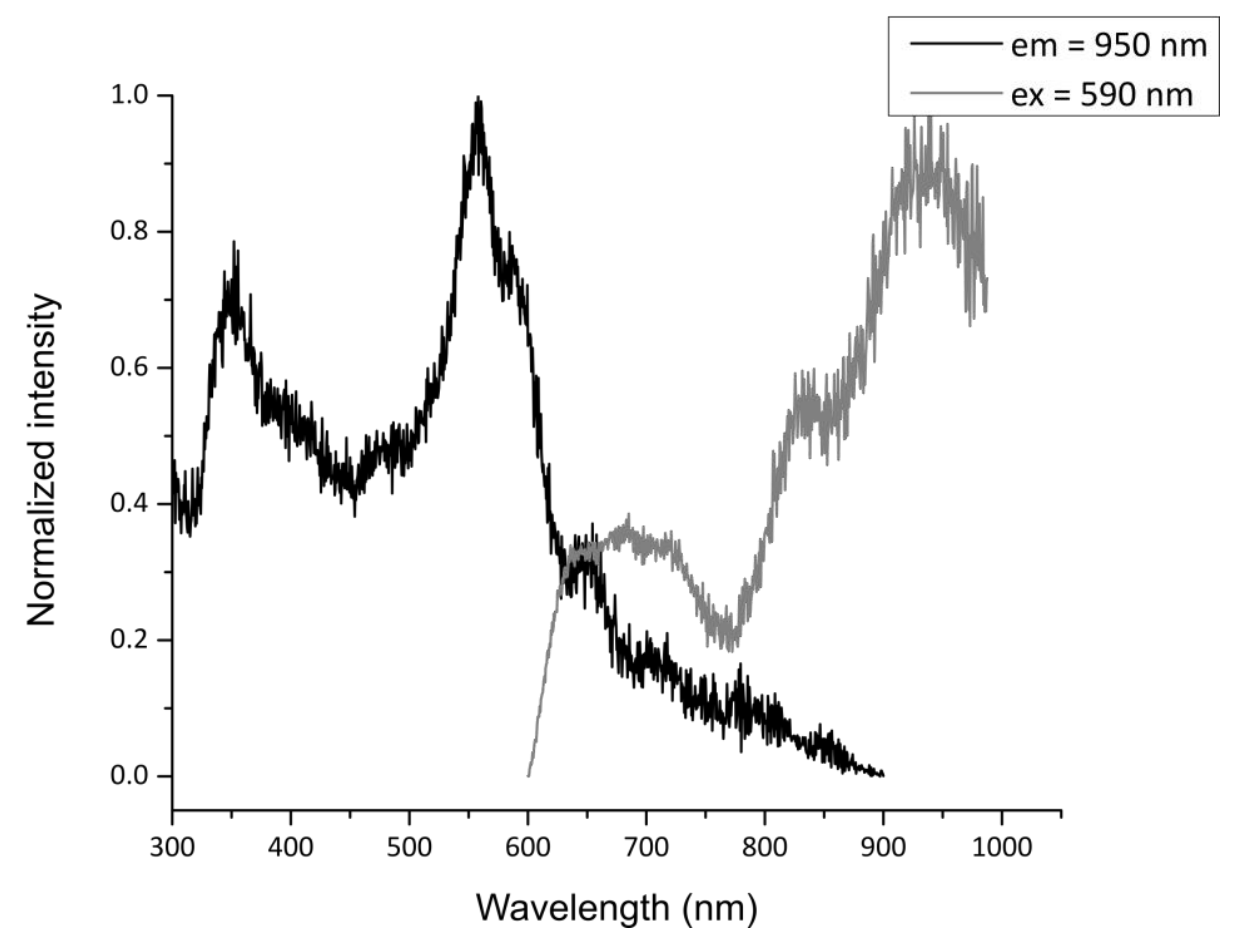

Figure S4. Normalized emission (excited at $590 \mathrm{~nm}$ ) and excitation spectra (monitored at $950 \mathrm{~nm}$ ) of compound $\mathbf{3 b}-\mathrm{H}_{2}$ recorded in DCM . 


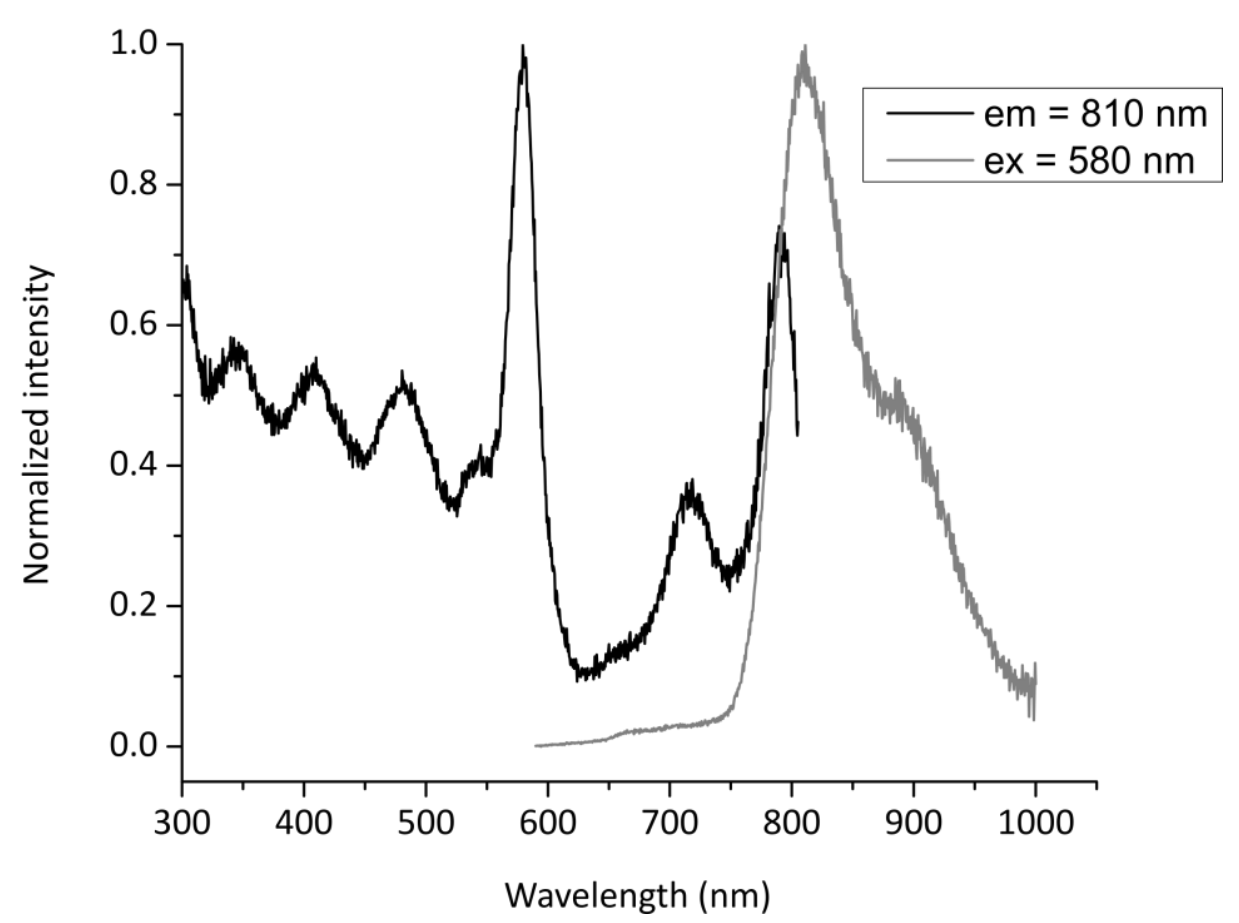

Figure S5. Normalized emission (excited at $580 \mathrm{~nm}$ ) and excitation spectra (monitored at $810 \mathrm{~nm}$ ) of compound $\mathbf{2 a}-\mathrm{Zn}$ recorded in toluene $+1 \%$ pyridine.

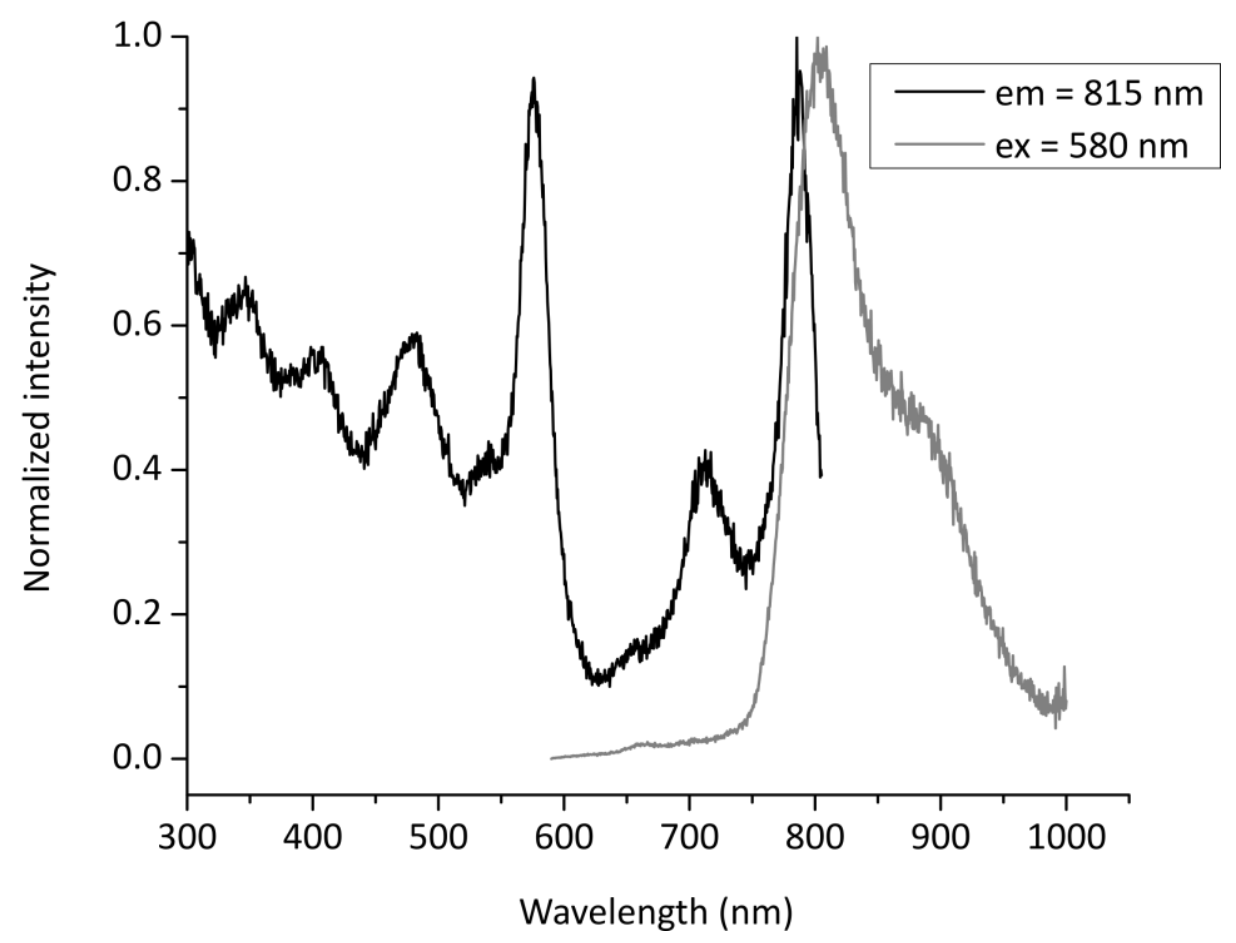

Figure S6. Normalized emission (excited at $580 \mathrm{~nm}$ ) and excitation spectra (monitored at $815 \mathrm{~nm}$ ) of compound $3 a-Z n$ recorded in toluene $+1 \%$ pyridine.. 


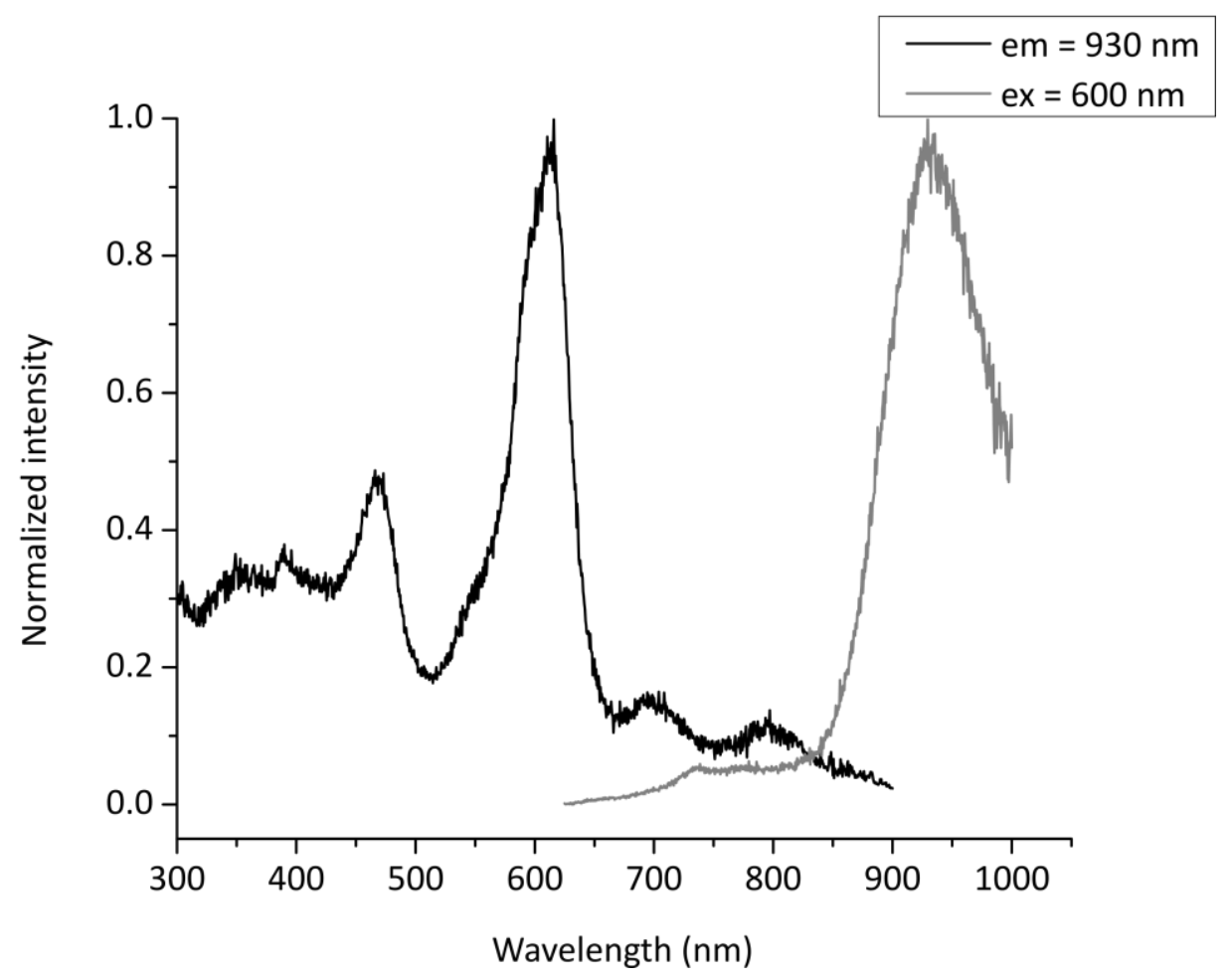

Figure S7. Normalized emission (excited at $600 \mathrm{~nm}$ ) and excitation spectra (monitored at $930 \mathrm{~nm}$ ) of compound $\mathbf{2 b}-\mathrm{Zn}$ recorded in toluene $+1 \%$ pyridine .

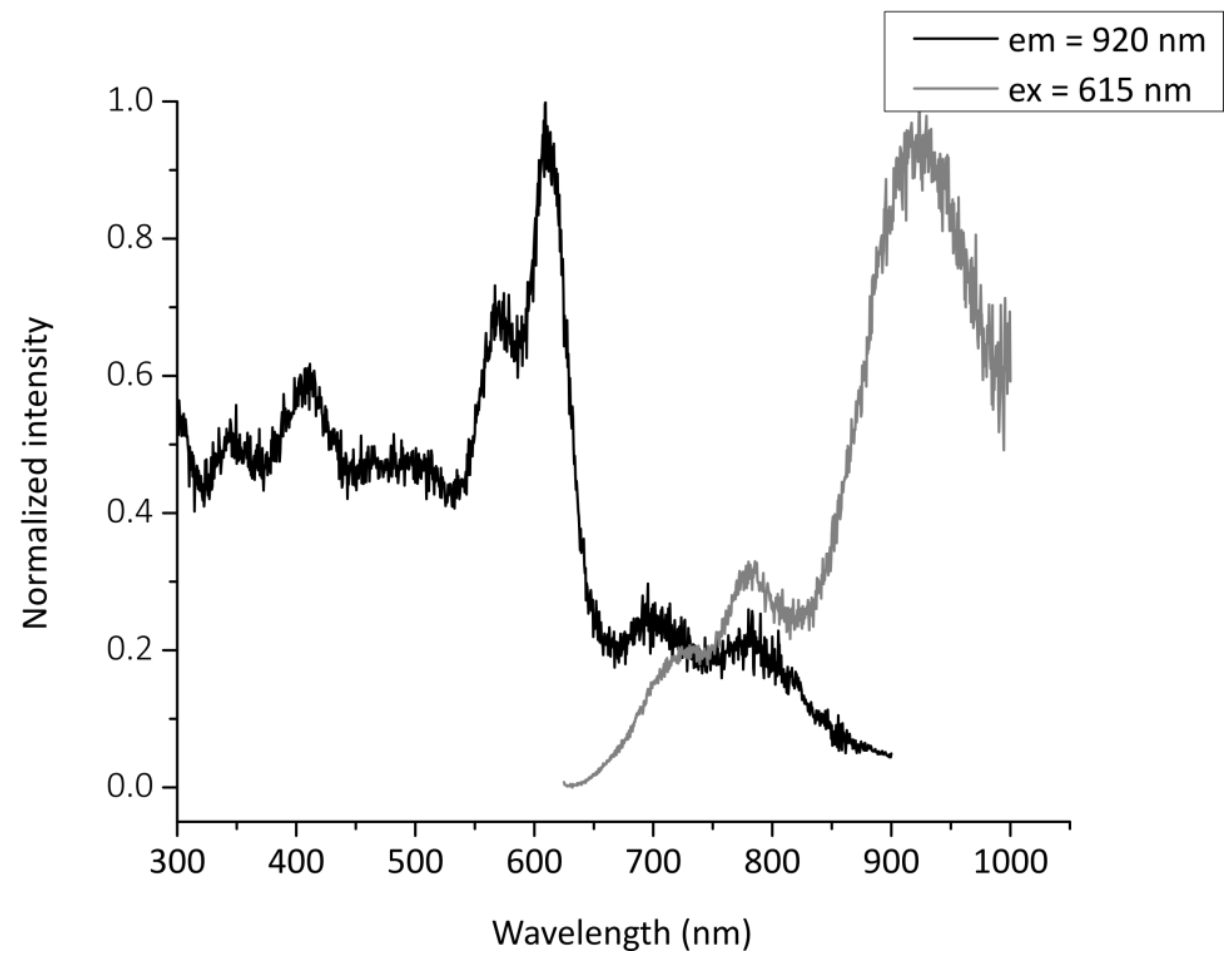

Figure S8. Normalized emission (excited at $615 \mathrm{~nm}$ ) and excitation spectra (monitored at $920 \mathrm{~nm}$ ) of compound $\mathbf{3 b}-\mathrm{Zn}$ recorded in toluene $+1 \%$ pyridine. 


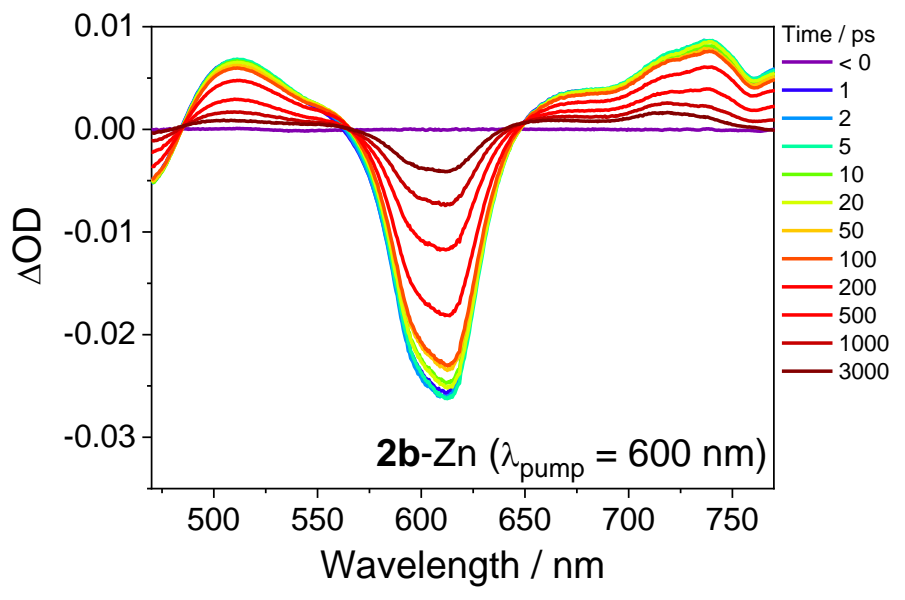

Figure 59. Femtosecond TA spectra of $\mathbf{2 b}-\mathrm{Zn}$ in toluene $+1 \%$ pyridine obtained following photoexcitation at $600 \mathrm{~nm}$.

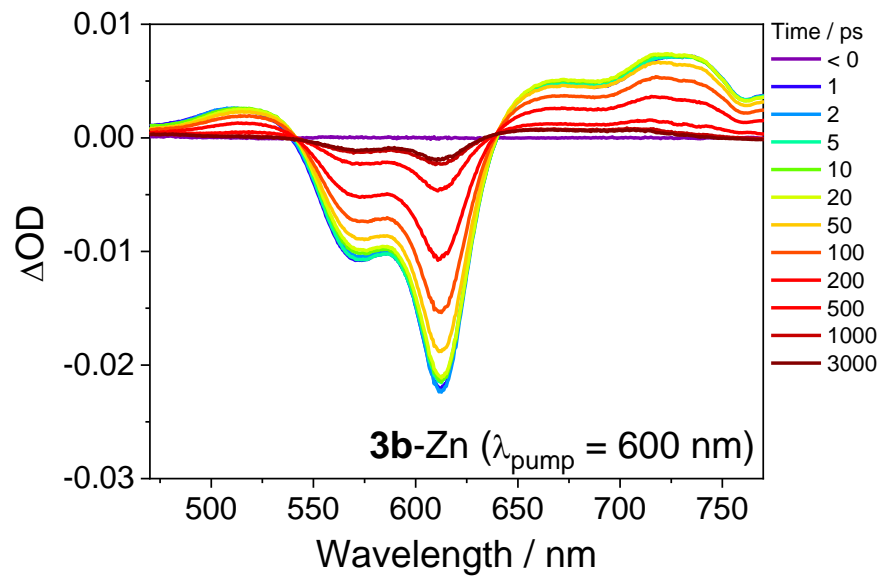

Figure S10. Femtosecond TA spectra of $\mathbf{3 b}-\mathrm{Zn}$ in toluene $+1 \%$ pyridine obtained following photoexcitation at $600 \mathrm{~nm}$.

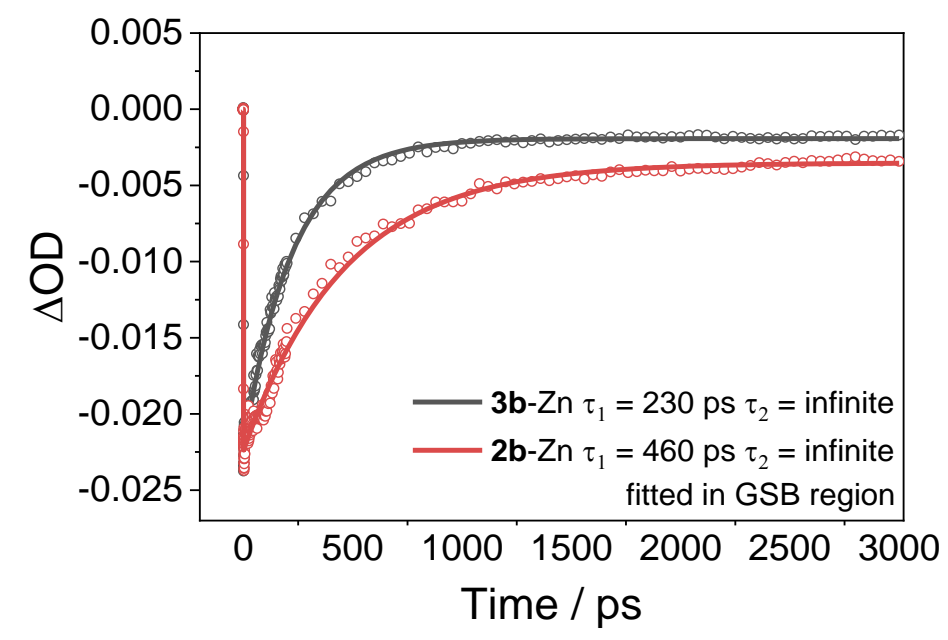

Figure S11. Decay profiles of $\mathbf{2} \mathbf{b}-\mathrm{Zn}$ and $\mathbf{3} \mathbf{b}-\mathrm{Zn}$ in toluene $+1 \%$ pyridine obtained following photoexcitation at $600 \mathrm{~nm}$. 


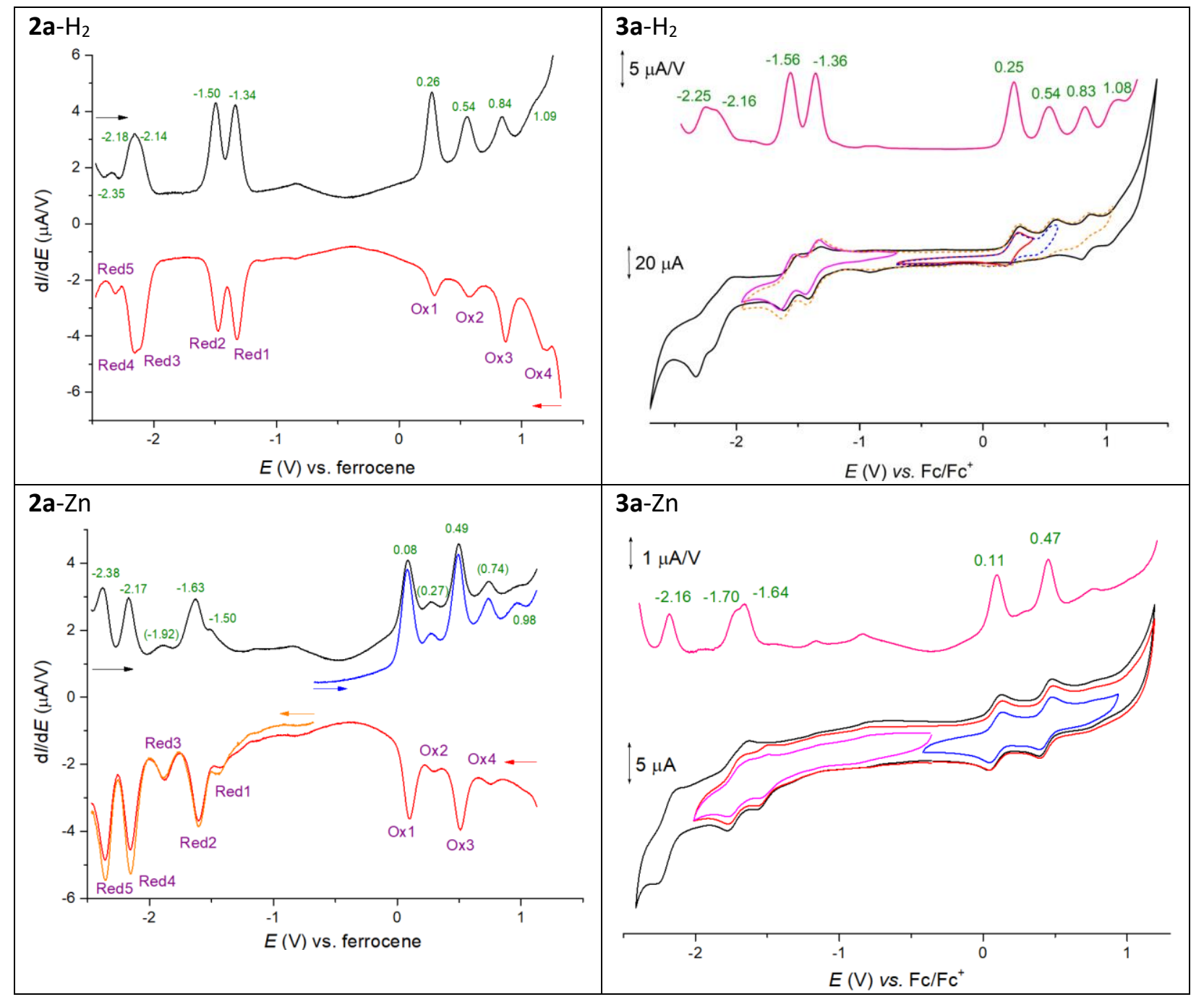

Figure S12. Differential pulse voltammograms and selected cyclic voltammograms for the NDA-fused porphyrins $2 \mathrm{a}-\mathrm{M}$ and $3 \mathrm{a}-\mathrm{M}(\mathrm{M}=2 \mathrm{H}, \mathrm{Zn})$. Conditions: dichloromethane, $\mathrm{TBAPF}_{6}$, glassy carbon electrode. 


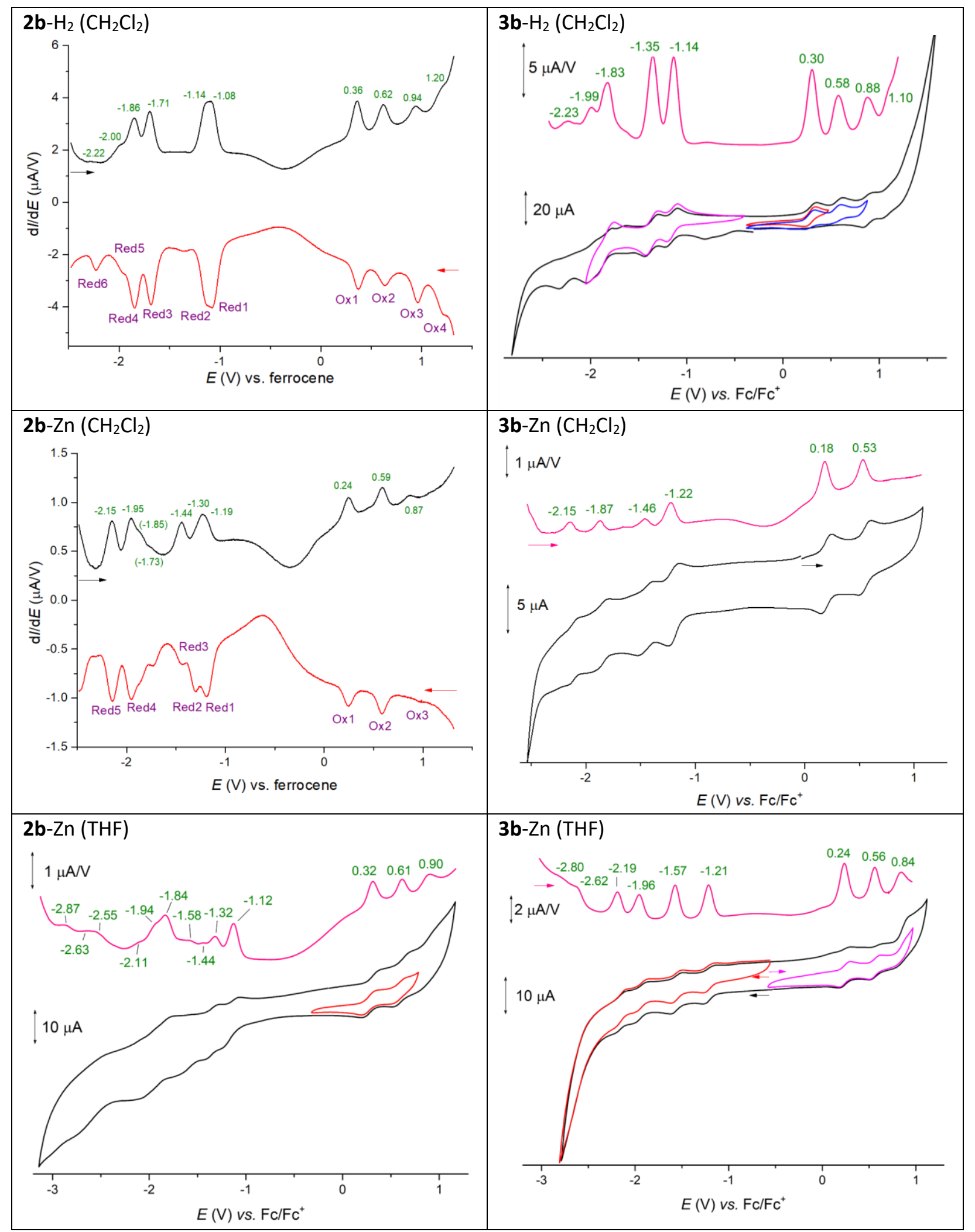

Figure S13. Differential pulse voltammograms and selected cyclic voltammograms for the NMI-fused porphyrins $\mathbf{2 b}-\mathrm{M}$ and $\mathbf{3 b}-\mathbf{M}(\mathrm{M}=2 \mathrm{H}, \mathrm{Zn})$. Conditions: solvent (as indicated), TBAPF ${ }_{6}$, glassy carbon electrode. 


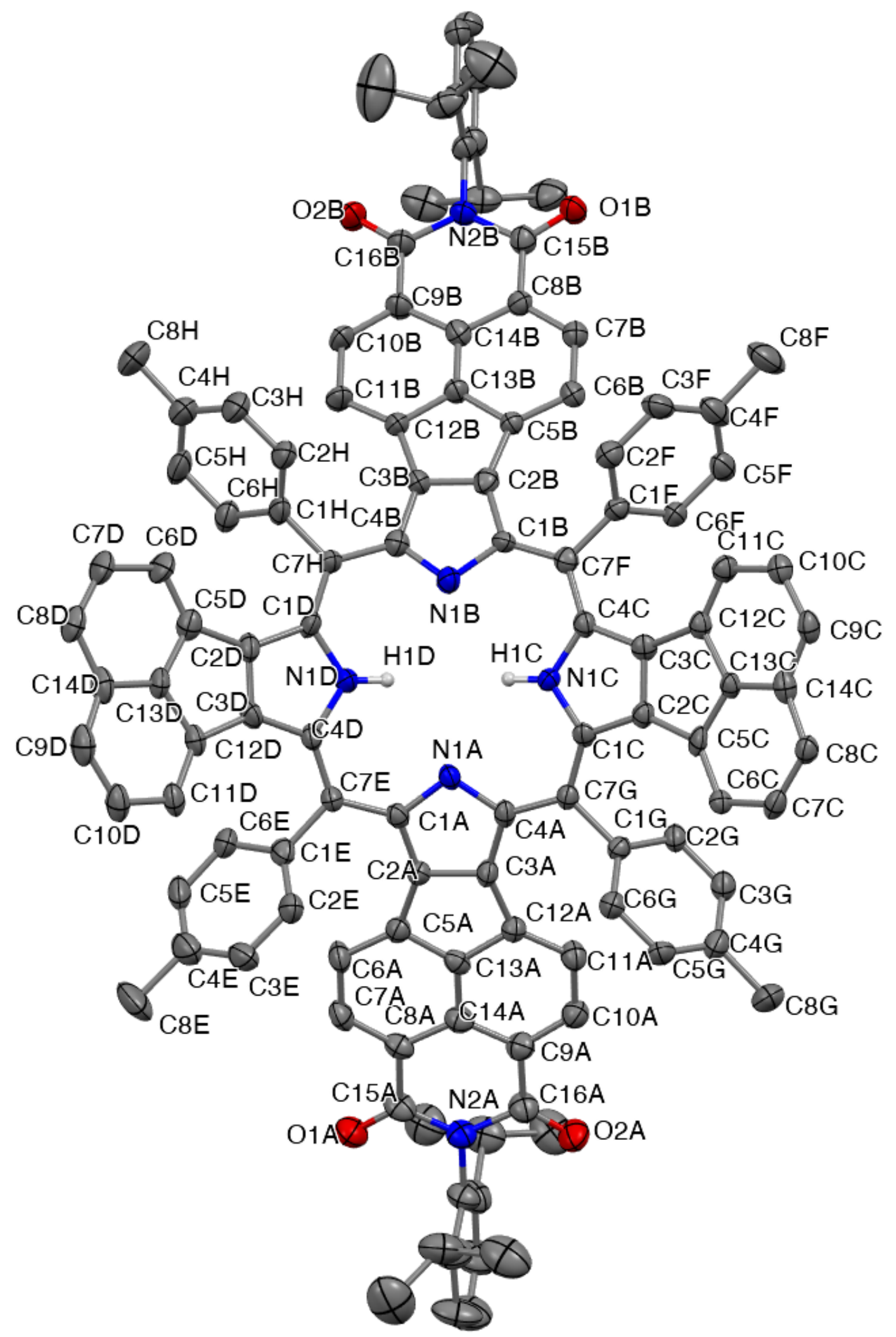

Figure S14. Molecular structure of compound $\mathbf{2 b}-\mathrm{H}_{2}$. The thermal ellipsoids represents $50 \%$ probability. (Hydrogen atoms and solvent molecule are omitted for clarity). 


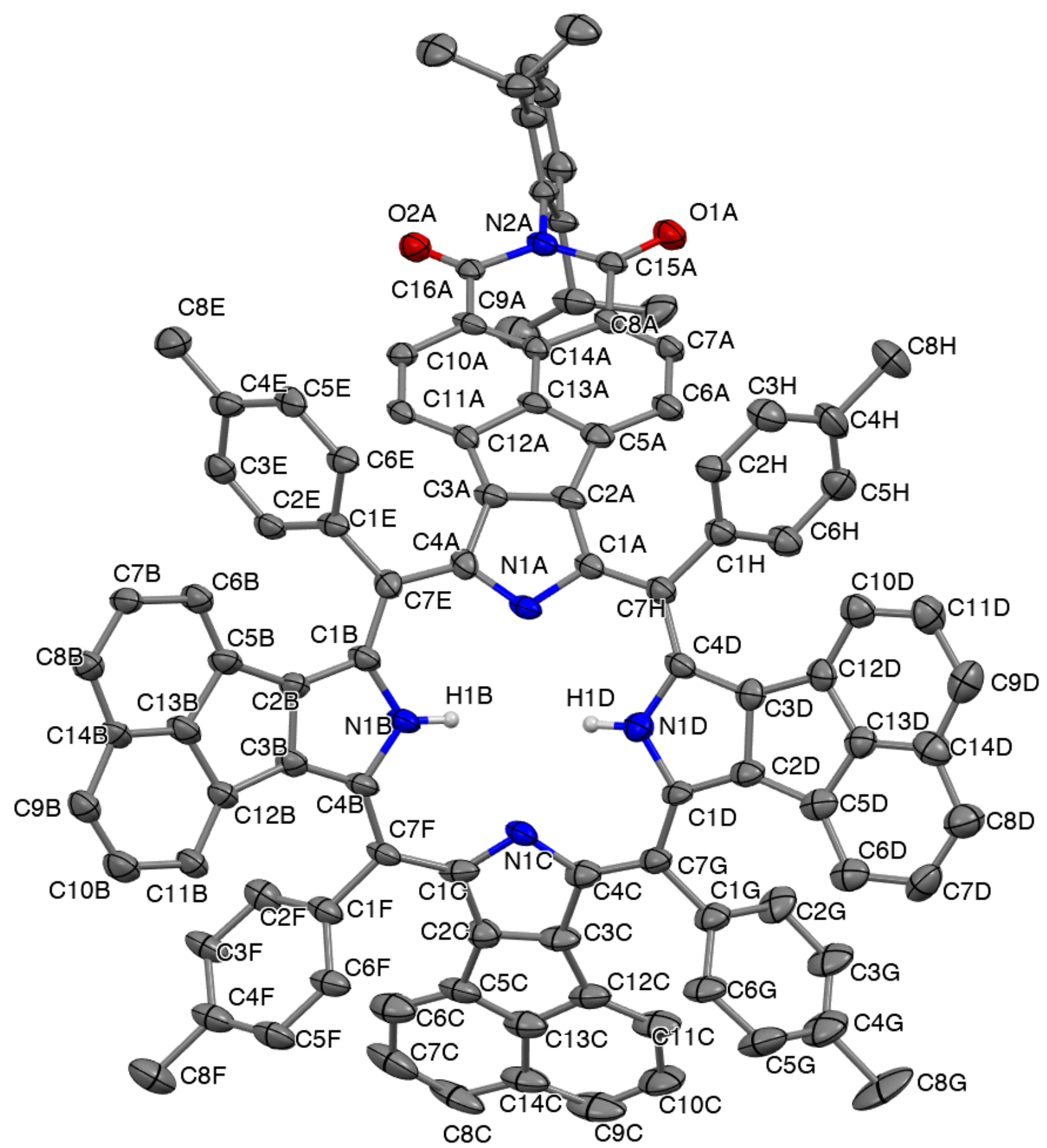

Figure S15. Molecular structure of compound $\mathbf{3 b}-\mathrm{H}_{2}$. The thermal ellipsoids represents $25 \%$ probability. (Hydrogen atoms or solvent molecule are omitted for clarity). 


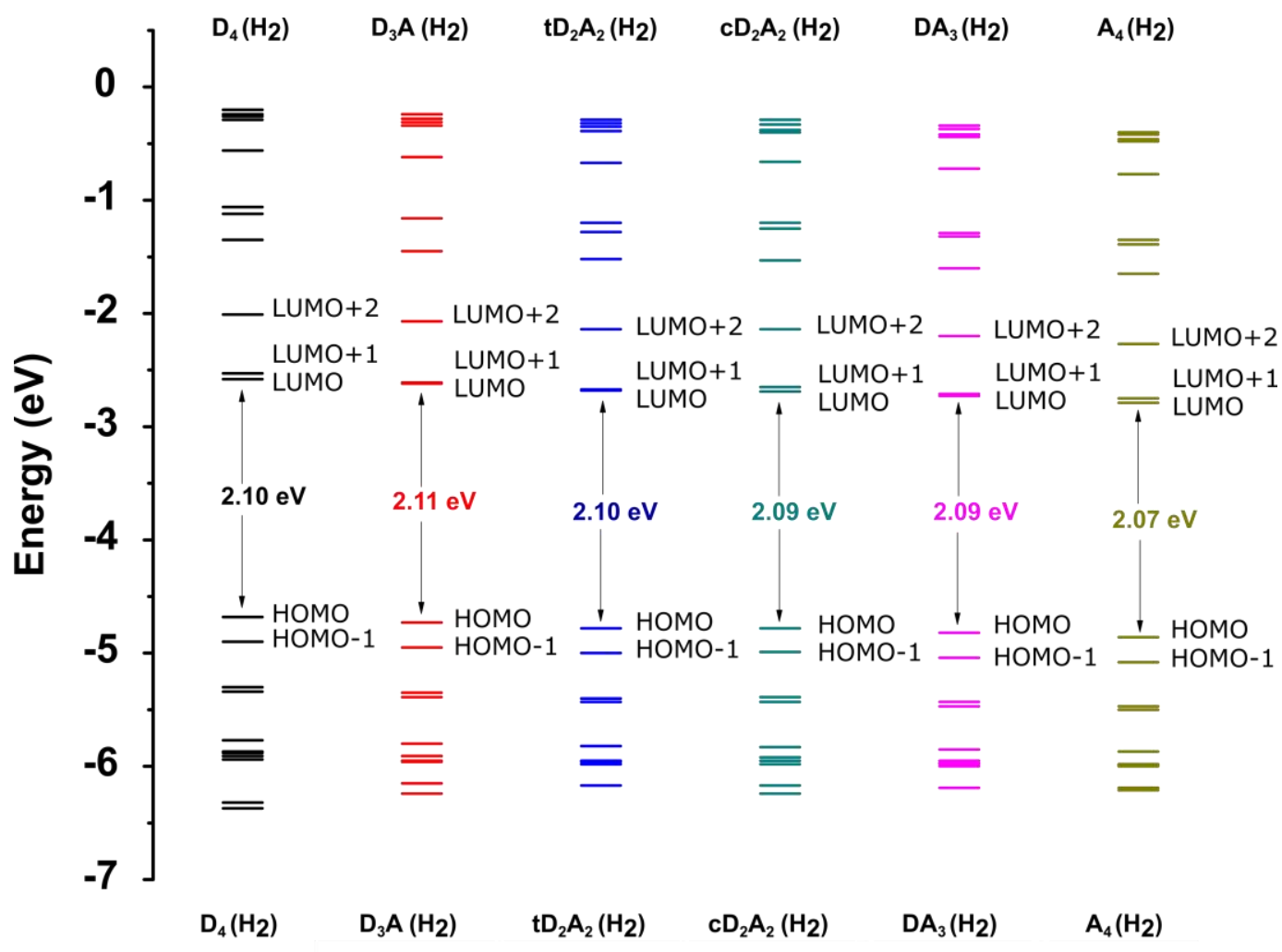

LUMO+2
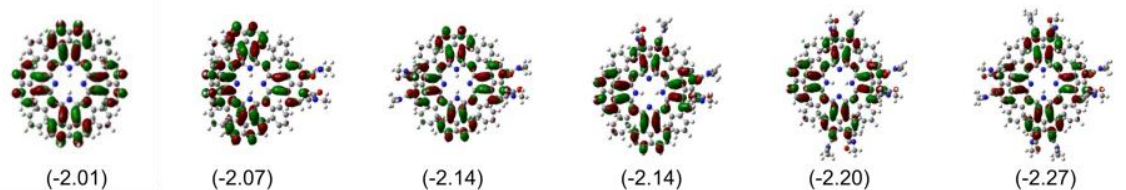

LUMO+1
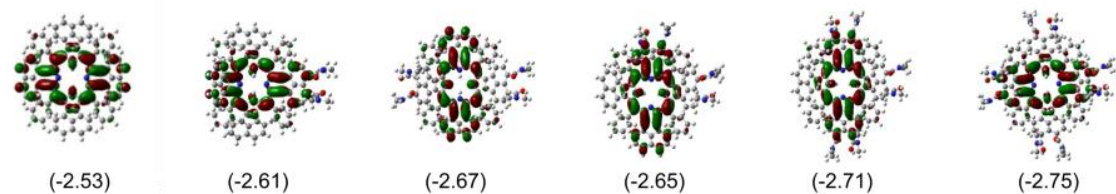

LUMO
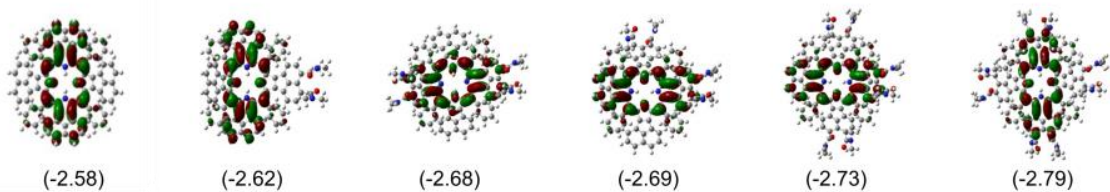

HOMO

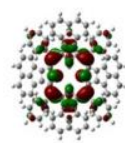

$(-4.68)$

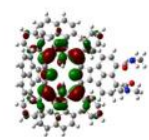

$(-4.73)$

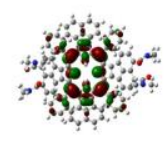

$(-4.78)$

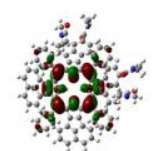

$(-4.78)$

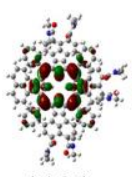

$(-4.82)$

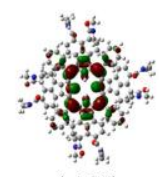

$(-4.86)$

HOMO-1

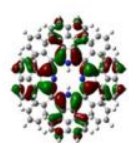

$(-4.90)$

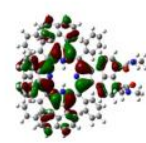

$(-4.95)$

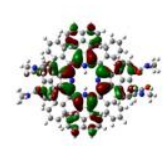

$(-5.00)$

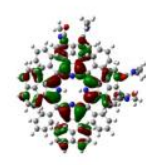

$(-4.99)$

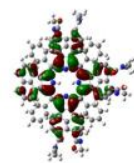

$(-5.04)$

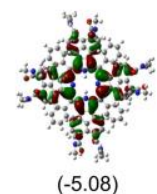

Figure S16. Kohn-Sham frontier orbital energy level diagram for various free base porphyrins containing peripheral naphthalene and napthalenediamide units. The $\mathrm{MO}$ diagrams indicate LUMO+2, LUMO+1, LUMO, HOMO and HOMO-1. All calculations were performed at the level of B3LYP/6-31g $(d, p)$ theory. 


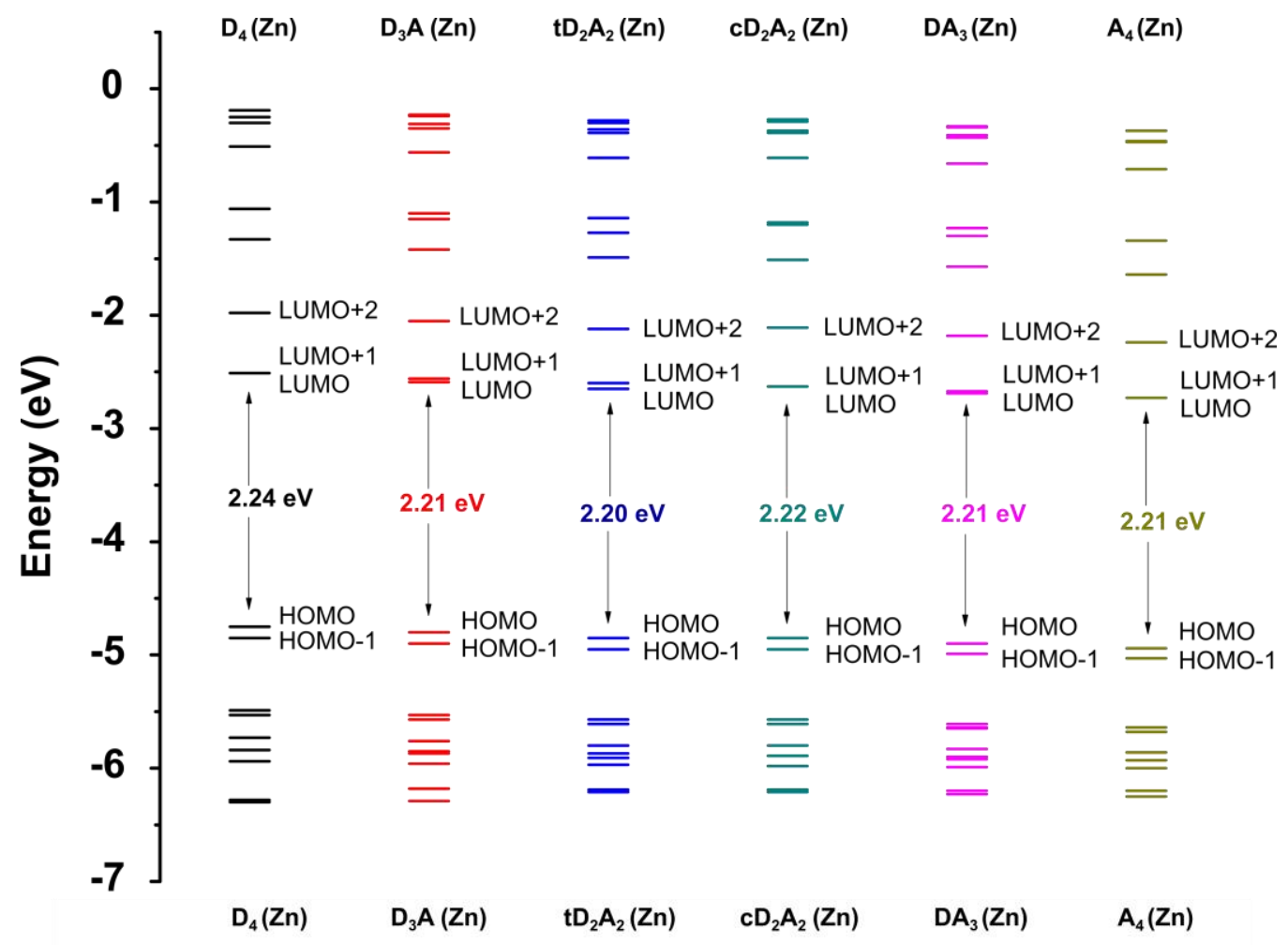

$\mathrm{LUMO}+2$

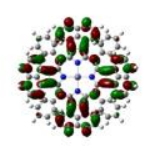

$(-1.98)$

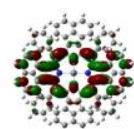

$(-2.51)$

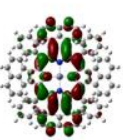

$(-2.51)$

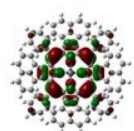

$(-4.75)$

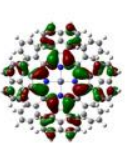

$(-4.85)$

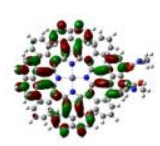

$(-2.05)$

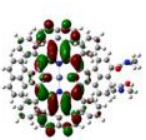

$(-2.56)$

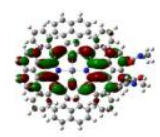

(-2.59)

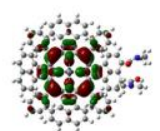

$(-4.80)$

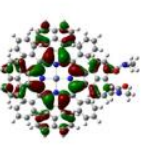

$(-4.90)$

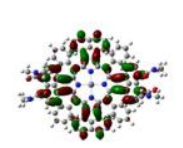

$(-2.12)$

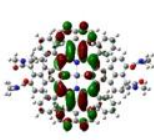

$(-2.60)$

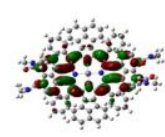

$(-2.65)$

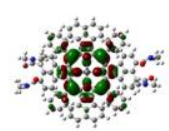

$(-4.85)$

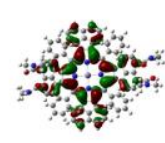

$(-4.95)$

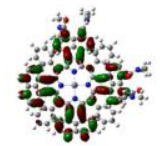

(-2.11)

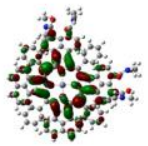

$(-2.63)$

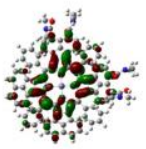

(-2.63)

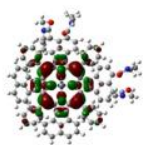

(-4.85)

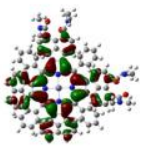

(-4.95)

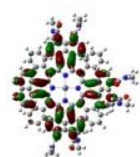

$(-2.18)$
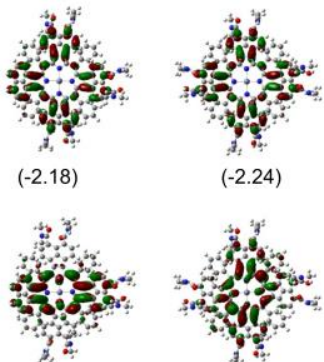

$(-2.67)$

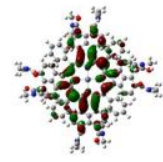

$(-2.73)$

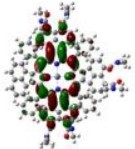

(-2.69)

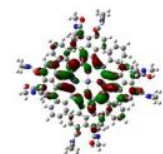

$(-2.73)$

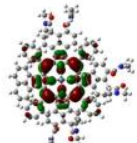

$(-4.90)$

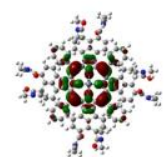

$(-4.94)$

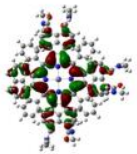

$(-4.99)$

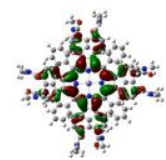

$(-5.03)$

Figure S17. Kohn-Sham frontier orbital energy level diagram for various zinc porphyrins containing peripheral naphthalene and napthalenediamide units. The $\mathrm{MO}$ diagrams indicate $\mathrm{LUMO}+2, \mathrm{LUMO}+1$, LUMO, HOMO and HOMO-1. All calculations were performed at the level of B3LYP/6-31g(d,p) theory. 

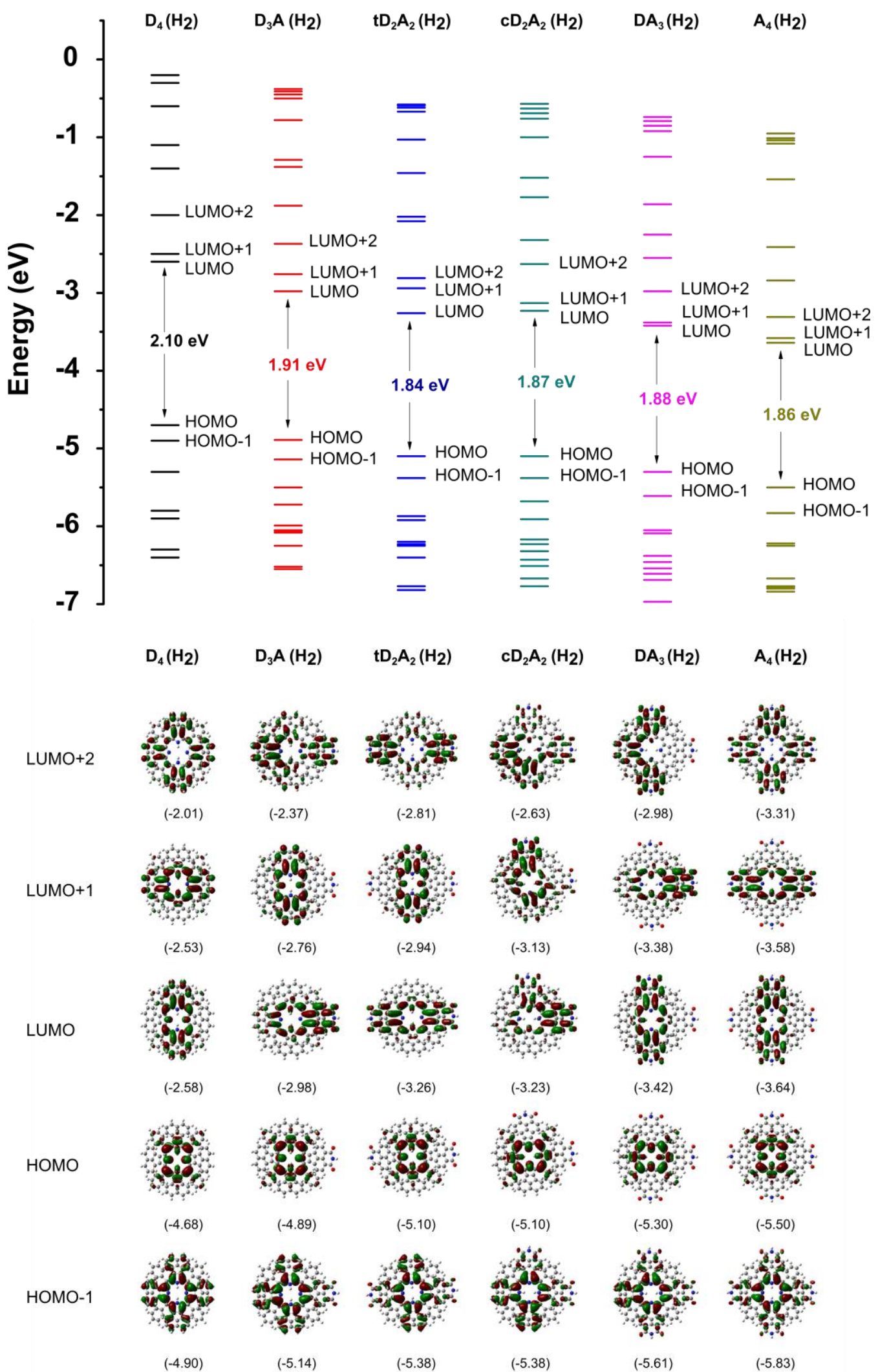

Figure S18. Kohn-Sham frontier orbital energy level diagram for various free base porphyrins containing peripheral naphthalene and napthalenemonoimide units. The $\mathrm{MO}$ diagrams indicate LUMO+2, LUMO+1, LUMO, HOMO and HOMO-1. All calculations were performed at the level of $B 3 \operatorname{LY} / 6-31 \mathrm{~g}(\mathrm{~d}, \mathrm{p})$ theory. 

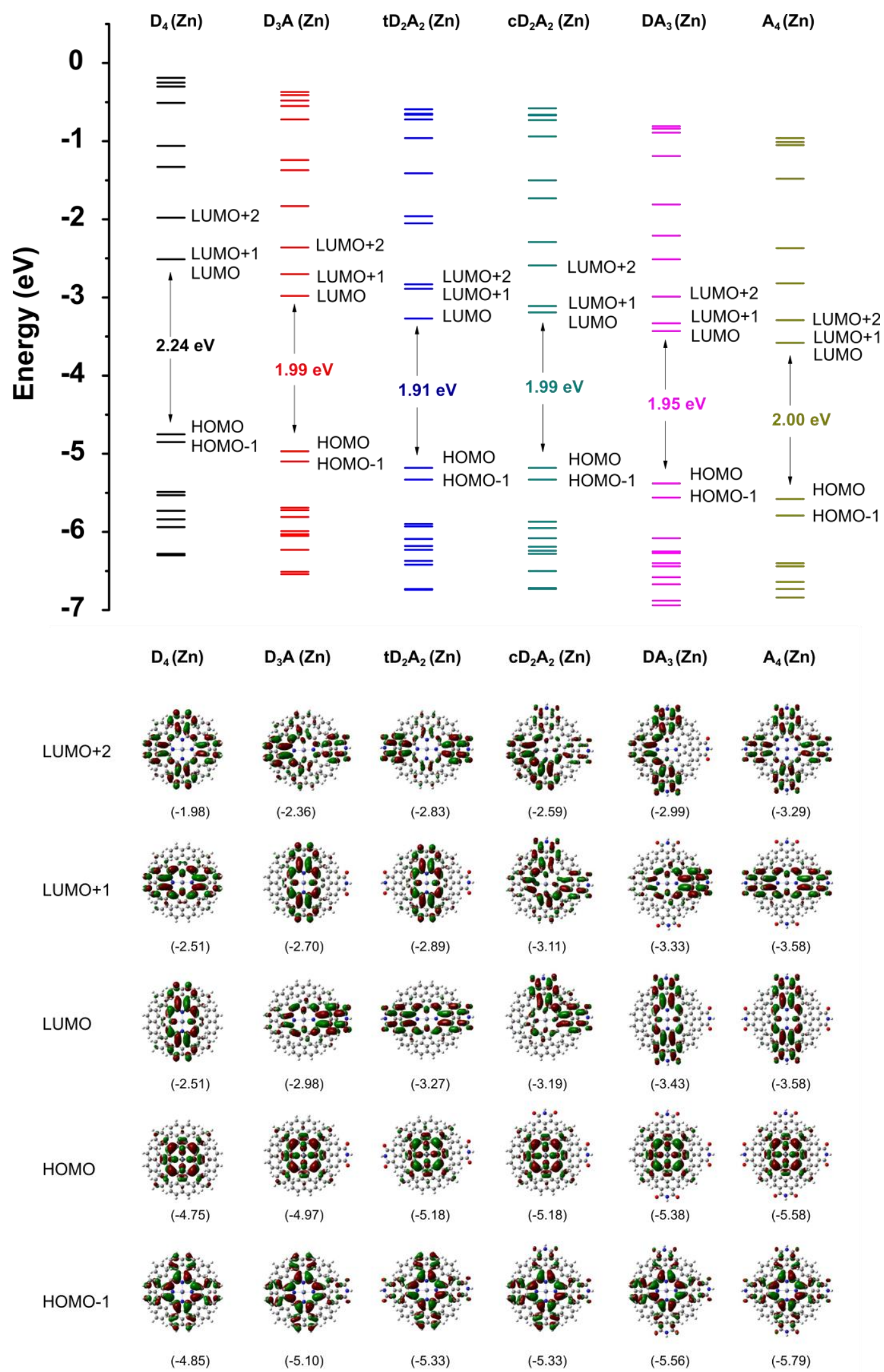

Figure S19. Kohn-Sham frontier orbital energy level diagram for various zinc porphyrins containing peripheral naphthalene and napthalenemonoimide units. The $\mathrm{MO}$ diagrams indicate $\mathrm{LUMO}+2$, LUMO+1, LUMO, HOMO and HOMO-1. All calculations were performed at the level of B3LYP/6$31 \mathrm{~g}(\mathrm{~d}, \mathrm{p})$ theory. 


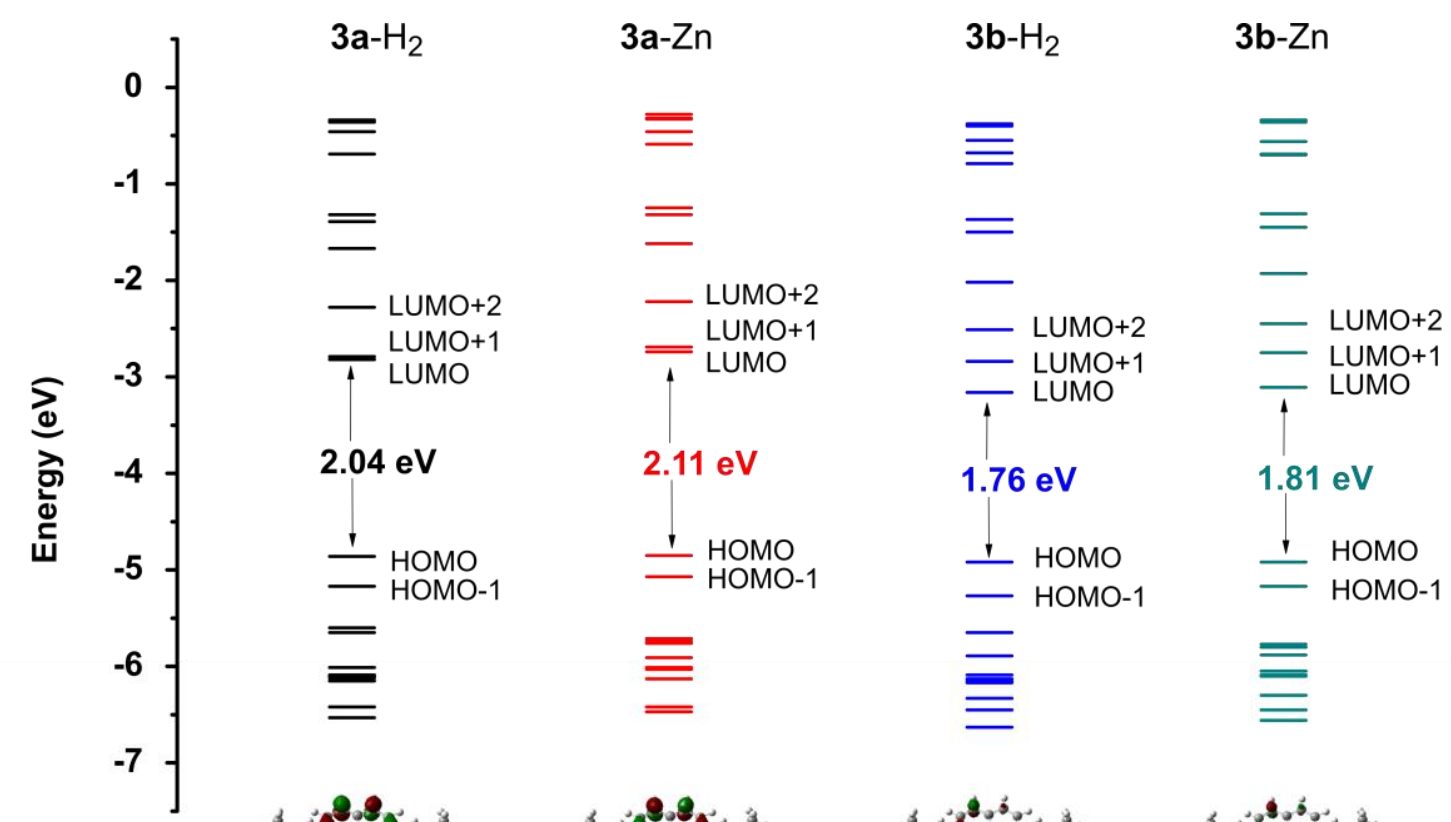

$\mathrm{LUMO}+2$
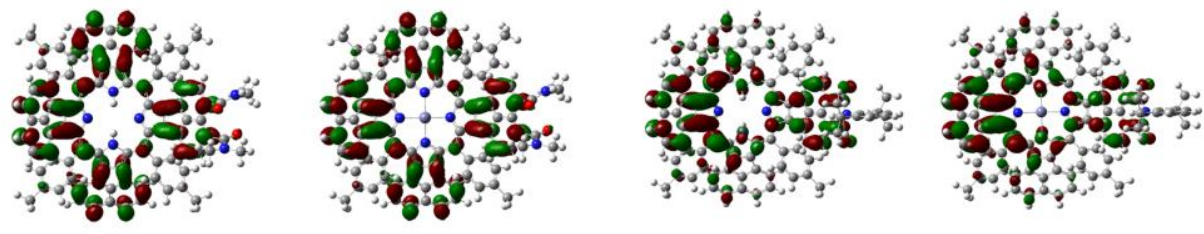

$(-2.28)$

$(-2.22)$

$(-2.51$

$(-2.45)$
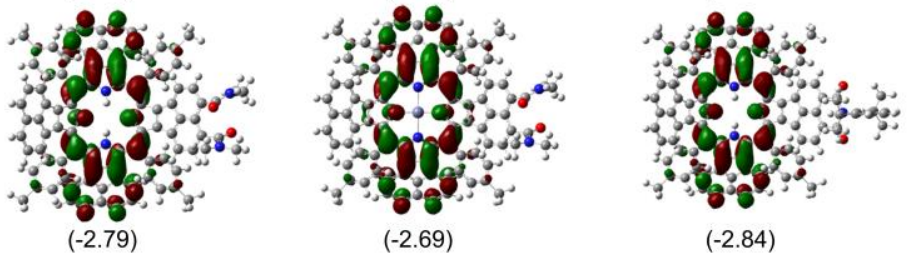

$(-2.84)$

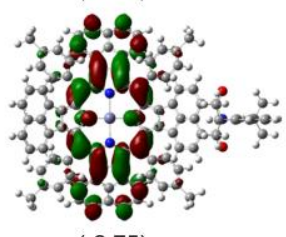

$(-2.75)$
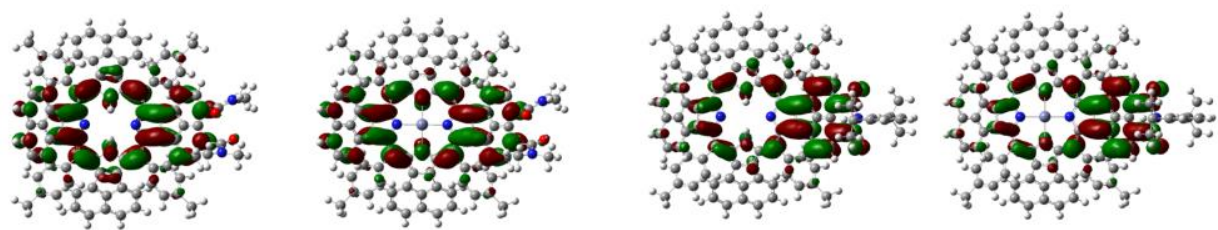

$(-2.74)$

$(-3.11)$

$(-3.16)$

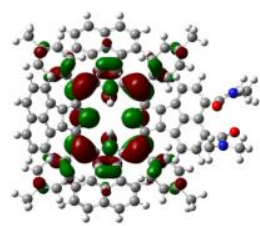

$(-4.86)$

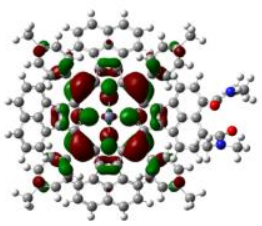

$(-4.85)$

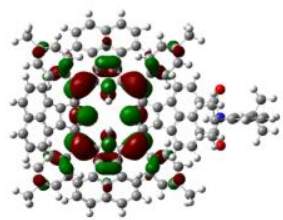

$(-4.92)$

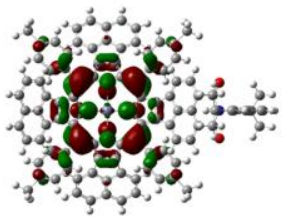

$(-4.92)$
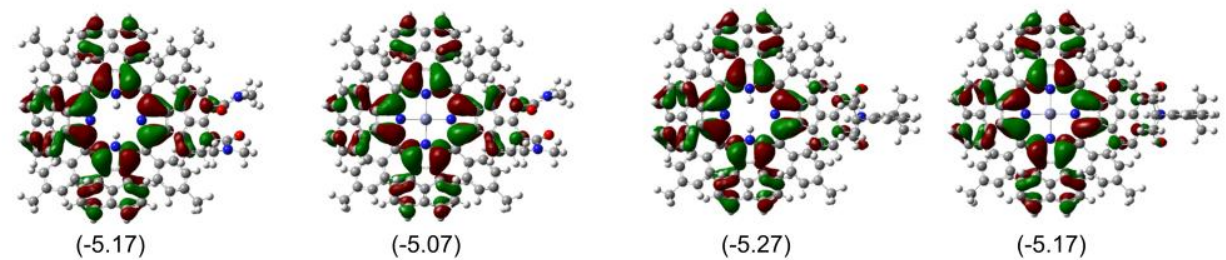

$(-5.17)$

Figure S20. Kohn-Sham frontier orbital energy level diagram for $\mathbf{3} a-\mathrm{H}_{2}, \mathbf{3 a}-\mathbf{Z n}, \mathbf{3} \mathbf{b}-\mathrm{H}_{2}$ and $\mathbf{3 b} \mathbf{b} \mathbf{Z n}$. The $\mathrm{MO}$ diagrams indicate LUMO+2, LUMO+1, LUMO, HOMO and HOMO-1. All calculations were performed at the level of B3LYP/6-31g $(d, p)$ theory with PCM (dichloromethane). 

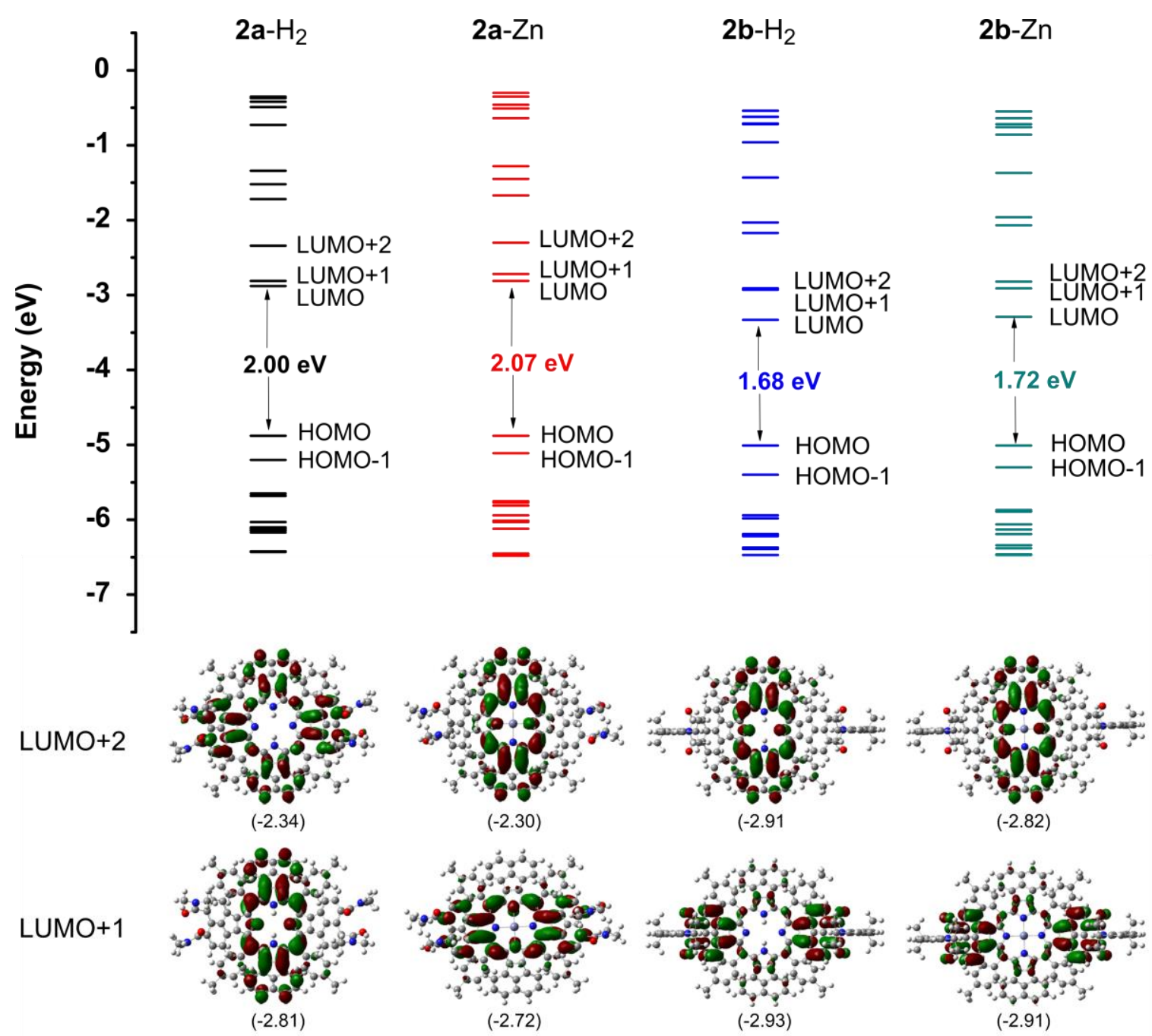

LUMO
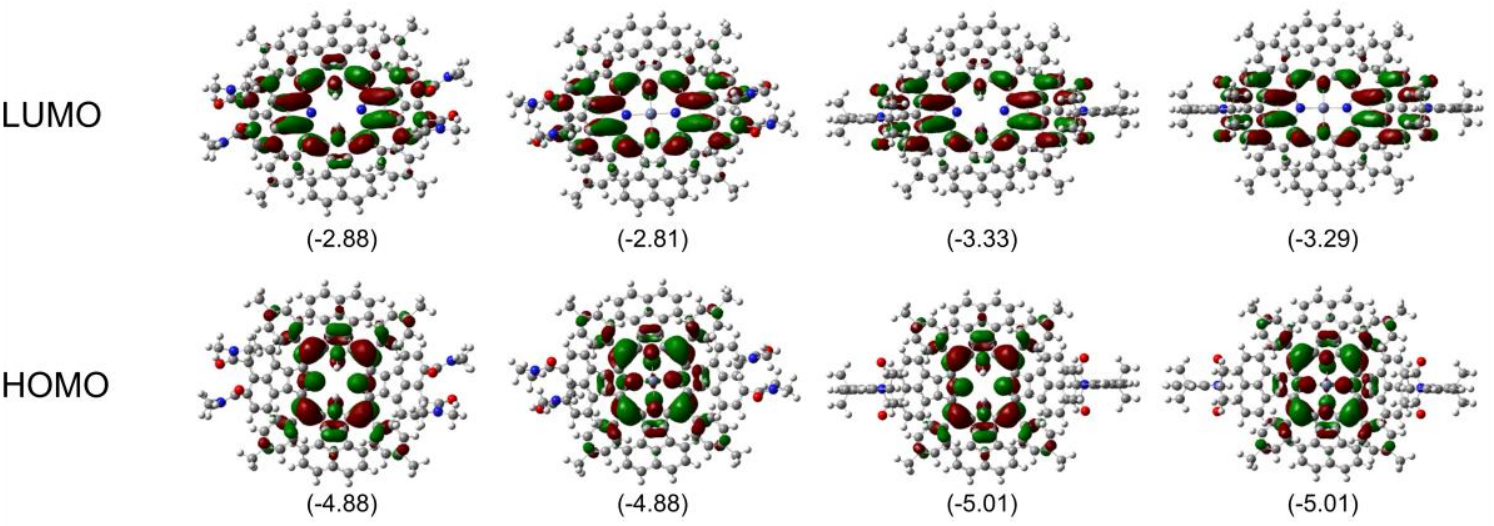

HOMO-1

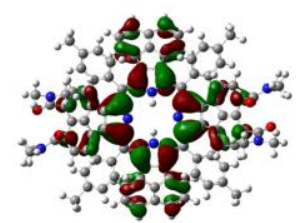

$(-5.20)$

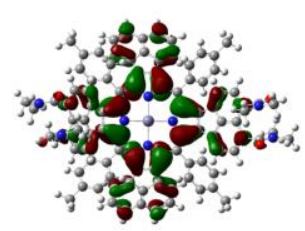

$(-2.11)$

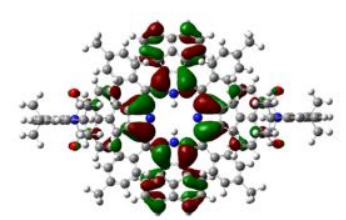

$(-5.40)$

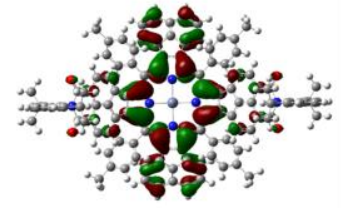

$(-5.30)$

Figure S21. Kohn-Sham frontier orbital energy level diagram for $\mathbf{2} \mathbf{a}-\mathrm{H}_{2}, \mathbf{2} \mathbf{a}-\mathbf{Z n}, \mathbf{2} \mathbf{b}-\mathrm{H}_{2}$ and $\mathbf{2} \mathbf{b}-\mathbf{Z n}$. The MO diagrams indicate LUMO+2, LUMO+1, LUMO, HOMO and HOMO-1. All calculations were performed at the level of B3LYP/6-31g $(d, p)$ theory with PCM (dichloromethane). 


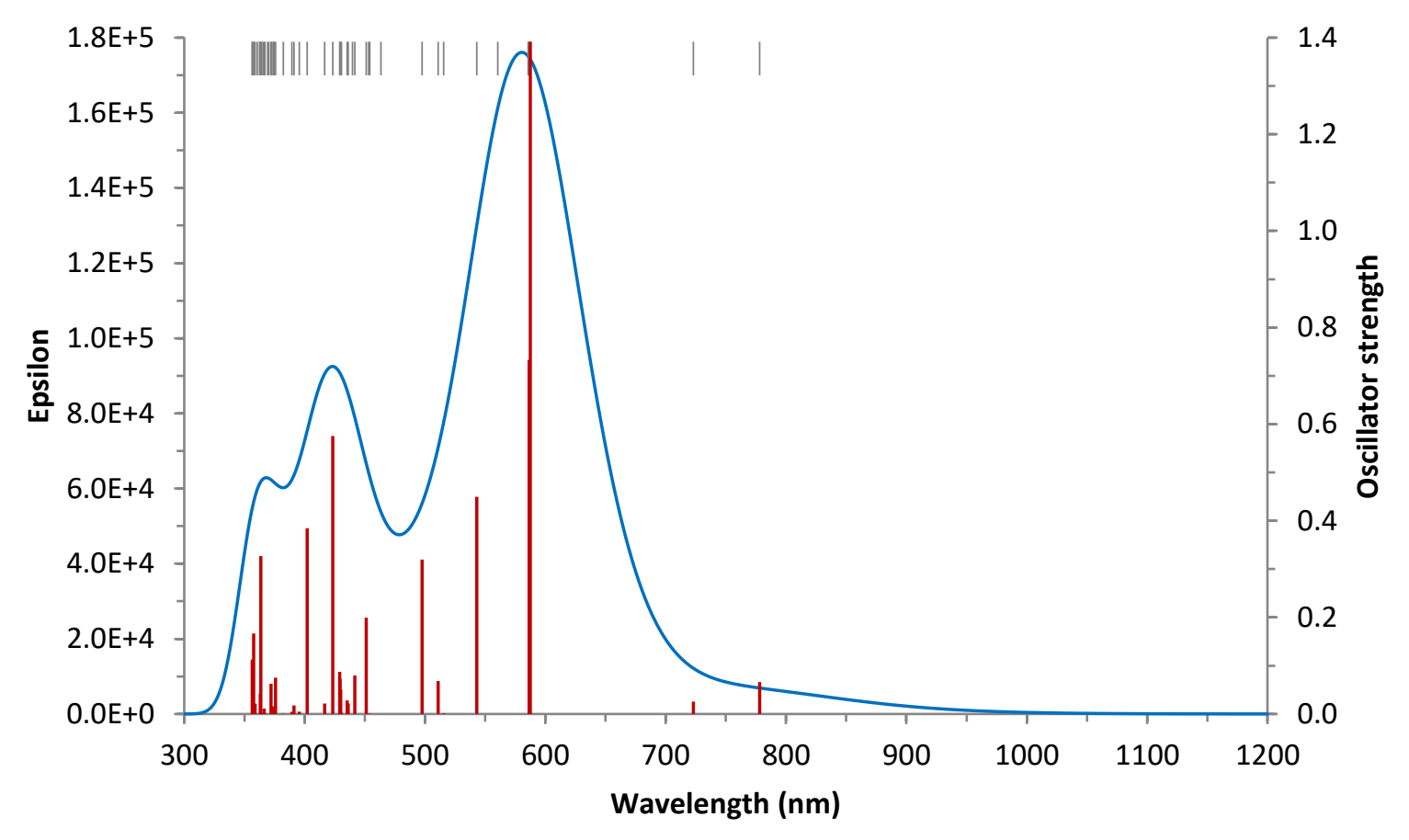

Figure S22. Electronic absorption spectrum of 2a- $\mathrm{H}_{2}$ simulated using time-dependent density functional theory (B3LYP/6-31G(d)/PCM $\left(\mathrm{CH}_{2} \mathrm{Cl}_{2}\right), 50$ transitions, linewidth factor $3000 \mathrm{~cm}^{-1}$ ).

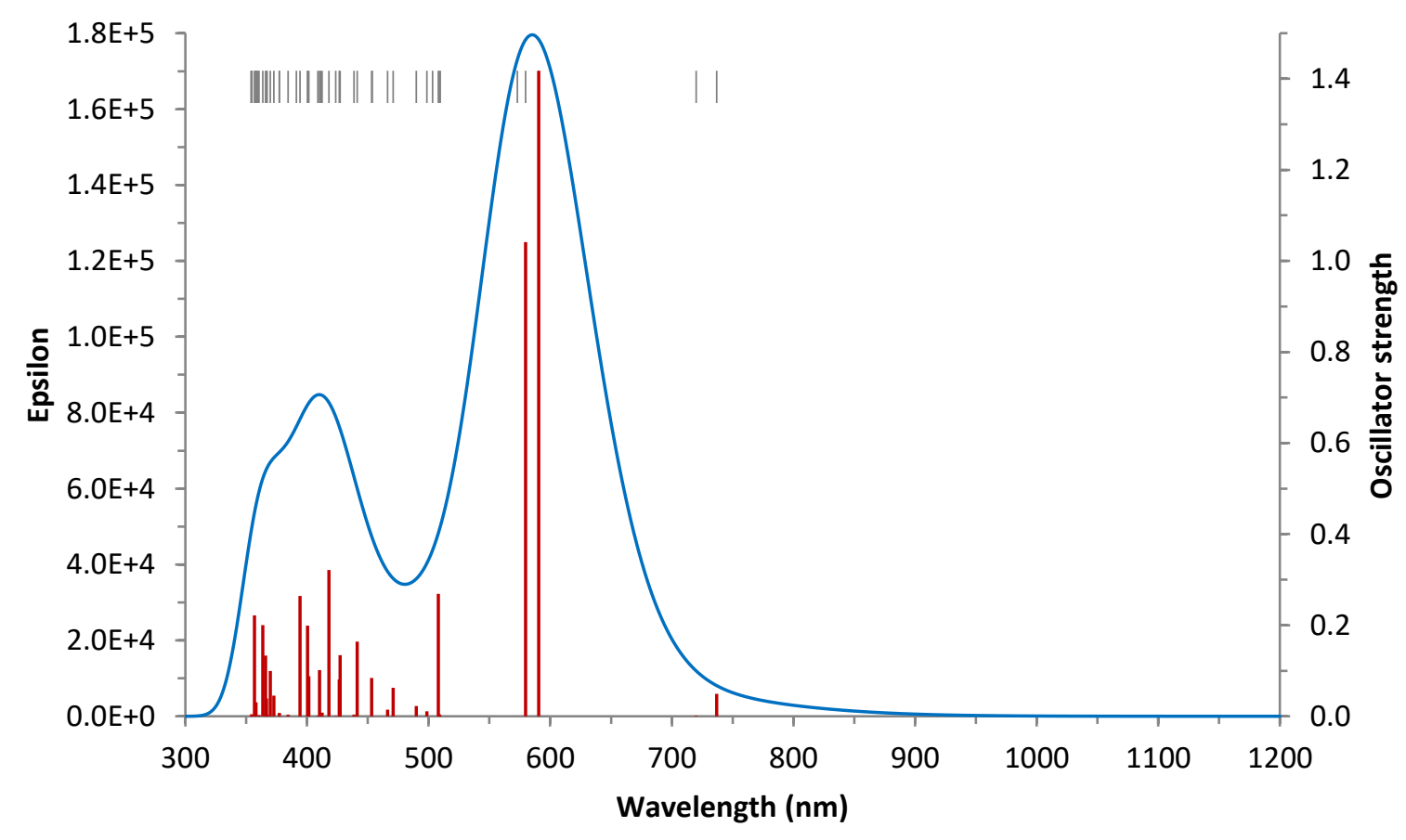

Figure S23. Electronic absorption spectrum of 2a-Zn simulated using time-dependent density functional theory (B3LYP/6-31G(d)/PCM $\left(\mathrm{CH}_{2} \mathrm{Cl}_{2}\right), 50$ transitions, linewidth factor $\left.3000 \mathrm{~cm}^{-1}\right)$. 


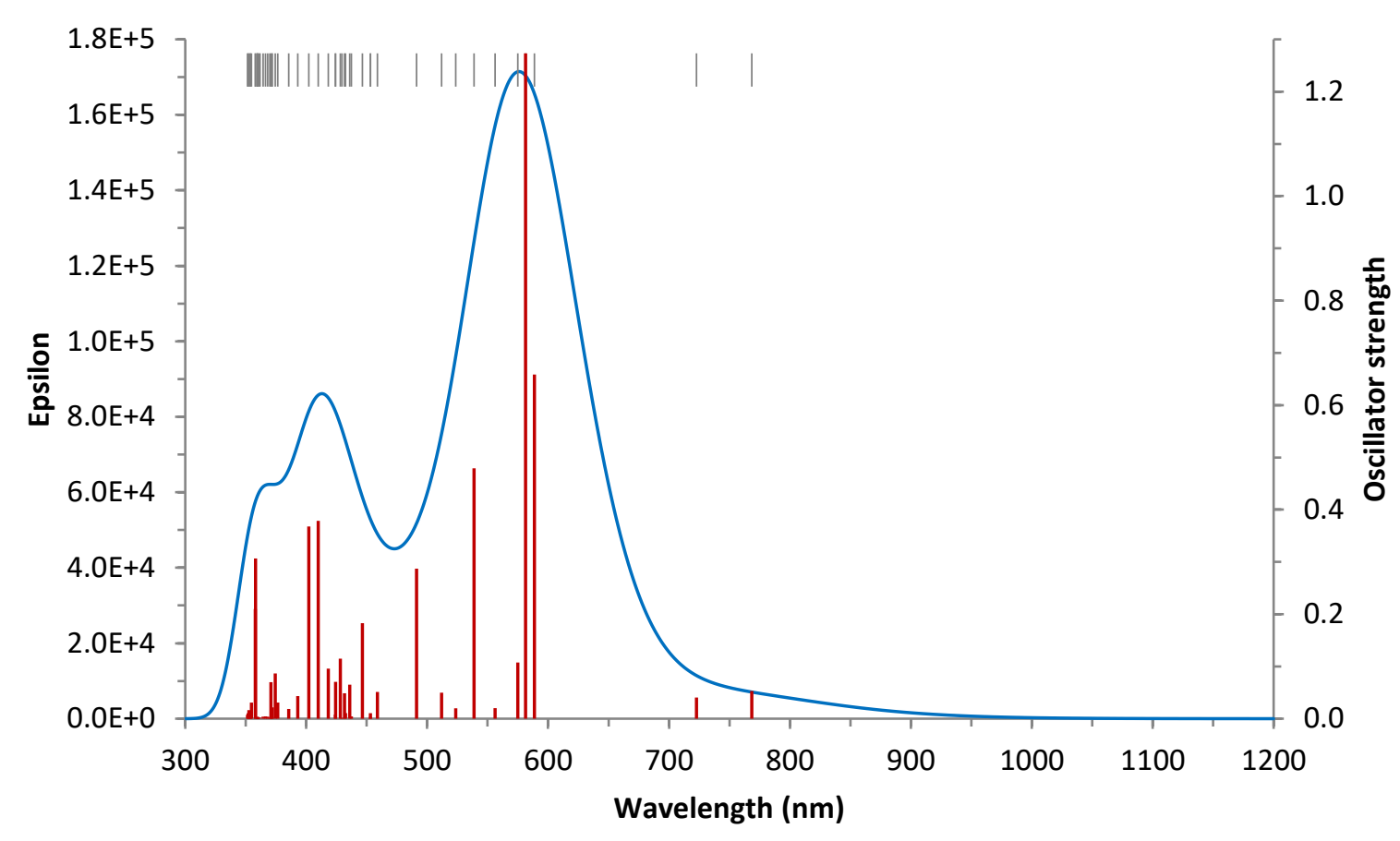

Figure S24. Electronic absorption spectrum of $3 a-H_{2}$ simulated using time-dependent density functional theory (B3LYP/6-31G(d)/PCM $\left(\mathrm{CH}_{2} \mathrm{Cl}_{2}\right), 50$ transitions, linewidth factor $3000 \mathrm{~cm}^{-1}$ ).

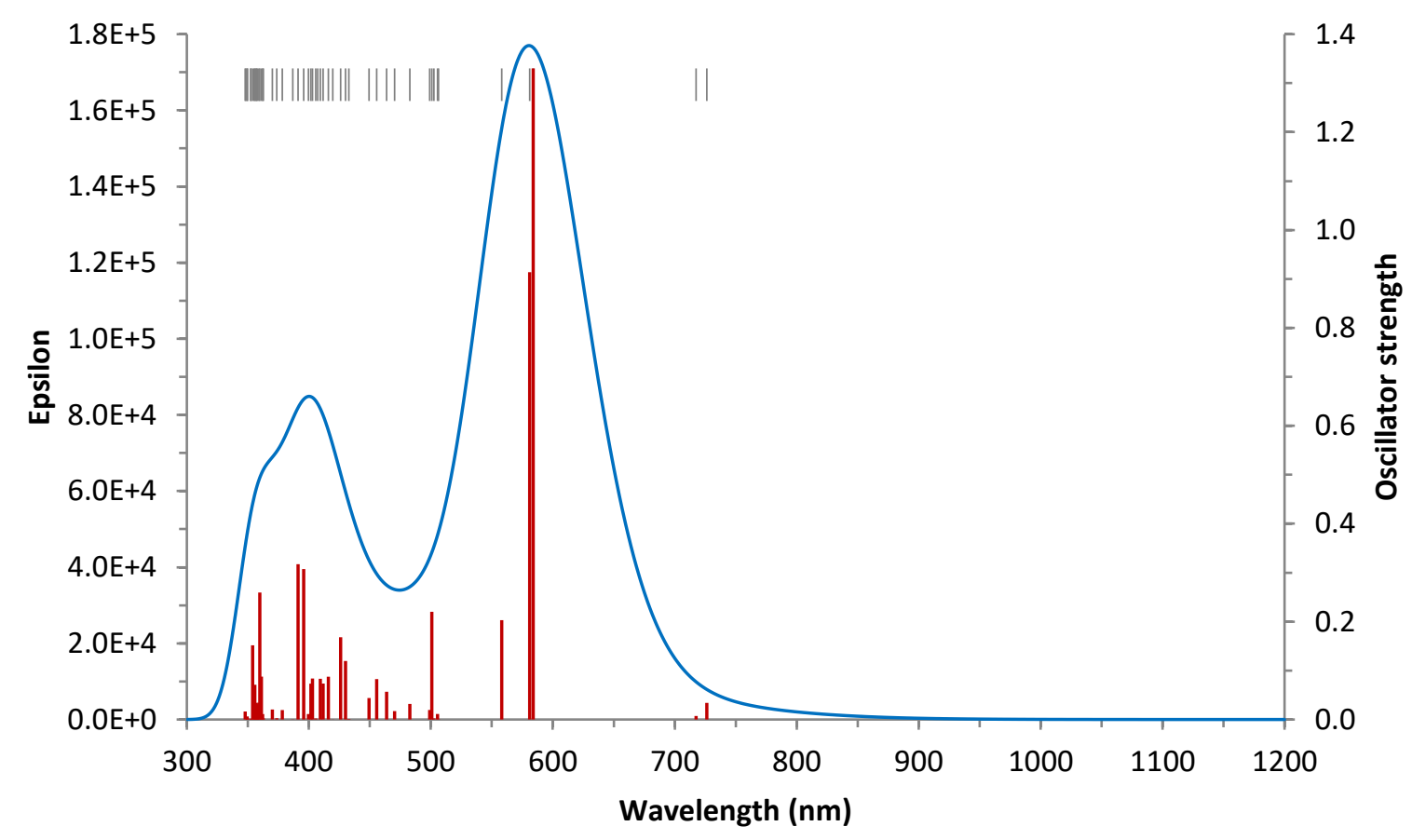

Figure S25. Electronic absorption spectrum of 3a-Zn simulated using time-dependent density functional theory (B3LYP/6-31G(d)/PCM $\left(\mathrm{CH}_{2} \mathrm{Cl}_{2}\right), 50$ transitions, linewidth factor $3000 \mathrm{~cm}^{-1}$ ). 


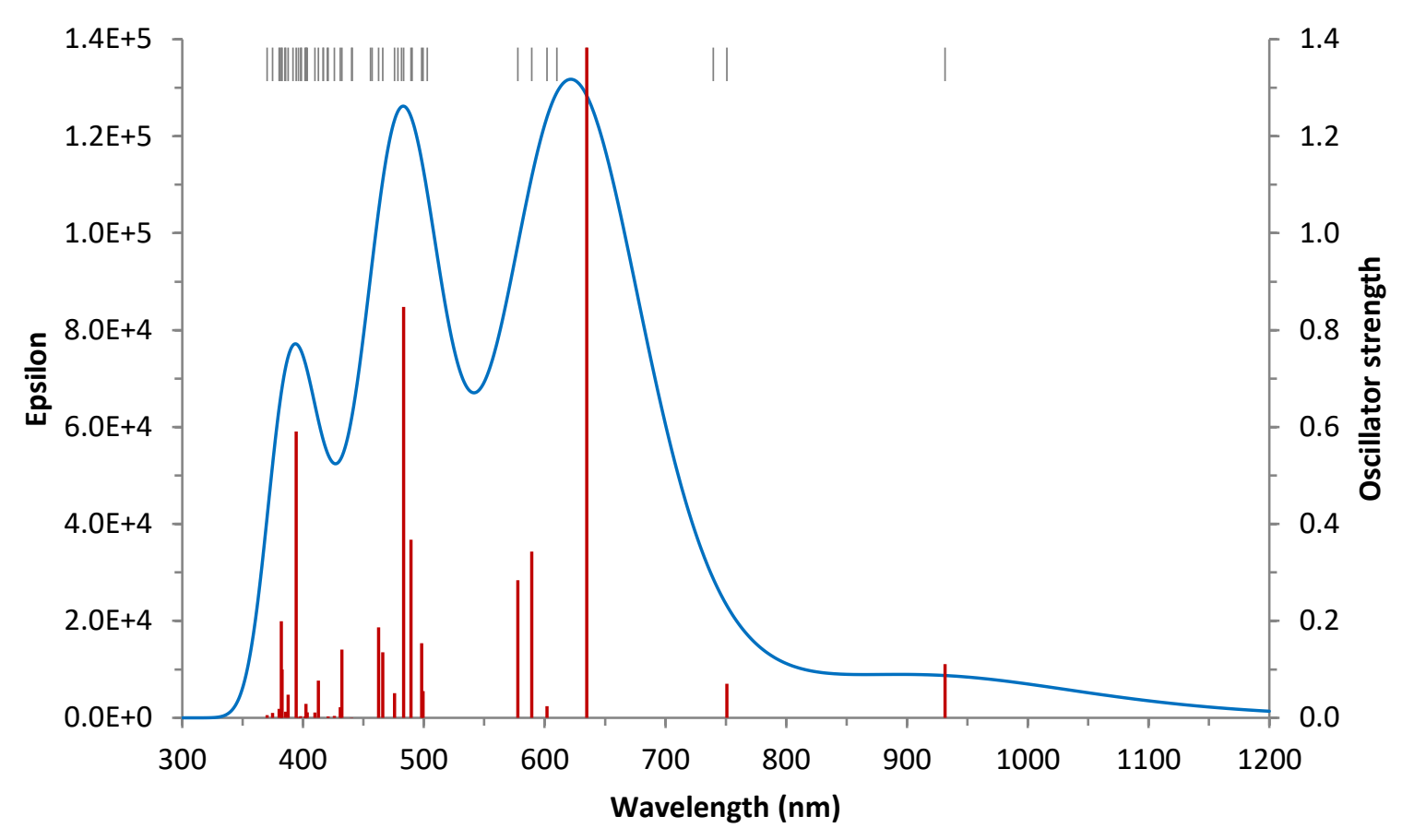

Figure S26. Electronic absorption spectrum of $\mathbf{2} \mathbf{b}-\mathrm{H}_{2}$ simulated using time-dependent density functional theory (B3LYP/6-31G(d)/PCM $\left(\mathrm{CH}_{2} \mathrm{Cl}_{2}\right), 50$ transitions, linewidth factor $3000 \mathrm{~cm}^{-1}$ ).

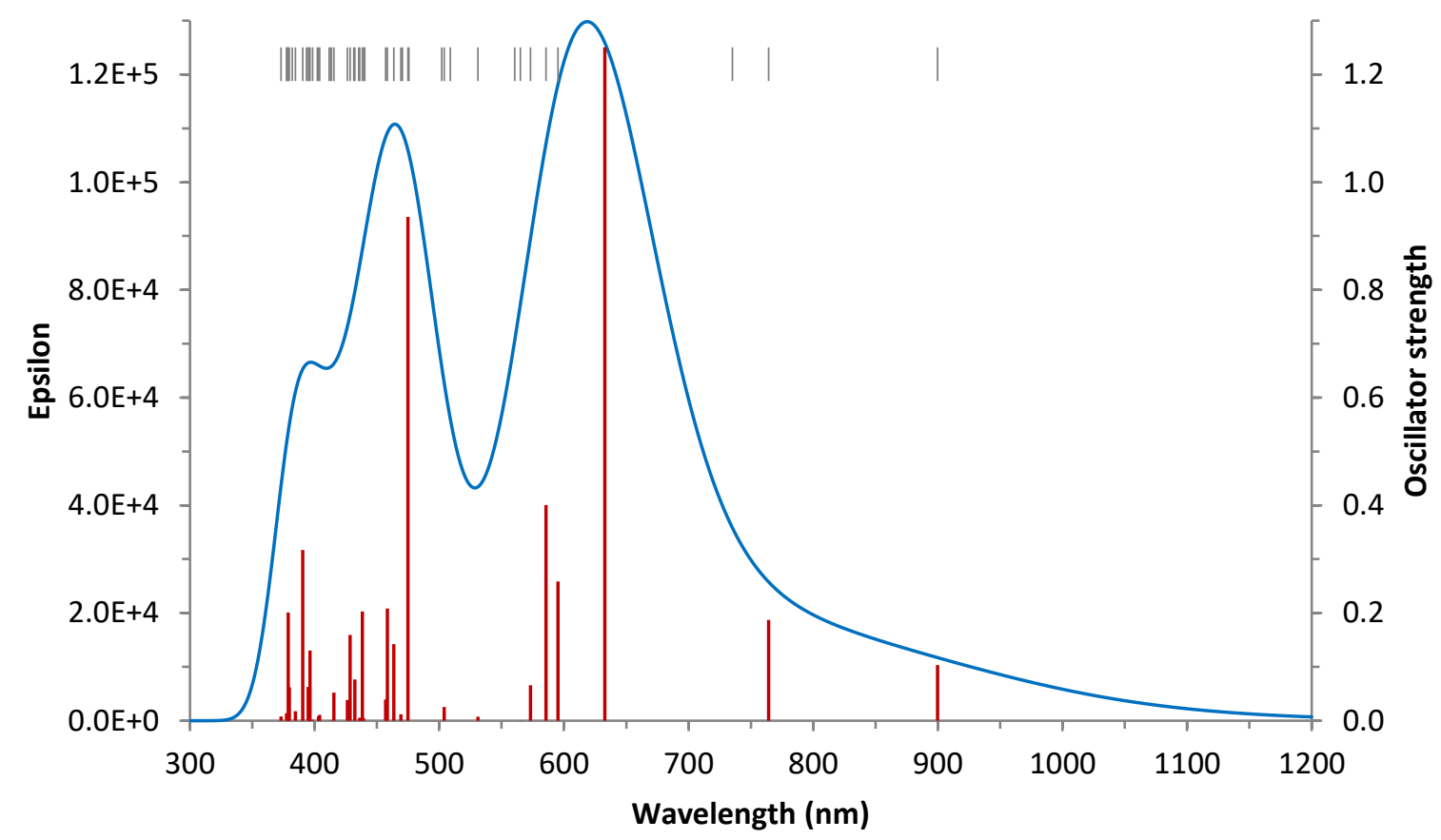

Figure S27. Electronic absorption spectrum of $\mathbf{2} \mathbf{b}-\mathrm{Zn}$ simulated using time-dependent density functional theory (B3LYP/6-31G(d)/PCM $\left(\mathrm{CH}_{2} \mathrm{Cl}_{2}\right), 50$ transitions, linewidth factor $3000 \mathrm{~cm}^{-1}$ ). 


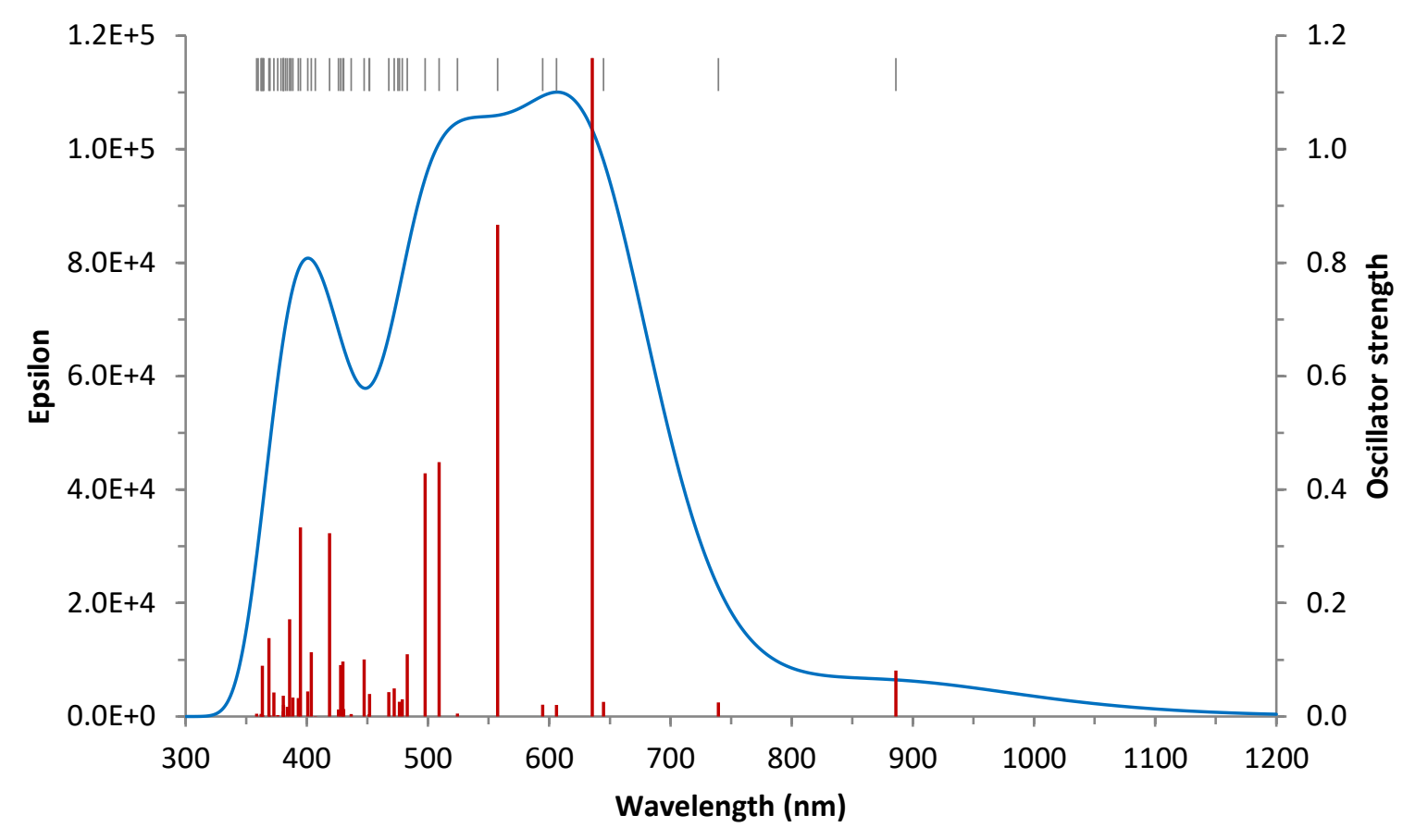

Figure S28. Electronic absorption spectrum of $\mathbf{3 b}-\mathrm{H}_{2}$ simulated using time-dependent density functional theory (B3LYP/6-31G(d)/PCM $\left(\mathrm{CH}_{2} \mathrm{Cl}_{2}\right), 50$ transitions, linewidth factor $3000 \mathrm{~cm}^{-1}$ ).

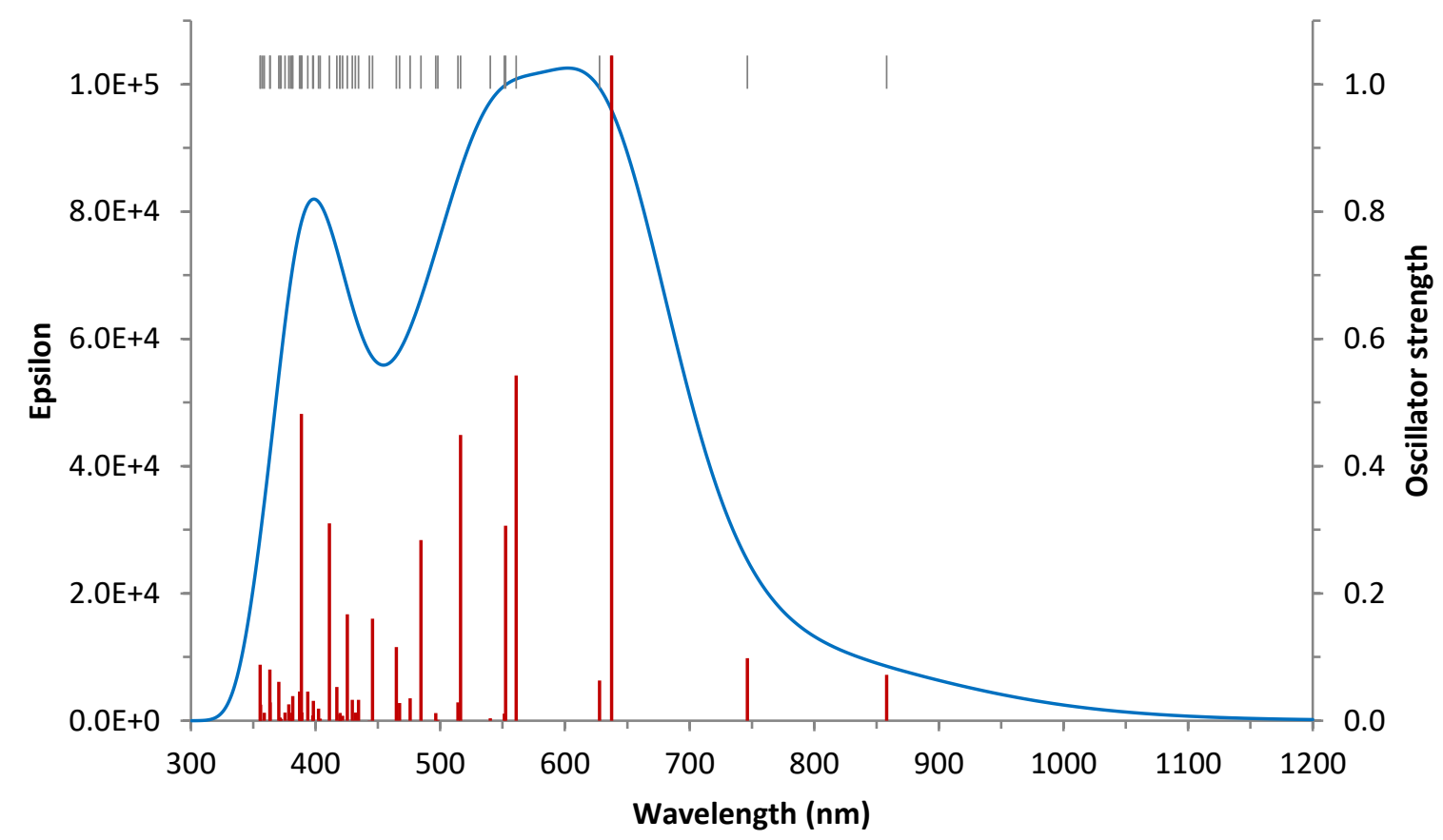

Figure S29. Electronic absorption spectrum of $\mathbf{3 b}$ - $\mathrm{Zn}$ simulated using time-dependent density functional theory (B3LYP/6-31G(d)/PCM $\left(\mathrm{CH}_{2} \mathrm{Cl}_{2}\right), 50$ transitions, linewidth factor $3000 \mathrm{~cm}^{-1}$ ). 
Additional Tables 
Table S1. Photophysical properties of compounds ${ }^{\mathrm{a}} \mathbf{2 a}-\mathrm{M}, \mathbf{2 b}-\mathrm{M}, \mathbf{3 a}-\mathrm{M}$ and $\mathbf{3 b}-\mathrm{M}$. (M $=2 \mathrm{H}$; DCM, $5 \mu \mathrm{M}$ and $\mathrm{M}=\mathrm{Zn}$; Toluene $+1 \%$ Pyridine, v/v, $5 \mu \mathrm{M})$.

\begin{tabular}{lll}
\hline Compounds & \multicolumn{1}{c}{$\lambda_{\text {abs }}(\mathrm{nm})(\log \varepsilon)$} & $\lambda_{\mathrm{em}}(\mathrm{nm})(\phi)$ \\
\hline 2a- $\mathrm{H}_{2}$ & $408(4.60), 568(5.29), 639(4.29), 709(4.17)$, & $837(0.84)$ \\
& $778(4.01)$ & \\
& $399(4.76), 559(5.37), 639(4.47), 710(4.24)$, & \\
3a- $\mathrm{H}_{2}$ & $803(3.73)$ & \\
& $462(4.74), 590(5.06), 659(4.37), 716(4.07)$, & $956(1.09)$ \\
2b- $\mathrm{H}_{2}$ & $823(3.95)$ & \\
& $400(4.71), 499(4.82), 556(5.01), 590(5.07)$, & $950(0.57)$ \\
3b- $\mathrm{H}_{2}$ & $652(4.37), 720(4.13), 834(3.84)$ & $810(-)$ \\
& $415(4.67), 541(4.71), 579(5.35), 704(4.34)$, & $815(-)$ \\
2a-Zn & $780(4.07)$ & \\
3a-Zn & $410(4.80), 540(4.85), 577(5.49), 700(4.47)$, & $930(-)$ \\
2b-Zn & $768(4.09)$ & \\
& $470(4.73), 597(4.98), 614(5.03), 700(4.22)$, & $920(-)$ \\
3b-Zn & $800(4.14), 864(3.95)$ & \\
& $409(4.70), 571(4.95), 613(5.11), 697(4.34)$, & \\
\hline
\end{tabular}

${ }^{a} \log \left(\varepsilon / \mathrm{mol}^{-1} \mathrm{dm}^{3} \mathrm{~cm}^{-1}\right)$-molar extinction coefficient, $\lambda_{\text {abs }}$ (absorption maxima), $\lambda_{\text {em }}$ (emission maxima), and $\phi(\%)$-quantum yield. 
Table S2. Electrochemical data for 2a-M, 2b-M, 3a-M and 3b-M. ( $M=2 H, Z n)$.

\begin{tabular}{|c|c|c|c|c|c|c|c|c|c|c|}
\hline Compounds & $E_{\mathrm{Ox} 1}$ & $E_{0 \times 2}$ & $E_{0 \times 3}$ & $E_{0 \times 4}$ & $E_{\text {Red1 }}$ & $E_{\text {Red2 }}$ & $E_{\text {Red3 }}$ & $E_{\text {Red4 }}$ & $E_{\text {Red5 }}$ & $\Delta E$ \\
\hline $2 \mathrm{a}-\mathrm{H}_{2}(\mathrm{DCM})$ & 0.26 & $0.54^{\mathrm{a}}$ & $0.84^{a}$ & $1.09^{a}$ & -1.34 & -1.50 & -2.14 & -2.18 & $-2.35^{a}$ & 1.60 \\
\hline $\mathbf{2 b}-\mathrm{H}_{2}(\mathrm{DCM})$ & 0.36 & 0.62 & $0.94^{a}$ & $1.20^{\mathrm{a}}$ & -1.08 & -1.14 & -1.71 & -1.86 & $\begin{array}{l}-2.00^{\mathrm{a}} \\
(-2.22)^{\mathrm{a}}\end{array}$ & 1.44 \\
\hline $3 a-H_{2}(D C M)$ & 0.25 & $0.54^{a}$ & $0.83^{a}$ & $1.08^{\mathrm{a}}$ & -1.36 & -1.56 & -2.16 & $-2.25^{a}$ & & 1.61 \\
\hline 3b- $\mathrm{H}_{2}(\mathrm{DCM})$ & 0.30 & $0.58^{a}$ & $0.88^{a}$ & $1.10^{\mathrm{a}}$ & -1.14 & -1.35 & -1.83 & $-1.99^{a}$ & $-2.23^{a}$ & 1.44 \\
\hline 2a-Zn (DCM) & 0.08 & $\begin{array}{l}0.49 \\
(0.27)^{b}\end{array}$ & $\begin{array}{l}0.98 \\
(0.74)^{b}\end{array}$ & & $\begin{array}{l}-1.63 \\
(-1.50)^{b}\end{array}$ & $(-1.92)^{b}$ & -2.17 & -2.38 & & 1.71 \\
\hline 2b-Zn (DCM) & 0.24 & 0.59 & $0.87^{a}$ & & -1.19 & -1.30 & -1.44 & -1.95 & -2.15 & 1.43 \\
\hline 3a-Zn (DCM) & 0.11 & 0.47 & $(0.75)^{\mathrm{b}}$ & & -1.64 & -1.70 & -2.16 & - & - & 1.75 \\
\hline 3b-Zn (DCM) & 0.18 & 0.53 & - & & -1.22 & -1.46 & -1.87 & -2.15 & - & 1.40 \\
\hline 2b-Zn (THF) & 0.32 & 0.61 & $0.91^{a}$ & & -1.12 & -1.32 & -1.44 & -1.58 & $\begin{array}{l}-1.84 \\
-1.94 \\
-2.11 \\
-2.55 \\
-2.63 \\
-2.87\end{array}$ & 1.44 \\
\hline 3b-Zn (THF) & 0.24 & 0.56 & 0.84 & & -1.21 & -1.57 & -1.96 & -2.19 & $\begin{array}{l}-2.62^{a} \\
-2.80^{a}\end{array}$ & 1.45 \\
\hline
\end{tabular}

a Irreversible couple. ${ }^{b}$ Couple due to a minor redox-active component.

Electrode potentials in volts, taken from differential pulse voltammetry (DP) calibrated with $\mathrm{Fc}^{+} / \mathrm{Fc}$ couple as internal standard. The values in parentheses are oxidation/reduction potentials of the products of irreversible reduction/oxidation. $\Delta E=$ $E_{O \times 1}-E_{R e d 1}$. All measurements were done in $\mathrm{DCM}$ as a solvent, with $\left[\mathrm{Bu}_{4} \mathrm{~N}\right] \mathrm{PF}_{6}$ as supporting electrolyte, glassy carbon working electrode, $\mathrm{AgCl} / \mathrm{Ag}$ reference electrode, and $\mathrm{Pt}$ rod as counter electrode. 
Table S3. Computational details (performed at B3LYP/6-31G(d)/PCM $\left(\mathrm{CH}_{2} \mathrm{Cl}_{2}\right)$ level of theory).

\begin{tabular}{ccccccc}
\hline Code $^{[a]}$ & $\begin{array}{c}\text { SCF } E^{[b]} \\
\text { a.u. }\end{array}$ & $\begin{array}{c}\text { ZPV } \\
\text { a.u. }\end{array}$ & $\begin{array}{c}\text { lowest freq. } \\
\mathbf{c m}^{[-1]}\end{array}$ & $\begin{array}{c}\text { SCF } E+\text { ZPV } \\
\text { a.u. }\end{array}$ & $\begin{array}{c}\boldsymbol{H}^{[\mathrm{e}]} \\
\text { a.u. }\end{array}$ & $\begin{array}{c}\boldsymbol{G}^{[\mathrm{f}]} \\
\text { a.u. }\end{array}$ \\
\hline $\mathbf{2 a}-\mathrm{H}_{2}$ & -4594.360688 & 1.483299 & 4.02 & -4592.877389 & -4592.781179 & -4593.019228 \\
\hline $\mathbf{2 b}-\mathrm{H}_{2}$ & -5100.681425 & 1.681037 & 7.25 & -5099.000388 & -5098.895799 & -5099.15017 \\
\hline $\mathbf{3 a}-\mathrm{H}_{2}$ & -4099.708778 & 1.317564 & 8.23 & -4098.391214 & -4098.308059 & -4098.515596 \\
\hline $\mathbf{3 b}-\mathrm{H}_{2}$ & -4352.869410 & 1.416527 & 6.58 & -4351.452883 & -4351.365548 & -4351.581934 \\
\hline $\mathbf{2 a}-\mathrm{Zn}$ & -6372.386227 & 1.461276 & 6.87 & -6370.924951 & -6370.828316 & -6371.065456 \\
\hline $\mathbf{2 b}-\mathrm{Zn}$ & -6878.709759 & 1.658716 & 1.20 & -6877.051043 & -6876.945628 & -6877.205977 \\
\hline $\mathbf{3 a}-\mathrm{Zn}$ & -5877.737652 & 1.295637 & 8.97 & -5876.442015 & -5876.358375 & -5876.565579 \\
\hline $\mathbf{3 b}-\mathrm{Zn}$ & -6130.898033 & 1.394502 & 7.27 & -6129.503531 & -6129.415609 & -6129.632390 \\
\hline
\end{tabular}

[a] Structure code (see the zip file for Cartesian coordinates). [b] SCF electronic energy. [c] Zero-point vibrational energy. [d] Lowest vibrational frequency. [e] Enthalpy. [f] Gibbs free energy.

Table S4. HOMO-LUMO bandgap comparison of various phenyl and tolyl meso-substituted free base porphyrins containing peripheral naphthalene and napthalenemonoimide units and their zinc complexes. All calculations were performed at the level of B3LYP/6-31g(d,p) theory.

\begin{tabular}{|c|c|c|c|c|}
\hline Code $^{[a]}$ & Formula & $\begin{array}{c}\text { HOMO } \\
(\mathrm{eV})\end{array}$ & $\begin{array}{c}\text { LUMO } \\
(\mathrm{eV})\end{array}$ & $\begin{array}{l}\text { HLG } \\
(\mathrm{eV}) \\
\end{array}$ \\
\hline $1 b^{\prime}-H_{2} \_p h$ & $\mathrm{C}_{92} \mathrm{H}_{42} \mathrm{~N}_{8} \mathrm{O}_{8}$ & -5.50 & -3.64 & 1.86 \\
\hline $1 b^{\prime}-H_{2 \_}$tol & $\mathrm{C}_{96} \mathrm{H}_{50} \mathrm{~N}_{8} \mathrm{O}_{8}$ & -5.38 & -3.58 & 1.81 \\
\hline $2 b^{\prime}-H_{2} \_p h$ & $\mathrm{C}_{88} \mathrm{H}_{44} \mathrm{~N}_{6} \mathrm{O}_{4}$ & -5.10 & -3.26 & 1.84 \\
\hline 2b'- $\mathrm{H}_{2}$ ttol & $\mathrm{C}_{92} \mathrm{H}_{52} \mathrm{~N}_{6} \mathrm{O}_{4}$ & -4.99 & -3.19 & 1.80 \\
\hline $3 b^{\prime}-H_{2} \_p h$ & $\mathrm{C}_{86} \mathrm{H}_{45} \mathrm{~N}_{5} \mathrm{O}_{2}$ & -4.89 & -2.98 & 1.91 \\
\hline $3 b^{\prime}-H_{2 \_}$tol & $\mathrm{C}_{90} \mathrm{H}_{53} \mathrm{~N}_{5} \mathrm{O}_{2}$ & -4.79 & -2.91 & 1.88 \\
\hline $8 b^{\prime}-H_{2} \_p h$ & $\mathrm{C}_{84} \mathrm{H}_{46} \mathrm{~N}_{4}$ & -4.68 & -2.58 & 2.10 \\
\hline $8 b^{\prime}-H_{2 \_}$tol & $\mathrm{C}_{88} \mathrm{H}_{54} \mathrm{~N}_{4}$ & -4.58 & -2.51 & 2.07 \\
\hline $1 b^{\prime}-Z n \_p h$ & $\mathrm{C}_{92} \mathrm{H}_{40} \mathrm{~N}_{8} \mathrm{O}_{8} \mathrm{Zn}$ & -5.58 & -3.58 & 2.00 \\
\hline $1 b^{\prime}-Z n \_$tol & $\mathrm{C}_{96} \mathrm{H}_{48} \mathrm{~N}_{8} \mathrm{O}_{8} \mathrm{Zn}$ & -5.46 & -3.52 & 1.95 \\
\hline $2 b^{\prime}-Z n \_p h$ & $\mathrm{C}_{88} \mathrm{H}_{42} \mathrm{~N}_{6} \mathrm{O}_{4} \mathrm{Zn}$ & -5.18 & -3.27 & 1.91 \\
\hline $2 b^{\prime}-Z n \_t o l$ & $\mathrm{C}_{92} \mathrm{H}_{50} \mathrm{~N}_{6} \mathrm{O}_{4} \mathrm{Zn}$ & -5.07 & -3.20 & 1.87 \\
\hline $3 b^{\prime}-Z n \_p h$ & $\mathrm{C}_{86} \mathrm{H}_{43} \mathrm{~N}_{5} \mathrm{O}_{2} \mathrm{Zn}$ & -4.97 & -2.98 & 1.99 \\
\hline $3 b^{\prime}-Z n \_t o l$ & $\mathrm{C}_{90} \mathrm{H}_{51} \mathrm{~N}_{5} \mathrm{O}_{2} \mathrm{Zn}$ & -4.87 & -2.92 & 1.95 \\
\hline $8 b^{\prime}-Z n \_p h$ & $\mathrm{C}_{84} \mathrm{H}_{44} \mathrm{~N}_{4} \mathrm{Zn}$ & -4.75 & -2.51 & 2.24 \\
\hline $8 b^{\prime}-Z n \_$tol & $\mathrm{C}_{88} \mathrm{H}_{52} \mathrm{~N}_{4} \mathrm{Zn}$ & -4.65 & -2.45 & 2.21 \\
\hline
\end{tabular}

[a] Structure code (see the zip file for Cartesian coordinates). 
Table S5. Electronic transitions calculated for $\mathbf{2 a}-\mathrm{H}_{2}$ using the TD/PCM(DCM)/B3LYP/6-31G(d,p) level of theory.

\begin{tabular}{|c|c|c|c|c|}
\hline No. & $\begin{array}{l}\text { Energy } \\
\left(\mathrm{cm}^{-1}\right)\end{array}$ & $\begin{array}{c}\lambda \\
(\mathrm{nm})\end{array}$ & $f^{[a]}$ & $\begin{array}{c}\text { Major } \\
\text { excitations }^{[\mathrm{b}]}\end{array}$ \\
\hline 1 & 12852 & 778.1 & 0.066 & $\begin{array}{l}\mathrm{H}-1 » \mathrm{~L}+1(17 \%) \\
\text { HOMO»LUMO } \\
(82 \%)\end{array}$ \\
\hline 2 & 13831 & 723.0 & 0.026 & $\begin{array}{l}\text { H-1»LUMO (27\%) } \\
\text { HOMO»L+1 (72\%) }\end{array}$ \\
\hline 3 & 17021 & 587.5 & 1.392 & $\begin{array}{l}\text { H-1»LUMO (71\%) } \\
\text { HOMO»L+1 (26\%) }\end{array}$ \\
\hline 4 & 17049 & 586.5 & 0.733 & $\begin{array}{l}\mathrm{H}-3 » \mathrm{LUMO}(16 \%) \\
\mathrm{H}-1 » \mathrm{~L}+1(70 \%) \\
\text { HOMO»LUMO } \\
(12 \%)\end{array}$ \\
\hline 5 & 17073 & 585.7 & 0.000 & HOMO»L+2 (91\%) \\
\hline 6 & 17841 & 560.5 & 0.000 & H-2»LUMO (87\%) \\
\hline 7 & 18414 & 543.1 & 0.450 & $\begin{array}{l}\mathrm{H}-3 » \mathrm{LUMO}(77 \%) \\
\mathrm{H}-1 » \mathrm{~L}+1(11 \%)\end{array}$ \\
\hline 8 & 19398 & 515.5 & 0.002 & $\mathrm{H}-2 » \mathrm{~L}+1$ (98\%) \\
\hline 9 & 19570 & 511.0 & 0.068 & $H-3 » L+1(99 \%)$ \\
\hline 10 & 20095 & 497.6 & 0.320 & $\mathrm{H}-1 » \mathrm{~L}+2(98 \%)$ \\
\hline 11 & 21578 & 463.4 & 0.000 & HOMO»L+3 (90\%) \\
\hline 12 & 22018 & 454.2 & 0.000 & $\begin{array}{l}H-7 » L+1(44 \%) \\
H-4 » L+1(35 \%)\end{array}$ \\
\hline 13 & 22063 & 453.2 & 0.001 & $H-6 » L+1(92 \%)$ \\
\hline 14 & 22163 & 451.2 & 0.199 & H-4»LUMO (96\%) \\
\hline 15 & 22638 & 441.7 & 0.080 & H-6»LUMO (95\%) \\
\hline 16 & 22738 & 439.8 & 0.000 & $\begin{array}{l}\mathrm{H}-7 » \mathrm{~L}+1(20 \%) \\
\mathrm{H}-5 » \mathrm{LUMO}(70 \%)\end{array}$ \\
\hline 17 & 22924 & 436.2 & 0.022 & H-7»LUMO (89\%) \\
\hline 18 & 22969 & 435.4 & 0.028 & $\mathrm{H}-2 » \mathrm{~L}+2(86 \%)$ \\
\hline 19 & 23221 & 430.7 & 0.002 & $\begin{array}{l}\mathrm{H}-5 » \mathrm{LUMO}(15 \%) \\
\mathrm{H}-3 » \mathrm{~L}+2(62 \%)\end{array}$ \\
\hline 20 & 23255 & 430.0 & 0.051 & $\begin{array}{l}H-7 » L+1(11 \%) \\
H-5 » L+1(29 \%) \\
H-4 » L+1(32 \%) \\
H-3 » L+2(19 \%)\end{array}$ \\
\hline 21 & 23284 & 429.5 & 0.073 & H-8»LUMO (94\%) \\
\hline 22 & 23301 & 429.2 & 0.087 & $\begin{array}{l}H-7 » L+1(11 \%) \\
H-5 » L+1(60 \%) \\
H-4 » L+1(16 \%)\end{array}$ \\
\hline 23 & 23618 & 423.4 & 0.575 & $\begin{array}{l}\mathrm{H}-8 » \mathrm{~L}+1(14 \%) \\
\mathrm{HOMO} » \mathrm{~L}+4(76 \%)\end{array}$ \\
\hline 24 & 24001 & 416.7 & 0.022 & $\begin{array}{l}\mathrm{H}-8 » \mathrm{~L}+1(82 \%) \\
\mathrm{HOMO} » \mathrm{~L}+4(13 \%)\end{array}$ \\
\hline 25 & 24867 & 402.1 & 0.385 & HOMO»L+5 (81\%) \\
\hline 26 & 25277 & 395.6 & 0.005 & $H-1 » L+3(89 \%)$ \\
\hline 27 & 25564 & 391.2 & 0.018 & H-9»LUMO (88\%) \\
\hline 28 & 25677 & 389.5 & 0.005 & H-10»LUMO (93\%) \\
\hline 29 & 26155 & 382.3 & 0.001 & $\begin{array}{l}\mathrm{H}-11 » \mathrm{LUMO}(60 \%) \\
\mathrm{H}-1 » \mathrm{~L}+4(29 \%)\end{array}$ \\
\hline 30 & 26606 & 375.9 & 0.075 & $\begin{array}{l}\mathrm{H}-11 » \mathrm{~L}+1(29 \%) \\
\mathrm{H}-9 » \mathrm{~L}+1(45 \%)\end{array}$ \\
\hline
\end{tabular}

\begin{tabular}{|c|c|c|c|c|}
\hline 31 & 26672 & 374.9 & 0.002 & $\begin{array}{l}H-7 » L+2(12 \%) \\
H-4 » L+2(61 \%)\end{array}$ \\
\hline 32 & 26711 & 374.4 & 0.001 & H-12»LUMO (82\%) \\
\hline 33 & 26751 & 373.8 & 0.016 & H-13»LUMO (73\%) \\
\hline 34 & 26846 & 372.5 & 0.000 & $\begin{array}{l}H-6 » L+2(44 \%) \\
H-3 » L+3(15 \%) \\
H-2 » L+4(11 \%)\end{array}$ \\
\hline 35 & 26872 & 372.1 & 0.063 & $\begin{array}{l}H-3 » L+4(24 \%) \\
H-2 » L+3(45 \%)\end{array}$ \\
\hline 36 & 27006 & 370.3 & 0.000 & $\begin{array}{l}H-6 » L+2(38 \%) \\
H-3 » L+3(21 \%) \\
H-2 » L+4(16 \%)\end{array}$ \\
\hline 37 & 27076 & 369.3 & 0.000 & $H-10 » L+1(83 \%)$ \\
\hline 38 & 27241 & 367.1 & 0.001 & $\begin{array}{l}H-7 » L+2(61 \%) \\
H-4 » L+2(16 \%)\end{array}$ \\
\hline 39 & 27294 & 366.4 & 0.011 & $\begin{array}{l}H-11 » L+1(23 \%) \\
H-9 » L+1(41 \%) \\
H-5 » L+2(12 \%)\end{array}$ \\
\hline 40 & 27363 & 365.5 & 0.001 & H-14»LUMO (85\%) \\
\hline 41 & 27453 & 364.3 & 0.001 & $\begin{array}{l}\mathrm{H}-15 » \mathrm{LUMO}(36 \%) \\
\mathrm{H}-11 » \mathrm{~L}+1(19 \%) \\
\mathrm{H}-5 » \mathrm{~L}+2(29 \%)\end{array}$ \\
\hline 42 & 27499 & 363.6 & 0.327 & $\begin{array}{l}\mathrm{H}-18 » \mathrm{LUMO}(14 \%) \\
\mathrm{H}-11 » \mathrm{LUMO}(19 \%) \\
\mathrm{H}-1 » \mathrm{~L}+4(38 \%)\end{array}$ \\
\hline 43 & 27537 & 363.2 & 0.043 & $\begin{array}{l}\mathrm{H}-15 » \mathrm{LUMO}(37 \%) \\
\mathrm{H}-5 » \mathrm{~L}+2(33 \%)\end{array}$ \\
\hline 44 & 27582 & 362.6 & 0.000 & H-17»LUMO (75\%) \\
\hline 45 & 27729 & 360.6 & 0.000 & $\mathrm{H}-14 » \mathrm{~L}+1$ (74\%) \\
\hline 46 & 27866 & 358.9 & 0.021 & H-18»LUMO (66\%) \\
\hline 47 & 27946 & 357.8 & 0.002 & H-16»LUMO (87\%) \\
\hline 48 & 27956 & 357.7 & 0.167 & $\begin{array}{l}H-18 » L+1(26 \%) \\
H-11 » L+1(10 \%) \\
H-1 » L+5(43 \%)\end{array}$ \\
\hline 49 & 28044 & 356.6 & 0.001 & $H-8 » L+2(68 \%)$ \\
\hline 50 & 28051 & 356.5 & 0.112 & $\mathrm{H}-15 » \mathrm{~L}+1$ (78\%) \\
\hline
\end{tabular}

[a] Oscillator strength. [b] Contributions smaller than $10 \%$ are not included. $\mathrm{H}=\mathrm{HOMO}, \mathrm{L}=\mathrm{LUMO}$. Orbitals are numbered consecutively regardless of possible degeneracies. 
Table S6. Electronic transitions calculated for $2 a-Z n$ using the TD/PCM(DCM)/B3LYP/6-31G(d,p) level of theory.

\begin{tabular}{|c|c|c|c|c|}
\hline No. & $\begin{array}{l}\text { Energy } \\
\left(\mathrm{cm}^{-1}\right)\end{array}$ & $\begin{array}{c}\lambda \\
(\mathrm{nm})\end{array}$ & $f^{[\mathrm{a}]}$ & $\begin{array}{c}\text { Major } \\
\text { excitations }^{[\mathrm{b}]}\end{array}$ \\
\hline 1 & 13570 & 736.9 & 0.049 & $\begin{array}{l}\mathrm{H}-1 » \mathrm{~L}+1(19 \%) \\
\text { HOMO»LUMO } \\
(80 \%)\end{array}$ \\
\hline 2 & 13888 & 720.0 & 0.001 & $\begin{array}{l}\mathrm{H}-1 » \mathrm{LUMO}(35 \%) \\
\mathrm{HOMO} » \mathrm{~L}+1(64 \%)\end{array}$ \\
\hline 3 & 16934 & 590.5 & 1.418 & $\begin{array}{l}\mathrm{H}-1 » L U M O(64 \%) \\
\text { HOMO»L+1 (33\%) }\end{array}$ \\
\hline 4 & 17249 & 579.7 & 1.041 & $\begin{array}{l}\mathrm{H}-1 » \mathrm{~L}+1(79 \%) \\
\text { HOMO»LUMO } \\
(18 \%)\end{array}$ \\
\hline 5 & 17452 & 573.0 & 0.000 & HOMO»L+2 (99\%) \\
\hline 6 & 19624 & 509.6 & 0.002 & H-4»LUMO (93\%) \\
\hline 7 & 19652 & 508.9 & 0.004 & H-2»LUMO (85\%) \\
\hline 8 & 19685 & 508.0 & 0.269 & $\mathrm{H}-1 » \mathrm{~L}+2(95 \%)$ \\
\hline 9 & 19869 & 503.3 & 0.000 & $H-3 » L+1(94 \%)$ \\
\hline 10 & 20057 & 498.6 & 0.011 & $H-2 » L+1(86 \%)$ \\
\hline 11 & 20413 & 489.9 & 0.023 & H-3»LUMO (96\%) \\
\hline 12 & 21238 & 470.8 & 0.063 & $\begin{array}{l}\mathrm{H}-5 » \text { LUMO (84\%) } \\
\mathrm{H}-2 » \text { LUMO (12\%) }\end{array}$ \\
\hline 13 & 21446 & 466.3 & 0.015 & $H-4 » L+1(97 \%)$ \\
\hline 14 & 22041 & 453.7 & 0.000 & HOMO»L+3 (95\%) \\
\hline 15 & 22067 & 453.2 & 0.084 & $H-5 » L+1$ (87\%) \\
\hline 16 & 22662 & 441.3 & 0.164 & H-6»LUMO (97\%) \\
\hline 17 & 22796 & 438.7 & 0.004 & H-7»LUMO (85\%) \\
\hline 18 & 23406 & 427.2 & 0.134 & $\mathrm{H}-7 » \mathrm{~L}+1$ (91\%) \\
\hline 19 & 23444 & 426.5 & 0.081 & H-8»LUMO (92\%) \\
\hline 20 & 23607 & 423.6 & 0.001 & $\begin{array}{l}\mathrm{H}-7 » \mathrm{LUMO}(10 \%) \\
\mathrm{H}-6 » \mathrm{~L}+1(82 \%)\end{array}$ \\
\hline 21 & 23921 & 418.0 & 0.321 & $\begin{array}{l}\mathrm{H}-12 » \mathrm{LUMO}(19 \%) \\
\mathrm{H}-8 » \mathrm{~L}+1(19 \%) \\
\text { HOMO»L+4 (49\%) }\end{array}$ \\
\hline 22 & 24247 & 412.4 & 0.008 & $\begin{array}{l}\mathrm{H}-12 » \mathrm{LUMO}(17 \%) \\
\mathrm{H}-8 » \mathrm{~L}+1(63 \%)\end{array}$ \\
\hline 23 & 24318 & 411.2 & 0.000 & $H-2 » L+2(88 \%)$ \\
\hline 24 & 24372 & 410.3 & 0.101 & $\begin{array}{l}\mathrm{H}-4 » \mathrm{~L}+2(51 \%) \\
\mathrm{HOMO} » \mathrm{~L}+4(19 \%)\end{array}$ \\
\hline 25 & 24454 & 408.9 & 0.001 & $\begin{array}{l}H-12 » L+1(11 \%) \\
H-3 » L+2(67 \%)\end{array}$ \\
\hline 26 & 24906 & 401.5 & 0.088 & $\begin{array}{l}\mathrm{H}-12 » \mathrm{~L}+1(27 \%) \\
\mathrm{HOMO} » \mathrm{~L}+5(29 \%)\end{array}$ \\
\hline 27 & 24964 & 400.6 & 0.003 & $H-1 » L+3$ (93\%) \\
\hline 28 & 24972 & 400.5 & 0.199 & $\begin{array}{l}\mathrm{H}-12 » \mathrm{LUMO}(29 \%) \\
\mathrm{H}-12 » \mathrm{~L}+1(10 \%) \\
\mathrm{H}-4 » \mathrm{~L}+2(21 \%) \\
\text { HOMO»L+4 (13\%) } \\
\text { HOMO»L+5 (11\%) }\end{array}$ \\
\hline 29 & 25363 & 394.3 & 0.264 & $\begin{array}{l}\mathrm{H}-12 » \mathrm{~L}+1(28 \%) \\
\mathrm{H}-1 » \mathrm{~L}+4(15 \%) \\
\mathrm{HOMO} » \mathrm{~L}+5(37 \%)\end{array}$ \\
\hline 30 & 25556 & 391.3 & 0.000 & $\mathrm{H}-5 » \mathrm{~L}+2$ (84\%) \\
\hline
\end{tabular}

\begin{tabular}{|c|c|c|c|c|}
\hline 31 & 26011 & 384.4 & 0.004 & $\begin{array}{l}\mathrm{H}-9 » \mathrm{LUMO}(56 \%) \\
\mathrm{H}-1 » \mathrm{~L}+4(30 \%)\end{array}$ \\
\hline 32 & 26505 & 377.3 & 0.007 & H-10»LUMO (91\%) \\
\hline 33 & 26510 & 377.2 & 0.000 & H-11»LUMO (91\%) \\
\hline 34 & 26827 & 372.8 & 0.045 & $\begin{array}{l}H-9 » L+1(48 \%) \\
H-7 » L+2(18 \%) \\
H-1 » L+5(17 \%)\end{array}$ \\
\hline 35 & 27041 & 369.8 & 0.100 & $H-6 » L+2(73 \%)$ \\
\hline 36 & 27233 & 367.2 & 0.003 & H-13»LUMO (89\%) \\
\hline 37 & 27272 & 366.7 & 0.039 & $\begin{array}{l}H-9 » L+1(15 \%) \\
H-7 » L+2(62 \%)\end{array}$ \\
\hline 38 & 27328 & 365.9 & 0.133 & $\begin{array}{l}\mathrm{H}-14 » \mathrm{LUMO}(19 \%) \\
\mathrm{H}-7 » \mathrm{~L}+2(11 \%) \\
\mathrm{H}-1 » \mathrm{~L}+4(24 \%) \\
\mathrm{HOMO} \text { ( }+5(10 \%)\end{array}$ \\
\hline 39 & 27498 & 363.7 & 0.200 & $\begin{array}{l}\text { H-19»LUMO (21\%) } \\
\text { H-14»LUMO (60\%) }\end{array}$ \\
\hline 40 & 27737 & 360.5 & 0.003 & $\begin{array}{l}\mathrm{H}-17 » \text { LUMO (22\%) } \\
\mathrm{H}-15 » L U M O(35 \%) \\
\mathrm{H}-8 » \mathrm{~L}+2(33 \%)\end{array}$ \\
\hline 41 & 27805 & 359.6 & 0.000 & $\mathrm{H}-18 »$ LUMO (87\%) \\
\hline 42 & 27854 & 359.0 & 0.000 & H-16»LUMO (90\%) \\
\hline 43 & 27902 & 358.4 & 0.000 & $H-15 » L+1(68 \%)$ \\
\hline 44 & 27929 & 358.0 & 0.031 & $\begin{array}{l}H-16 » L+1(53 \%) \\
H-10 » L+1(12 \%) \\
H-3 » L+3(18 \%)\end{array}$ \\
\hline 45 & 27975 & 357.5 & 0.000 & $\begin{array}{l}\text { H-15»LUMO (56\%) } \\
H-8 » L+2(28 \%)\end{array}$ \\
\hline 46 & 28025 & 356.8 & 0.222 & $\begin{array}{l}H-19 » L+1(23 \%) \\
H-9 » L+1(11 \%) \\
H-1 » L+5(41 \%)\end{array}$ \\
\hline 47 & 28188 & 354.8 & 0.000 & $\begin{array}{l}\mathrm{H}-17 » \mathrm{LUMO}(20 \%) \\
\mathrm{H}-11 » \mathrm{~L}+1(60 \%)\end{array}$ \\
\hline 48 & 28206 & 354.5 & 0.005 & H-19»LUMO (64\%) \\
\hline 49 & 28234 & 354.2 & 0.001 & $\begin{array}{l}H-17 » L U M O(17 \%) \\
H-17 » L+1(12 \%) \\
H-13 » L+1(10 \%) \\
H-11 » L+1(33 \%)\end{array}$ \\
\hline 50 & 28238 & 354.1 & 0.000 & $\mathrm{H}-10 » \mathrm{~L}+1$ (83\%) \\
\hline
\end{tabular}

[a] Oscillator strength. [b] Contributions smaller than $10 \%$ are not included. $\mathrm{H}=\mathrm{HOMO}, \mathrm{L}=\mathrm{LUMO}$. Orbitals are numbered consecutively regardless of possible degeneracies. 
Table S7. Electronic transitions calculated for $\mathbf{2} \mathbf{b}-\mathrm{H}_{2}$ using the TD/PCM(DCM)/B3LYP/6-31G(d,p) level of theory.

\begin{tabular}{|c|c|c|c|c|}
\hline No. & $\begin{array}{l}\text { Energy } \\
\left(\mathrm{cm}^{-1}\right)\end{array}$ & $\begin{array}{c}\lambda \\
(\mathrm{nm})\end{array}$ & $f^{[\mathrm{a}]}$ & $\begin{array}{c}\text { Major } \\
\text { excitations }^{[\mathrm{b}]}\end{array}$ \\
\hline 1 & 10735 & 931.5 & 0.111 & $\begin{array}{l}\text { HOMO»LUMO } \\
(95 \%)\end{array}$ \\
\hline 2 & 13318 & 750.9 & 0.070 & $\begin{array}{l}\mathrm{H}-1 » \mathrm{LUMO}(61 \%) \\
\mathrm{HOMO} » \mathrm{~L}+2(38 \%)\end{array}$ \\
\hline 3 & 13520 & 739.6 & 0.000 & HOMO»L+1 (99\%) \\
\hline 4 & 15751 & 634.9 & 1.383 & $\begin{array}{l}\mathrm{H}-1 » \mathrm{LUMO}(39 \%) \\
\mathrm{HOMO} » \mathrm{~L}+2(58 \%)\end{array}$ \\
\hline 5 & 16390 & 610.1 & 0.000 & H-2»LUMO (89\%) \\
\hline 6 & 16613 & 602.0 & 0.024 & $\begin{array}{l}\mathrm{H}-3 » \mathrm{LUMO}(71 \%) \\
\mathrm{H}-2 » \mathrm{~L}+1(10 \%) \\
\mathrm{H}-1 » \mathrm{~L}+2(17 \%)\end{array}$ \\
\hline 7 & 16968 & 589.3 & 0.343 & $\begin{array}{l}\mathrm{H}-3 » \mathrm{LUMO}(14 \%) \\
\mathrm{H}-1 » \mathrm{~L}+2(60 \%) \\
\mathrm{HOMO} \text { ( }+3(21 \%)\end{array}$ \\
\hline 8 & 17306 & 577.8 & 0.284 & $H-1 » L+1(99 \%)$ \\
\hline 9 & 19888 & 502.8 & 0.000 & $\begin{array}{l}\text { H-4»LUMO (73\%) } \\
\text { HOMO»L+4 (13\%) }\end{array}$ \\
\hline 10 & 20026 & 499.4 & 0.055 & H-5»LUMO (98\%) \\
\hline 11 & 20073 & 498.2 & 0.154 & H-6»LUMO (84\%) \\
\hline 12 & 20396 & 490.3 & 0.000 & HOMO»L+4 (84\%) \\
\hline 13 & 20435 & 489.4 & 0.368 & $\begin{array}{l}\mathrm{H}-6 » \mathrm{LUMO}(14 \%) \\
\mathrm{H}-2 » \mathrm{~L}+1(49 \%) \\
\mathrm{HOMO} \text { ( }+3(22 \%)\end{array}$ \\
\hline 14 & 20694 & 483.2 & 0.848 & $\begin{array}{l}\mathrm{H}-2 » \mathrm{~L}+1(25 \%) \\
\mathrm{H}-1 » \mathrm{~L}+2(12 \%) \\
\mathrm{HOMO} » \mathrm{~L}+3(50 \%)\end{array}$ \\
\hline 15 & 20768 & 481.5 & 0.000 & $\begin{array}{l}\mathrm{H}-4 » \mathrm{LUMO}(17 \%) \\
\mathrm{H}-3 » \mathrm{~L}+1(70 \%)\end{array}$ \\
\hline 16 & 20897 & 478.5 & 0.000 & $H-2 » L+2(97 \%)$ \\
\hline 17 & 21020 & 475.7 & 0.051 & $H-3 » L+2(94 \%)$ \\
\hline 18 & 21461 & 466.0 & 0.135 & H-7»LUMO (94\%) \\
\hline 19 & 21620 & 462.5 & 0.187 & H-8»LUMO (93\%) \\
\hline 20 & 21874 & 457.2 & 0.000 & $\begin{array}{l}H-6 » L+1(15 \%) \\
H-5 » L+2(78 \%)\end{array}$ \\
\hline 21 & 21937 & 455.8 & 0.000 & $\begin{array}{l}H-6 » L+2(74 \%) \\
H-5 » L+1(15 \%)\end{array}$ \\
\hline 22 & 22690 & 440.7 & 0.000 & H-9»LUMO (90\%) \\
\hline 23 & 22717 & 440.2 & 0.001 & H-10»LUMO (88\%) \\
\hline 24 & 23142 & 432.1 & 0.141 & $H-4 » L+2(95 \%)$ \\
\hline 25 & 23213 & 430.8 & 0.022 & $H-1 » L+3(79 \%)$ \\
\hline 26 & 23479 & 425.9 & 0.004 & $H-4 » L+1(89 \%)$ \\
\hline 27 & 23767 & 420.8 & 0.003 & $\begin{array}{l}H-6 » L+2(17 \%) \\
H-5 » L+1(81 \%)\end{array}$ \\
\hline 28 & 23803 & 420.1 & 0.000 & $\begin{array}{l}H-6 » L+1(82 \%) \\
H-5 » L+2(16 \%)\end{array}$ \\
\hline 29 & 23996 & 416.7 & 0.000 & $\begin{array}{l}\mathrm{H}-12 » \mathrm{~L}+1(12 \%) \\
\mathrm{H}-11 » \mathrm{LUMO}(82 \%)\end{array}$ \\
\hline 30 & 24000 & 416.7 & 0.000 & $\begin{array}{l}\mathrm{H}-12 » \operatorname{LUMO}(83 \%) \\
\mathrm{H}-11 » \mathrm{~L}+1(12 \%)\end{array}$ \\
\hline 31 & 24232 & 412.7 & 0.077 & $\mathrm{H}-1 » \mathrm{~L}+4(87 \%)$ \\
\hline
\end{tabular}

\begin{tabular}{|c|c|c|c|c|}
\hline 32 & 24401 & 409.8 & 0.011 & $\begin{array}{l}\mathrm{H}-13 » L U M O(65 \%) \\
\mathrm{H}-8 » \mathrm{~L}+1(10 \%) \\
\text { HOMO»L+5 (18\%) }\end{array}$ \\
\hline 33 & 24785 & 403.5 & 0.011 & $\begin{array}{l}\mathrm{H}-15 » \mathrm{LUMO}(63 \%) \\
\mathrm{H}-7 » \mathrm{~L}+1(23 \%)\end{array}$ \\
\hline 34 & 24835 & 402.7 & 0.000 & $H-8 » L+2(87 \%)$ \\
\hline 35 & 24851 & 402.4 & 0.029 & $H-7 » L+2(87 \%)$ \\
\hline 36 & 24897 & 401.7 & 0.003 & $\mathrm{H}-14 » \mathrm{LUMO}(94 \%)$ \\
\hline 37 & 25090 & 398.6 & 0.000 & H-16»LUMO (95\%) \\
\hline 38 & 25123 & 398.0 & 0.003 & $\begin{array}{l}\mathrm{H}-17 » \mathrm{LUMO}(18 \%) \\
\mathrm{H}-13 » \mathrm{LUMO}(14 \%) \\
\mathrm{H}-8 » \mathrm{~L}+1(60 \%)\end{array}$ \\
\hline 39 & 25243 & 396.2 & 0.002 & $\begin{array}{l}\mathrm{H}-15 » \mathrm{LUMO}(30 \%) \\
\mathrm{H}-7 » \mathrm{~L}+1(58 \%)\end{array}$ \\
\hline 40 & 25362 & 394.3 & 0.591 & $\begin{array}{l}\mathrm{H}-17 » \mathrm{LUMO}(53 \%) \\
\mathrm{H}-8 » \mathrm{~L}+1(10 \%) \\
\text { HOMO»L+5 (27\%) }\end{array}$ \\
\hline 41 & 25534 & 391.6 & 0.000 & $\begin{array}{l}H-3 » L+4(11 \%) \\
H-2 » L+3(78 \%)\end{array}$ \\
\hline 42 & 25798 & 387.6 & 0.048 & $\begin{array}{l}H-3 » L+3(72 \%) \\
H-2 » L+4(15 \%)\end{array}$ \\
\hline 43 & 25940 & 385.5 & 0.013 & $\begin{array}{l}\mathrm{H}-18 » \mathrm{LUMO}(75 \%) \\
\mathrm{H}-7 » \mathrm{~L}+1(14 \%)\end{array}$ \\
\hline 44 & 25978 & 384.9 & 0.000 & H-19»LUMO (87\%) \\
\hline 45 & 26136 & 382.6 & 0.100 & H-20»LUMO (86\%) \\
\hline 46 & 26178 & 382.0 & 0.199 & $\begin{array}{l}\mathrm{H}-17 » \mathrm{LUMO}(17 \%) \\
\mathrm{H}-8 » \mathrm{~L}+1(13 \%) \\
\mathrm{H}-1 » \mathrm{~L}+3(10 \%) \\
\mathrm{HOMO}(\mathrm{L}+5(35 \%)\end{array}$ \\
\hline 47 & 26261 & 380.8 & 0.000 & $H-9 » L+1$ (90\%) \\
\hline 48 & 26303 & 380.2 & 0.019 & $\mathrm{H}-10 » \mathrm{~L}+1$ (81\%) \\
\hline 49 & 26685 & 374.7 & 0.010 & $\mathrm{H}-21 »$ LUMO (74\%) \\
\hline 50 & 27010 & 370.2 & 0.006 & $H-9 » L+2(96 \%)$ \\
\hline
\end{tabular}

[a] Oscillator strength. [b] Contributions smaller than $10 \%$ are not included. $\mathrm{H}=\mathrm{HOMO}, \mathrm{L}=\mathrm{LUMO}$. Orbitals are numbered consecutively regardless of possible degeneracies. 
Table S8. Electronic transitions calculated for $\mathbf{2 b}-\mathrm{Zn}$ using the TD/PCM(DCM)/B3LYP/6-31G(d,p) level of theory.

\begin{tabular}{|c|c|c|c|c|}
\hline No. & $\begin{array}{c}\text { Energy } \\
\left(\mathrm{cm}^{-1}\right)\end{array}$ & $\begin{array}{c}\lambda \\
(\mathrm{nm})\end{array}$ & $f^{[\mathrm{a}]}$ & $\begin{array}{c}\text { Major } \\
\text { excitations }^{[\mathrm{b}]}\end{array}$ \\
\hline 1 & 11114 & 899.8 & 0.103 & $\begin{array}{l}\text { HOMO»LUMO } \\
(96 \%)\end{array}$ \\
\hline 2 & 13085 & 764.2 & 0.187 & $\begin{array}{l}\text { H-1»LUMO (72\%) } \\
\text { HOMO»L+2 (27\%) }\end{array}$ \\
\hline 3 & 13602 & 735.2 & 0.000 & HOMO»L+1 (100\%) \\
\hline 4 & 15802 & 632.8 & 1.250 & $\begin{array}{l}\text { H-1»LUMO (28\%) } \\
\text { HOMO»L+2 (69\%) }\end{array}$ \\
\hline 5 & 16800 & 595.2 & 0.259 & $\mathrm{H}-1 » \mathrm{~L}+1$ (99\%) \\
\hline 6 & 17076 & 585.6 & 0.401 & $\begin{array}{l}H-1 » L+2(79 \%) \\
H O M O » L+3(12 \%)\end{array}$ \\
\hline 7 & 17446 & 573.2 & 0.066 & $\begin{array}{l}\text { H-6»LUMO (10\%) } \\
\text { H-3»LUMO (78\%) }\end{array}$ \\
\hline 8 & 17697 & 565.1 & 0.000 & H-2»LUMO (99\%) \\
\hline 9 & 17839 & 560.6 & 0.000 & $\begin{array}{l}\mathrm{H}-5 » \text { LUMO (21\%) } \\
\mathrm{H}-4 » \text { LUMO (67\%) }\end{array}$ \\
\hline 10 & 18831 & 531.0 & 0.007 & $\begin{array}{l}\text { H-6»LUMO (70\%) } \\
\text { H-3»LUMO (14\%) }\end{array}$ \\
\hline 11 & 19651 & 508.9 & 0.000 & $\begin{array}{l}H-5 » L U M O(13 \%) \\
H-4 » L U M O(10 \%) \\
H-3 » L+1(18 \%) \\
H-2 » L+2(56 \%)\end{array}$ \\
\hline 12 & 19843 & 504.0 & 0.026 & $\begin{array}{l}H-3 » L+2(66 \%) \\
H-2 » L+1(29 \%)\end{array}$ \\
\hline 13 & 19921 & 502.0 & 0.000 & $\begin{array}{l}\mathrm{H}-5 » \text { LUMO (55\%) } \\
\mathrm{H}-4 » \text { LUMO (17\%) } \\
\mathrm{H}-2 » \mathrm{~L}+2(21 \%)\end{array}$ \\
\hline 14 & 21024 & 475.7 & 0.000 & HOMO»L+4 (96\%) \\
\hline 15 & 21059 & 474.9 & 0.936 & HOMO»L+3 (73\%) \\
\hline 16 & 21257 & 470.4 & 0.000 & $\begin{array}{l}H-3 » L+1(72 \%) \\
H-2 » L+2(18 \%)\end{array}$ \\
\hline 17 & 21312 & 469.2 & 0.012 & $\begin{array}{l}H-3 » L+2(30 \%) \\
H-2 » L+1(69 \%)\end{array}$ \\
\hline 18 & 21574 & 463.5 & 0.142 & H-7»LUMO (96\%) \\
\hline 19 & 21816 & 458.4 & 0.208 & H-8»LUMO (93\%) \\
\hline 20 & 21884 & 456.9 & 0.039 & $\begin{array}{l}\mathrm{H}-6 » \mathrm{LUMO}(17 \%) \\
\mathrm{H}-5 » \mathrm{~L}+1(14 \%) \\
\mathrm{H}-4 » \mathrm{~L}+1(57 \%)\end{array}$ \\
\hline 21 & 22716 & 440.2 & 0.000 & $H-6 » L+1(83 \%)$ \\
\hline 22 & 22767 & 439.2 & 0.005 & $H-4 » L+2(88 \%)$ \\
\hline 23 & 22814 & 438.3 & 0.203 & $\mathrm{H}-11 » \mathrm{LUMO}(78 \%)$ \\
\hline 24 & 22927 & 436.2 & 0.006 & H-9»LUMO (85\%) \\
\hline 25 & 22971 & 435.3 & 0.000 & H-10»LUMO (87\%) \\
\hline 26 & 23134 & 432.3 & 0.077 & $\begin{array}{l}H-6 » L+2(13 \%) \\
H-1 » L+3(65 \%)\end{array}$ \\
\hline 27 & 23179 & 431.4 & 0.000 & $\begin{array}{l}H-5 » L+1(75 \%) \\
H-4 » L+1(19 \%)\end{array}$ \\
\hline 28 & 23338 & 428.5 & 0.159 & $H-5 » L+2(87 \%)$ \\
\hline
\end{tabular}

\begin{tabular}{|c|c|c|c|c|}
\hline 29 & 23459 & 426.3 & 0.038 & $\begin{array}{l}H-6 » L+2(81 \%) \\
H-1 » L+3(11 \%)\end{array}$ \\
\hline 30 & 24070 & 415.5 & 0.052 & $\mathrm{H}-1 » \mathrm{~L}+4(89 \%)$ \\
\hline 31 & 24187 & 413.4 & 0.000 & H-12»LUMO (78\%) \\
\hline 32 & 24219 & 412.9 & 0.001 & $\begin{array}{l}\mathrm{H}-13 » \mathrm{LUMO}(81 \%) \\
\mathrm{H}-12 » \mathrm{~L}+1(11 \%)\end{array}$ \\
\hline 33 & 24291 & 411.7 & 0.000 & H-14»LUMO (77\%) \\
\hline 34 & 24751 & 404.0 & 0.011 & $\begin{array}{l}\mathrm{H}-15 » \mathrm{LUMO}(74 \%) \\
\mathrm{H}-7 » \mathrm{~L}+1(15 \%)\end{array}$ \\
\hline 35 & 24805 & 403.1 & 0.008 & H-16»LUMO (91\%) \\
\hline 36 & 24866 & 402.2 & 0.000 & H-17»LUMO (96\%) \\
\hline 37 & 25102 & 398.4 & 0.002 & $\begin{array}{l}\mathrm{H}-15 » \mathrm{LUMO}(22 \%) \\
\mathrm{H}-7 » \mathrm{~L}+1(65 \%)\end{array}$ \\
\hline 38 & 25234 & 396.3 & 0.130 & $\begin{array}{l}\mathrm{H}-14 » \mathrm{LUMO}(10 \%) \\
\mathrm{H}-11 » \mathrm{~L}+2(11 \%) \\
\mathrm{H}-8 » \mathrm{~L}+1(59 \%)\end{array}$ \\
\hline 39 & 25261 & 395.9 & 0.030 & $H-7 » L+2(90 \%)$ \\
\hline 40 & 25327 & 394.8 & 0.063 & $\begin{array}{l}\mathrm{H}-18 » \mathrm{LUMO}(22 \%) \\
\mathrm{H}-11 » \mathrm{~L}+2(40 \%) \\
\mathrm{H}-8 » \mathrm{~L}+1(11 \%) \\
\mathrm{HOMO} » \mathrm{~L}+5(20 \%)\end{array}$ \\
\hline 41 & 25416 & 393.5 & 0.000 & $H-8 » L+2(89 \%)$ \\
\hline 42 & 25611 & 390.5 & 0.317 & $\begin{array}{l}\mathrm{H}-18 » \mathrm{LUMO}(47 \%) \\
\mathrm{H}-11 » \mathrm{~L}+2(28 \%)\end{array}$ \\
\hline 43 & 26003 & 384.6 & 0.018 & $\begin{array}{l}\mathrm{H}-19 » \mathrm{LUMO}(77 \%) \\
\mathrm{H}-7 » \mathrm{~L}+1(13 \%)\end{array}$ \\
\hline 44 & 26175 & 382.0 & 0.000 & H-20»LUMO (84\%) \\
\hline 45 & 26336 & 379.7 & 0.062 & H-21»LUMO (87\%) \\
\hline 46 & 26399 & 378.8 & 0.201 & $\begin{array}{l}\mathrm{H}-18 » \mathrm{LUMO}(14 \%) \\
\mathrm{H}-2 » \mathrm{~L}+4(15 \%) \\
\text { HOMO»L+5 (29\%) }\end{array}$ \\
\hline 47 & 26448 & 378.1 & 0.000 & $H-9 » L+1$ (89\%) \\
\hline 48 & 26478 & 377.7 & 0.000 & $\mathrm{H}-11 » \mathrm{~L}+1$ (87\%) \\
\hline 49 & 26491 & 377.5 & 0.014 & $H-10 » L+1(81 \%)$ \\
\hline 50 & 26806 & 373.1 & 0.008 & $\begin{array}{l}\mathrm{H}-22 » \mathrm{LUMO}(62 \%) \\
\mathrm{H}-17 » \mathrm{~L}+1(11 \%) \\
\mathrm{H}-3 » \mathrm{~L}+3(13 \%)\end{array}$ \\
\hline
\end{tabular}

[a] Oscillator strength. [b] Contributions smaller than $10 \%$ are not included. $\mathrm{H}=\mathrm{HOMO}, \mathrm{L}=\mathrm{LUMO}$. Orbitals are numbered consecutively regardless of possible degeneracies. 
Table S9. Electronic transitions calculated for $3 a-H_{2}$ using the TD/PCM(DCM)/B3LYP/6-31G(d,p) level of theory.

\begin{tabular}{|c|c|c|c|c|}
\hline No. & $\begin{array}{l}\text { Energy } \\
\left(\mathrm{cm}^{-1}\right)\end{array}$ & $\begin{array}{c}\lambda \\
(\mathrm{nm})\end{array}$ & $f^{[a]}$ & $\begin{array}{c}\text { Major } \\
\text { excitations }^{[\mathrm{b}]}\end{array}$ \\
\hline \multirow[t]{2}{*}{1} & 13013 & 768.5 & 0.053 & $\mathrm{H}-1 » \mathrm{~L}+1(19 \%)$ \\
\hline & & & & $\begin{array}{l}\text { HOMO»LUMO } \\
(79 \%)\end{array}$ \\
\hline \multirow[t]{2}{*}{2} & 13836 & 722.7 & 0.041 & H-1»LUMO (25\%) \\
\hline & & & & HOMO»L+1 (74\%) \\
\hline \multirow[t]{5}{*}{3} & 16986 & 588.7 & 0.659 & H-3»LUMO (10\%) \\
\hline & & & & $H-1 » L+1$ (59\%) \\
\hline & & & & HOMO»LUMO \\
\hline & & & & $(13 \%)$ \\
\hline & & & & HOMO»L+2 (15\%) \\
\hline \multirow[t]{2}{*}{4} & 17200 & 581.4 & 1.273 & H-1»LUMO (73\%) \\
\hline & & & & HOMO»L+1 (24\%) \\
\hline \multirow[t]{2}{*}{5} & 17392 & 575.0 & 0.108 & H-2»LUMO (23\%) \\
\hline & & & & HOMO»L+2 (66\%) \\
\hline \multirow[t]{3}{*}{6} & 17979 & 556.2 & 0.020 & H-3»LUMO (18\%) \\
\hline & & & & H-2»LUMO (60\%) \\
\hline & & & & HOMO»L+2 (17\%) \\
\hline \multirow[t]{3}{*}{7} & 18560 & 538.8 & 0.479 & H-3»LUMO (66\%) \\
\hline & & & & H-2»LUMO (10\%) \\
\hline & & & & $\mathrm{H}-1 » \mathrm{~L}+1(10 \%)$ \\
\hline 8 & 19097 & 523.6 & 0.020 & $H-2 » L+1(98 \%)$ \\
\hline 9 & 19533 & 512.0 & 0.050 & $H-3 » L+1(98 \%)$ \\
\hline 10 & 20356 & 491.3 & 0.287 & $\mathrm{H}-1 » \mathrm{~L}+2(98 \%)$ \\
\hline \multirow[t]{3}{*}{11} & 21791 & 458.9 & 0.051 & $H-7 » L+1(10 \%)$ \\
\hline & & & & $H-4 » L+1(11 \%)$ \\
\hline & & & & HOMO»L+3 (73\%) \\
\hline 12 & 22067 & 453.2 & 0.003 & $H-6 » L+1(82 \%)$ \\
\hline \multirow[t]{3}{*}{13} & 22069 & 453.1 & 0.011 & $H-7 » L+1(36 \%)$ \\
\hline & & & & $H-4 » L+1(25 \%)$ \\
\hline & & & & HOMO»L+3 (22\%) \\
\hline 14 & 22397 & 446.5 & 0.183 & H-4»LUMO (95\%) \\
\hline \multirow[t]{4}{*}{15} & 22864 & 437.4 & 0.004 & $H-7 » L+1(28 \%)$ \\
\hline & & & & H-6»LUMO (17\%) \\
\hline & & & & H-5»LUMO (27\%) \\
\hline & & & & $H-4 » L+1(23 \%)$ \\
\hline 16 & 22935 & 436.0 & 0.065 & H-6»LUMO (75\%) \\
\hline 17 & 23121 & 432.5 & 0.011 & $H-2 » L+2(81 \%)$ \\
\hline \multirow[t]{2}{*}{18} & 23166 & 431.7 & 0.049 & H-7»LUMO (69\%) \\
\hline & & & & $\mathrm{H}-5 » \mathrm{~L}+1(25 \%)$ \\
\hline \multirow[t]{2}{*}{19} & 23280 & 429.6 & 0.001 & H-5»LUMO (58\%) \\
\hline & & & & $H-4 » L+1(32 \%)$ \\
\hline \multirow[t]{2}{*}{20} & 23351 & 428.2 & 0.115 & H-7»LUMO (23\%) \\
\hline & & & & $H-5 » L+1(70 \%)$ \\
\hline 21 & 23568 & 424.3 & 0.071 & H-8»LUMO (91\%) \\
\hline 22 & 23578 & 424.1 & 0.008 & $H-3 » L+2(84 \%)$ \\
\hline 23 & 23908 & 418.3 & 0.096 & $H-8 » L+1(90 \%)$ \\
\hline 24 & 24393 & 410.0 & 0.379 & HOMO»L+4 (84\%) \\
\hline \multirow[t]{2}{*}{25} & 24866 & 402.2 & 0.368 & $H-1 » L+3(10 \%)$ \\
\hline & & & & HOMO»L+5 (77\%) \\
\hline 26 & 25444 & 393.0 & 0.043 & $\mathrm{H}-1 » \mathrm{~L}+3$ (77\%) \\
\hline 27 & 25938 & 385.5 & 0.019 & H-9»LUMO (91\%) \\
\hline \multirow[t]{2}{*}{28} & 26561 & 376.5 & 0.031 & H-10»LUMO (70\%) \\
\hline & & & & $\mathrm{H}-1 » \mathrm{~L}+4(24 \%)$ \\
\hline
\end{tabular}

\begin{tabular}{|c|c|c|c|c|}
\hline 29 & 26709 & 374.4 & 0.087 & $\begin{array}{l}H-10 » L+1(48 \%) \\
H-9 » L+1(29 \%) \\
H-1 » L+5(10 \%)\end{array}$ \\
\hline 30 & 26891 & 371.9 & 0.022 & $\begin{array}{l}\mathrm{H}-11 » \mathrm{LUMO}(10 \%) \\
\mathrm{H}-3 » \mathrm{~L}+3(47 \%)\end{array}$ \\
\hline 31 & 26910 & 371.6 & 0.004 & $\begin{array}{l}H-7 » L+2(16 \%) \\
H-4 » L+2(60 \%)\end{array}$ \\
\hline 32 & 26967 & 370.8 & 0.070 & $\begin{array}{l}\mathrm{H}-12 » \mathrm{LUMO}(47 \%) \\
\mathrm{H}-2 » \mathrm{~L}+3(14 \%) \\
\mathrm{H}-2 » \mathrm{~L}+4(15 \%)\end{array}$ \\
\hline 33 & 27033 & 369.9 & 0.002 & $\mathrm{H}-11 »$ LUMO (79\%) \\
\hline 34 & 27162 & 368.2 & 0.004 & $H-6 » L+2(70 \%)$ \\
\hline 35 & 27296 & 366.4 & 0.004 & $\begin{array}{l}H-13 » L+1(10 \%) \\
H-10 » L+1(23 \%) \\
H-9 » L+1(58 \%)\end{array}$ \\
\hline 36 & 27443 & 364.4 & 0.004 & $\begin{array}{l}H-7 » L+2(50 \%) \\
H-4 » L+2(23 \%)\end{array}$ \\
\hline 37 & 27641 & 361.8 & 0.000 & $\begin{array}{l}\mathrm{H}-13 » \mathrm{~L}+1(18 \%) \\
\mathrm{H}-12 » \mathrm{LUMO}(23 \%) \\
\mathrm{H}-5 » \mathrm{~L}+2(18 \%)\end{array}$ \\
\hline 38 & 27678 & 361.3 & 0.002 & $\mathrm{H}-13 »$ LUMO (78\%) \\
\hline 39 & 27771 & 360.1 & 0.002 & $\begin{array}{l}H-13 » L+1(53 \%) \\
H-5 » L+2(15 \%)\end{array}$ \\
\hline 40 & 27794 & 359.8 & 0.003 & $H-12 » L+1(67 \%)$ \\
\hline 41 & 27805 & 359.6 & 0.004 & $\begin{array}{l}\mathrm{H}-16 » \text { LUMO (10\%) } \\
\mathrm{H}-14 » \mathrm{LUMO}(48 \%) \\
\mathrm{H}-12 » \mathrm{~L}+1(10 \%)\end{array}$ \\
\hline 42 & 27829 & 359.3 & 0.003 & $\begin{array}{l}H-5 » L+2(41 \%) \\
H-2 » L+3(15 \%) \\
H-2 » L+4(13 \%)\end{array}$ \\
\hline 43 & 27925 & 358.1 & 0.307 & $\begin{array}{l}\mathrm{H}-17 » \text { LUMO (25\%) } \\
\mathrm{H}-10 » \text { LUMO (11\%) } \\
\mathrm{H}-1 » \mathrm{~L}+4(33 \%)\end{array}$ \\
\hline 44 & 27941 & 357.9 & 0.210 & $\begin{array}{l}H-17 » L+1(18 \%) \\
H-10 » L+1(10 \%) \\
H-1 » L+5(43 \%)\end{array}$ \\
\hline 45 & 28191 & 354.7 & 0.031 & $\begin{array}{l}\mathrm{H}-17 » \text { LUMO (12\%) } \\
\mathrm{H}-15 » \mathrm{LUMO}(33 \%) \\
\mathrm{H}-14 » \mathrm{~L}+1(19 \%)\end{array}$ \\
\hline 46 & 28252 & 354.0 & 0.010 & $\begin{array}{l}\mathrm{H}-17 » \mathrm{LUMO}(19 \%) \\
\mathrm{H}-14 » \mathrm{~L}+1(30 \%) \\
\mathrm{H}-8 » \mathrm{~L}+2(11 \%) \\
\mathrm{H}-1 » \mathrm{~L}+4(10 \%)\end{array}$ \\
\hline 47 & 28274 & 353.7 & 0.003 & $\begin{array}{l}\mathrm{H}-18 » \text { LUMO (38\%) } \\
\mathrm{H}-16 » \text { LUMO }(32 \%)\end{array}$ \\
\hline 48 & 28358 & 352.6 & 0.016 & $\mathrm{H}-11 » \mathrm{~L}+1$ (47\%) \\
\hline 49 & 28410 & 352.0 & 0.010 & $\begin{array}{l}H-11 » L+1(31 \%) \\
H-8 » L+2(29 \%)\end{array}$ \\
\hline 50 & 28450 & 351.5 & 0.007 & $\mathrm{H}-15 » \mathrm{~L}+1$ (73\%) \\
\hline
\end{tabular}

[a] Oscillator strength. [b] Contributions smaller than $10 \%$ are not included. $\mathrm{H}=\mathrm{HOMO}, \mathrm{L}=\mathrm{LUMO}$. Orbitals are numbered consecutively regardless of possible degeneracies. 
Table S10. Electronic transitions calculated for 3a-Zn using the TD/PCM(DCM)/B3LYP/6-31G(d,p) level of theory.

\begin{tabular}{|c|c|c|c|c|}
\hline No. & $\begin{array}{l}\text { Energy } \\
\left(\mathrm{cm}^{-1}\right)\end{array}$ & $\begin{array}{c}\lambda \\
(\mathrm{nm})\end{array}$ & $f^{[a]}$ & $\begin{array}{c}\text { Major } \\
\text { excitations }^{[\mathrm{b}]}\end{array}$ \\
\hline \multirow[t]{2}{*}{1} & 13768 & 726.3 & 0.034 & $H-1 » L+1(23 \%)$ \\
\hline & & & & $\begin{array}{l}\text { HOMO»LUMO } \\
(76 \%)\end{array}$ \\
\hline \multirow[t]{2}{*}{2} & 13937 & 717.5 & 0.007 & $\mathrm{H}-1 »$ LUMO (31\%) \\
\hline & & & & HOMO»L+1 (67\%) \\
\hline \multirow[t]{2}{*}{3} & 17124 & 584.0 & 1.330 & $\mathrm{H}-1 »$ LUMO (67\%) \\
\hline & & & & HOMO»L+1 (30\%) \\
\hline \multirow[t]{4}{*}{4} & 17209 & 581.1 & 0.914 & $H-1 » L+1(66 \%)$ \\
\hline & & & & HOMO»LUMO \\
\hline & & & & $(19 \%)$ \\
\hline & & & & HOMO»L+2 (12\%) \\
\hline 5 & 17916 & 558.2 & 0.203 & HOMO»L+2 (87\%) \\
\hline 6 & 19750 & 506.3 & 0.000 & $\mathrm{H}-4 »$ LUMO (90\%) \\
\hline 7 & 19781 & 505.5 & 0.011 & H-2»LUMO (80\%) \\
\hline 8 & 19899 & 502.5 & 0.002 & $H-3 » L+1(83 \%)$ \\
\hline 9 & 19967 & 500.8 & 0.220 & $H-1 » L+2(88 \%)$ \\
\hline 10 & 20036 & 499.1 & 0.020 & $H-2 » L+1(80 \%)$ \\
\hline 11 & 20712 & 482.8 & 0.032 & H-3»LUMO (92\%) \\
\hline 12 & 21262 & 470.3 & 0.017 & $H-4 » L+1$ (89\%) \\
\hline 13 & 21562 & 463.8 & 0.057 & $\mathrm{H}-5 »$ LUMO (85\%) \\
\hline 14 & 21948 & 455.6 & 0.083 & $H-5 » L+1(84 \%)$ \\
\hline 15 & 22253 & 449.4 & 0.044 & HOMO»L+3 (95\%) \\
\hline \multirow[t]{2}{*}{16} & 23105 & 432.8 & 0.001 & $H-7 » L+1(14 \%)$ \\
\hline & & & & H-6»LUMO (80\%) \\
\hline 17 & 23251 & 430.1 & 0.120 & H-7»LUMO (94\%) \\
\hline 18 & 23469 & 426.1 & 0.168 & $H-6 » L+1(95 \%)$ \\
\hline \multirow[t]{2}{*}{19} & 23830 & 419.6 & 0.000 & $H-7 » L+1(81 \%)$ \\
\hline & & & & H-6»LUMO (15\%) \\
\hline 20 & 24036 & 416.0 & 0.087 & $\mathrm{H}-8 »$ LUMO (93\%) \\
\hline \multirow[t]{4}{*}{21} & 24289 & 411.7 & 0.073 & H-10»LUMO (37\%) \\
\hline & & & & $H-8 » L+1(24 \%)$ \\
\hline & & & & $H-4 » L+2(13 \%)$ \\
\hline & & & & HOMO»L+4 (16\%) \\
\hline \multirow[t]{2}{*}{22} & 24424 & 409.4 & 0.083 & $H-8 » L+1(41 \%)$ \\
\hline & & & & $H-2 » L+2(33 \%)$ \\
\hline \multirow[t]{3}{*}{23} & 24550 & 407.3 & 0.000 & H-10»LUMO (18\%) \\
\hline & & & & $H-8 » L+1(24 \%)$ \\
\hline & & & & $H-2 » L+2(44 \%)$ \\
\hline \multirow[t]{2}{*}{24} & 24649 & 405.7 & 0.002 & $\mathrm{H}-10 » \mathrm{~L}+1$ (39\%) \\
\hline & & & & $H-3 » L+2(47 \%)$ \\
\hline \multirow[t]{2}{*}{25} & 24814 & 403.0 & 0.084 & $H-4 » L+2(46 \%)$ \\
\hline & & & & HOMO»L+4 (31\%) \\
\hline \multirow[t]{4}{*}{26} & 24894 & 401.7 & 0.073 & $\mathrm{H}-10 » \mathrm{~L}+1$ (14\%) \\
\hline & & & & $H-3 » L+2(28 \%)$ \\
\hline & & & & $H-1 » L+3(11 \%)$ \\
\hline & & & & HOMO»L+5 (36\%) \\
\hline \multirow[t]{2}{*}{27} & 25019 & 399.7 & 0.011 & $H-10 » L+1(16 \%)$ \\
\hline & & & & $H-1 » L+3(70 \%)$ \\
\hline \multirow[t]{3}{*}{28} & 25265 & 395.8 & 0.307 & $\mathrm{H}-10 »$ LUMO (26\%) \\
\hline & & & & $\mathrm{H}-4 » \mathrm{~L}+2(22 \%)$ \\
\hline & & & & HOMO»L+4 (34\%) \\
\hline \multirow[t]{3}{*}{29} & 25564 & 391.2 & 0.317 & $H-10 » L+1(20 \%)$ \\
\hline & & & & $H-1 » L+3(11 \%)$ \\
\hline & & & & HOMO»L+5 (43\%) \\
\hline 30 & 25849 & 386.9 & 0.000 & $H-5 » L+2(83 \%)$ \\
\hline 31 & 26436 & 378.3 & 0.019 & H-9»LUMO (82\%) \\
\hline \multirow[t]{2}{*}{32} & 26758 & 373.7 & 0.003 & $\mathrm{H}-11 » L U M O(61 \%)$ \\
\hline & & & & $H-1 » L+4(27 \%)$ \\
\hline
\end{tabular}

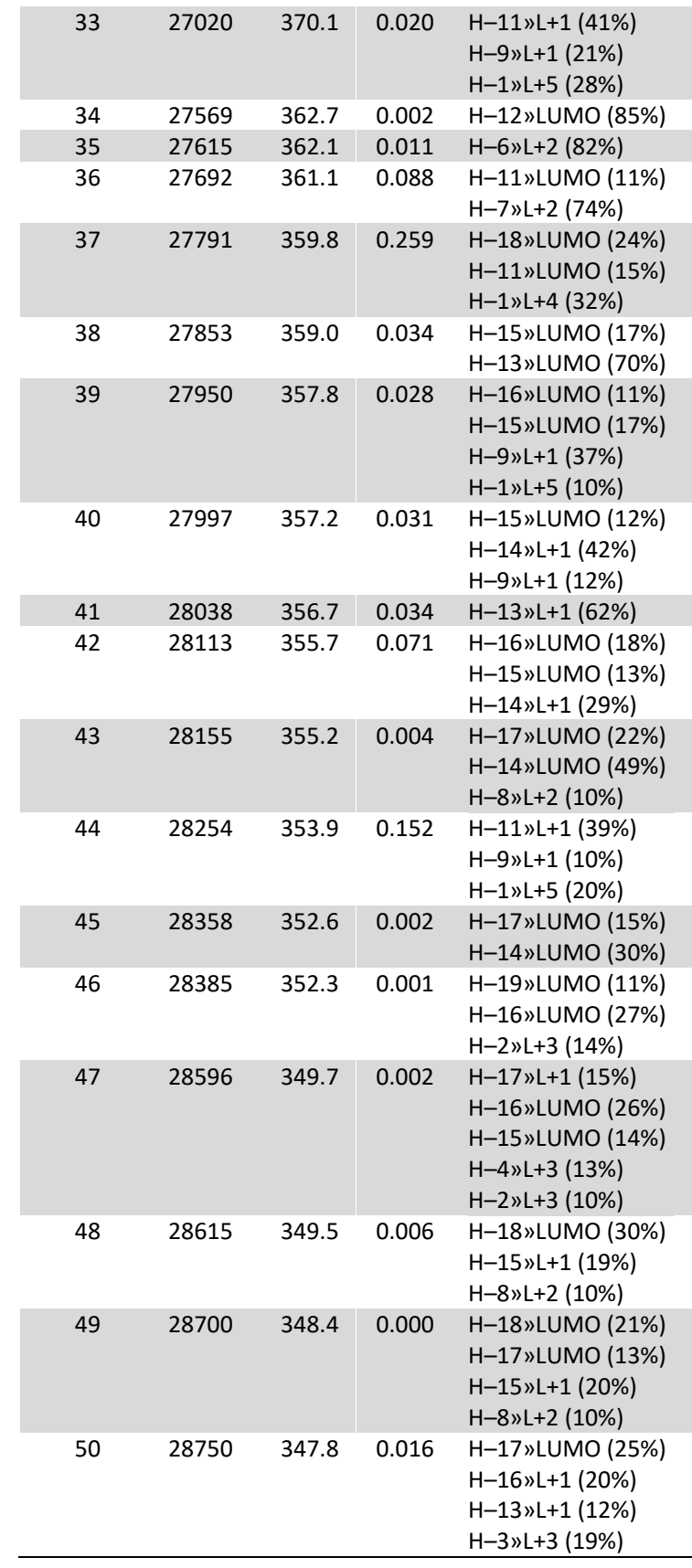

[a] Oscillator strength. [b] Contributions smaller than $10 \%$ are not included. $\mathrm{H}=\mathrm{HOMO}, \mathrm{L}=\mathrm{LUMO}$. Orbitals are numbered consecutively regardless of possible degeneracies. 
Table S11. Electronic transitions calculated for $\mathbf{3 b}-\mathrm{H}_{2}$ using the TD/PCM(DCM)/B3LYP/6-31G(d,p) level of theory.

\begin{tabular}{|c|c|c|c|c|}
\hline No. & $\begin{array}{l}\text { Energy } \\
\left(\mathrm{cm}^{-1}\right)\end{array}$ & $\begin{array}{c}\lambda \\
(\mathrm{nm})\end{array}$ & $f^{[a]}$ & $\begin{array}{c}\text { Major } \\
\text { excitations }^{[\mathrm{b}]}\end{array}$ \\
\hline 1 & 11286 & 886.0 & 0.081 & $\begin{array}{l}\text { HOMO»LUMO } \\
(94 \%)\end{array}$ \\
\hline 2 & 13521 & 739.6 & 0.025 & $\begin{array}{l}\mathrm{H}-1 » \mathrm{LUMO}(49 \%) \\
\text { HOMO»L+1 (49\%) }\end{array}$ \\
\hline 3 & 15508 & 644.8 & 0.026 & $\begin{array}{l}H-1 » L+1(33 \%) \\
H O M O » L+2(63 \%)\end{array}$ \\
\hline 4 & 15735 & 635.5 & 1.161 & $\begin{array}{l}\mathrm{H}-1 » \mathrm{LUMO}(50 \%) \\
\text { HOMO»L+1 (45\%) }\end{array}$ \\
\hline 5 & 16502 & 606.0 & 0.020 & H-2»LUMO (81\%) \\
\hline 6 & 16818 & 594.6 & 0.021 & $\mathrm{H}-3 »$ LUMO (83\%) \\
\hline 7 & 17940 & 557.4 & 0.867 & $\begin{array}{l}\mathrm{H}-1 » \mathrm{~L}+1(43 \%) \\
\mathrm{HOMO} » \mathrm{~L}+2(31 \%)\end{array}$ \\
\hline 8 & 19074 & 524.3 & 0.005 & $H-2 » L+1(95 \%)$ \\
\hline 9 & 19641 & 509.1 & 0.448 & $H-1 » L+2(89 \%)$ \\
\hline 10 & 20096 & 497.6 & 0.429 & HOMO»L+3 (86\%) \\
\hline 11 & 20710 & 482.9 & 0.110 & $\begin{array}{l}\mathrm{H}-7 » \text { LUMO (15\%) } \\
\mathrm{H}-4 » \text { LUMO (76\%) }\end{array}$ \\
\hline 12 & 20888 & 478.7 & 0.030 & $\begin{array}{l}\mathrm{H}-6 » \text { LUMO (68\%) } \\
\mathrm{H}-5 » \text { LUMO (18\%) }\end{array}$ \\
\hline 13 & 20991 & 476.4 & 0.026 & $H-3 » L+1(89 \%)$ \\
\hline 14 & 21047 & 475.1 & 0.000 & $\begin{array}{l}\mathrm{H}-6 » \text { LUMO (23\%) } \\
\mathrm{H}-5 » \text { LUMO (70\%) }\end{array}$ \\
\hline 15 & 21183 & 472.1 & 0.050 & $H-2 » L+2(84 \%)$ \\
\hline 16 & 21385 & 467.6 & 0.043 & $\begin{array}{l}\mathrm{H}-7 » \text { LUMO (75\%) } \\
\mathrm{H}-4 » \text { LUMO (14\%) }\end{array}$ \\
\hline 17 & 22137 & 451.7 & 0.040 & $\begin{array}{l}\mathrm{H}-8 » \mathrm{LUMO}(19 \%) \\
\mathrm{H}-6 » \mathrm{~L}+1(68 \%)\end{array}$ \\
\hline 18 & 22153 & 451.4 & 0.004 & $\begin{array}{l}H-7 » L+1(48 \%) \\
H-4 » L+1(37 \%)\end{array}$ \\
\hline 19 & 22357 & 447.3 & 0.101 & $\begin{array}{l}\mathrm{H}-8 » \mathrm{LUMO}(74 \%) \\
\mathrm{H}-6 » \mathrm{~L}+1(19 \%)\end{array}$ \\
\hline 20 & 22905 & 436.6 & 0.004 & $\mathrm{H}-3 » \mathrm{~L}+2(81 \%)$ \\
\hline 21 & 23237 & 430.4 & 0.013 & $\begin{array}{l}H-7 » L+1(41 \%) \\
H-4 » L+1(55 \%)\end{array}$ \\
\hline 22 & 23269 & 429.8 & 0.097 & $\mathrm{H}-5 » \mathrm{~L}+1$ (86\%) \\
\hline 23 & 23371 & 427.9 & 0.091 & $\mathrm{H}-1 » \mathrm{~L}+3(75 \%)$ \\
\hline 24 & 23470 & 426.1 & 0.012 & H-9»LUMO (91\%) \\
\hline 25 & 23881 & 418.7 & 0.323 & HOMO»L+4 (84\%) \\
\hline 26 & 24572 & 407.0 & 0.001 & H-12»LUMO (88\%) \\
\hline 27 & 24773 & 403.7 & 0.113 & $\begin{array}{l}\text { H-10»LUMO (51\%) } \\
\text { HOMO»L+5 (35\%) }\end{array}$ \\
\hline 28 & 24954 & 400.7 & 0.044 & $\mathrm{H}-8 » \mathrm{~L}+1(80 \%)$ \\
\hline 29 & 25336 & 394.7 & 0.333 & $\begin{array}{l}\mathrm{H}-10 » L \mathrm{LMO}(33 \%) \\
\mathrm{H}-4 » \mathrm{~L}+2(25 \%) \\
\mathrm{HOMO} \text { ( }+5 \text { (29\%) }\end{array}$ \\
\hline 30 & 25448 & 393.0 & 0.033 & $\mathrm{H}-11 » L U M O(90 \%)$ \\
\hline
\end{tabular}

\begin{tabular}{|c|c|c|c|c|}
\hline 31 & 25742 & 388.5 & 0.034 & $\begin{array}{l}\text { H-17»LUMO (16\%) } \\
\text { H-13»LUMO (48\%) } \\
H-4 » L+2(20 \%)\end{array}$ \\
\hline 32 & 25842 & 387.0 & 0.000 & $\begin{array}{l}\text { H-16»LUMO (30\%) } \\
\text { H-14»LUMO (52\%) }\end{array}$ \\
\hline 33 & 25920 & 385.8 & 0.171 & $\begin{array}{l}\text { H-13»LUMO (30\%) } \\
H-4 » L+2(37 \%) \\
\text { HOMO»L+5 (14\%) }\end{array}$ \\
\hline 34 & 26048 & 383.9 & 0.017 & $H-6 » L+2(81 \%)$ \\
\hline 35 & 26148 & 382.4 & 0.000 & $\begin{array}{l}\mathrm{H}-16 » \text { LUMO (21\%) } \\
\mathrm{H}-5 » \mathrm{~L}+2(46 \%)\end{array}$ \\
\hline 36 & 26265 & 380.7 & 0.020 & $\mathrm{H}-7 » \mathrm{~L}+2(83 \%)$ \\
\hline 37 & 26273 & 380.6 & 0.009 & $\begin{array}{l}\text { H-16»LUMO (31\%) } \\
H-14 » L U M O(21 \%) \\
H-5 » L+2(30 \%)\end{array}$ \\
\hline 38 & 26278 & 380.6 & 0.037 & $\begin{array}{l}\text { H-17»LUMO (18\%) } \\
\text { H-15»LUMO (59\%) }\end{array}$ \\
\hline 39 & 26409 & 378.7 & 0.000 & $H-2 » L+3(85 \%)$ \\
\hline 40 & 26598 & 376.0 & 0.003 & $\begin{array}{l}\text { H-17»LUMO (52\%) } \\
\text { H-15»LUMO (27\%) }\end{array}$ \\
\hline 41 & 26824 & 372.8 & 0.042 & $\begin{array}{l}\text { H-18»LUMO (76\%) } \\
\text { H-14»LUMO (10\%) }\end{array}$ \\
\hline 42 & 27059 & 369.6 & 0.002 & $\begin{array}{l}H-10 » L+1(19 \%) \\
H-3 » L+3(57 \%)\end{array}$ \\
\hline 43 & 27122 & 368.7 & 0.138 & $\begin{array}{l}H-10 » L+1(59 \%) \\
H-3 » L+3(17 \%)\end{array}$ \\
\hline 44 & 27437 & 364.5 & 0.000 & $\begin{array}{l}\text { H-26»LUMO (14\%) } \\
\text { H-19»LUMO (45\%) } \\
H-9 » L+1(20 \%)\end{array}$ \\
\hline 45 & 27486 & 363.8 & 0.002 & $\begin{array}{l}\text { H-19»LUMO (14\%) } \\
H-9 » L+1(68 \%)\end{array}$ \\
\hline 46 & 27527 & 363.3 & 0.090 & $H-1 » L+4(60 \%)$ \\
\hline 47 & 27584 & 362.5 & 0.001 & $H-2 » L+4(74 \%)$ \\
\hline 48 & 27603 & 362.3 & 0.005 & $\mathrm{H}-11 » \mathrm{~L}+1$ (80\%) \\
\hline 49 & 27791 & 359.8 & 0.000 & H-25»LUMO (83\%) \\
\hline 50 & 27889 & 358.6 & 0.005 & $\begin{array}{l}\mathrm{H}-26 » L \mathrm{~L} M 0(11 \%) \\
\mathrm{H}-15 » \mathrm{~L}+1(15 \%) \\
\mathrm{H}-13 » \mathrm{~L}+1(37 \%) \\
\mathrm{H}-1 » \mathrm{~L}+5(18 \%)\end{array}$ \\
\hline
\end{tabular}

[a] Oscillator strength. [b] Contributions smaller than $10 \%$ are not included. $\mathrm{H}=\mathrm{HOMO}, \mathrm{L}=\mathrm{LUMO}$. Orbitals are numbered consecutively regardless of possible degeneracies. 
Table S12.Electronic transitions calculated for $3 b-Z n$ using the TD/PCM(DCM)/B3LYP/6-31G(d,p) level of theory.

\begin{tabular}{|c|c|c|c|c|}
\hline No. & $\begin{array}{l}\text { Energy } \\
\left(\mathrm{cm}^{-1}\right)\end{array}$ & $\begin{array}{c}\lambda \\
(\mathrm{nm})\end{array}$ & $f^{[\mathrm{a}]}$ & $\begin{array}{c}\text { Major } \\
\text { excitations }^{[\mathrm{b}]}\end{array}$ \\
\hline 1 & 11653 & 858.1 & 0.072 & $\begin{array}{l}\text { HOMO»LUMO } \\
(96 \%)\end{array}$ \\
\hline 2 & 13398 & 746.4 & 0.098 & $\begin{array}{l}\text { H-1»LUMO (62\%) } \\
\text { HOMO»L+1 (36\%) }\end{array}$ \\
\hline 3 & 15687 & 637.5 & 1.045 & $\begin{array}{l}\text { H-1»LUMO (37\%) } \\
\text { HOMO»L+1 (56\%) }\end{array}$ \\
\hline 4 & 15929 & 627.8 & 0.063 & $\begin{array}{l}\mathrm{H}-1 » \mathrm{~L}+1(45 \%) \\
\mathrm{HOMO} » \mathrm{~L}+2(52 \%)\end{array}$ \\
\hline 5 & 17828 & 560.9 & 0.543 & $\begin{array}{l}\mathrm{H}-6 » \text { LUMO (12\%) } \\
\mathrm{H}-4 » L U M O(11 \%) \\
\mathrm{H}-2 » L U M O(14 \%) \\
\mathrm{H}-1 » \mathrm{~L}+1(32 \%) \\
\text { HOMO»L+2 (24\%) }\end{array}$ \\
\hline 6 & 18102 & 552.4 & 0.306 & $\begin{array}{l}\mathrm{H}-4 » L U M O(16 \%) \\
\mathrm{H}-2 » L U M O(30 \%) \\
\mathrm{H}-1 » \mathrm{~L}+1(14 \%) \\
\text { HOMO»L+2 (22\%) }\end{array}$ \\
\hline 7 & 18136 & 551.4 & 0.011 & $\begin{array}{l}\mathrm{H}-6 » \text { LUMO (11\%) } \\
\mathrm{H}-4 » \text { LUMO (30\%) } \\
\mathrm{H}-2 » \text { LUMO (49\%) }\end{array}$ \\
\hline 8 & 18514 & 540.1 & 0.004 & H-3»LUMO (96\%) \\
\hline 9 & 19369 & 516.3 & 0.449 & $H-1 » L+2$ (91\%) \\
\hline 10 & 19448 & 514.2 & 0.029 & $\begin{array}{l}\mathrm{H}-6 » \text { LUMO (33\%) } \\
\mathrm{H}-5 » L U M O(16 \%) \\
\mathrm{H}-4 » L U M O(31 \%) \\
\mathrm{H}-3 » \mathrm{~L}+1(13 \%)\end{array}$ \\
\hline 11 & 20077 & 498.1 & 0.001 & $H-3 » L+1(79 \%)$ \\
\hline 12 & 20145 & 496.4 & 0.012 & $\begin{array}{l}H-4 » L+1(15 \%) \\
H-2 » L+1(75 \%)\end{array}$ \\
\hline 13 & 20639 & 484.5 & 0.284 & $\begin{array}{l}\text { H-5»LUMO (27\%) } \\
\text { HOMO»L+3 (62\%) }\end{array}$ \\
\hline 14 & 21016 & 475.8 & 0.035 & $\begin{array}{l}\mathrm{H}-6 » \mathrm{LUMO}(23 \%) \\
\mathrm{H}-5 » \mathrm{LUMO}(45 \%) \\
\text { HOMO»L+3 (28\%) }\end{array}$ \\
\hline 15 & 21396 & 467.4 & 0.028 & $\begin{array}{l}\mathrm{H}-7 » \mathrm{LUMO}(24 \%) \\
\mathrm{H}-4 » \mathrm{~L}+1(58 \%) \\
\mathrm{H}-2 » \mathrm{~L}+1(14 \%)\end{array}$ \\
\hline 16 & 21515 & 464.8 & 0.116 & $\begin{array}{l}\mathrm{H}-7 » \mathrm{LUMO}(73 \%) \\
\mathrm{H}-4 » \mathrm{~L}+1(17 \%)\end{array}$ \\
\hline 17 & 22439 & 445.6 & 0.160 & $\mathrm{H}-8 »$ LUMO (88\%) \\
\hline 18 & 22567 & 443.1 & 0.000 & $\begin{array}{l}H-4 » L+2(11 \%) \\
H-2 » L+2(74 \%)\end{array}$ \\
\hline 19 & 23018 & 434.4 & 0.033 & $\begin{array}{l}H-6 » L+1(28 \%) \\
H-5 » L+1(43 \%) \\
H-1 » L+3(21 \%)\end{array}$ \\
\hline 20 & 23155 & 431.9 & 0.013 & H-10»LUMO (82\%) \\
\hline 21 & 23285 & 429.5 & 0.033 & $\begin{array}{l}H-5 » L+1(12 \%) \\
H-3 » L+2(15 \%) \\
H-1 » L+3(55 \%)\end{array}$ \\
\hline 22 & 23505 & 425.4 & 0.167 & $\begin{array}{l}H-6 » L+1(57 \%) \\
H-5 » L+1(36 \%)\end{array}$ \\
\hline 23 & 23717 & 421.6 & 0.008 & H-9»LUMO (94\%) \\
\hline 24 & 23830 & 419.6 & 0.012 & $\mathrm{H}-3 » \mathrm{~L}+2(75 \%)$ \\
\hline 25 & 23839 & 419.5 & 0.010 & $H-7 » L+1$ (95\%) \\
\hline 26 & 23979 & 417.0 & 0.053 & $\begin{array}{l}H-4 » L+2(76 \%) \\
H-2 » L+2(10 \%)\end{array}$ \\
\hline 27 & 24326 & 411.1 & 0.310 & HOMO»L+4 (77\%) \\
\hline
\end{tabular}

\begin{tabular}{|c|c|c|c|c|}
\hline \multirow{2}{*}{28} & \multirow{2}{*}{24773} & \multirow{2}{*}{403.7} & \multirow{2}{*}{0.003} & $\mathrm{H}-14 » \mathrm{LUMO}(64 \%)$ \\
\hline & & & & H-11»LUMO (20\%) \\
\hline \multirow[t]{3}{*}{29} & \multirow[t]{3}{*}{24853} & \multirow[t]{3}{*}{402.4} & \multirow[t]{3}{*}{0.019} & H-14»LUMO (24\%) \\
\hline & & & & H-11»LUMO (48\%) \\
\hline & & & & HOMO»L+5 (16\%) \\
\hline \multirow[t]{3}{*}{30} & \multirow{3}{*}{25113} & \multirow[t]{3}{*}{398.2} & \multirow[t]{3}{*}{0.031} & H-11»LUMO (14\%) \\
\hline & & & & $\mathrm{H}-10 » \mathrm{~L}+1$ (64\%) \\
\hline & & & & HOMO»L+5 (12\%) \\
\hline \multirow[t]{2}{*}{31} & \multirow[t]{2}{*}{25143} & \multirow[t]{2}{*}{397.7} & \multirow[t]{2}{*}{0.008} & $H-6 » L+2(51 \%)$ \\
\hline & & & & $H-5 » L+2(30 \%)$ \\
\hline 32 & 25399 & 393.7 & 0.046 & $H-8 » L+1(69 \%)$ \\
\hline \multirow[t]{3}{*}{33} & \multirow[t]{3}{*}{25711} & \multirow[t]{3}{*}{388.9} & \multirow[t]{3}{*}{0.013} & H-17»LUMO (14\%) \\
\hline & & & & H-15»LUMO (30\%) \\
\hline & & & & H-12»LUMO (45\%) \\
\hline \multirow[t]{3}{*}{34} & 25733 & 388.6 & 0.482 & H-18»LUMO (10\%) \\
\hline & & & & $\mathrm{H}-10 » \mathrm{~L}+1(18 \%)$ \\
\hline & & & & HOMO»L+5 (43\%) \\
\hline 35 & 25796 & 387.7 & 0.008 & H-17»LUMO (35\%) \\
\hline & & & & H-15»LUMO (11\%) \\
\hline & & & & H-12»LUMO (43\%) \\
\hline 36 & 25831 & 387.1 & 0.046 & H-13»LUMO (84\%) \\
\hline 37 & 26201 & 381.7 & 0.039 & H-16»LUMO (18\%) \\
\hline & & & & $H-7 » L+2(63 \%)$ \\
\hline 38 & 26240 & 381.1 & 0.013 & H-17»LUMO (10\%) \\
\hline & & & & H-15»LUMO (11\%) \\
\hline & & & & $H-8 » L+1(13 \%)$ \\
\hline & & & & $H-6 » L+2(21 \%)$ \\
\hline & & & & $H-5 » L+2(33 \%)$ \\
\hline 39 & 26324 & 379.9 & 0.004 & H-17»LUMO (24\%) \\
\hline & & & & H-15»LUMO (36\%) \\
\hline & & & & $H-5 » L+2(19 \%)$ \\
\hline 40 & 26421 & 378.5 & 0.026 & H-18»LUMO (15\%) \\
\hline & & & & H-16»LUMO (37\%) \\
\hline & & & & $H-7 » L+2(19 \%)$ \\
\hline & & & & $H-1 » L+4(19 \%)$ \\
\hline 41 & 26634 & 375.5 & 0.013 & H-18»LUMO (52\%) \\
\hline & & & & H-16»LUMO (26\%) \\
\hline 42 & 26861 & 372.3 & 0.003 & $H-3 » L+3(68 \%)$ \\
\hline 43 & 26916 & 371.5 & 0.005 & H-19»LUMO (34\%) \\
\hline & & & & $H-4 » L+3(13 \%)$ \\
\hline & & & & $H-2 » L+3(33 \%)$ \\
\hline 44 & 26993 & 370.5 & 0.061 & H-19»LUMO (50\%) \\
\hline & & & & $H-2 » L+3(16 \%)$ \\
\hline 45 & 27508 & 363.5 & 0.029 & $\mathrm{H}-11 » \mathrm{~L}+1$ (62\%) \\
\hline & & & & $H-1 » L+5(18 \%)$ \\
\hline 46 & 27526 & 363.3 & 0.080 & $H-1 » L+4(55 \%)$ \\
\hline 47 & 27867 & 358.8 & 0.013 & H-20»LUMO (63\%) \\
\hline & & & & $H-11 » L+1(11 \%)$ \\
\hline 48 & 27973 & 357.5 & 0.000 & H-25»LUMO (84\%) \\
\hline 49 & 28101 & 355.9 & 0.025 & $\mathrm{H}-16 » \mathrm{~L}+1$ (10\%) \\
\hline & & & & $H-13 » L+1$ (59\%) \\
\hline 50 & 28127 & 355.5 & 0.088 & $\mathrm{H}-12 » \mathrm{~L}+1$ (83\%) \\
\hline
\end{tabular}

[a] Oscillator strength. [b] Contributions smaller than $10 \%$ are not included. $\mathrm{H}=\mathrm{HOMO}, \mathrm{L}=\mathrm{LUMO}$. Orbitals are numbered consecutively regardless of possible degeneracies. 
Table S13. Crystal data and structure refinement for $\mathbf{2 b}-\mathrm{H}_{2}$ and $\mathbf{3 b}-\mathrm{H}_{2}$.

\begin{tabular}{|c|c|c|}
\hline Identification code & 2b- $\mathrm{H}_{2}(2015790)$ & 3b- $\mathrm{H}_{2}(2015791)$ \\
\hline Empirical formula & $\mathrm{C}_{135.3} \mathrm{H}_{117.3} \mathrm{Cl}_{26.4} \mathrm{~N}_{6} \mathrm{O}_{4}$ & $\mathrm{C}_{121.9} \mathrm{H}_{111.3} \mathrm{Cl}_{9.3} \mathrm{~N}_{5} \mathrm{O}_{2}$ \\
\hline Formula weight & 2835.98 & 2011.06 \\
\hline Temperature/K & $100(2)$ & $100(2)$ \\
\hline Crystal system & triclinic & monoclinic \\
\hline Space group & P-1 & $12 / a$ \\
\hline$a / \AA$ & $16.064(5)$ & $35.41(2)$ \\
\hline$b / \AA$ & $20.140(6)$ & $16.245(7)$ \\
\hline$c / \AA ̊$ & $21.720(9)$ & $42.180(3)$ \\
\hline$\alpha /^{\circ}$ & $91.95(3)$ & 90 \\
\hline$B /^{\circ}$ & $97.51(3)$ & $111.65(5)$ \\
\hline$\gamma /{ }^{\circ}$ & $93.50(3)$ & 90 \\
\hline Volume $/ \AA^{3}$ & $6948(4)$ & $22552(18)$ \\
\hline$z$ & 2 & 8 \\
\hline$D_{\text {calc }} \mathrm{g} / \mathrm{cm}^{3}$ & 1.356 & 1.185 \\
\hline$\mu / \mathrm{mm}^{-1}$ & 5.160 & 2.502 \\
\hline$F(000)$ & 2904.0 & 8414.0 \\
\hline Crystal size $/ \mathrm{mm}^{3}$ & $0.700 \times 0.090 \times 0.040$ & $0.460 \times 0.190 \times 0.080$ \\
\hline Radiation & CuK $\alpha(\lambda=1.54184)$ & $\mathrm{Cu} \mathrm{K \alpha}(\lambda=1.54184)$ \\
\hline $2 \theta$ range for data collection $/^{\circ}$ & 7.318 to 136.39 & 6.944 to 136.274 \\
\hline Index ranges & $\begin{array}{l}-17 \leq \mathrm{h} \leq 19,-23 \leq \mathrm{k} \leq 15,-25 \leq \mathrm{I} \leq \\
24\end{array}$ & $\begin{array}{l}-42 \leq \mathrm{h} \leq 42,-19 \leq \mathrm{k} \leq 12,-50 \leq \mathrm{I} \\
\leq 48\end{array}$ \\
\hline Reflections collected & 44082 & 47946 \\
\hline Independent reflections & $\begin{array}{l}24468\left[R_{\text {int }}=0.1082, R_{\text {sigma }}=\right. \\
0.1757]\end{array}$ & $\begin{array}{l}20155\left[R_{\text {int }}=0.1421, R_{\text {sigma }}=\right. \\
0.2001]\end{array}$ \\
\hline Data/restraints/parameters & $24468 / 102 / 1778$ & $20155 / 67 / 1300$ \\
\hline Goodness-of-fit on $F^{2}$ & 1.161 & 1.075 \\
\hline Final $R$ indexes $[1>=2 \sigma(I)]$ & $\mathrm{R}_{1}=0.1182, \mathrm{wR}_{2}=0.2904$ & $\mathrm{R}_{1}=0.1240, w \mathrm{R}_{2}=0.2718$ \\
\hline Final $R$ indexes [all data] & $R_{1}=0.1918, w R_{2}=0.3513$ & $\mathrm{R}_{1}=0.2826, \mathrm{wR}_{2}=0.3992$ \\
\hline Largest diff. peak/hole / e $\AA^{-3}$ & $1.11 /-0.71$ & $0.60 /-0.38$ \\
\hline
\end{tabular}


Table S14. Dihedral angles ${ }^{a}$ between opposing naphthalene/NMI moieties in $\mathbf{2} \mathbf{b}-\mathrm{H}_{2}, \mathbf{2} \mathbf{b}-\mathbf{Z n}, \mathbf{3} \mathbf{b}-\mathbf{H}_{2}$ and 3b-Zn obtained from experimental (XRD) and calculated (DFT) geometries.

\begin{tabular}{|c|c|c|c|}
\hline Compounds & $\begin{array}{c}\text { naphthalene/naphthalene } \\
\text { angle (deg) }\end{array}$ & $\begin{array}{c}\mathrm{NMI} / \mathrm{NMI} \\
\text { angle (deg) }\end{array}$ & $\begin{array}{c}\text { NMI/naphthalene } \\
\text { angle (deg) }\end{array}$ \\
\hline $2 \mathrm{~b}-\mathrm{H}_{2}$ (XRD) & 109.13 & 117.52 & - \\
\hline $3 b-H_{2}$ (XRD) & 128.81 & - & 90.18 \\
\hline $2 \mathrm{~b}-\mathrm{H}_{2}$ (DFT) & 104.00 & 98.32 & - \\
\hline $3 b-H_{2}$ (DFT) & 103.60 & - & 99.30 \\
\hline $2 b-Z n$ (DFT) & 106.85 & 102.40 & - \\
\hline 3b-Zn (DFT) & 106.19 & - & 105.19 \\
\hline
\end{tabular}

\footnotetext{
${ }^{a}$ For both NMI (naphthalenemonoimide) and naphthalene units the mean plane was calculated using the 10 carbon atoms of the two naphthalene rings.
} 
NMR Spectra 


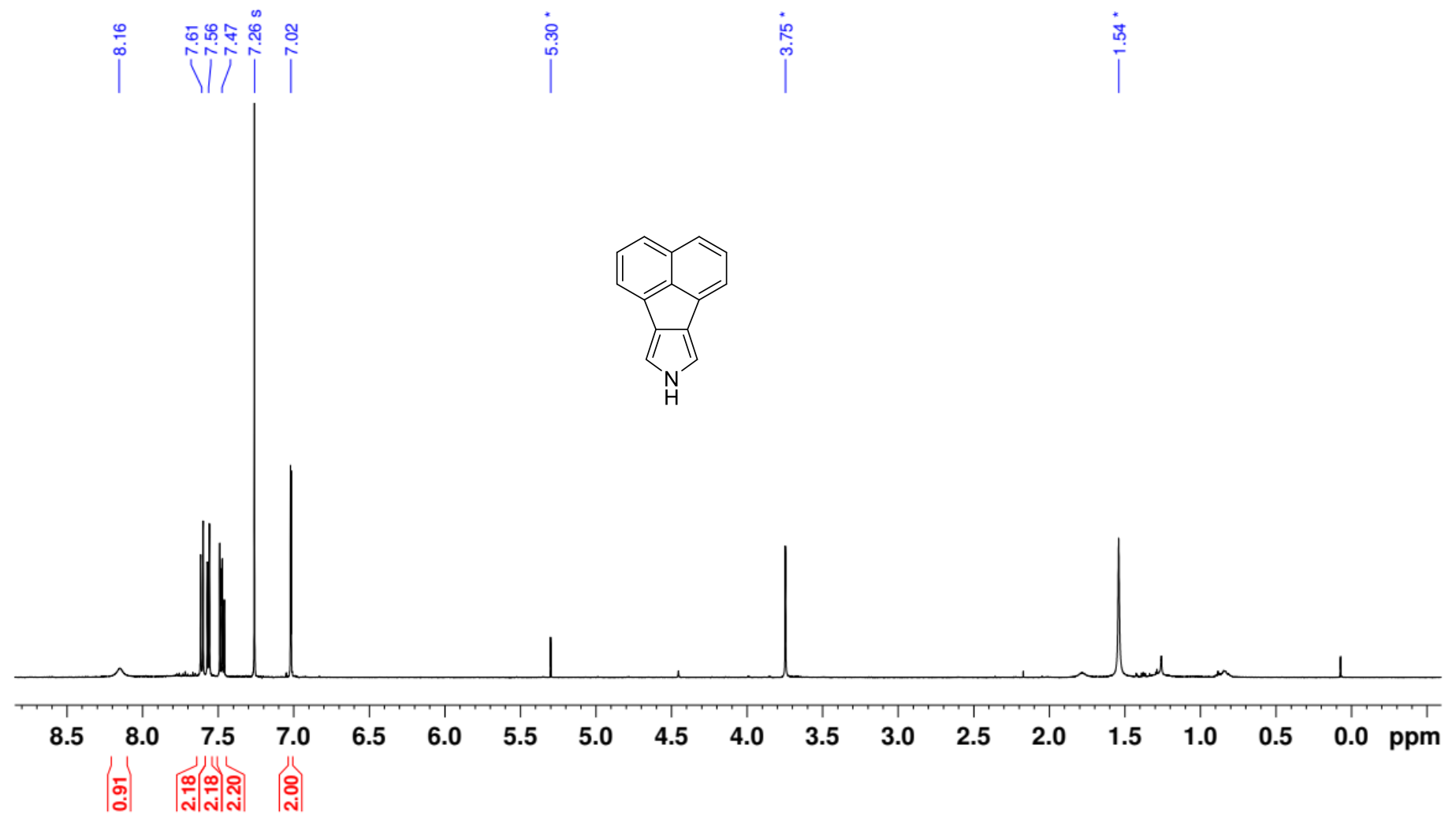

Figure S30. ${ }^{1} \mathrm{H}$ NMR spectrum of 4 ( $500 \mathrm{MHz}$, chloroform- $d$, $300 \mathrm{~K}$ ).
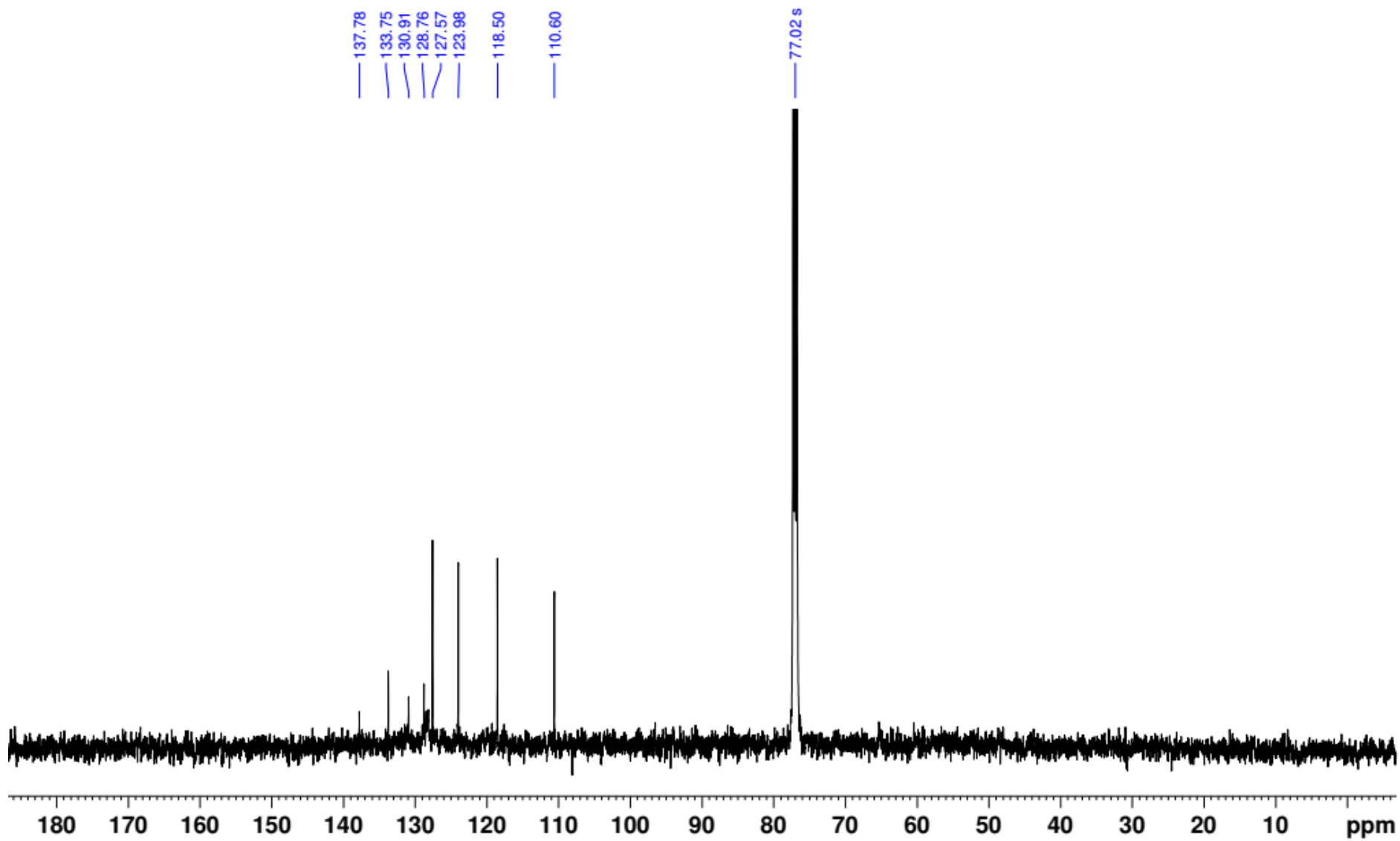

Figure S31. ${ }^{13} \mathrm{C}$ NMR spectrum of 4 (125 MHz, chloroform-d , $\left.300 \mathrm{~K}\right)$. 


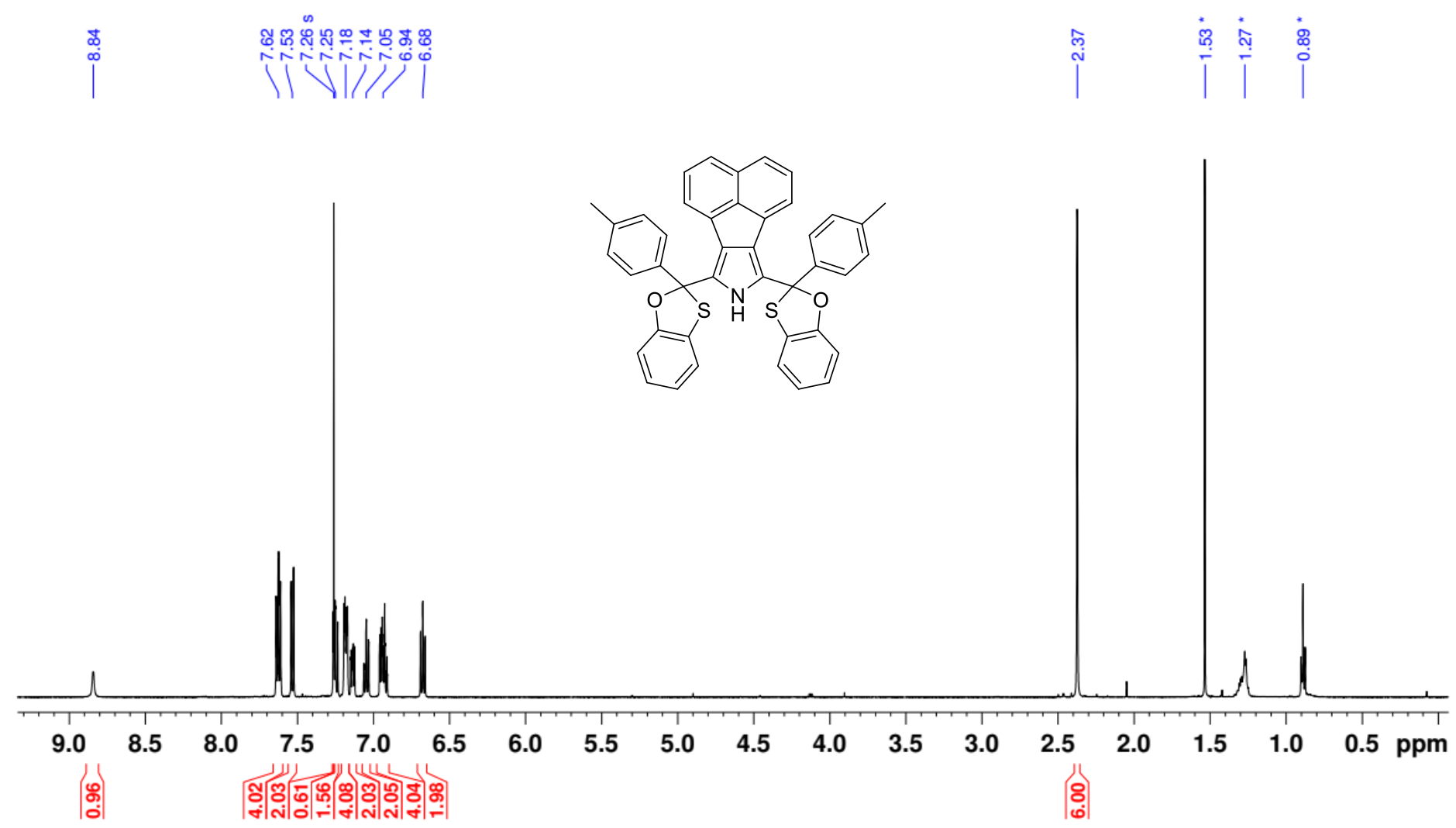

Figure S32. ${ }^{1} \mathrm{H}$ NMR spectrum of 5 ( $500 \mathrm{MHz}$, chloroform- $\left.d, 300 \mathrm{~K}\right)$.

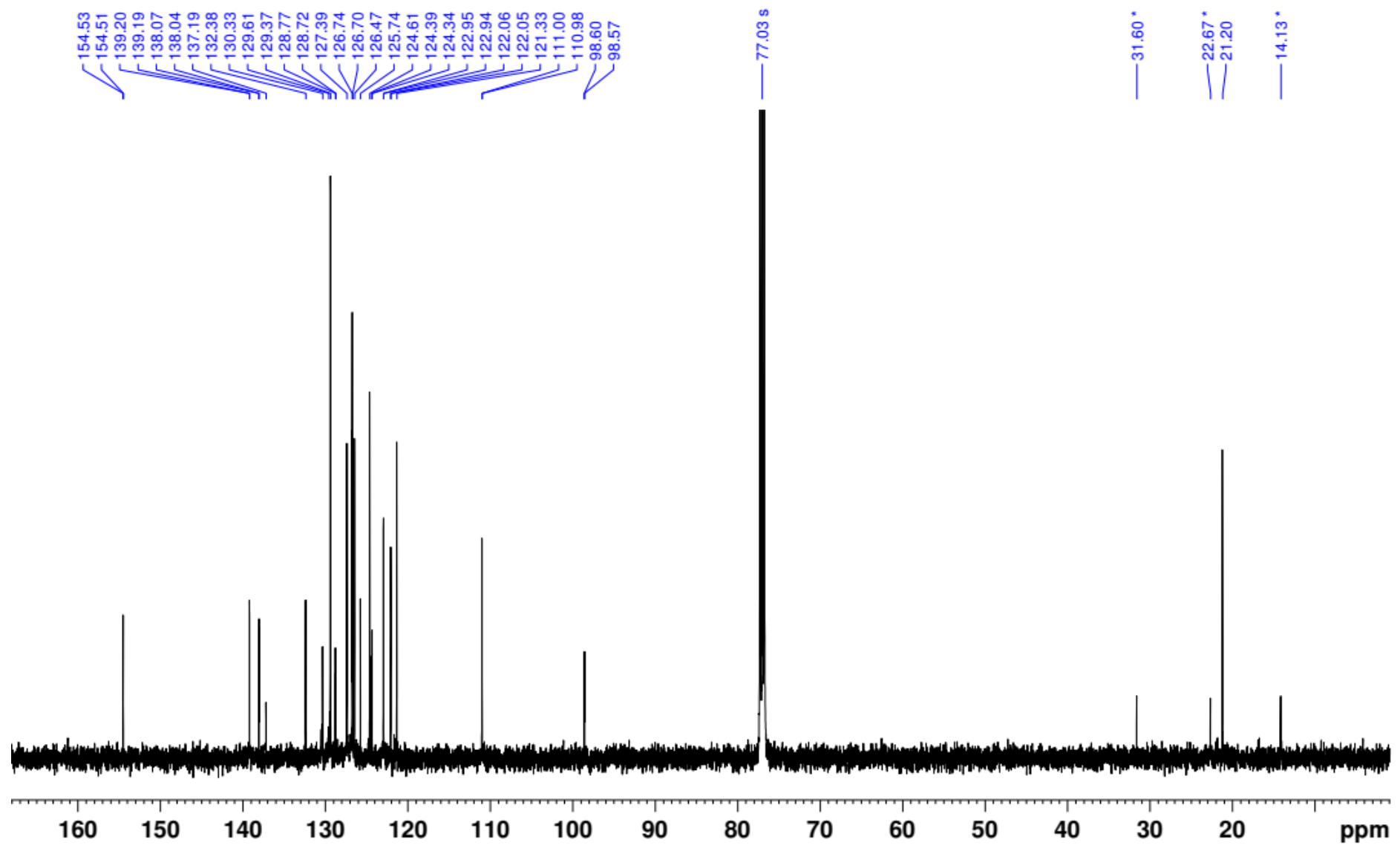

Figure S33. ${ }^{13} \mathrm{C}$ NMR spectrum of 5 (125 MHz, chloroform-d , $300 \mathrm{~K}$ ). 


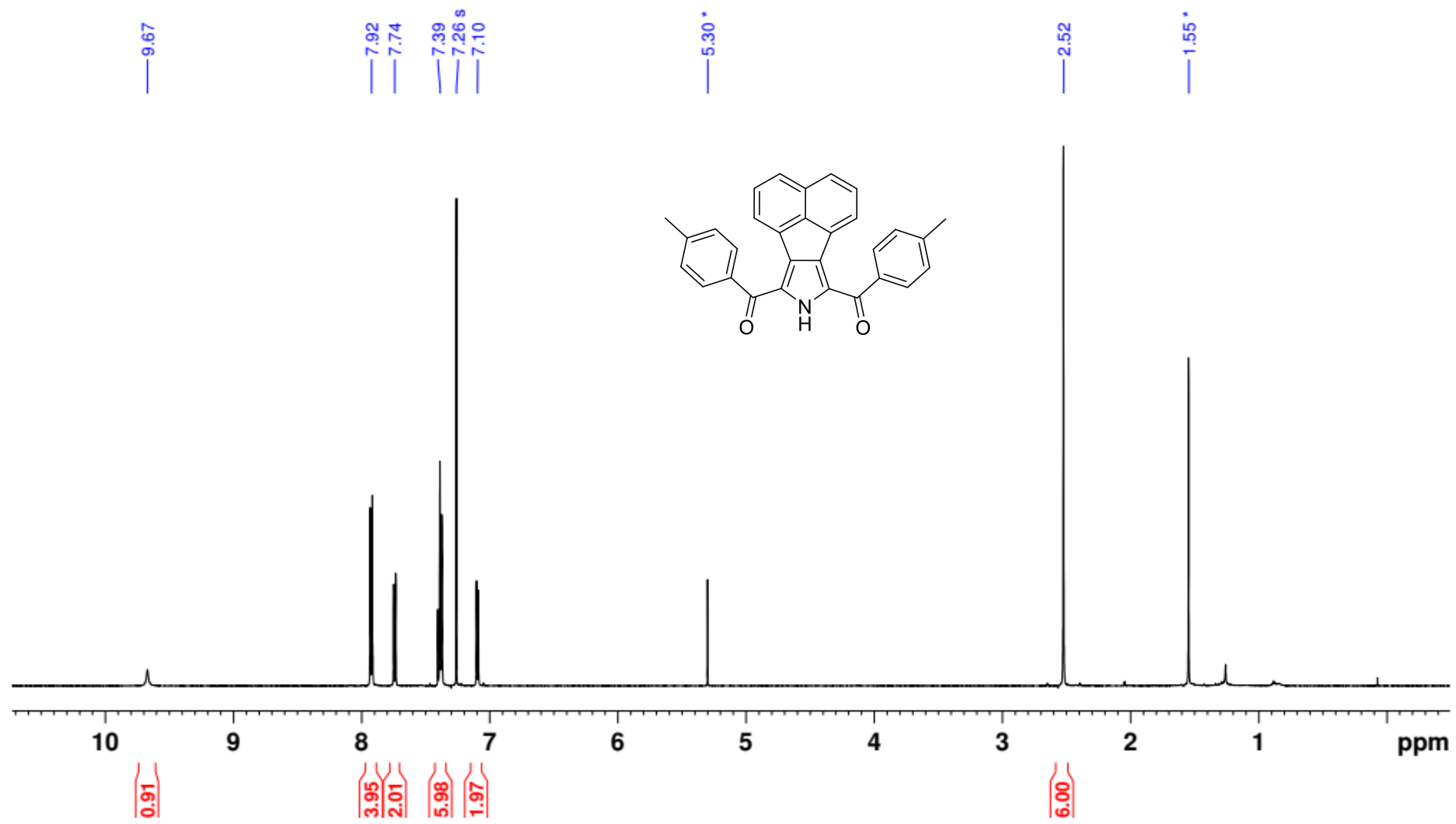

Figure S34. ${ }^{1} \mathrm{H}$ NMR spectrum of 6 ( $500 \mathrm{MHz}$, chloroform- $d$, $\left.300 \mathrm{~K}\right)$.

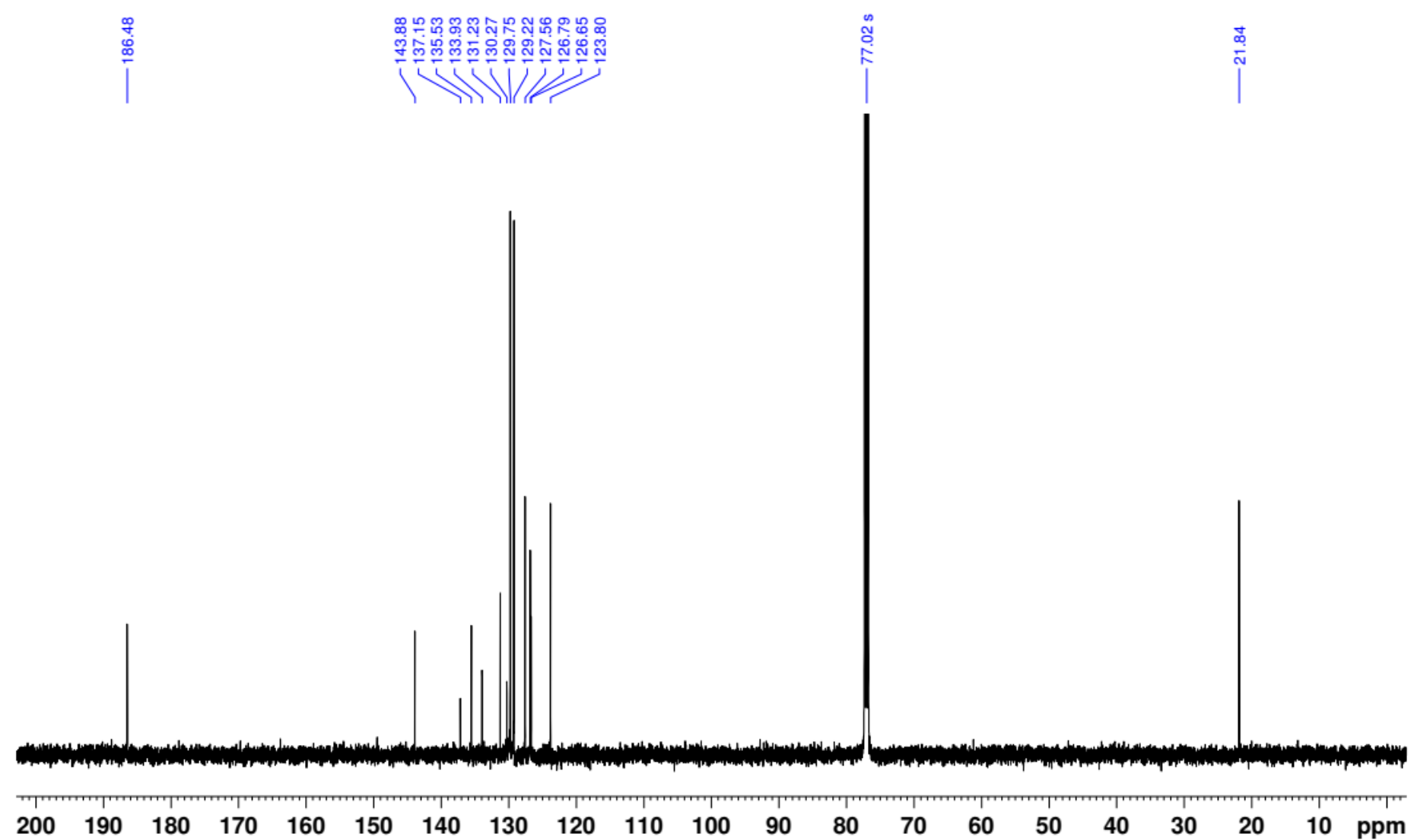

Figure S35. ${ }^{13} \mathrm{C}$ NMR spectrum of 6 (125 MHz, chloroform- $d$, $300 \mathrm{~K}$ ). 


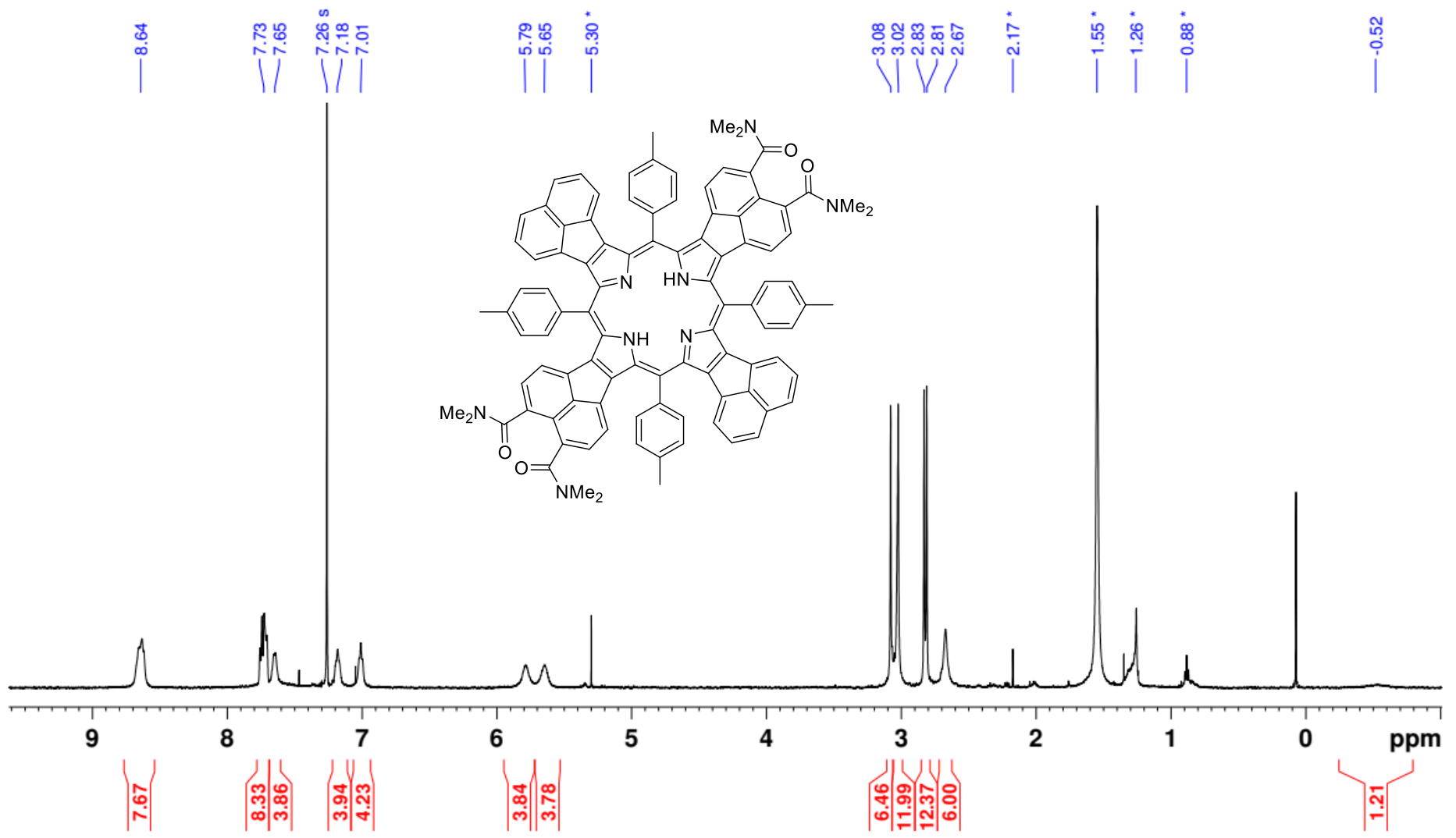

Figure S36. ${ }^{1} \mathrm{H}$ NMR spectrum of $\mathbf{2 a}-\mathrm{H}_{2}(500 \mathrm{MHz}$, chloroform-d , $300 \mathrm{~K})$.

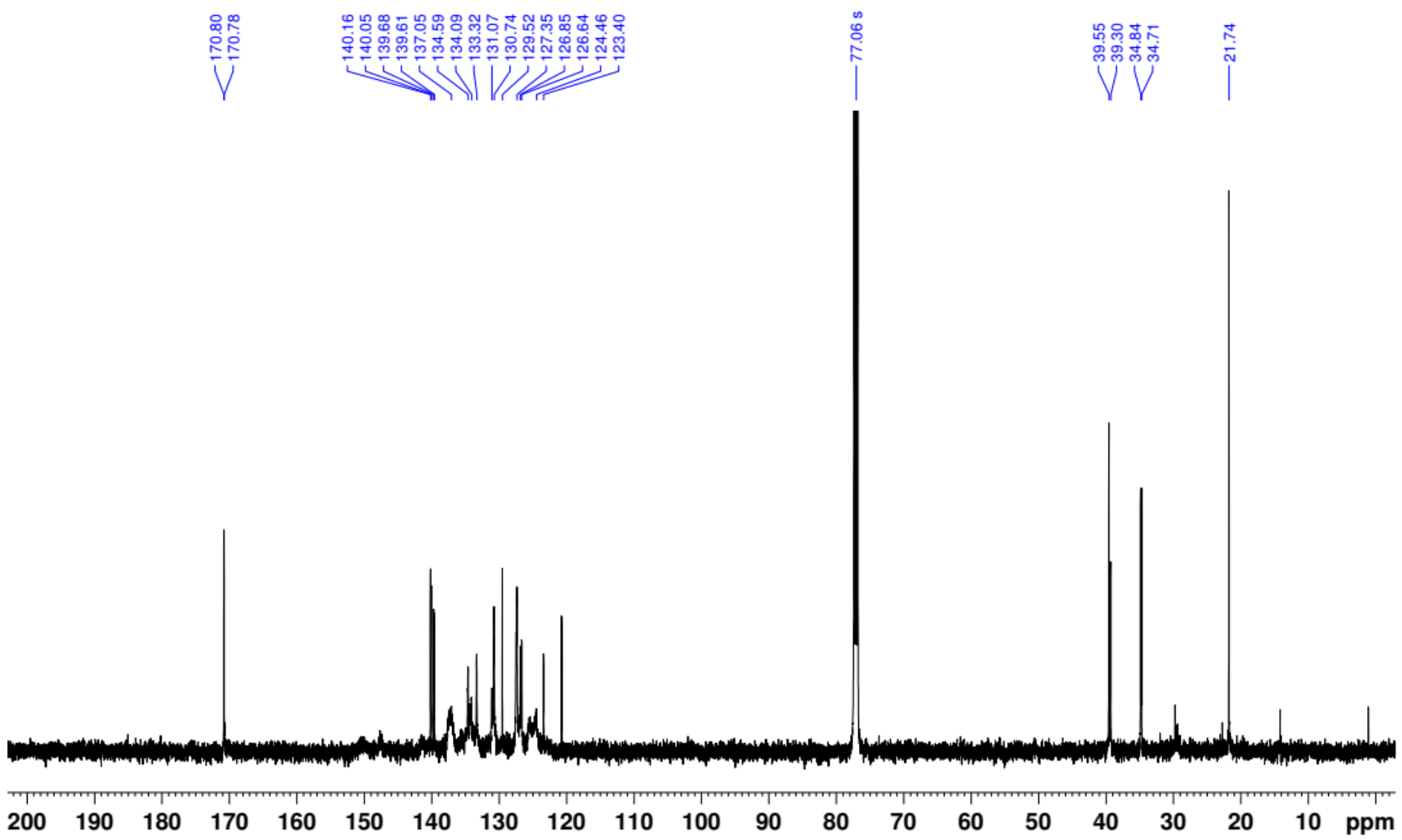

Figure S37. ${ }^{13} \mathrm{C}$ NMR spectrum of $2 \mathrm{a}-\mathrm{H}_{2}$ (151 MHz, chloroform- $d, 300 \mathrm{~K}$ ). 


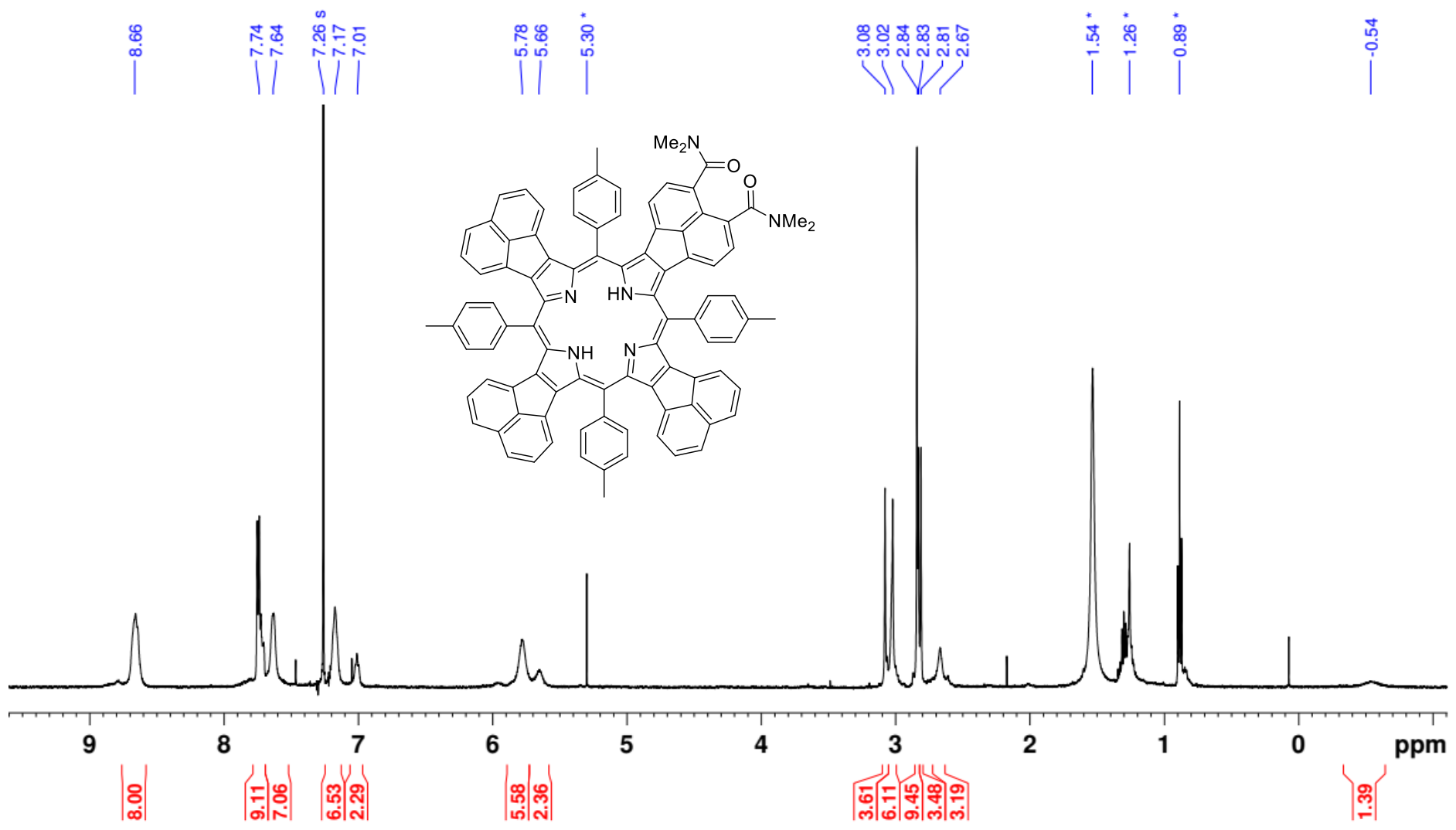

Figure S38. ${ }^{1} \mathrm{H}$ NMR spectrum of $3 \mathrm{a}-\mathrm{H}_{2}(500 \mathrm{MHz}$, chloroform-d , $300 \mathrm{~K})$.

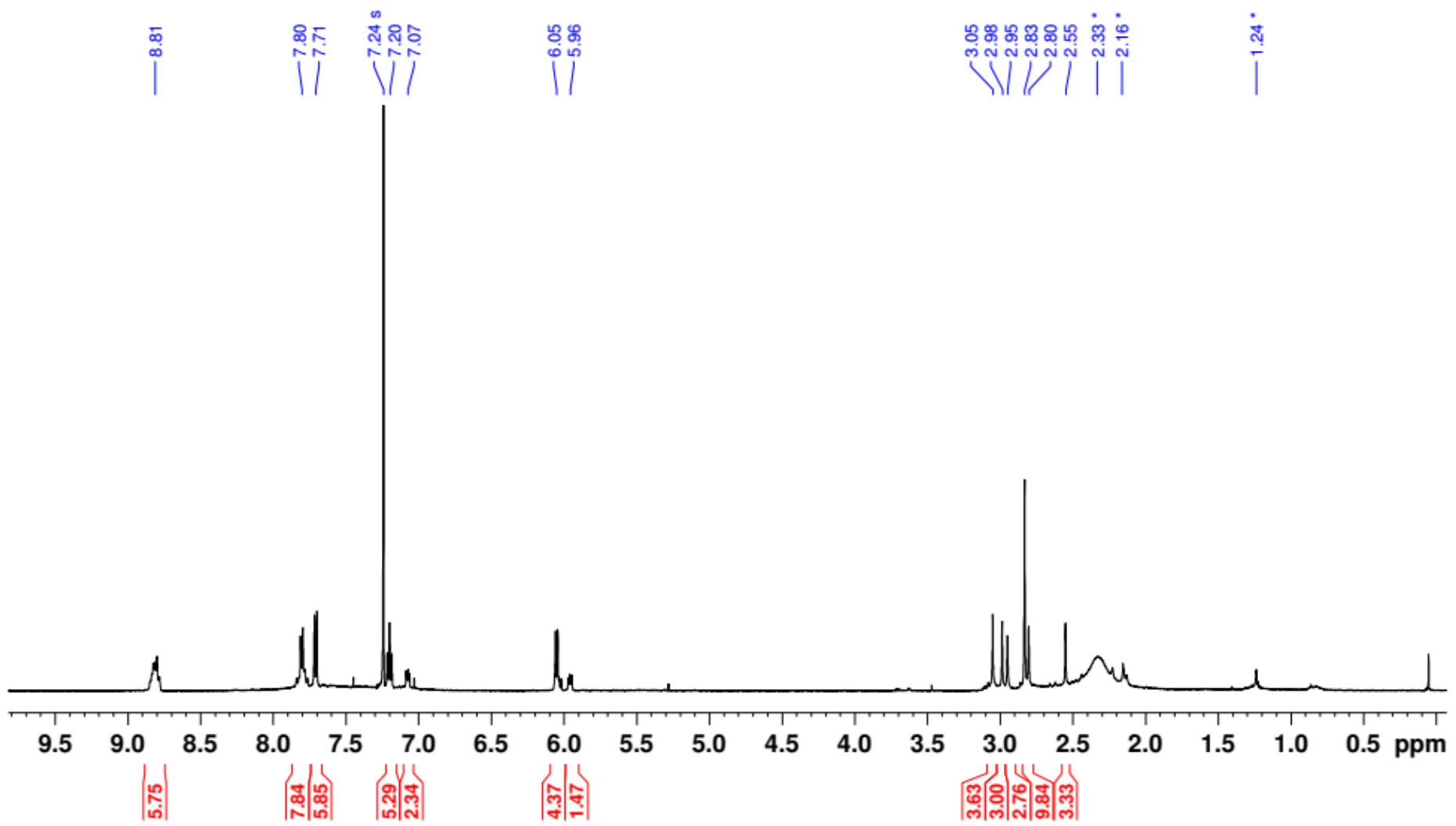

Figure S39. ${ }^{1} \mathrm{H}$ NMR spectrum of $3 \mathrm{a}-\mathrm{H}_{2}+\mathrm{TFA}(500 \mathrm{MHz}$, chloroform-d , $300 \mathrm{~K})$. 


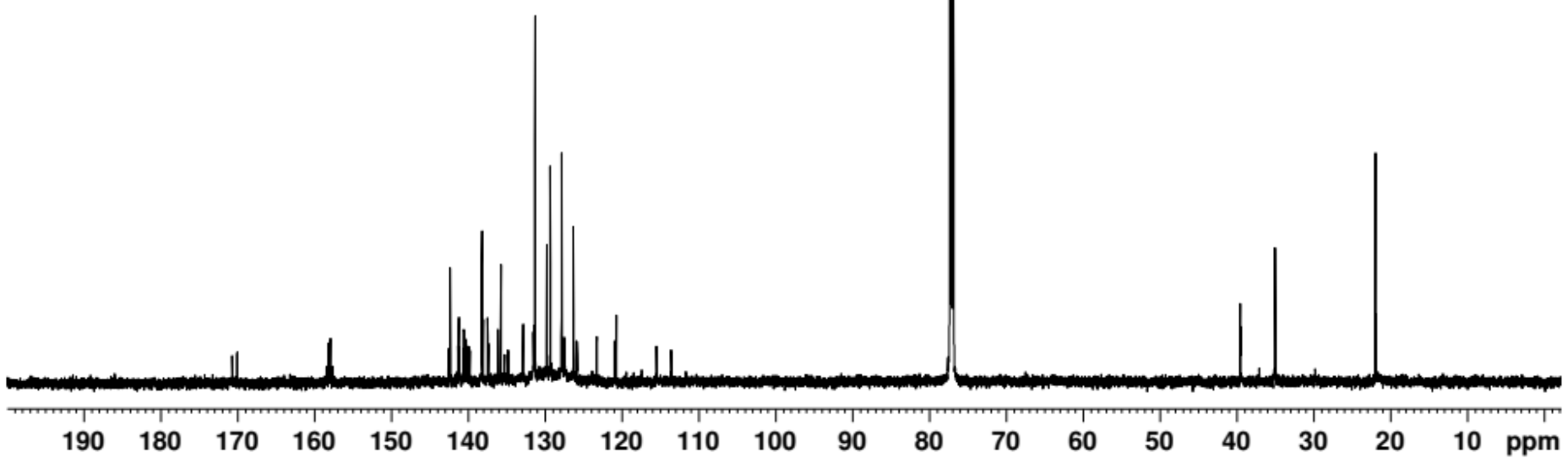

Figure S40. ${ }^{13} \mathrm{C}$ NMR spectrum of $3 \mathrm{a}-\mathrm{H}_{2}+$ TFA (151 MHz, chloroform-d , $300 \mathrm{~K}$ ).

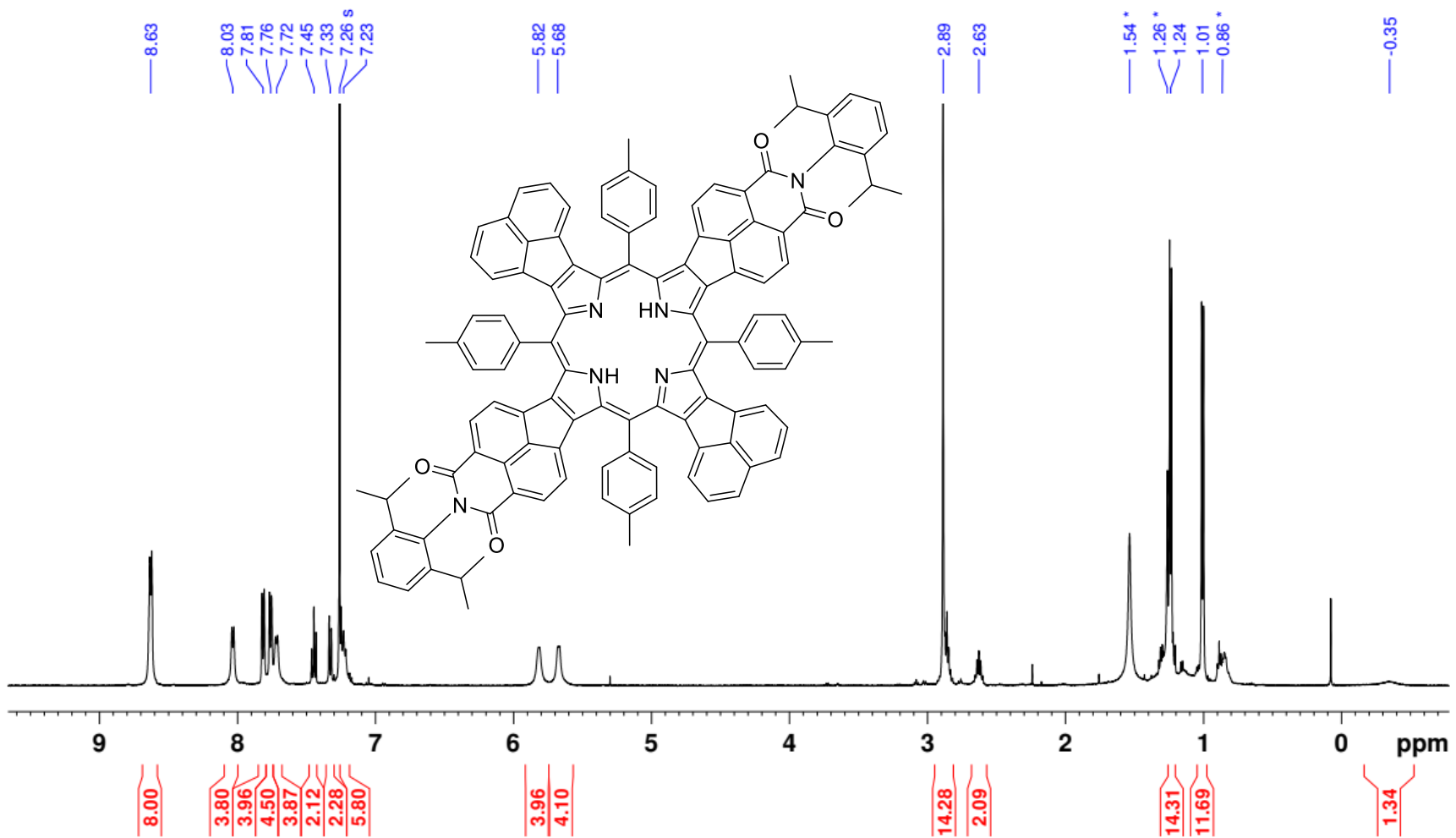

Figure S41. ${ }^{1} \mathrm{H}$ NMR spectrum of $\mathbf{2} \mathbf{b}-\mathrm{H}_{2}(500 \mathrm{MHz}$, chloroform- $d$, $300 \mathrm{~K})$. 


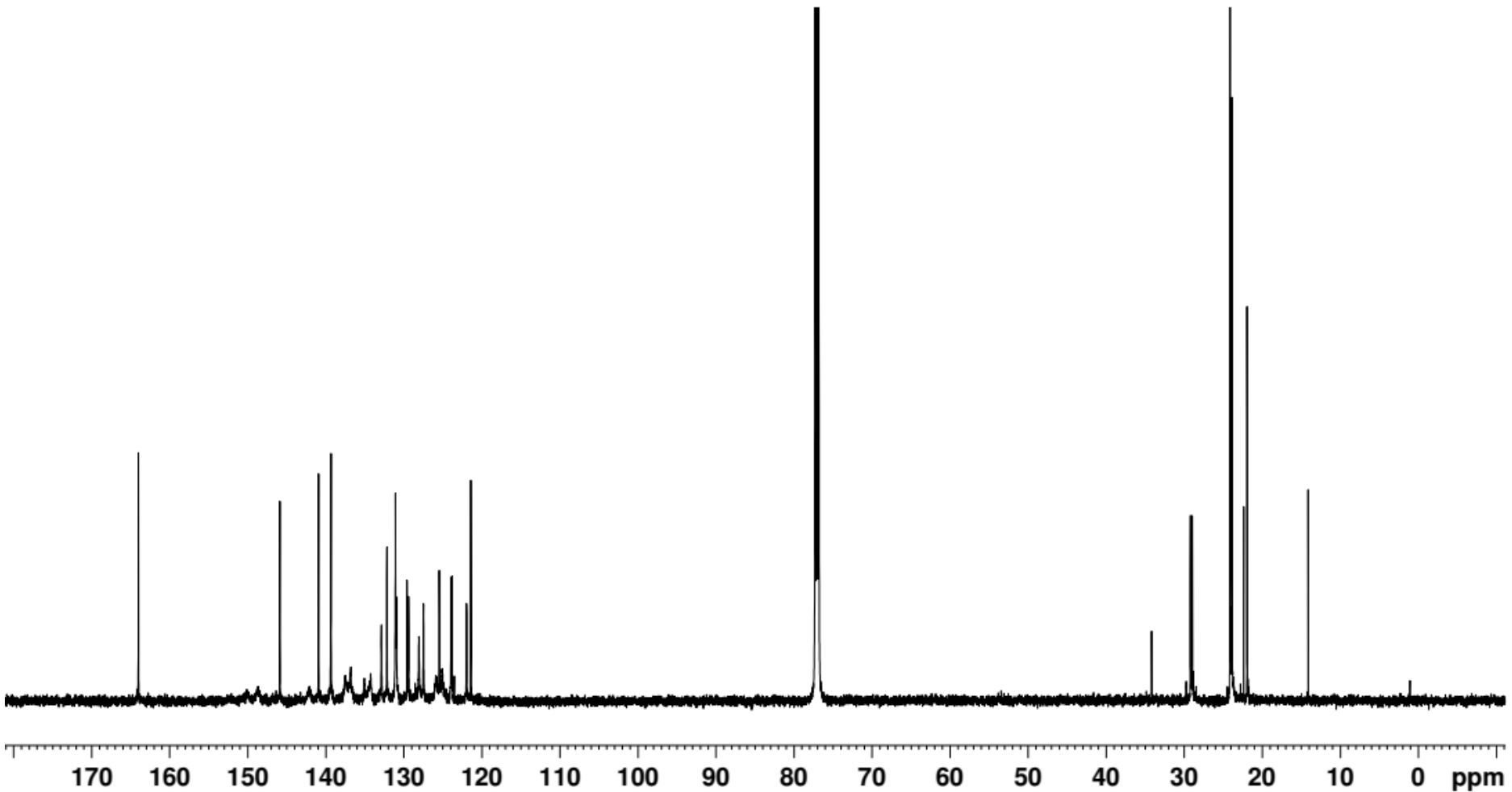

Figure $\mathbf{S 4 2} .{ }^{13} \mathrm{C}$ NMR spectrum of $\mathbf{2 b}-\mathrm{H}_{2}(151 \mathrm{MHz}$, chloroform-d , $300 \mathrm{~K}$ ).

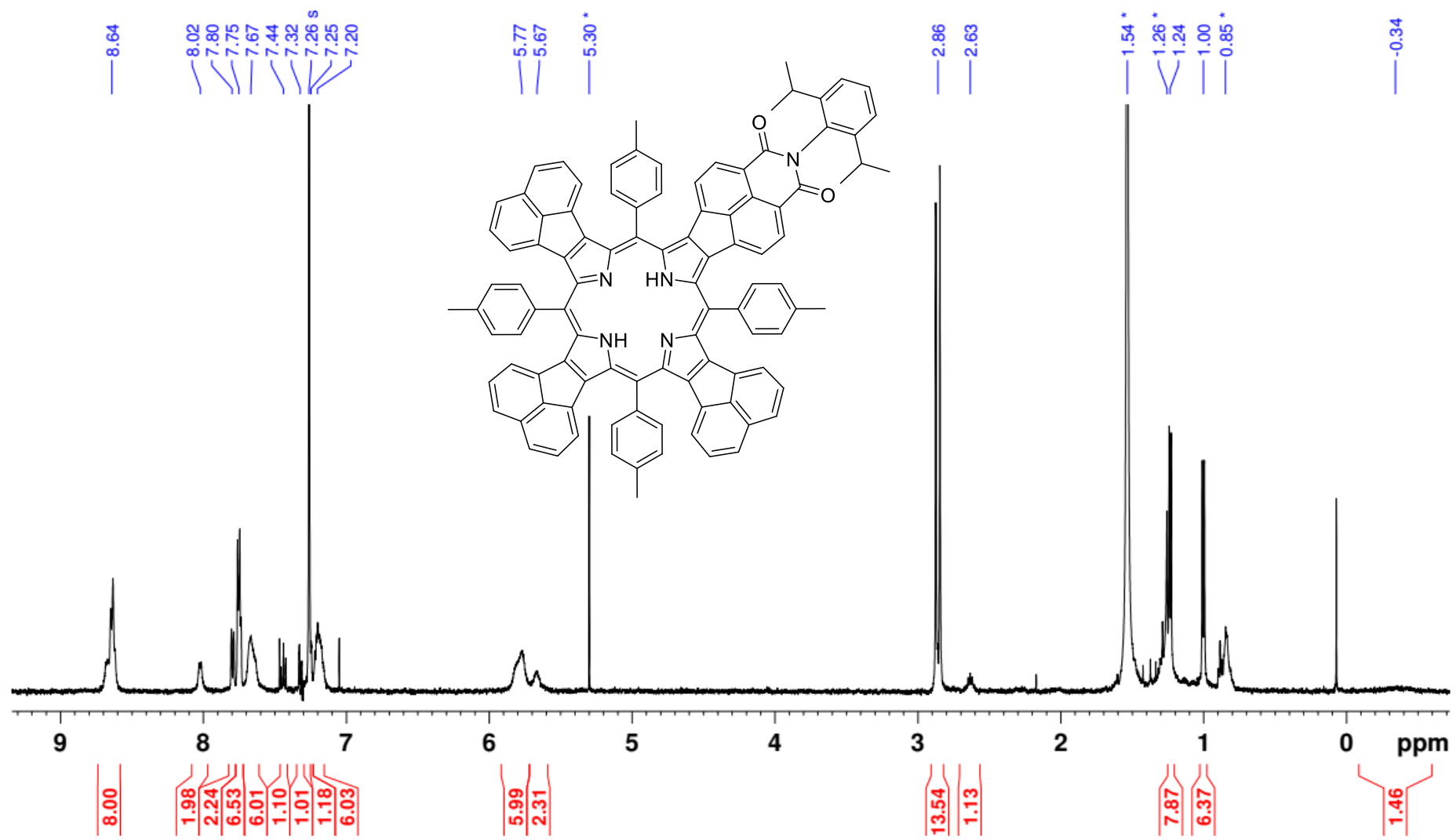

Figure S43. ${ }^{1} \mathrm{H}$ NMR spectrum of $3 b-\mathrm{H}_{2}(500 \mathrm{MHz}$, chloroform-d , $300 \mathrm{~K})$. 


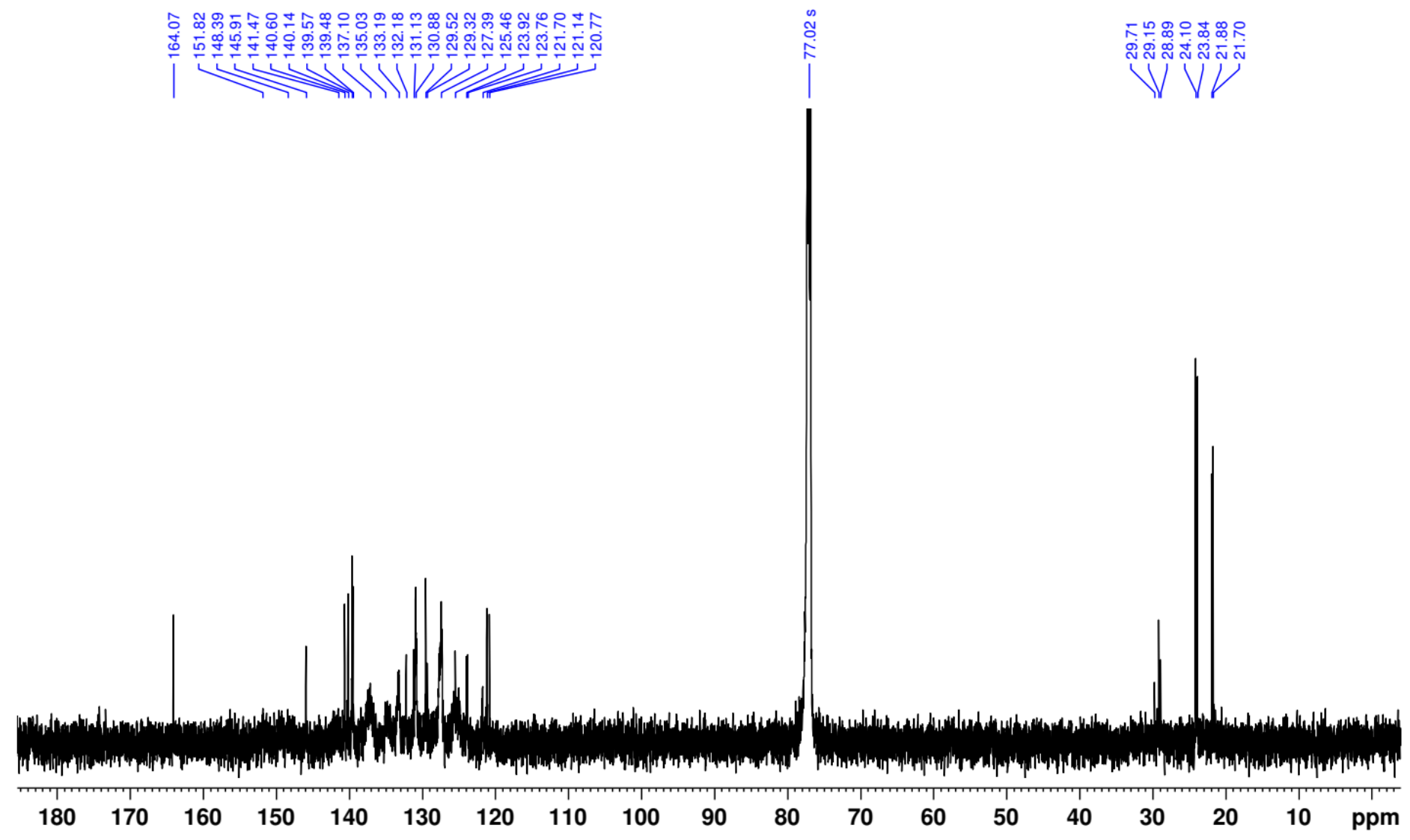

Figure S44. ${ }^{13} \mathrm{C}$ NMR spectrum of $\mathbf{3 b}-\mathrm{H}_{2}(151 \mathrm{MHz}$, chloroform-d , $300 \mathrm{~K})$.

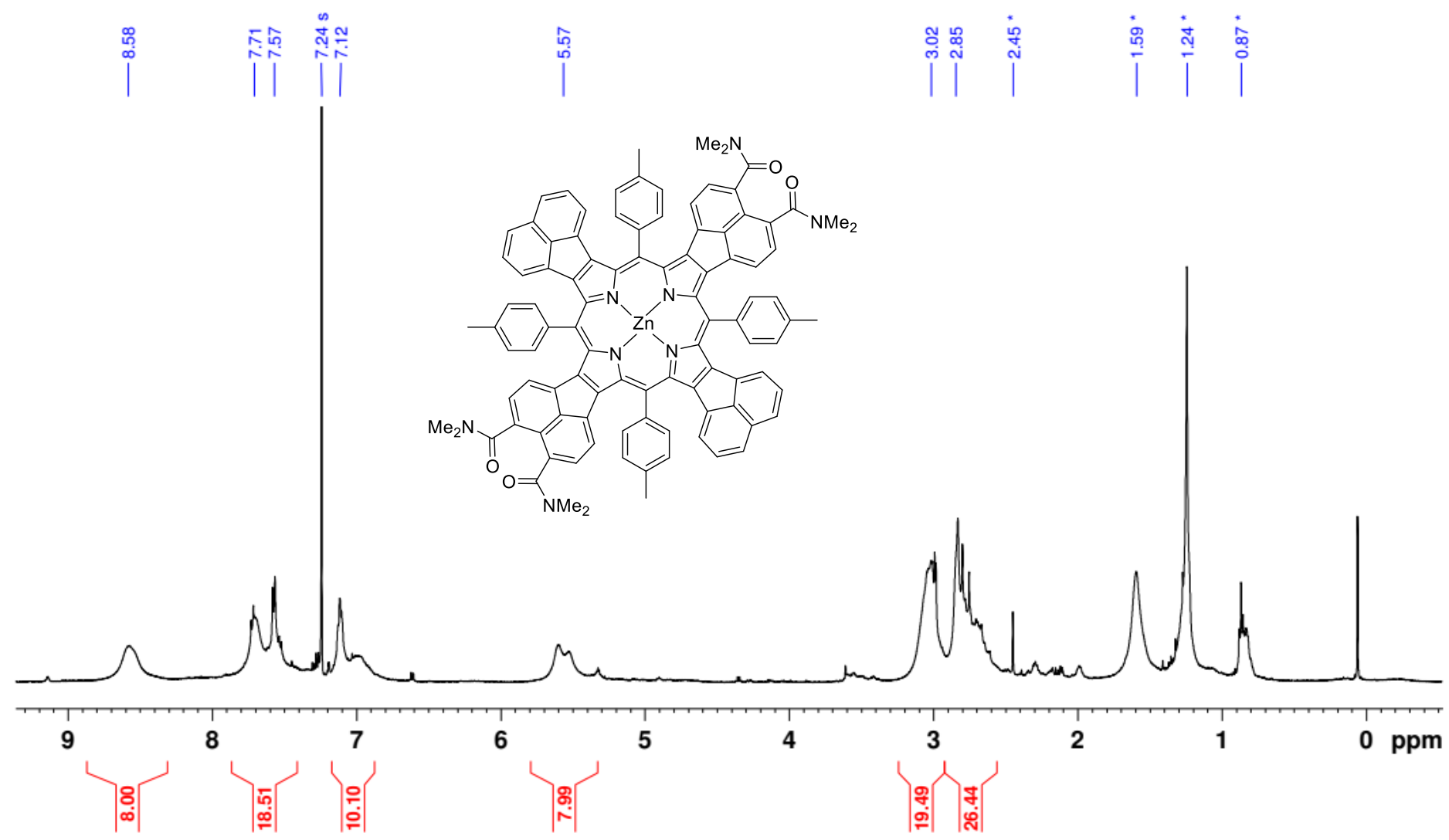

Figure S45. ${ }^{1} \mathrm{H}$ NMR spectrum of $2 \mathrm{a}-\mathrm{Zn}(500 \mathrm{MHz}$, chloroform-d , $300 \mathrm{~K})$. 
||

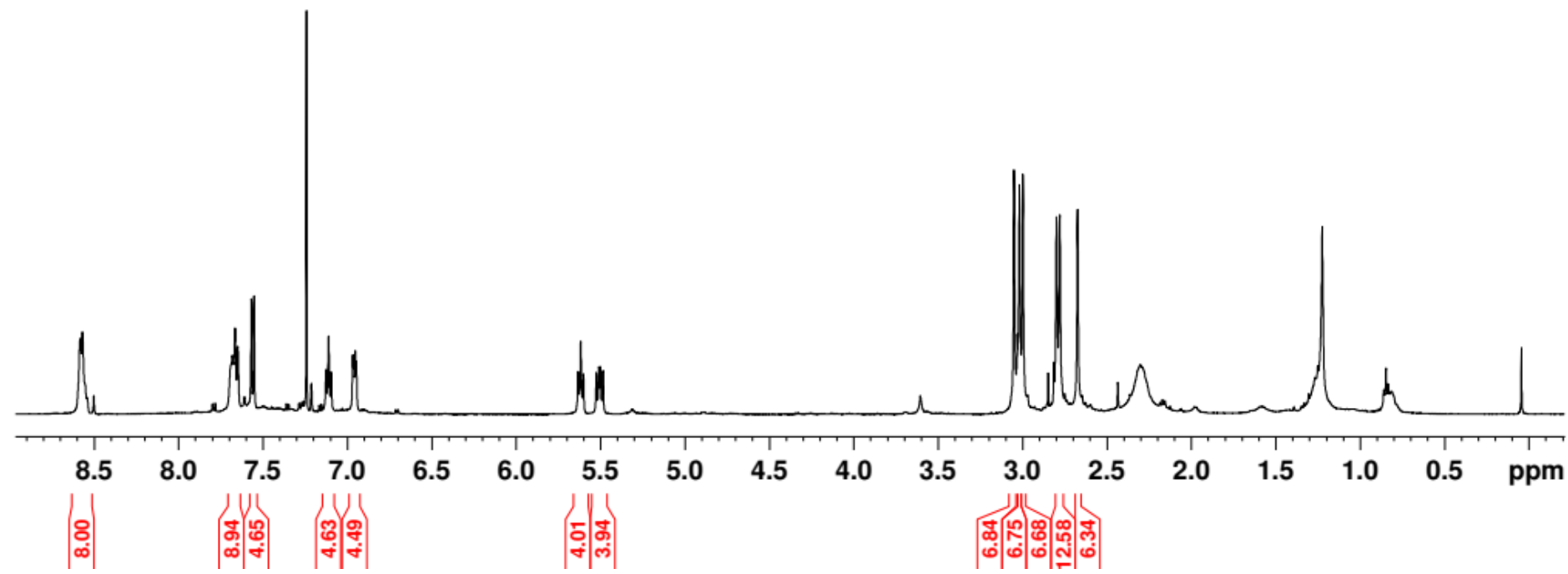

Figure S46. ${ }^{1} \mathrm{H}$ NMR spectrum of $2 \mathrm{a}-\mathrm{Zn}+$ Pyridine $_{5}(500 \mathrm{MHz}$, chloroform-d , $300 \mathrm{~K})$.

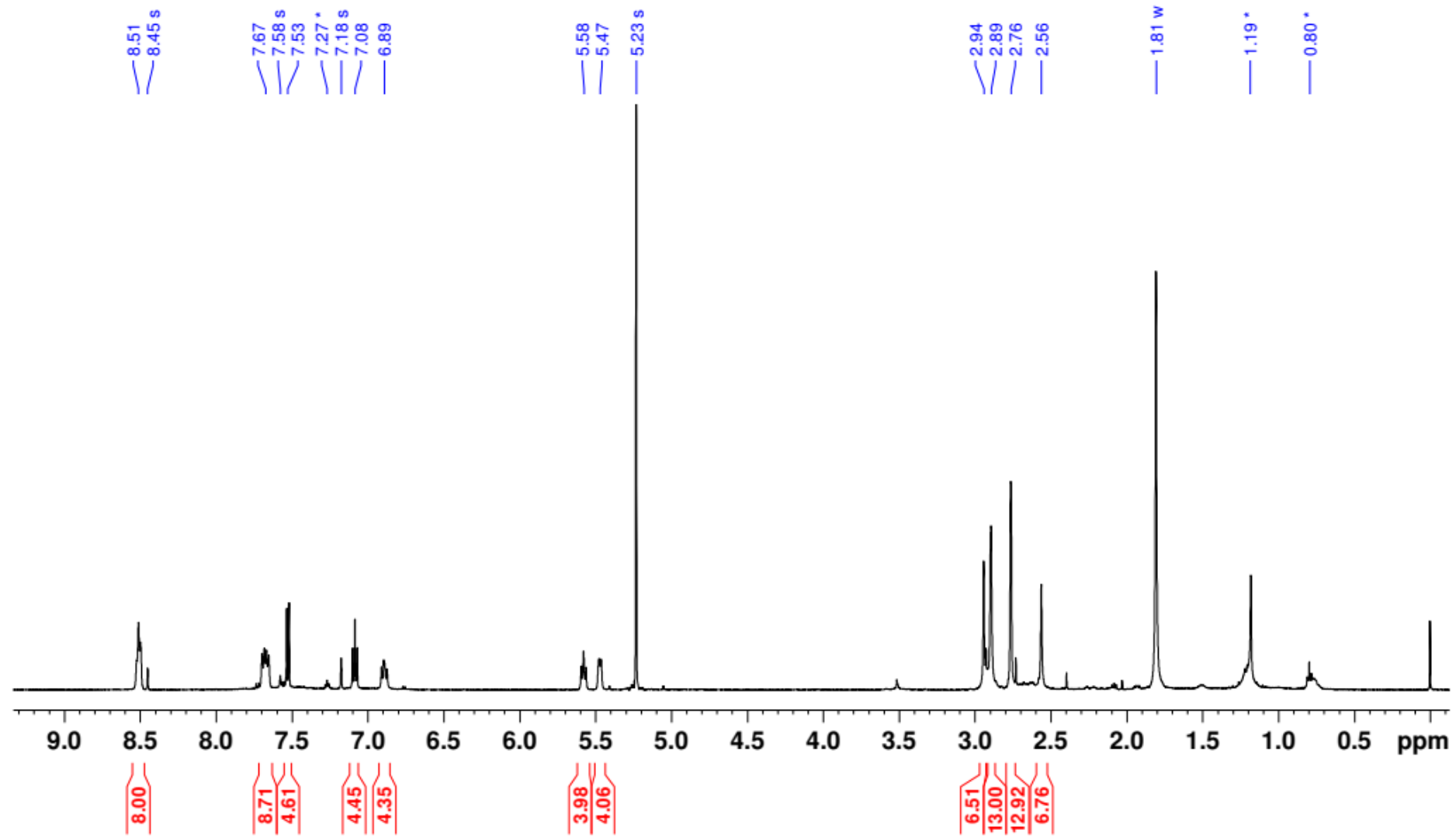

Figure S47. ${ }^{1} \mathrm{H}$ NMR spectrum of $2 \mathrm{a}-\mathrm{Zn}+$ Pyridine $\mathrm{d}_{5}(500 \mathrm{MHz}$, dichloromethane-d , $300 \mathrm{~K})$. 


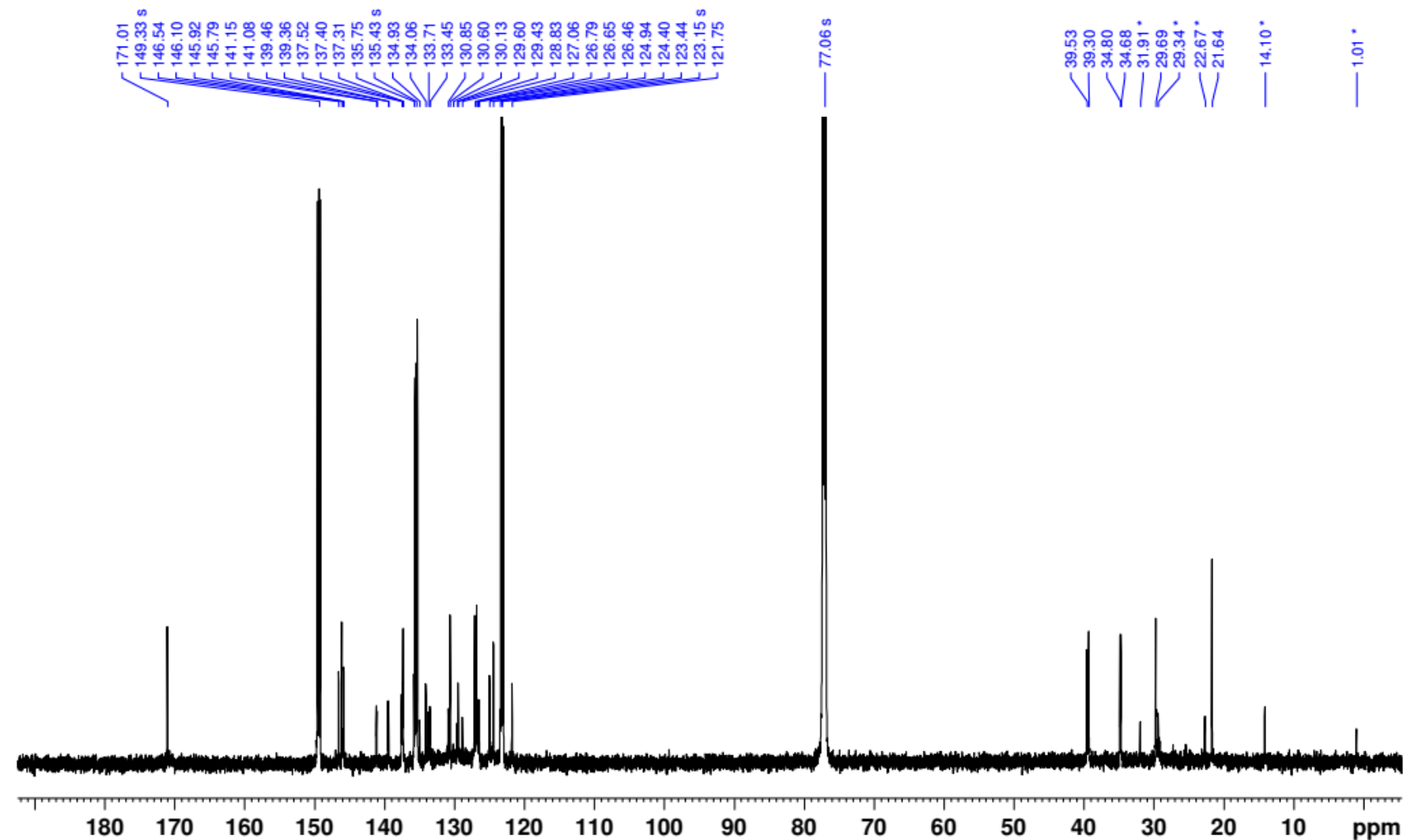

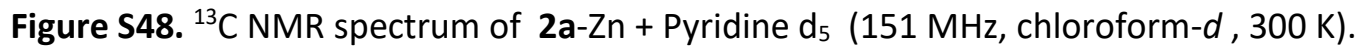

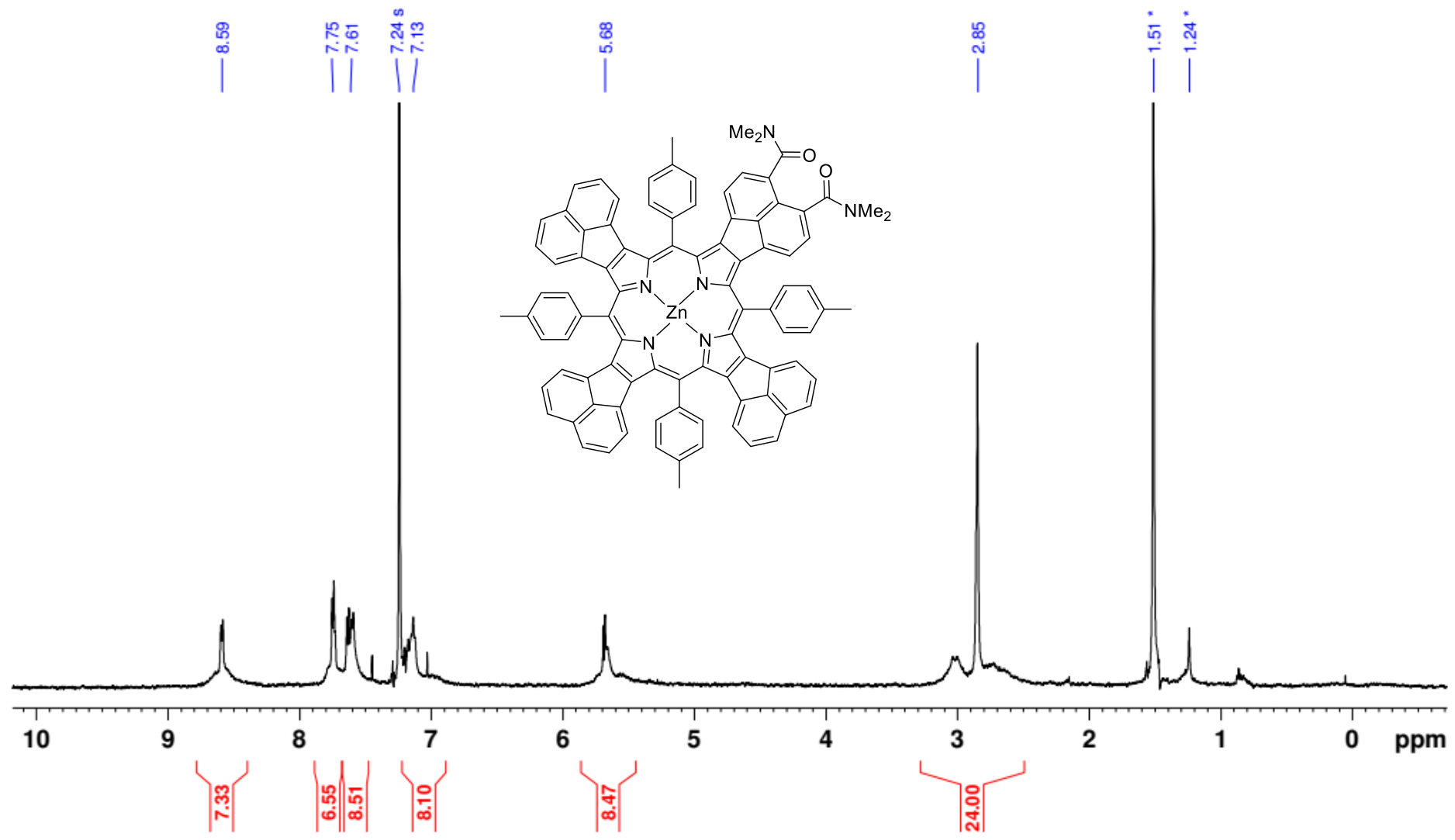

Figure S49. ${ }^{1} \mathrm{H}$ NMR spectrum of $3 \mathrm{a}-\mathrm{Zn}(500 \mathrm{MHz}$, chloroform-d , $300 \mathrm{~K})$. 


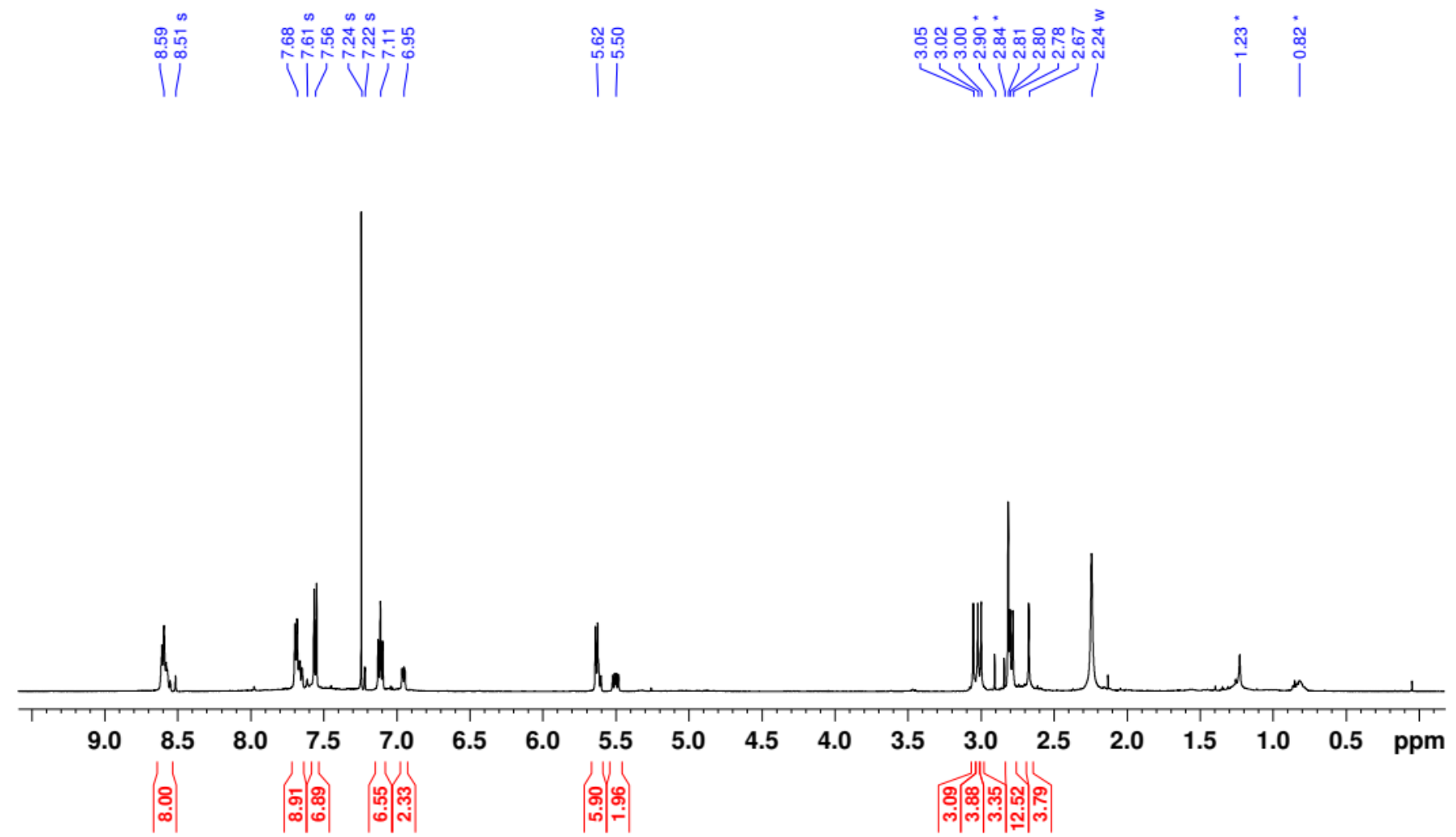

Figure S50. ${ }^{1} \mathrm{H}$ NMR spectrum of $3 a-Z n+$ pyridine $d_{5}(500 \mathrm{MHz}$, chloroform-d , $300 \mathrm{~K})$.

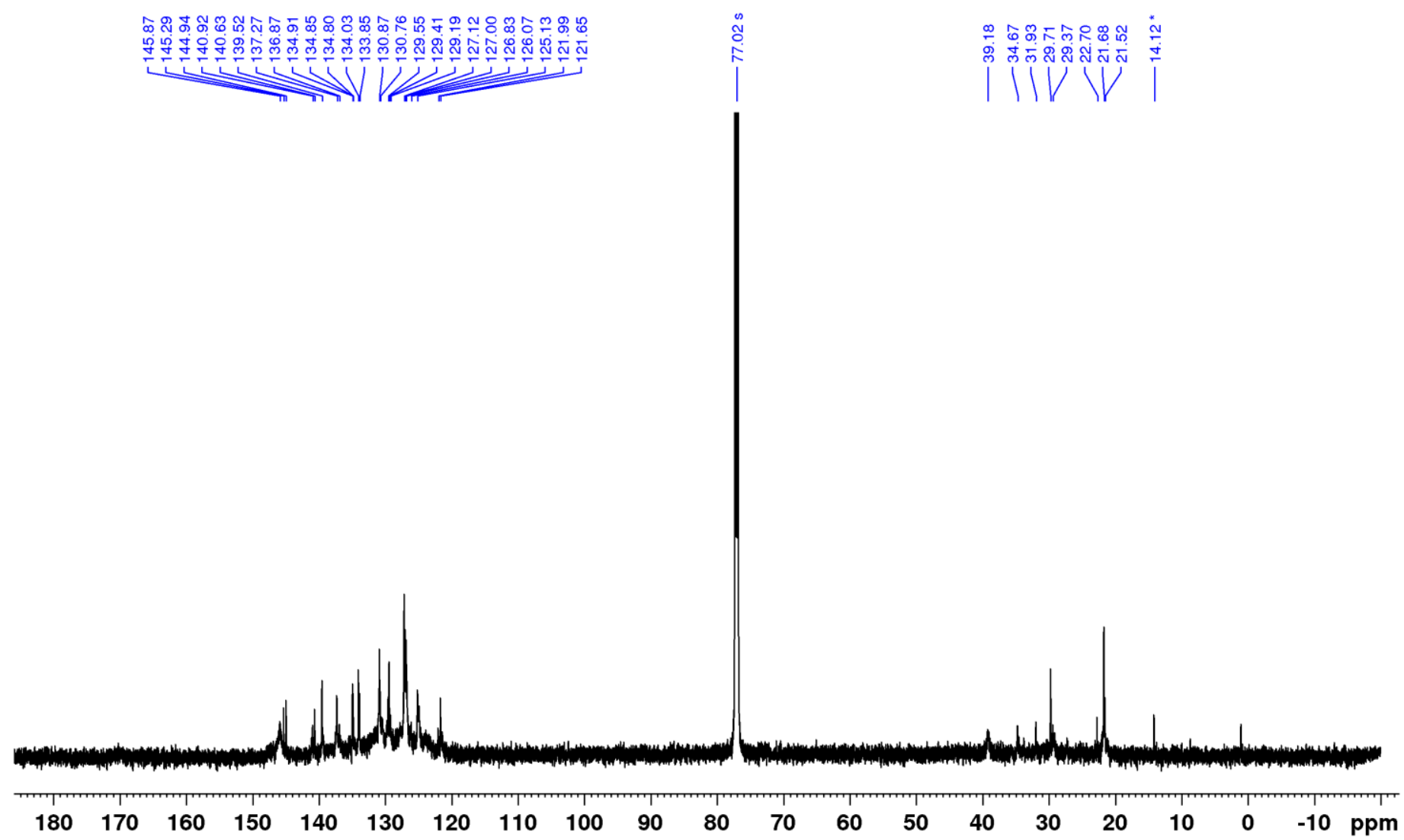

Figure S51. ${ }^{13} \mathrm{C}$ NMR spectrum of $3 a-Z n(151 \mathrm{MHz}$, chloroform- $d, 300 \mathrm{~K}$ ). 


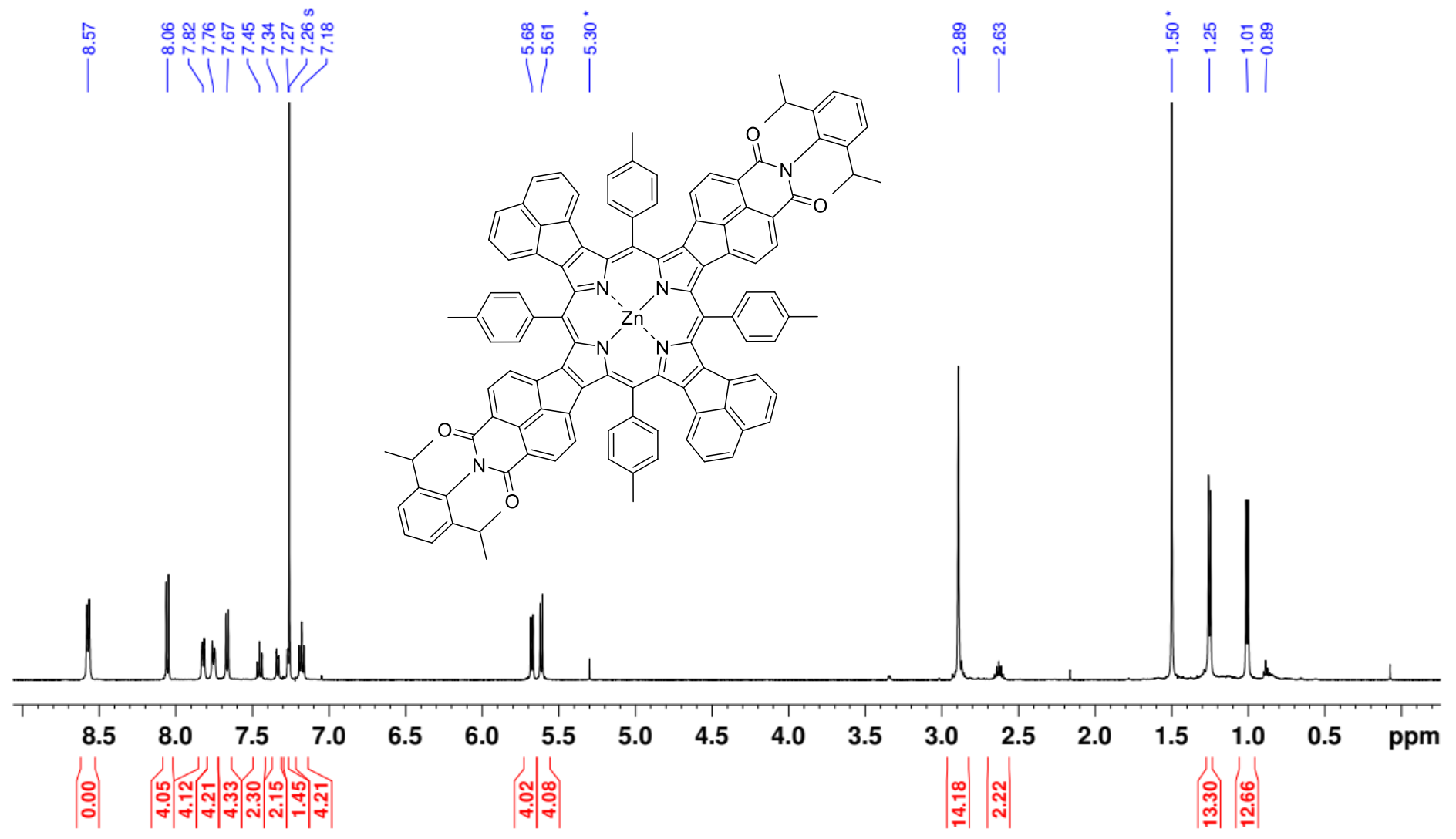

Figure S52. ${ }^{1} \mathrm{H}$ NMR spectrum of $\mathbf{2 b}-\mathrm{Zn}(500 \mathrm{MHz}$, chloroform-d , $300 \mathrm{~K})$.

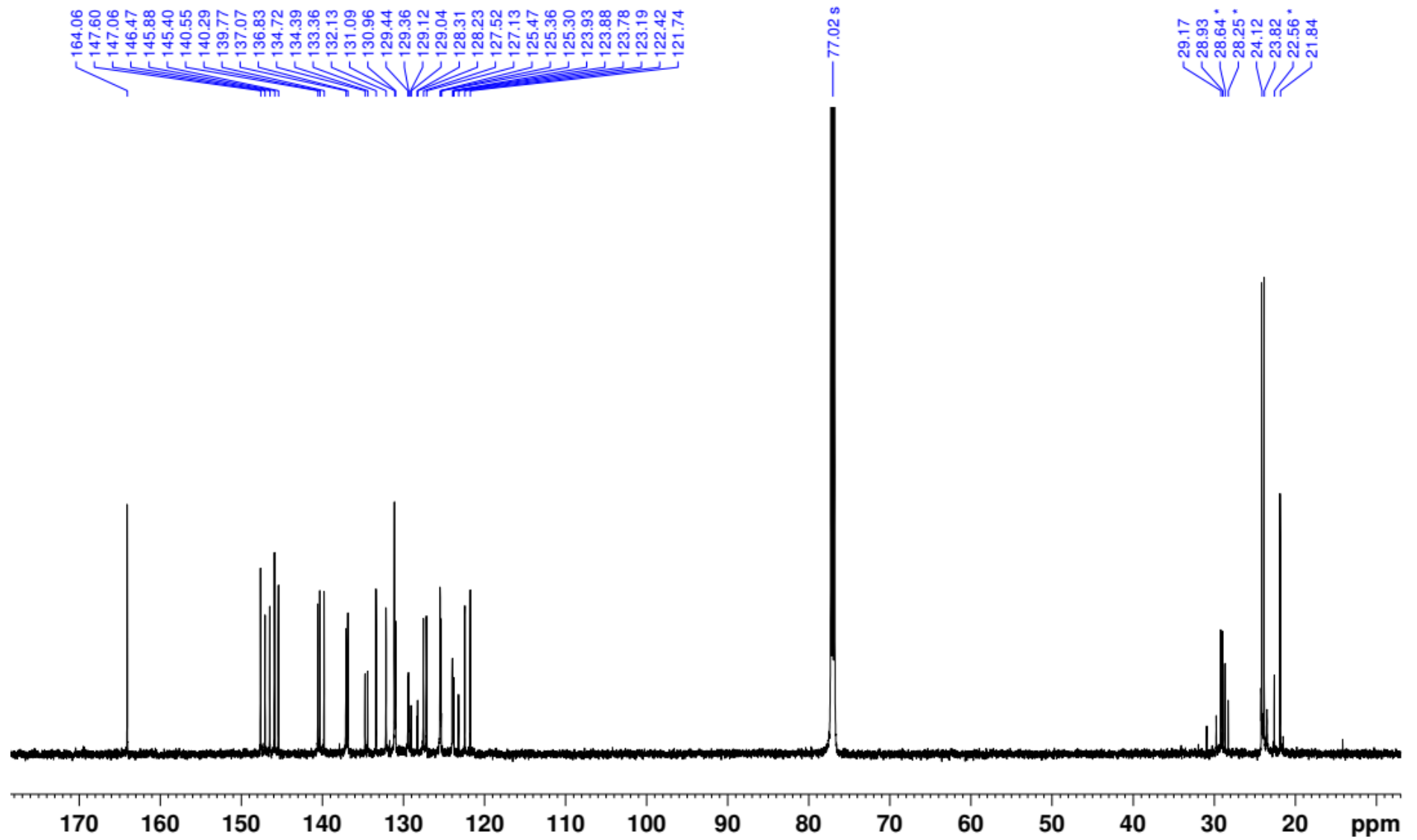

Figure S53. ${ }^{13} \mathrm{C}$ NMR spectrum of $\mathbf{2 b}-\mathrm{Zn}$ (151 MHz, chloroform- $d$, $300 \mathrm{~K}$ ). 


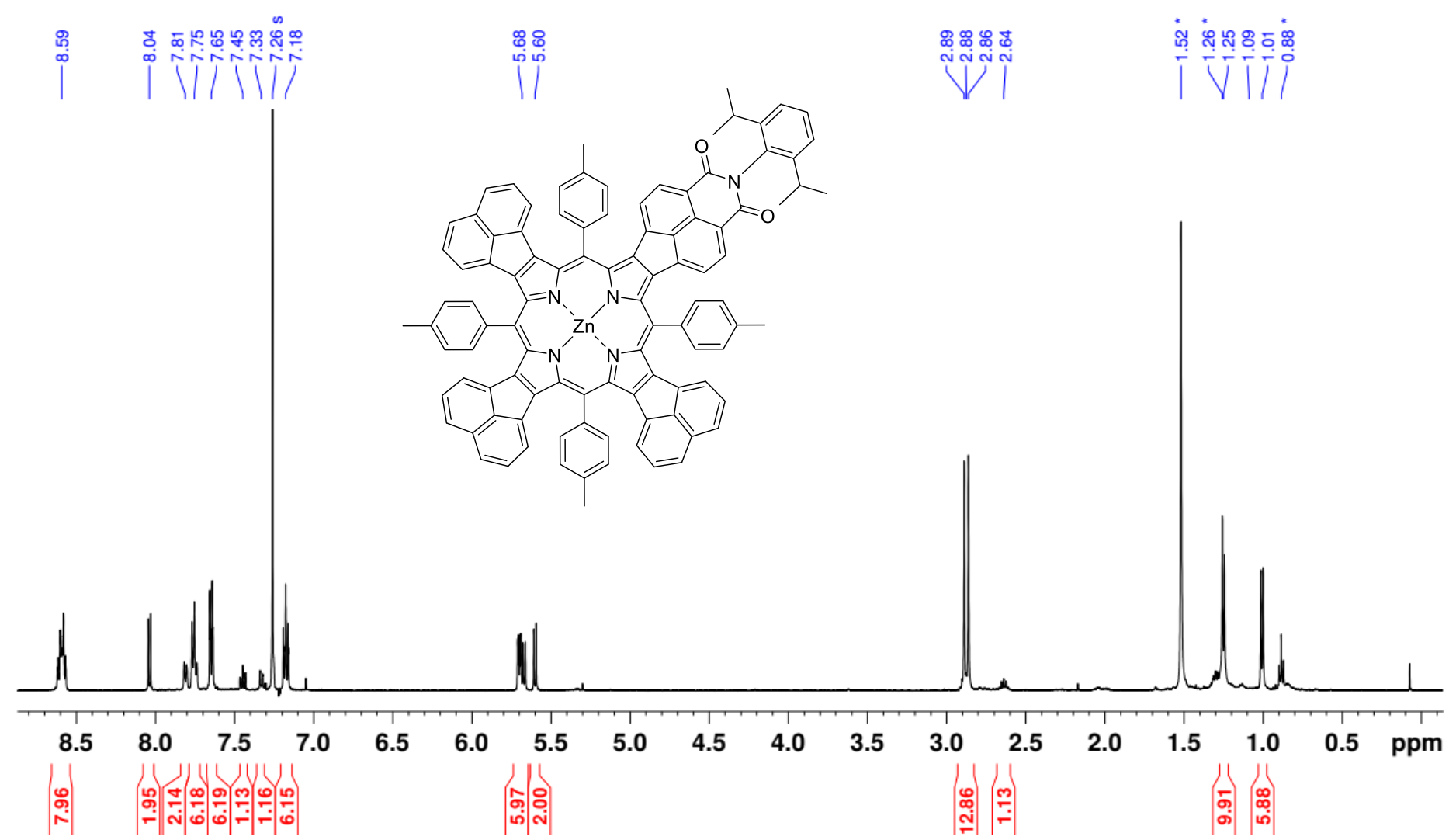

Figure S54. ${ }^{1} \mathrm{H}$ NMR spectrum of $3 \mathbf{b}-\mathrm{Zn}(500 \mathrm{MHz}$, chloroform-d , $300 \mathrm{~K})$.

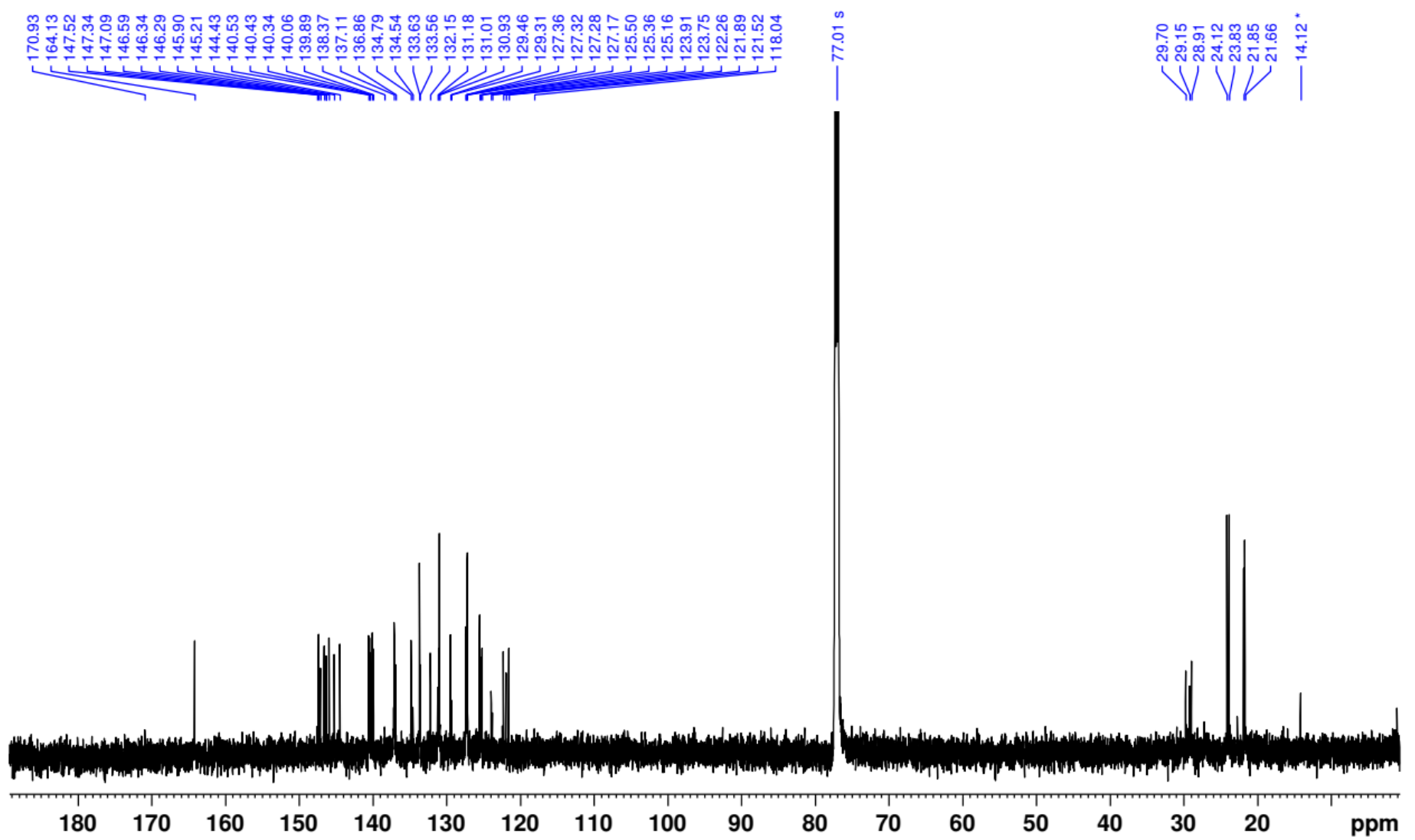

Figure S55. ${ }^{13} \mathrm{C}$ NMR spectrum of $3 \mathrm{~b}-\mathrm{Zn}$ (151 MHz, chloroform-d , $300 \mathrm{~K}$ ). 

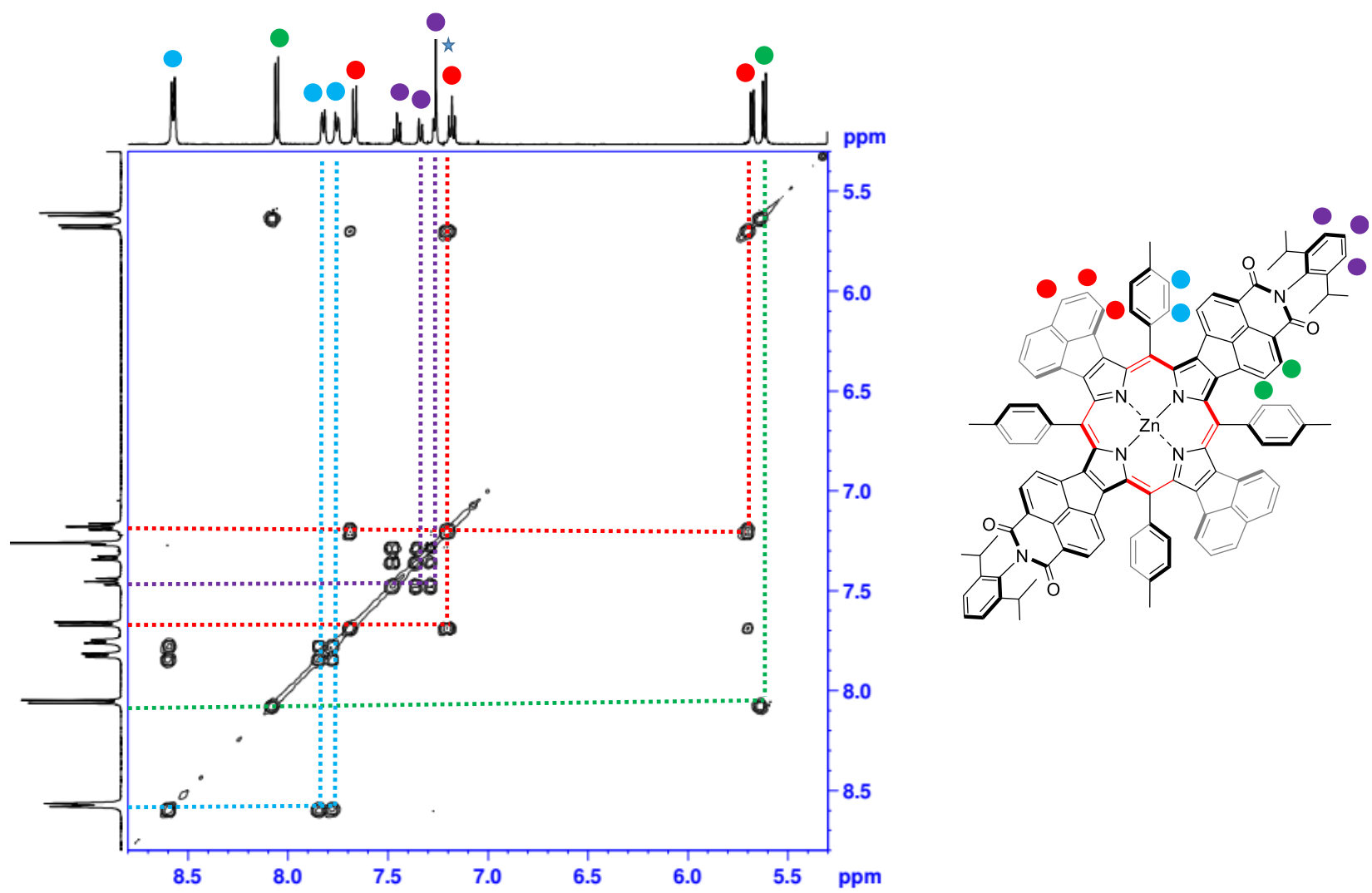

Figure S56. ${ }^{1} \mathrm{H}-{ }^{1} \mathrm{H}$ COSY NMR spectrum of $\mathbf{2 b}-\mathrm{Zn}(500 \mathrm{MHz}$, chloroform- $d$, $300 \mathrm{~K}$ ).
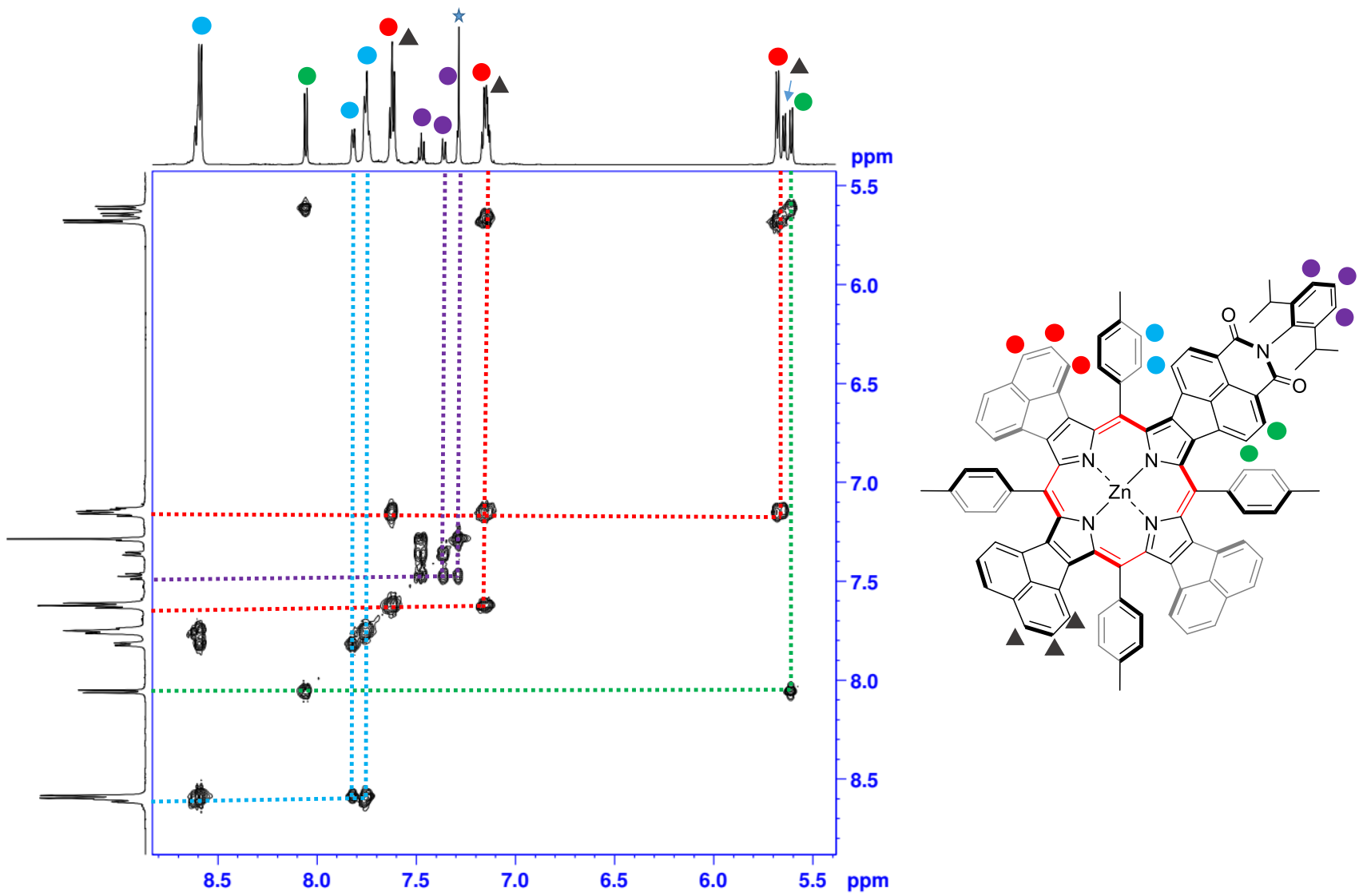

Figure S57. ${ }^{1} \mathrm{H}-{ }^{1} \mathrm{H}$ COSY NMR spectrum of $3 b-\mathrm{Zn}(500 \mathrm{MHz}$, chloroform-d , $300 \mathrm{~K}$ ). 
Mass Spectra 


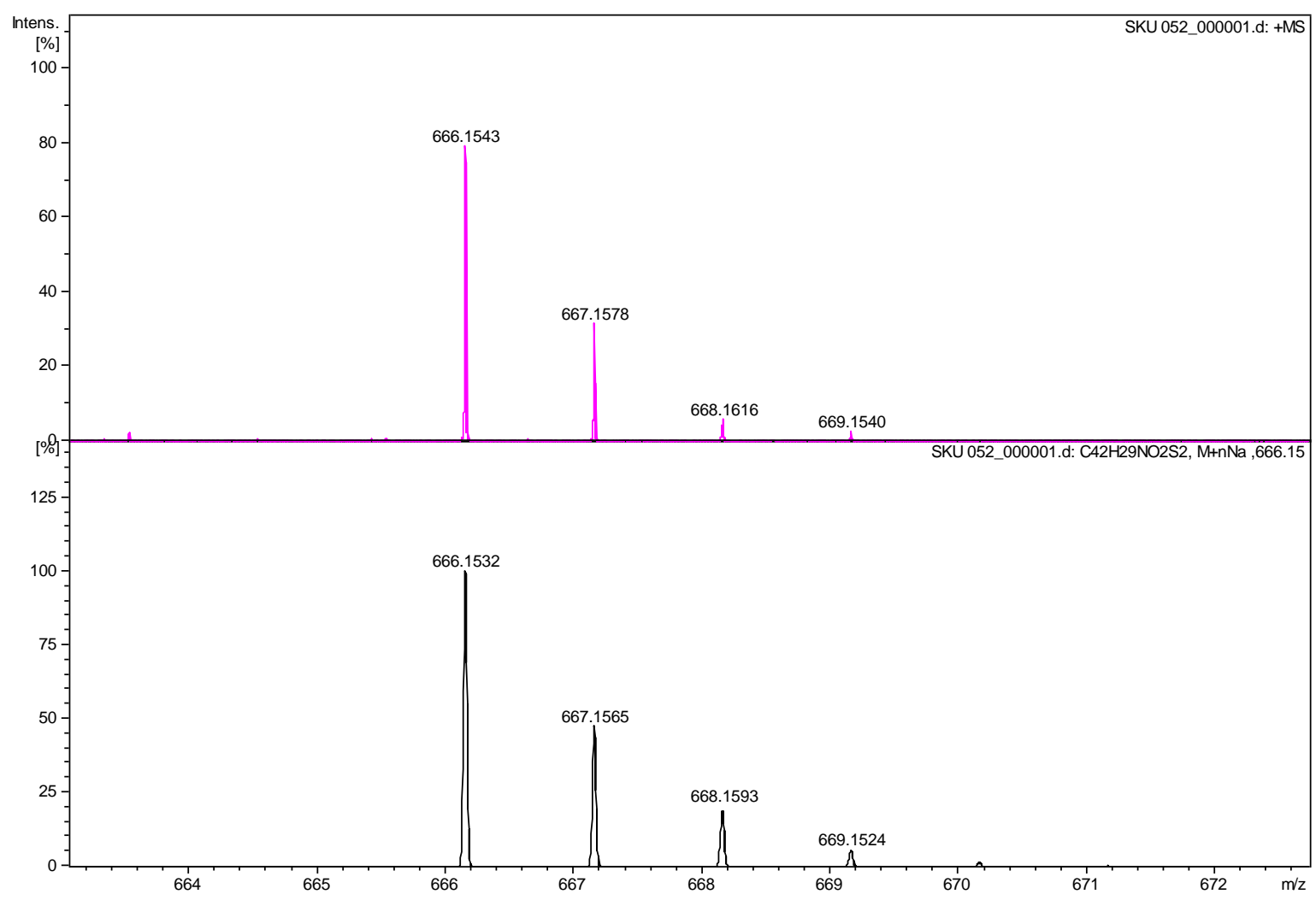

Figure S58. High resolution mass spectrum of $\mathbf{5}$ (ESI-TOF, top: experimental, bottom: simulated).

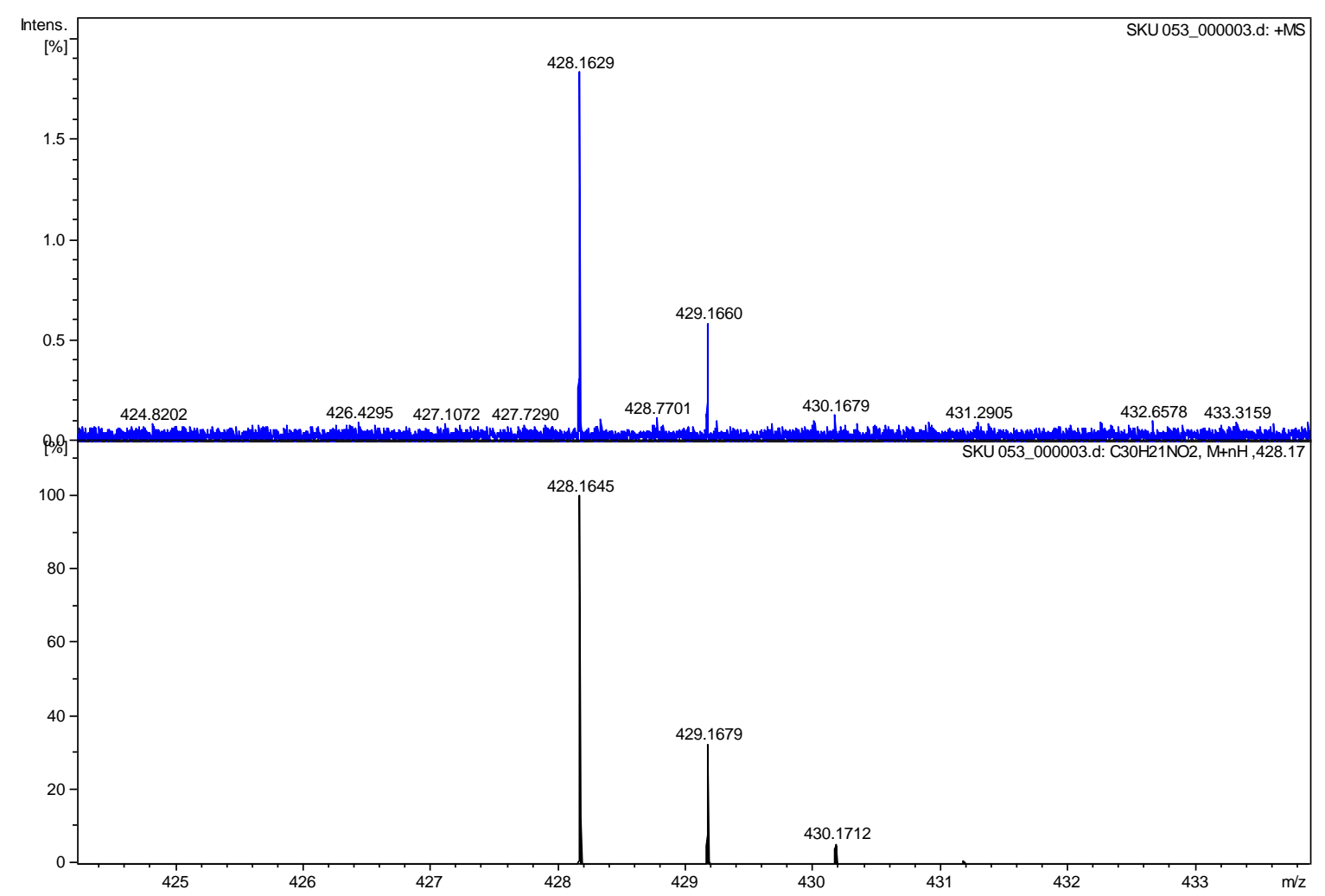

Figure S59. High resolution mass spectrum of 6 (ESI-TOF, top: experimental, bottom: simulated). 


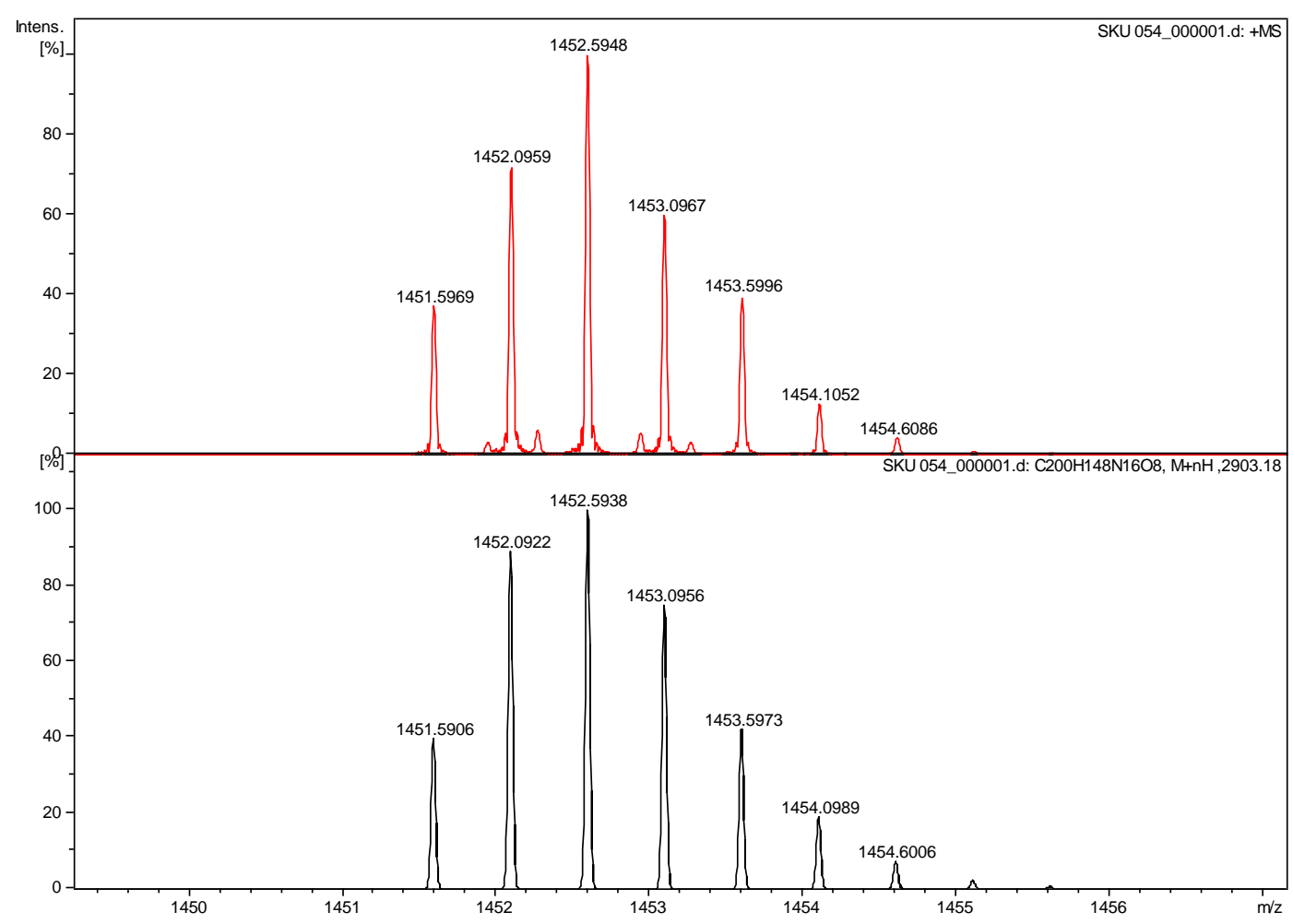

Figure $\mathbf{5 6 0}$. High resolution mass spectrum of $\mathbf{2 a - H _ { 2 }}$ (ESI-TOF, top: experimental, bottom: simulated).

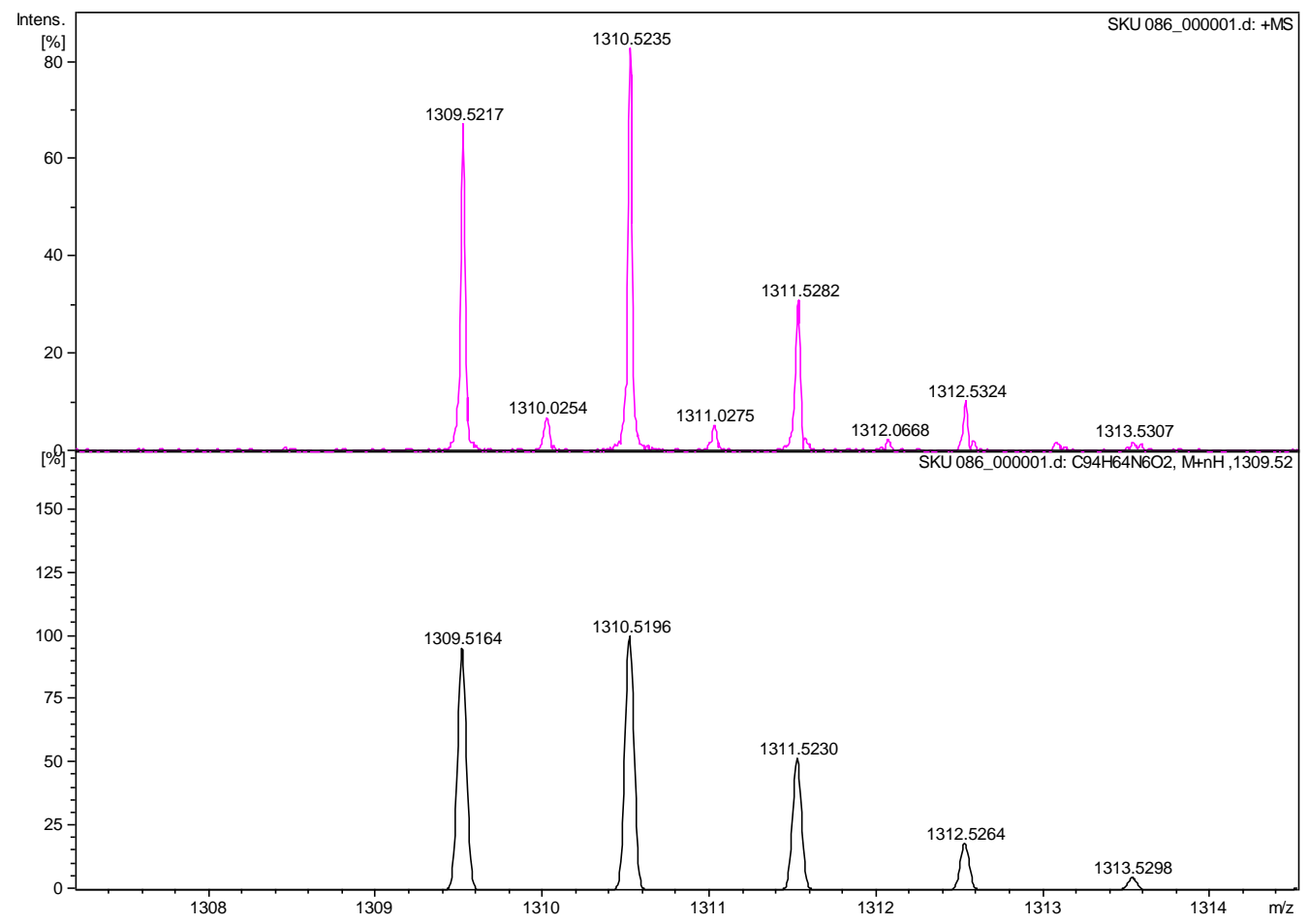

Figure S61. High resolution mass spectrum of 3a- $\mathrm{H}_{2}$ (ESI-TOF, top: experimental, bottom: simulated). 


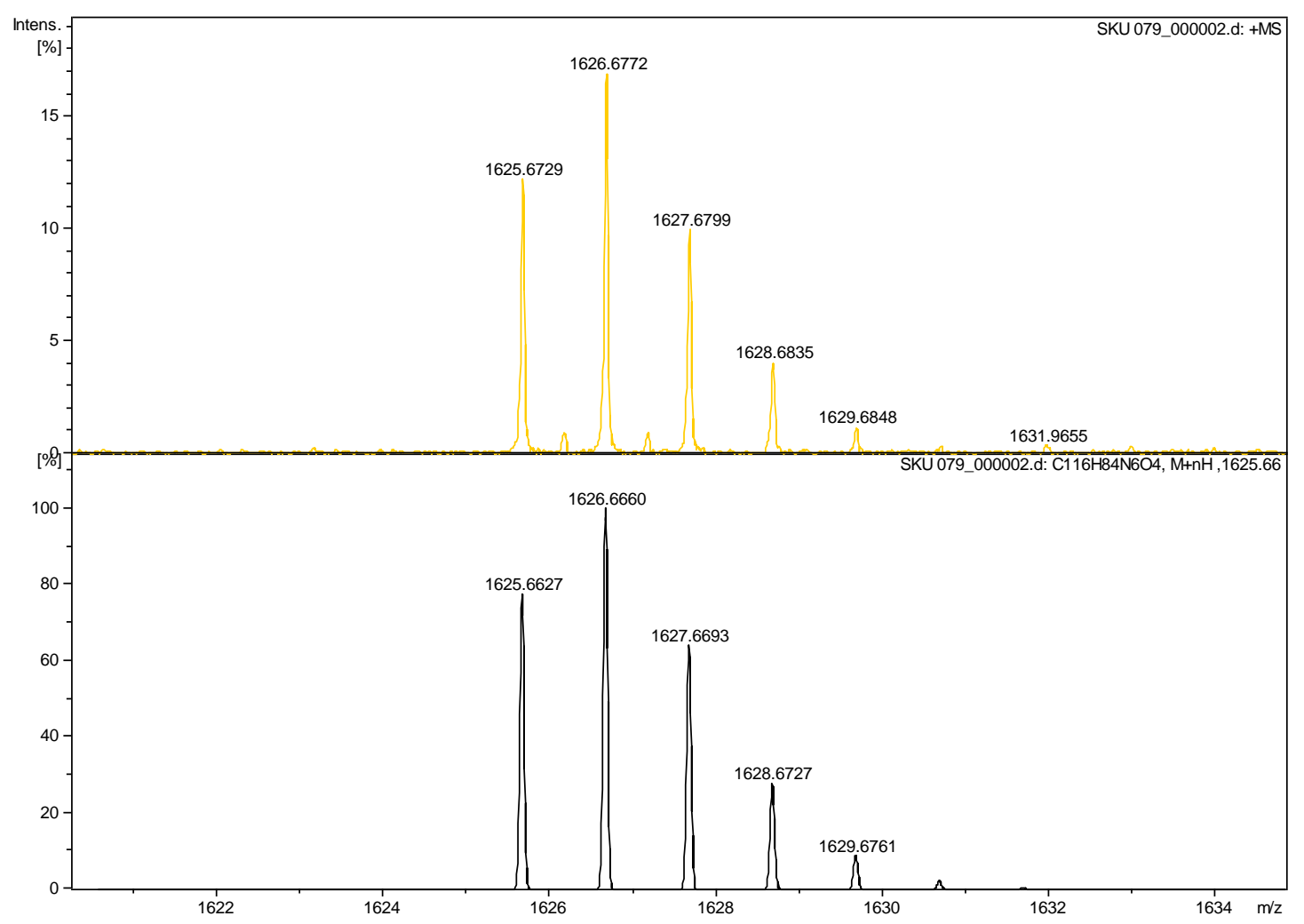

Figure S62. High resolution mass spectrum of $\mathbf{2} \mathbf{b}-\mathrm{H}_{2}$ (ESI-TOF, top: experimental, bottom: simulated).

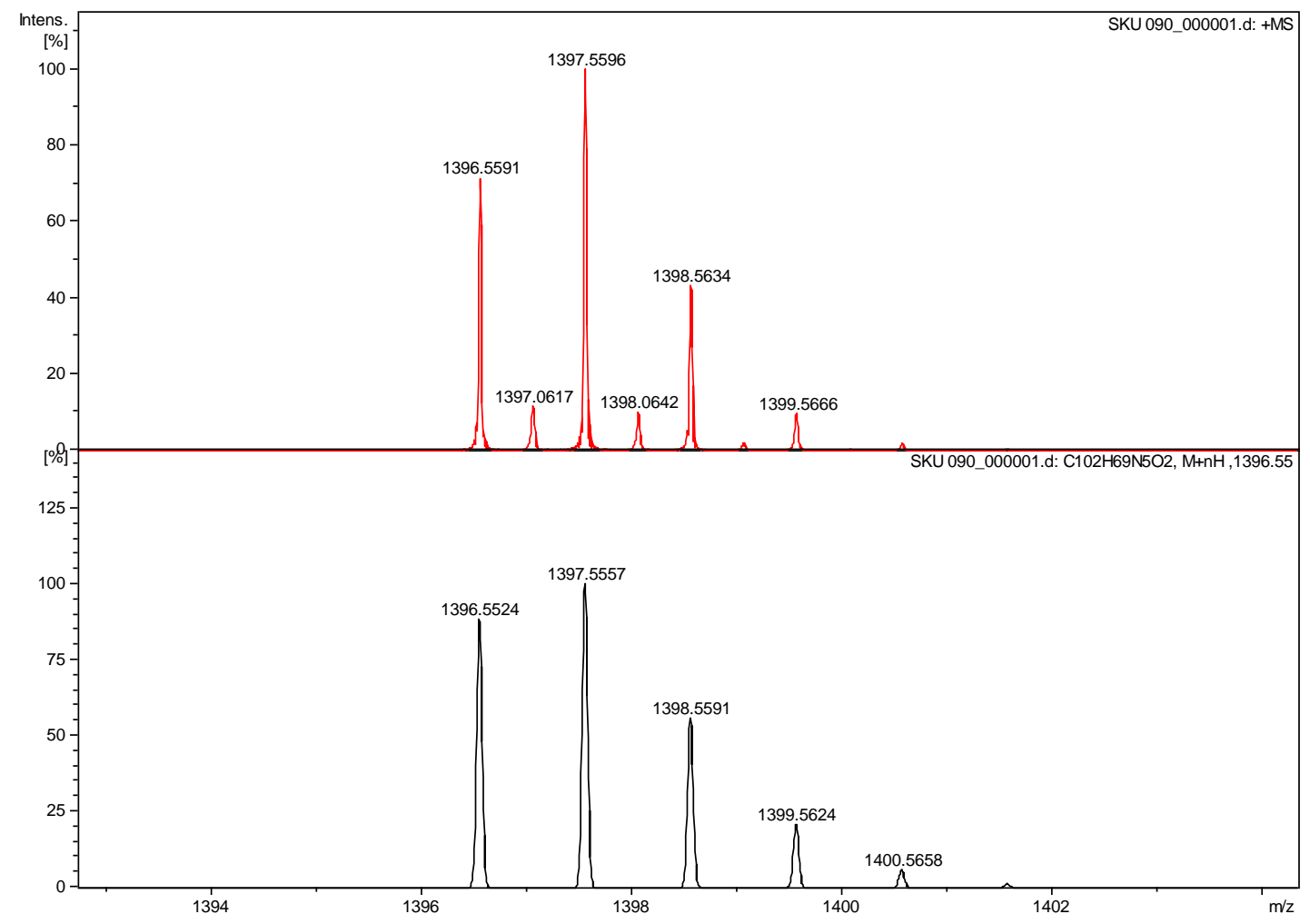

Figure S63. High resolution mass spectrum of $\mathbf{3 b} \mathbf{b}-\mathrm{H}_{2}$ (ESI-TOF, top: experimental, bottom: simulated). 


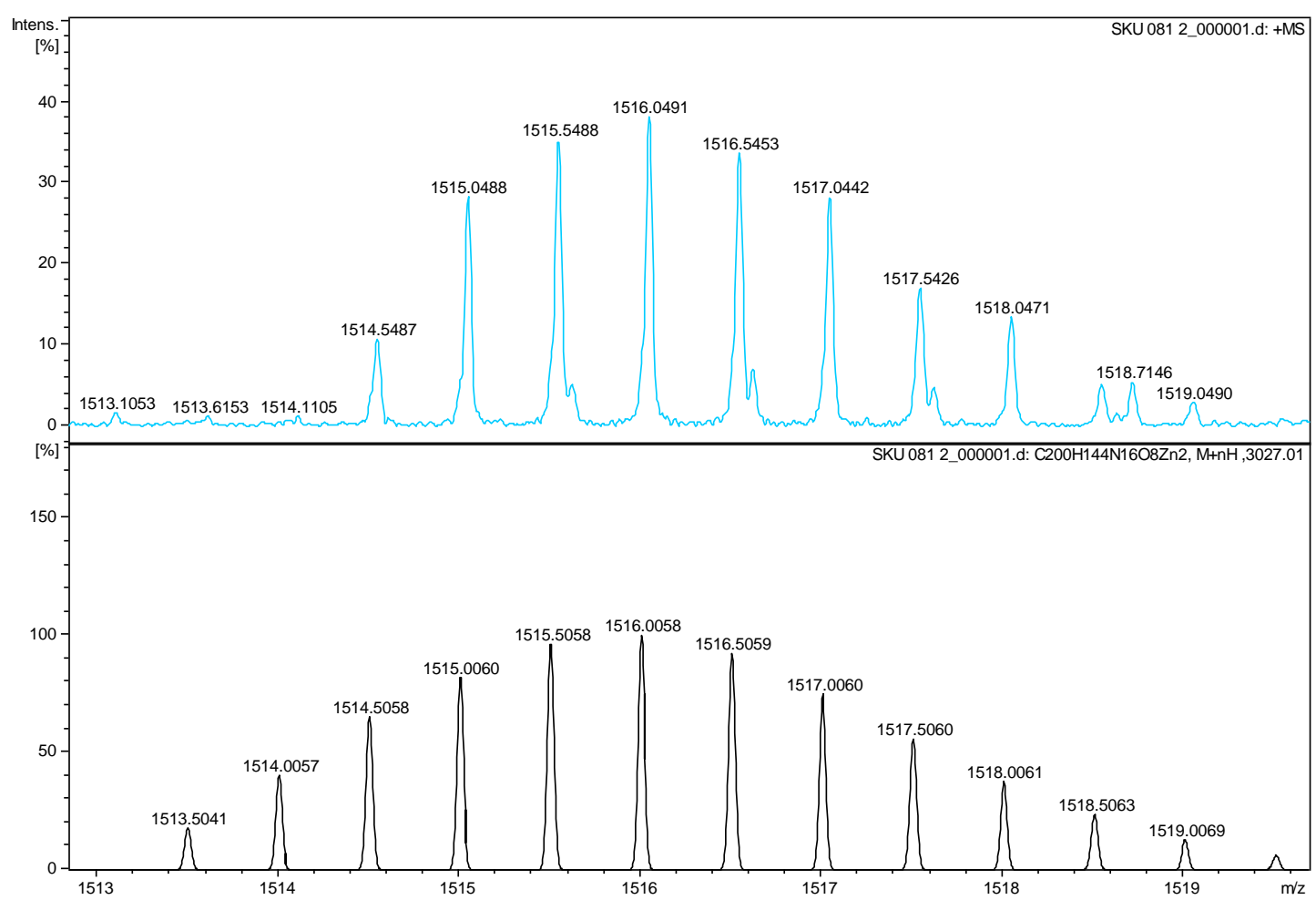

Figure S64. High resolution mass spectrum of 2a-Zn (ESI-TOF, top: experimental, bottom: simulated).

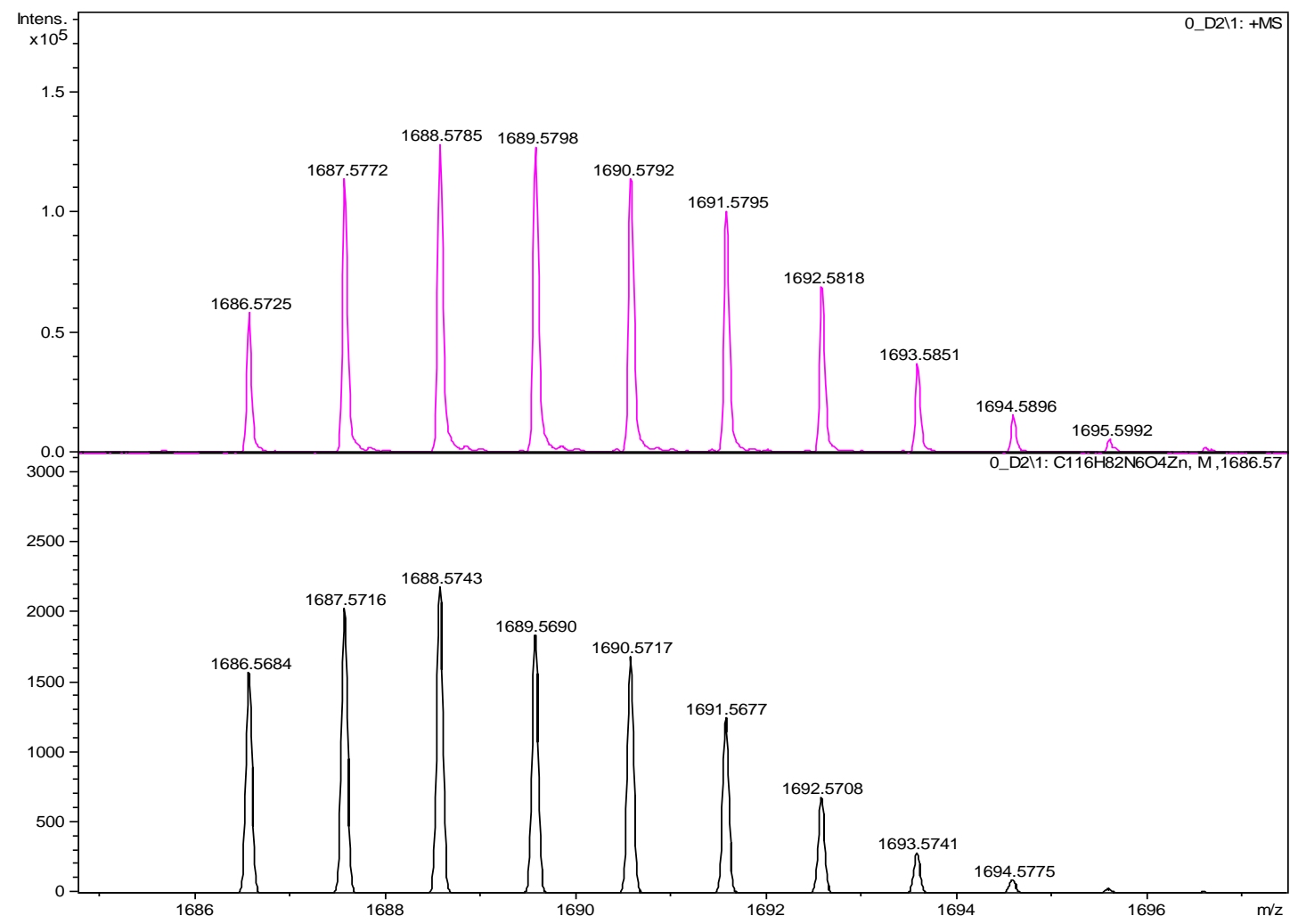

Figure 565. High resolution mass spectrum of $\mathbf{2 b - Z n ~ ( M A L D I - T O F , ~ t o p : ~ e x p e r i m e n t a l , ~ b o t t o m : ~ s i m u l a t e d ) . ~}$ 


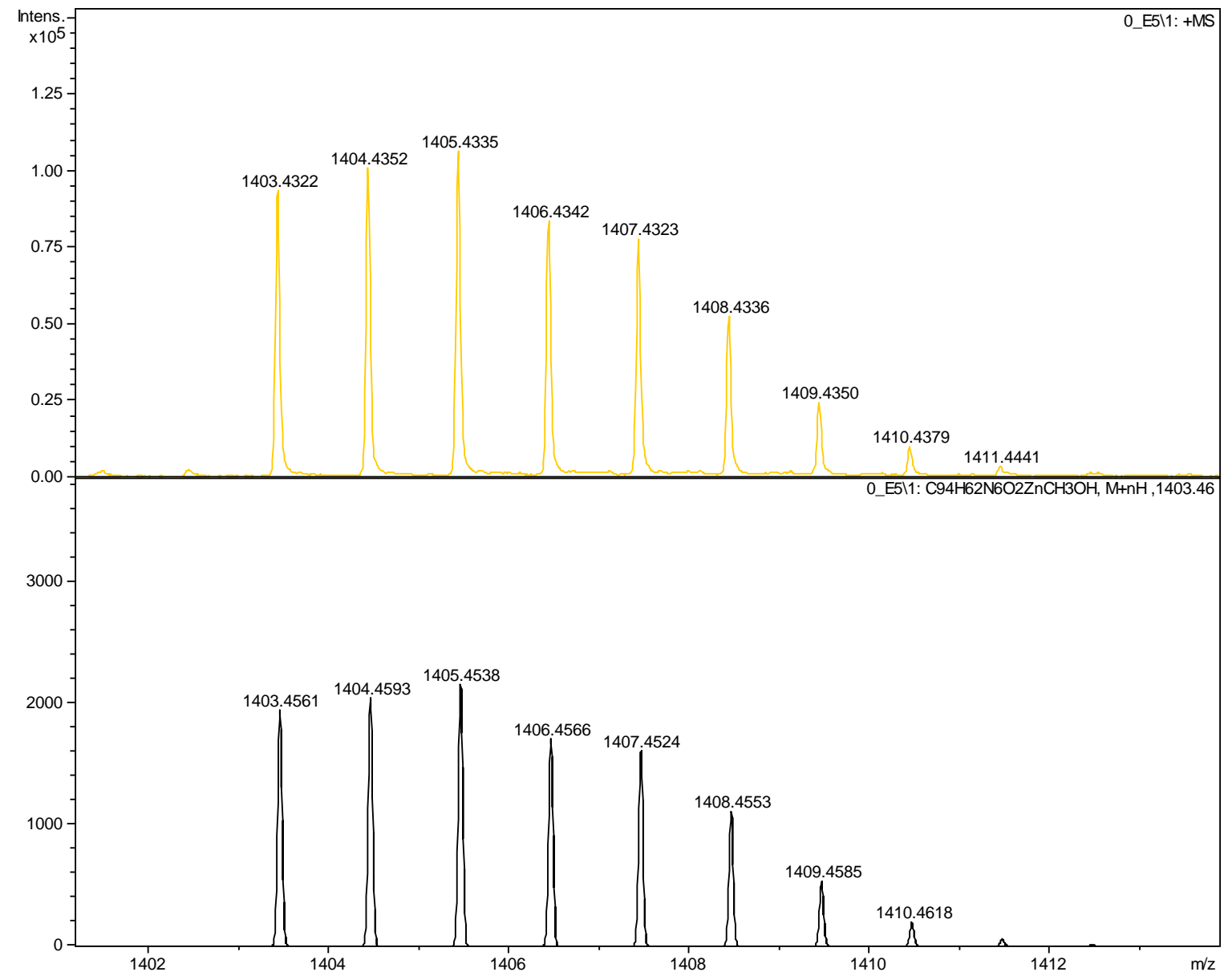

Figure S66. High resolution mass spectrum of 3a-Zn (MALDI-TOF, top: experimental, bottom: simulated). 


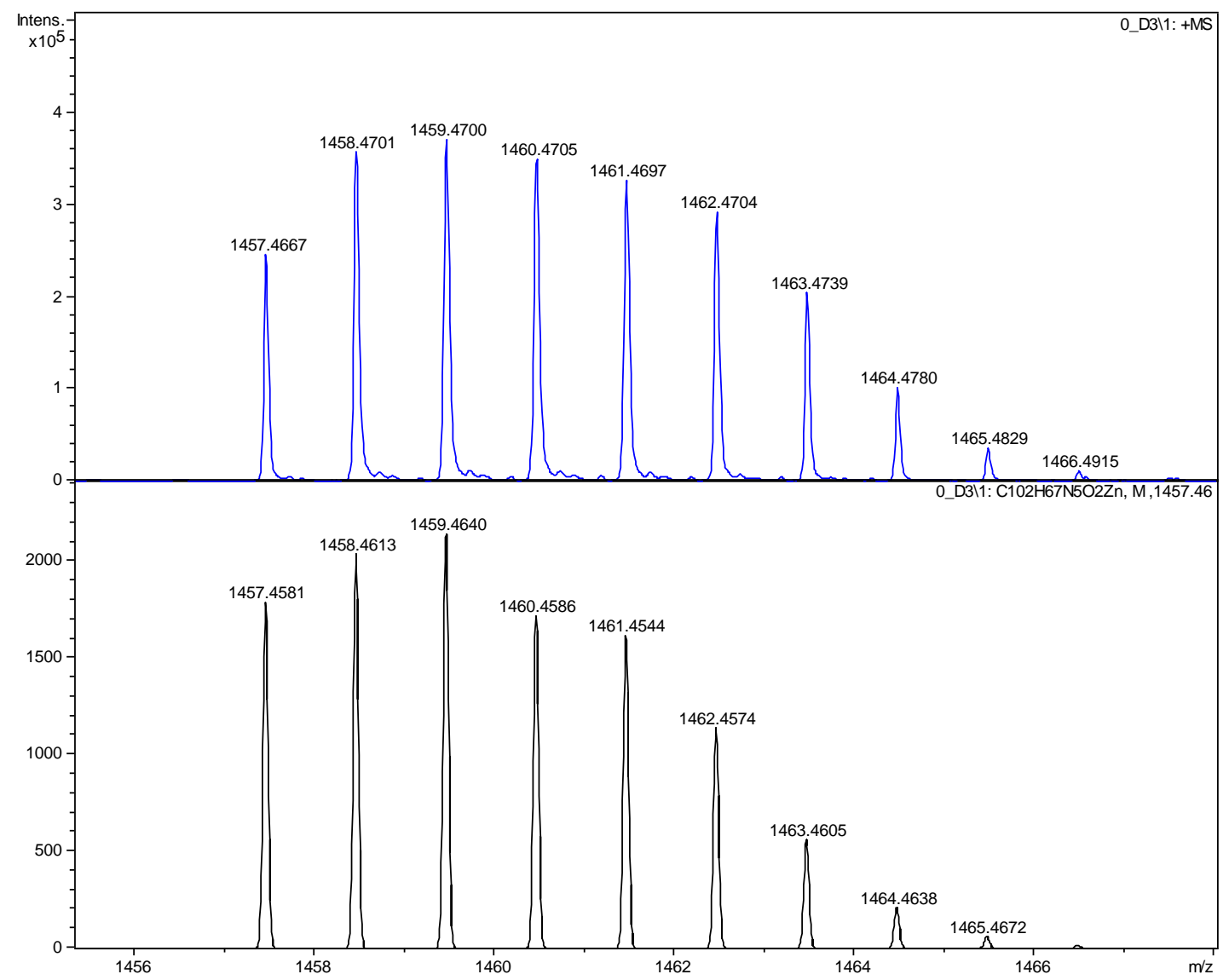

Figure S67. High resolution mass spectrum of $\mathbf{3 b}$-Zn (MALDI-TOF, top: experimental, bottom: simulated). 
References 
(1) Sheldrick, G. M. A Short History of SHELX. Acta Crystallographica Section A Foundations of Crystallography 2008, 64 (1), 112-122.

(2) Spackman, M. A.; Jayatilaka, D. Hirshfeld Surface Analysis. CrystEngComm 2009, 11 (1), 19-32.

(3) Turner, M. J.; McKinnon, J. J.; Jayatilaka, D.; Spackman, M. A. Visualisation and Characterisation of Voids in Crystalline Materials. CrystEngComm 2011, 13 (6), 1804-1813.

(4) Frisch, M. J.; Trucks, G. W.; Schlegel, H. B.; Scuseria, G. E.; Robb, M. A.; Cheeseman, J. R.; Scalmani, G.; Barone, V.; Petersson, G. A.; Nakatsuji, H.; Li, X.; Caricato, M.; Izmaylov, A. F.; Zheng, G.; Sonnenberg, J. L.; Hada, M.; Ehara, M.; Toyota, K.; Fukuda, R.; Hasegawa, J.; Ishida, M.; Nakajima, T.; Honda, Y.; Kitao, O.; Nakai, H.; Vreven, T.; Montgomery, Jr., J. A.; Peralta, J. E.; Ogliaro, F.; Bearpark, M.; Heyd, J. J.; Brothers, E.; Kudin, K. N.; Staroverov, V. N.; Kobayashi, R.; Normand, J.; Raghavachari, K.; Rendell, A.; Burant, J. C.; Iyengar, S. S.; Tomasi, J.; Cossi, M.; Millam, J. M.; Klene, M.; Adamo, C.; Gomperts, R.; Stratmann, R. E.; Yazyev, O.; Austin, A. J.; Cammi, R.; Pomelli, C.; Ochterski, J. W.; Martin, R. L.; Morokuma, K.; Zakrzewski, V. G.; Voth, G. A.; Salvador, P.; Dannenberg, J. J.; Dapprich, S.; Daniels, A. D.; Farkas, O.; Foresman, J. B.; Fox, D. J. Gaussian 16, Revision B.01; Wallingford CT, 2016.

(5) Grimme, S.; Bannwarth, C.; Shushkov, P. A Robust and Accurate Tight-Binding Quantum Chemical Method for Structures, Vibrational Frequencies, and Noncovalent Interactions of Large Molecular Systems Parametrized for All Spd-Block Elements $(Z=1-86)$. J. Chem. Theory Comput. 2017, 13 (5), 1989-2009.

(6) Bannwarth, C.; Ehlert, S.; Grimme, S. GFN2-XTB-An Accurate and Broadly Parametrized SelfConsistent Tight-Binding Quantum Chemical Method with Multipole Electrostatics and Density-Dependent Dispersion Contributions. Journal of Chemical Theory and Computation 2019, 15 (3), 1652-1671.

(7) Becke, A. D. Density-Functional Exchange-Energy Approximation with Correct Asymptotic Behavior. Phys. Rev., A 1988, 38 (6), 3098-3100.

(8) Becke, A. D. Density-functional Thermochemistry. III. The Role of Exact Exchange. J. Chem. Phys. 1993, 98 (7), 5648-5652.

(9) Lee, C.; Yang, W.; Parr, R. G. Development of the Colle-Salvetti Correlation-Energy Formula into a Functional of the Electron Density. Phys. Rev. B 1988, 37 (2), 785-789.

(10) Tomasi, J.; Mennucci, B.; Cammi, R. Quantum Mechanical Continuum Solvation Models. Chem. Rev. 2005, 105 (8), 2999-3094.

(11) Spence, J. D.; Lash, T. D. Porphyrins with Exocyclic Rings. 14. Synthesis of Tetraacenaphthoporphyrins, a New Family of Highly Conjugated Porphyrins with RecordBreaking Long-Wavelength Electronic Absorptions. The Journal of Organic Chemistry 2000, 65 (5), 1530-1539.

(12) McNeece, A. J.; Chang, M.-C.; Filatov, A. S.; Anderson, J. S. Redox Activity, Ligand Protonation, and Variable Coordination Modes of Diimino-Pyrrole Complexes of Palladium. Inorg. Chem. 2018, 57 (12), 7044-7050.

(13) Zhylitskaya, H.; Cybińska, J.; Chmielewski, P.; Lis, T.; Stępień, M. Bandgap Engineering in $\pi-$ Extended Pyrroles. a Modular Approach to Electron-Deficient Chromophores with MultiRedox Activity. J. Am. Chem. Soc. 2016, 138 (35), 11390-11398. 